\title{
SIPHON BREAKER DESIGN REQUIREMENTS FINAL REPORT
}

MARCH, 1993

PRINCIPAL INVESTIGATORS

D. T. NEILL, P.E. PROFESSOR OF ENGINEERING

\author{
A. G. STEPHENS \\ PROFESSOR OF ENGINEERING \\ DIRECTOR OF PH. D. PROGRAM
}

\section{SPONSORED BY}

USA DEPARTMENT OF ENERGY

NUCLEAR ENGINEERING RESEARCH PROGRAM

DE-FG07-88ER12820

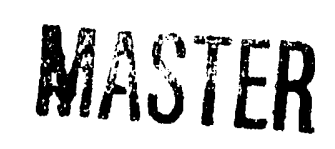

DISTRIBUTION OF THIS DOCUMENT IS UNLIMLTED

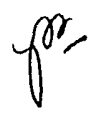


List of Figures . . . . . . . . . . . . . . . . iv

List of Tables . . . . . . . . . . . . . . . . iv

Abstract . . . . . . . . . . . . . . . . . . . v

Introduction . . . . . . . . . . . . . . . . . 1

Equipment . . . . . . . . . . . . . . . . . 1

operation . . . . . . . . . . . . . . . . 6

Typical Data and Results Plot Descriptions . . . . . . 8

Data Plots and Results Desciptions for

WF2X.XXX Test Series . . . . . . . . . . . . . . . . 21

Data Plots and Results Descriptions for

WF3X.XXX Test Series . . . . . . . . . . . . . 63

Data Plots and Results Descriptions for

WF4X.XXX Test Series . . . . . . . . . . . . . . 123

Data Plots and Results Descriptions for

WF5X.XXX Test Series . . . . . . . . . . . . . . . 154

Conclusions . . . . . . . . . . . . . . . . 222

\section{DISCLAIMER}

This report was prepared as an account of work sponsored by an agency of the United States Government. Neither the United States Government nor any agency thereof, nor any of their employees, makes any warranty, express or implied, or assumes any legal liability or responsibility for the accuracy, completeness, ur usefulness of any information, apparatus, product, or process disclosed, or represents that its use would not infringe privately owned rights. Reference herein to any specific commercial product, process, or service by trade name, trademark, manufacturer, or otherwise does not necessarily constitute or imply its endorsement, recommendation, or favoring by the United States Government or any agency thereof. The views and opinions of authors expressed herein do not necessarily state or reflect those of the United States Government or any agency thereof. 


\section{Pages}

1. Siphon Breaker test stand Layout . . . . . . . . . 2

2.-10. Typical Data and Results Plots . . . . . . 9-17

11.-47. Data and Calculated Air Void Fractions for

WF2X.XXX Test Series . . . . . . . . . 22-58

48.-101. Data and Calculated Air Void Fractions for WF3X.XXX Test Series. . . . . . . . . 64-117

102.-128. Data and Calculated Air Void Fractions for WF4X.XXX Test Series . . . . . . . . 124-150

129.-188. Data and Calculated Air Void Fractions for WF5X.XXX Test Series . . . . . . . . . 155-214

\section{IIBT OF TABLES}

1.

Flow Orifice Hole Diameters . . . . . . . . 5

2 .

Typical Friction K-Factors . . . . . . . . . 5 
SIPHON BREAKER

DESIGN REQUIREMENTS

FINAL REPORT

by

D. T. Neill and A. G. Stephens

\begin{abstract}
This report presents the measured data from a series of siphon breaker tests run between 1988-1991. The siphon test stand employed a 4-inch acrylic pipe downcomer with a $1323 \mathrm{~cm}$ (43 feet) fall distance. Orifice plates were used to fix the water and anti-siphon air flow rates. Tests were run at different combinations of water and anti-siphon air flows resulting in three distinctly different flow regimes: water-fall at the top of the downcomer, partial sweep-out of the two-phase flow, and full sweep-out of the two-phase flow. Many of the test runs were video taped to reveal the type of flow present in the downcomer as a siphon test progressed. A video tape showing representative cases of each test series is available for loan from Idaho State University at (208) 236-2902.
\end{abstract}




\section{INTPRODOCTION}

The Siphon Breaker Design Requirements Project was intended to provide experimental data on siphon flow effects. In addition, the experimental system was to be modeled with the RELAP code and the pxedicted and measured performances compared.

This report describes the design and operation of the siphon breaker experimental equipment from 1989 to 1991 . In addition the test results for all the experimental runs made in 1990 and 1991 are presented and described. Unfortunately, we have not been able to obtain useful results from a RELAP 5 model of the siphon system; consequently, we are unable to present any predictive calculations for comparison with the data presented. We have had lots of expert advice from several sources on using the RELAP code but to date our efforts have remained unsuccessful. After an extra year of effort, admittedly part-time but a lot of that, we choose to abandon the modeling efforts and produce this report describing the experimental equipment and test results.

\section{EOUIPYENT}

The siphon breaker test stand layout is shown on Figure 1. The principal components are a 500-gallon upper tank, 4-inch siphon upcomer, apex and downcomer pipe, a lower catch tank, a return pump and associated return piping. The upcomer, apex and downcomer are made of clear acrylic pipe so the flow patterns can be observed and video taped during test runs. Each upcomer and downcomer acrylic pipe section is about 6-feet long with a slip-on flange cemented to one end and a lap-joint flange cemented to the other end. The pipe sections are installed with a slip-on flange mating to a lap-joint flange so the bolt holes can be easily aligned at each joint. A pair of 3/16-inch diameter holes, 180 degrees apart, are drilled from the outside edge of the slip-on flange rim through the acrylic pipe as instrument taps. A 1/8-inch pipe thread is tapped into each hole at the flange rim for tubing connections.

ordinary, opaque, 3-inch PVC pipe is used to connect the outlet from the bottom of the upper tank to the acrylic upcomer. That PVC pipe contains a turbine flow meter, an electric actuated ball valve and a concentric reducer for connecting to the acrylic upcomer pipe. The turbine flow meter measures the water flow from the upper tank during a siphon test run. The ball valve is used to isolate the upper tank so the apex piping, which is about 4-feet above the top of the upper tank, can be filled with water before siphon flow is started. That provision 


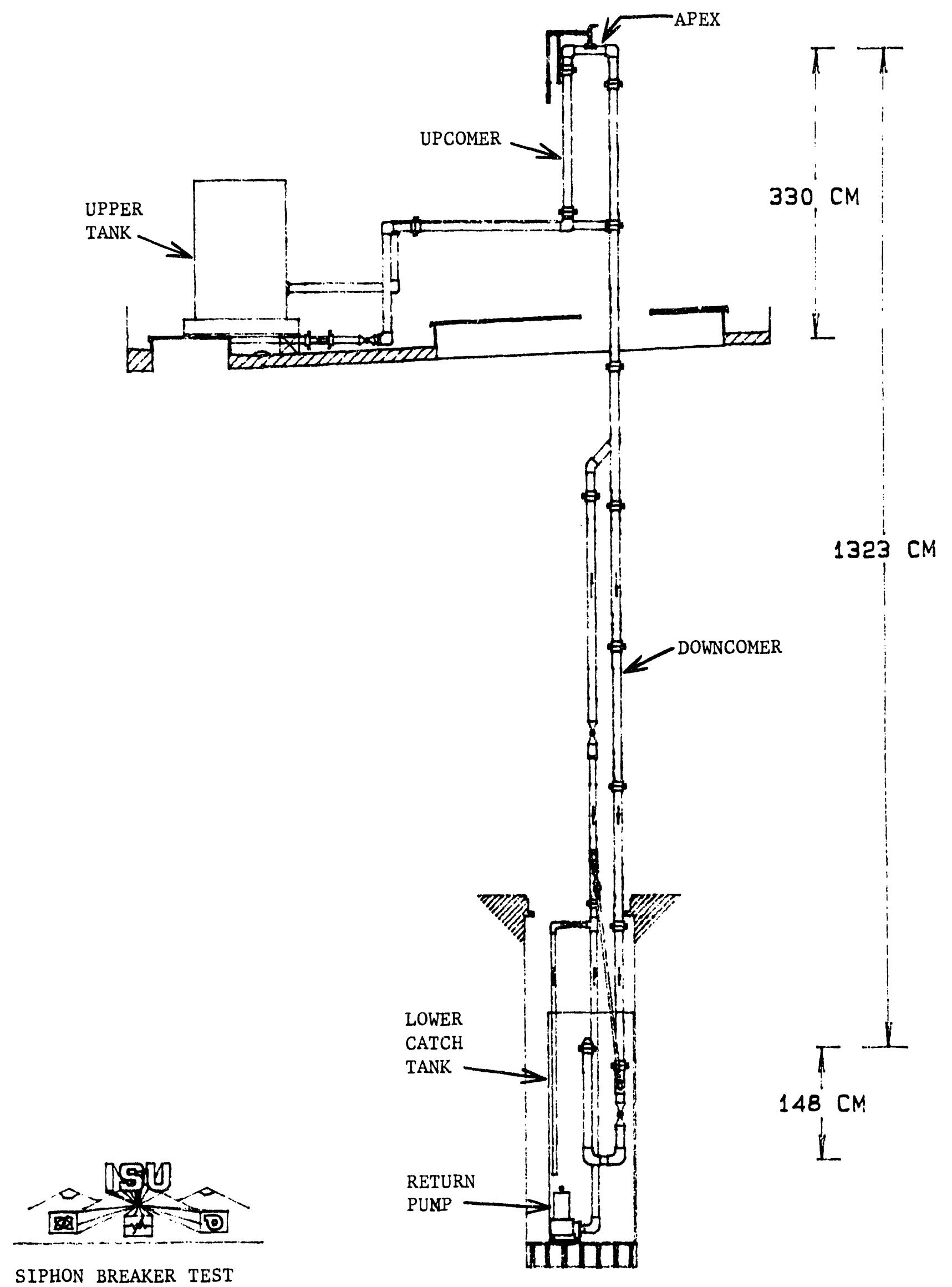

STAND LAYOUT 
means that there will be a minimum of air trapped in the siphon piping which must be swept-out before data collection can begin.

The horizontal section of the apex is about 30 inches long and has a 3/4-inch anti-siphon inlet air line connected at its top, center. The inlet air line is equipped with a turbine meter to measure inlet air flow, an orifice assembly to reproducibly control the air flow, and an electric actuated ball valve. That ball valve is used to start the anti-siphon air flow when the water level in the upper tank reaches a prescribed height. An orifice plate with a specified hole size is installed in the orifice assembly to provide different inlet air flow rates. About 3-feet of 3/8-inch polyethylene tubing is connected between the orifice assembly and the block valve in order to distribute the pressure drop and avoid limiting the air flow due to a critical pressure ratio at any one location. The air inlet line at the apex also has a separate atmospheric vent equipped with a solenoid vent valve which is used when the downcomer and apex pipe are being filled in preparation for a test run.

The acrylic downcomer pipe extends to the first flange below floor level. The rest of the downcomer is 4-inch PVC pipe which continues down through a manually operated ball valve, around a 180 degree bend and upward to the discharge orifice assembly. The manual ball valve is operated from floor level by means of a cable "reach rod." An orifice plate with a specified hole size is installed in the discharge orifice assembly to provide for different siphon flow rates. The siphon discharge is pointed upward to preclude the possibility of any air "backing" into the siphon piping during periods of low water flow. A steel bowl, which isn't shown on Figure 1 , is mounted about 2-feet above the outlet of the discharge orifice to deflect the water back into the lower catch tank.

A submersible return pump sets at the bottom of the lower catch tank. It is connected by a 4-inch PVC pipe back to the upper tank. A manual ball valve is located in that line just above floor level. There is also a 2-inch PVC pipe with a manual ball valve provided to permit bypassing return flow directly back into the lower catch tank. The block valve and the bypass valve are operated together to control return flow and minimize water hammer shocks to the acrylic and PVC piping. A 2-inch PVC cross-over line is connected between the return pump discharge line and the PVC downcomer pipe just above the manual ball valve. That cross-over line is used to fill the downcomer pipe all the way to the apex in preparation for a test.

An instrument list for the siphon breaker test stand is given below:

* turbine meter to measure siphon water flow from the upper tank, 
*turbine meter to measure air flow into the siphon pipe apex,

*dp cell to measure pressure difference between the siphon apex and the atmosphere, usually a vacuum,

*dp cells (2) to measure differential pressure along adjacent 6-foot lengths about midway down the downcomer pipe,

*dp cell to measure pressure difference between the discharge orifice and the atmosphere,

*dp cell to measure water level in the upper tank, and

*dp cell to measure water level in the lower tank.

Thermocouples are installed at several locations to measure water temperatures but they were abandoned after a few tests due to erratic readings. We simply measured the water temperature in the lower tank with a thermometer between test runs. There were no measurable water temperature changes during any of the test runs.

A gamma ray densitometer was to be installed near the center of each 6-foot section of downcomer pipe where the downcomer dp cells were located. We were unable to get all the associated electronic equipment working at the same time and finally abandoned the effort.

A PC based data logger system is used to record all measurements during a test run. The data collection program is written to obtain five sets of data, average each of the five values for a given parameter and write the average onto the hard disc. There are nine parameters in a data set. Reading and averaging the five data sets takes 1 to 2 seconds, then writing takes another second so that the total data logging cycle is 2 to 3 seconds long. Averaging the five data values is done to minimize the effects of electronic noise which is endemic in the data collection system. Most of the electronic noise probably came from electromagnetic pick-up along the instrument wiring. The noise remained significant in spite of our best efforts to shield the wiring and ground the signal loops. The data collection system probably should be converted to 4-20 milliamp signals to avoid so much noise in the future.

The diameter of the holes in the orifice plates used to control the flow of siphon water and the anti-siphon air are summarized in Table 1. The numbers in the first column are used to identify the orifice sizes in the test numbering scheme. 


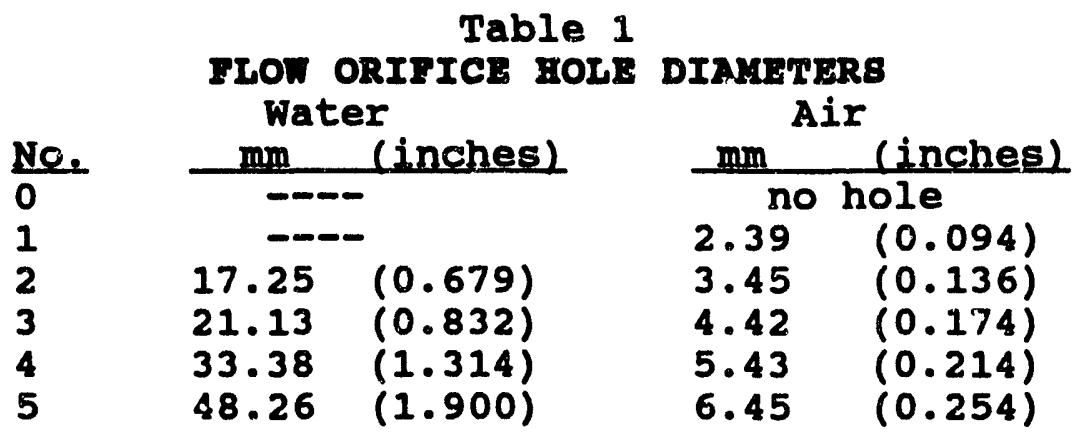

The test numbering scheme incorporates the orifice size numbers in the test name as well as a test sequence number. A typical test number is WF23.007; the first digit, 2 , is the water orifice size, the second digit, 3 , is the air orifice size and the test sequence number, 7, follows the decimal. During the WF55. Xxx test series the air flow over-ranged the turbine meter so we had to change the rotor to one which accommodated the higher air flow. This new rotor required a new calibration factor in the data reduction program so we changed the subsequent test series numbers to WG5x.XXX. We reran some of the tests at smaller air orifice sizes so there are a few tests in the same series with WF or WG in their number.

We started the tests at the small water orifice size and worked though increasing air orifice sizes until the siphon broke immediately when the anti-siphon block valve was opened. We then changed to the next larger water orifice and the smallest air orifice to start the next test series. As a general rule we replicated a test at least three times and sometimes more if there was any indication that the test was unsatisfactory due to an instrument failure or an operating glitch.

A special test series was run at each water orifice size with the anti-siphon air flow blocked throughout the run. The data from these "water flow only" tests were intended for calculating the friction $\mathrm{K}$-factors along the flow path from the upper tank to the discharge. These calculated friction $\mathrm{K}$-factors did not remain constant with flow nor from test to test. The best estimates for typical values are reported in Table 2 .

Table 2

TYPICAI FRICTIOA K-FACTORS

Inlet section -- upper tank to apex

Downcomer section -- apex to discharge Discharge orifice

$$
\begin{aligned}
& 16 .+/-2 . \\
& 25 .+/-i . \\
& 0.15+/-0.05
\end{aligned}
$$

The pipe friction $\mathrm{K}$-factors are based on the average velocity in the 4-inch I.D. acrylic pipe even though some of the pipe is PVC and some 3-inches in diameter. The discharge orifice $\mathrm{K}$-factor is based on the average velocity through the orifice diameter. of course these friction $K$-factors are for single phase water 
flow only so the downcomer and discharge values cannot be used once the anti-siphon air valve is opened and air bubbles reach the downcomer or discharge regions.

\section{OPERATION}

A typical test run starts with the upper tank full of water, the ball valve in the upper tank outlet closed, the siphon piping, including the apex pipe, completely full of water and the apex vent valve open to the atmosphere. The siphon ball valve below floor level is closed and the siphon discharge piping is also full of water. The lower catch tank is, of course, nearly empty. This condition is maintained for several minutes while all instruments and the data collection system are checked. Then the apex vent valve is closed and the ball valve in the upper tank outlet is opened. Opening that ball valve pulls a small vacuum on the apex but does not start any flow since the downcomer block valve below floor level remains closed. This condition is held for about 30 seconds to be sure no air is leaking into the apex through either the vent or the anti-siphon air block valves. Next the downcomer ball valve is opened which allows water to be siphoned from the upper tank over the apex, down the downcomer through the U-bend at the bottom of the downcomer and discharged through the orifice into the lower catch tank. This "all water" flow is allowed to continue for 30 to 40 seconds to sweep-out the small amount of air trapped in the piping and to allow verifying that the instruments and data collection system are operating correctly.

At a predesignated water level in the upper tank, the anti-siphon air block valve at the apex is opened. Opening that valve permits an immediate inrush of air, which usually causes all the dp cell readings to spike up, before settling into a slowly increasing air flow. The inlet air flow increases because the water level in the upper tank is decreasing. The air entering the horizontal apex pipe generally flows along the top of the pipe separate from the water which flows along the bottom of the pipe. The air and water are mixed into a bubbly flow at the 90-degree elbow between the horizontal apex and the vertical downcomer pipe sections. The inrushing air also causes the water flow to spike down abruptly and then settle into a slowly decreasing flow as air accumulates in the downcomer and as the water level in the upper tank decreases. The air accumulation in the downcomer generally takes the form of a bubbly two-phase flow front which moves down the downcomer pipe at about the same velocity as the water flow. Behind the bubbly two-phase flow front the density of air bubbles gradual increases due to an accumulation of air. In some cases the air collects into larger bubbles which appear to move down the downcomer at a velocity a bit slower than the bubbly two-phase flow. 
The siphon flow continues to decrease in a smooth transient until "broken" when the upper tank empties or the density in the downcomer decreases sufficiently due to air accumulation. The water flow over the apex stops when the siphon breaks but water will continue to drain from the downcomer for sometime depending on the anti-siphon air flow rate. Also the water in the upcomer pipe flows back into the upper tank during this period. Data collection is stopped shortly after the siphon breaks.

After the test run is over, the block valves in the upper tank outlet line and the anti-siphon air line are closed. Then the return pump bypass valve and the apex vent valve are opened. The return pump is started and the return line block valve opened to send water flow into the upper tank. The return pump bypass valve is slowly closed to gradually increase the return water flow. While the upper tank is filling some return water flow is diverted into the downcomer pipe through the cross-over line. After water fills the downcomer discharge pipe to above the downcomer block valve it is closed to prevent further flow out the discharge orifice and to keep the discharge pipe full. Water continues to fill the upper tank and the downcomer piping simultaneously. When the downcomer pipe is full the water will flow over the apex and fill the upcomer pipe before filling the horizontal apex pipe completely. When the upper tank is full the return line and outlet pipe block valves are closed. Some return water flow is continued through the cross-over line into the downcomer pipe until it fills the apex pipe and leaks out the apex vent. The cross-over block valve is closed and the return pump is stopped. The system is then ready to start another test run. 
TYPICAI DATA AND REBUTYS PLOT DEBCRIPIIONS

There are so much siphon breaker data and calculated results that we have elected to present them as plots in separate report sections for each test series. However, since the same type plots are used for each test series we want to discuss the common features of the plots in this section. That arrangement will allow us to minimize duplicate descriptions, to provide an easily accessible description for the reader to refer to repeatedly, and to concentrate on the comparison of the data and results in their respective sections.

We made video tapes of many of the test runs. These have been edited into a single tape which shows the most interesting features of the air-water interaction within the downcomer and shows at least one test run from each series. The VCR tape takes about 20 minutes to view.

Figures 2-10 are from the first series of siphon breaker tests. Just the basic features common to or typical of all plots will be described now. The same type plots in the same sequence will be repeated in the data and results presentation sections which will follow this section.

Figure 2 shows the volume of water remaining in the upper tank during a test run. The adjusted time scale on the horizontal or abscissa axis is set equal to zero when the anti-siphon air block valve is opened in order to provide a common event reference for all tests. The anti-siphon air valve was opened at remaining water volumes of about 1000 liters, 700 liters and 350 liters for the three tests shown on Figure 2 . The cylindrical volume of the upper tank is 1026 liters/meter of height; so for each 100 liters of water drained the water level dropped about 0.1 meter. The test numbers and the plot symbol legend are given in the upper right-hand corner of the plot.

Figure 3 shows the water flow as measured by the turbine meter in the pipe between the bottom of the upper tank and the siphun upcomer. Opening the anti-siphon air valve at the apex always causes a significant downward spike in the water flow reading before it recovered and then declined as air accumulated in the downcomer section. Each separately plotted symbol is the average of five data values read over a period of about 2 seconds so the flow dip was quite severe; the water flow may have almost stopped momentarily.

Figure 4 shows the anti-siphon inlet air flow as measured by the turbine meter located near the siphon apex. We believe the apparent slow build-up of the air flow is the result of several factors. The electrically operated ball valve in the air line always took a second or two to open, there is inertia in the turbine rotor and it is possible that some residual water was in 


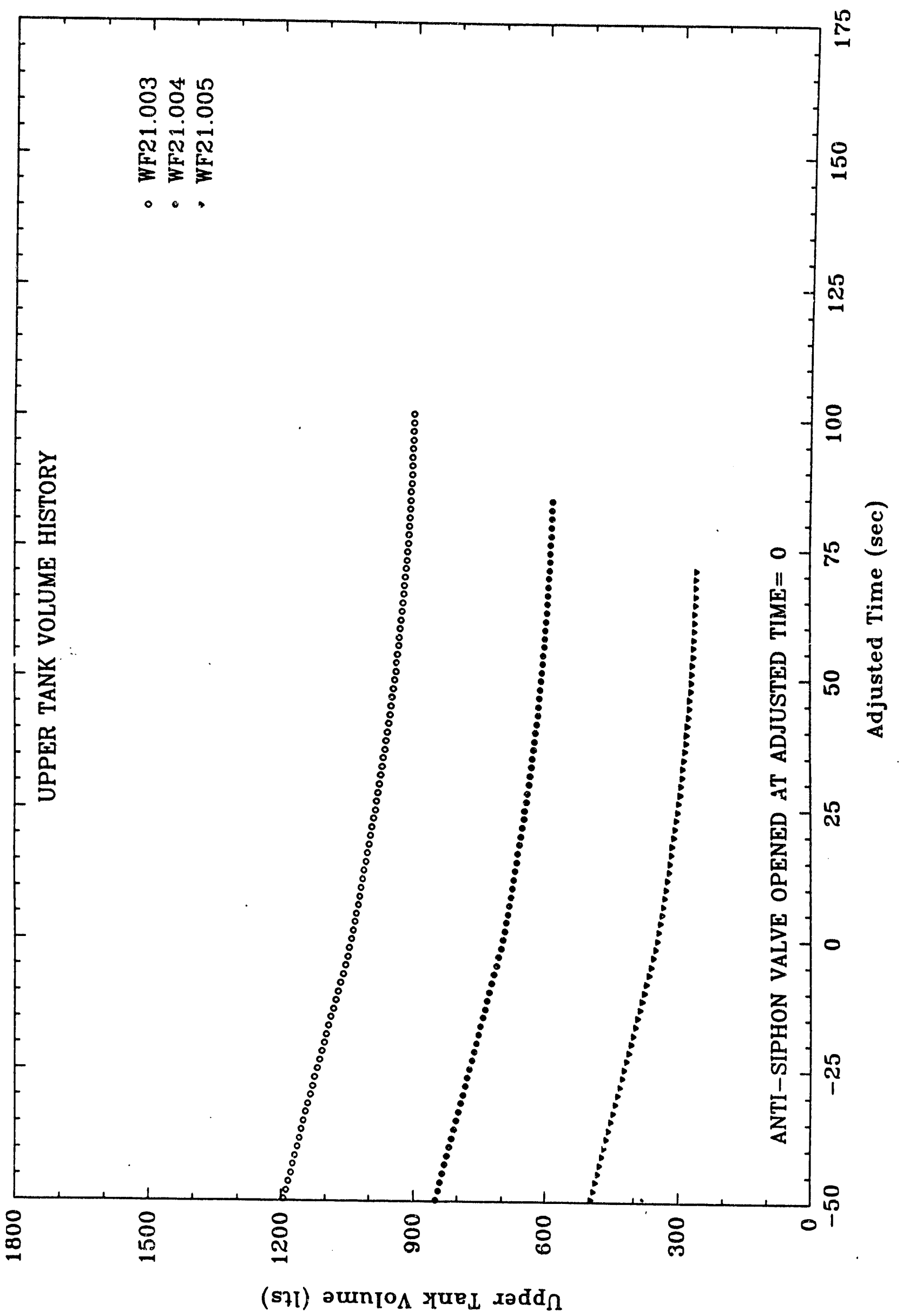


Figure Number 3

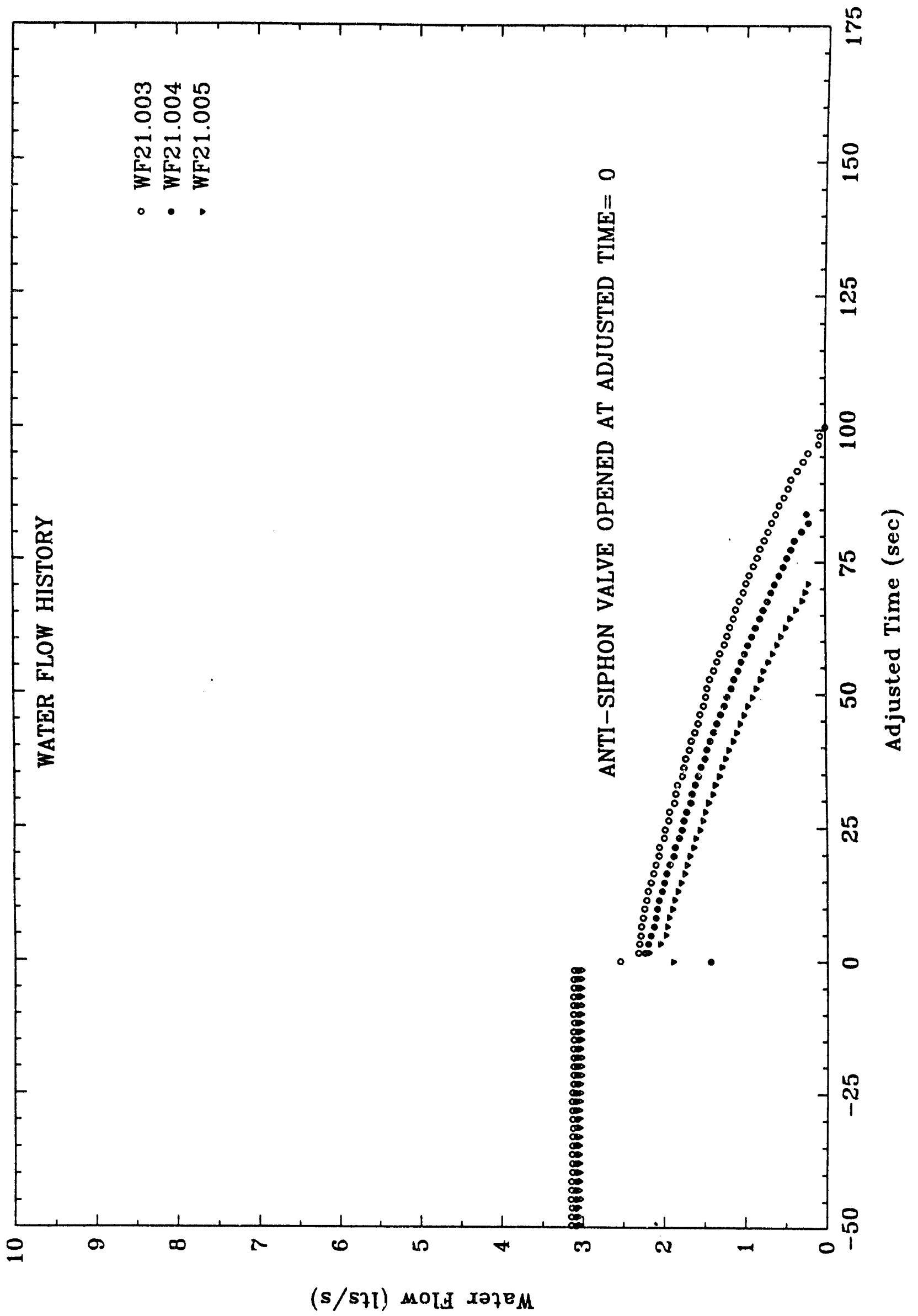


Figure Number 4

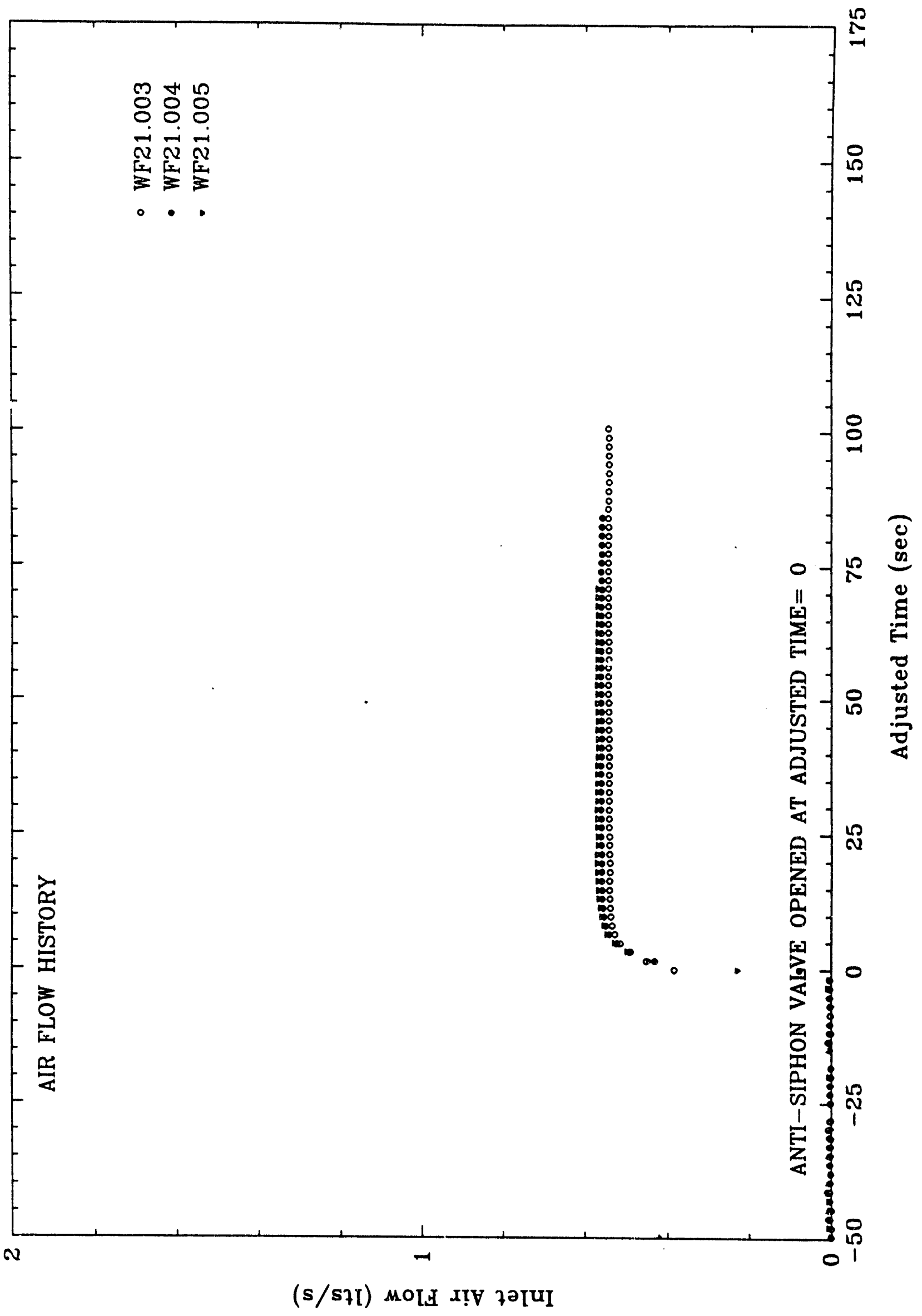




$$
4
$$




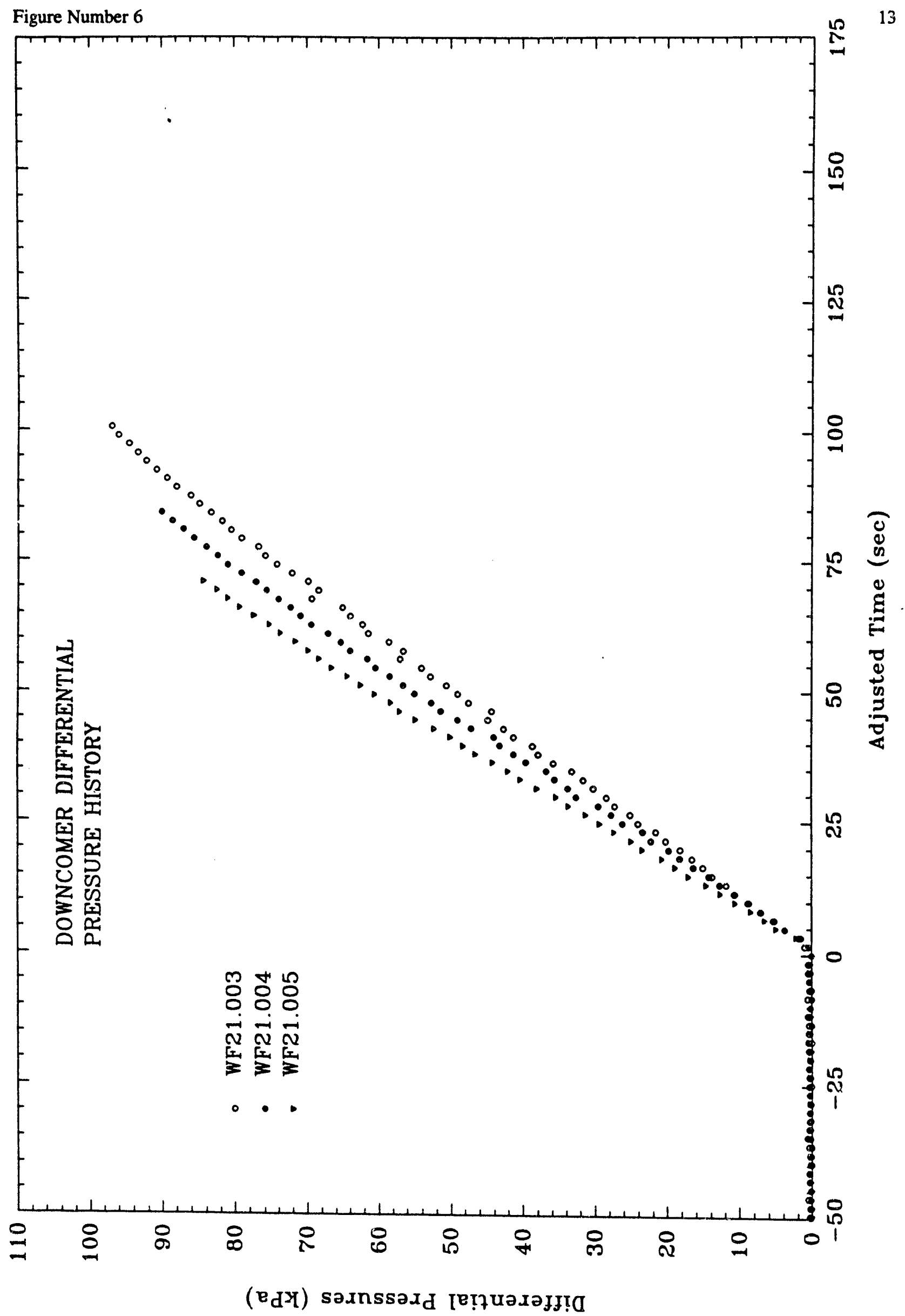




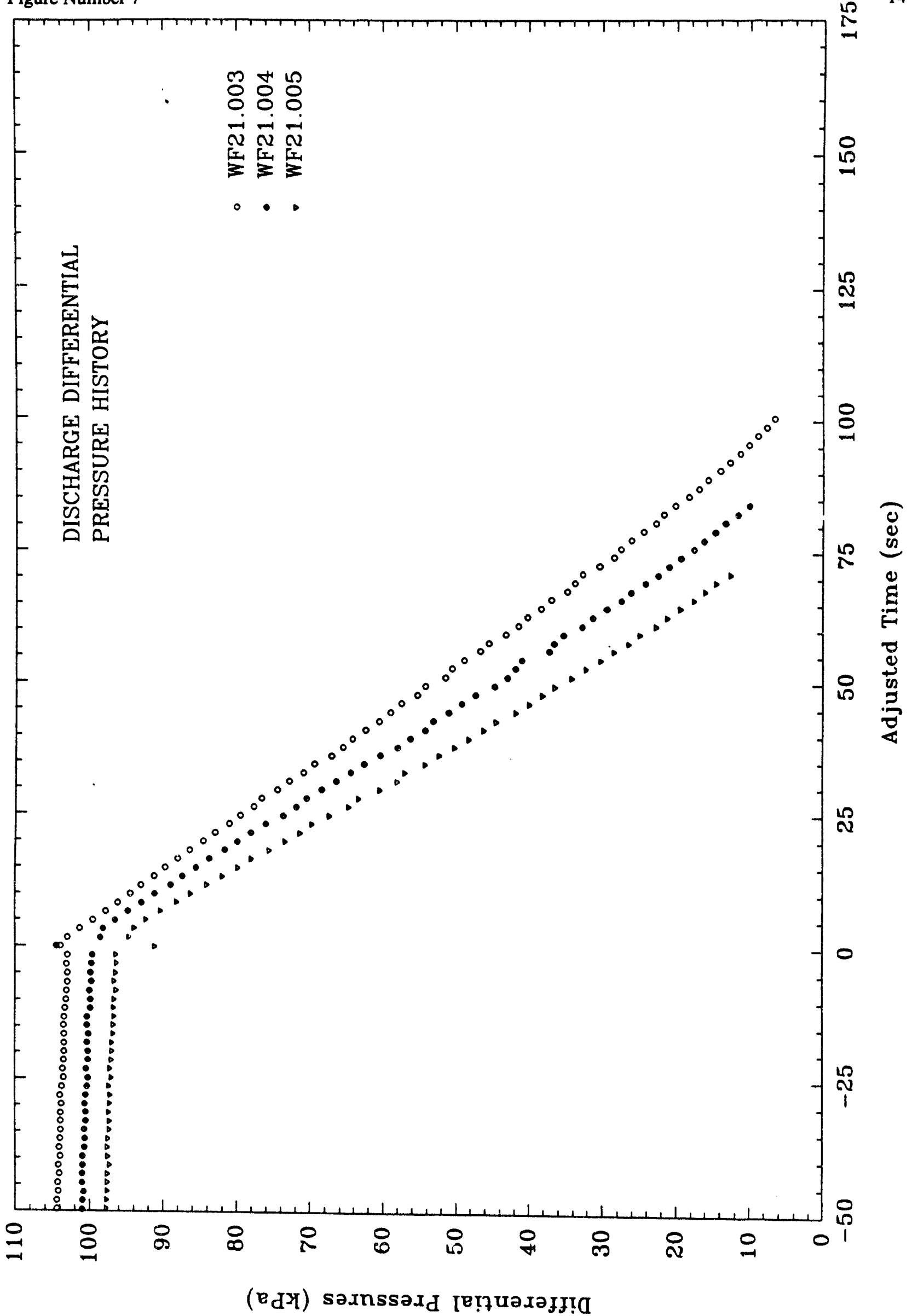


Figure Number 8

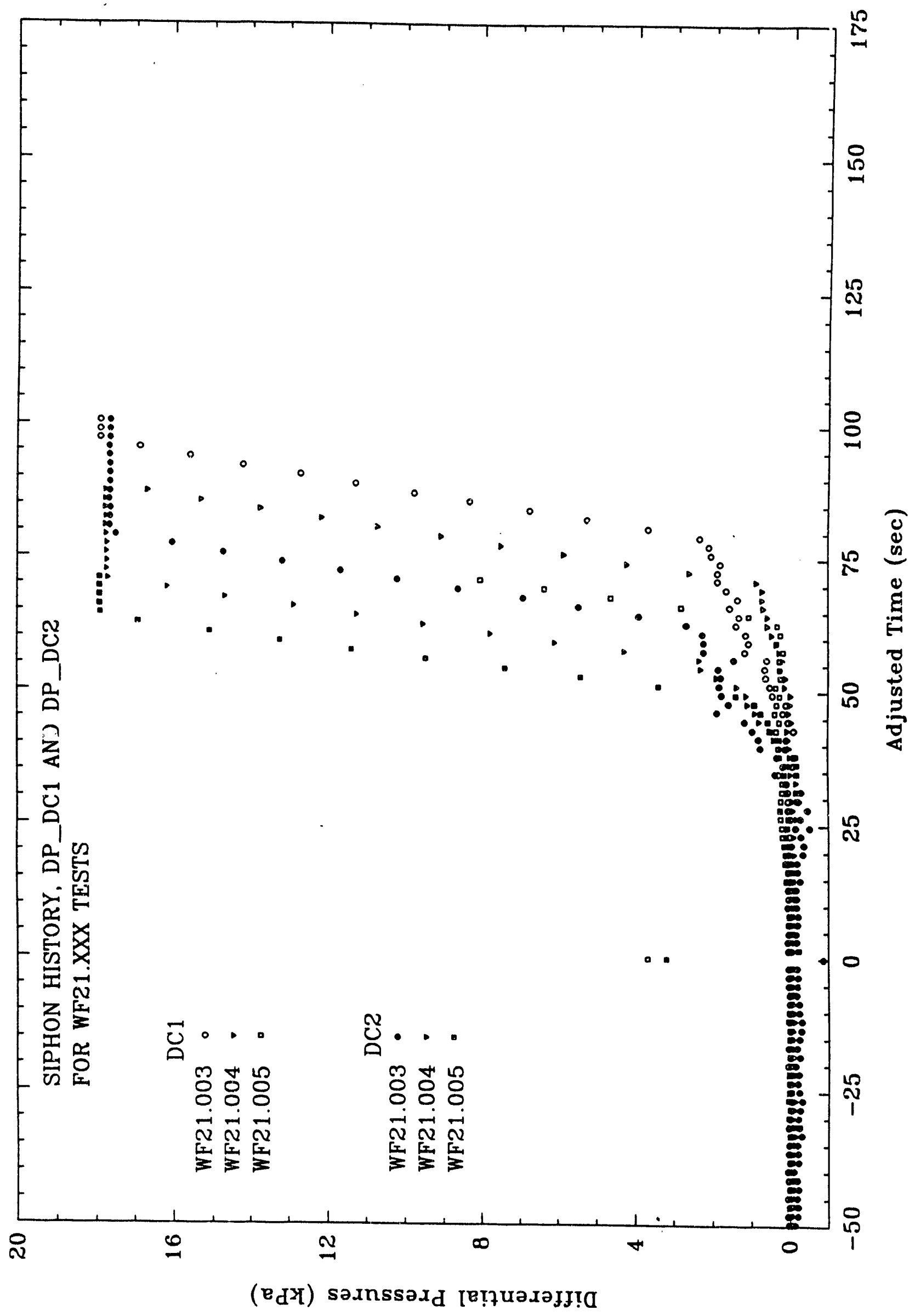


Figure Number 9

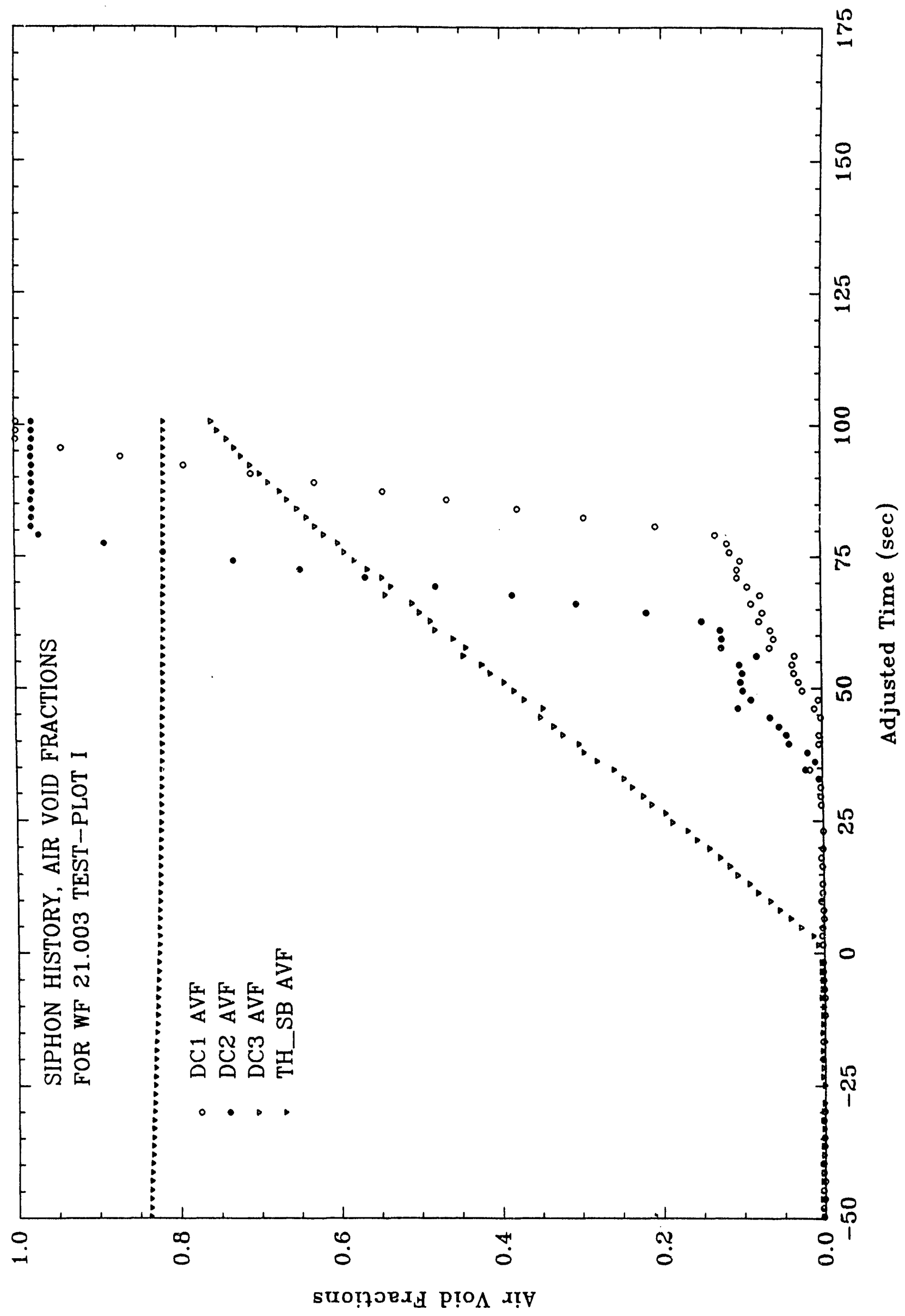


Figure Number 10

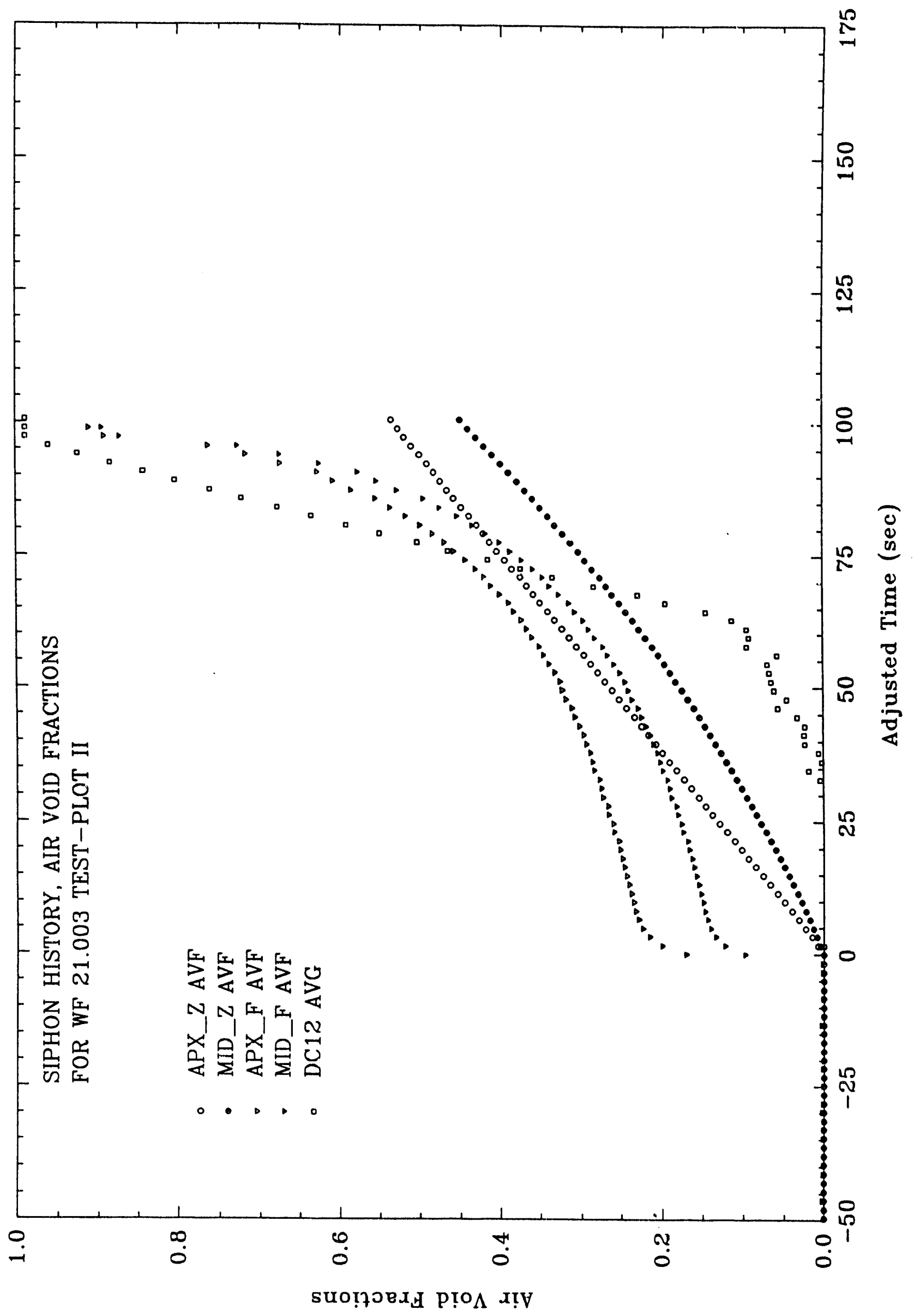


the air line. Water could overflow into the air line during filling and venting of the siphon apex.

Figure 5 shows the pressure, actually a vacuum, measured at the siphon apex by a dp cell referenced to the atmosphere. There is usually a spike when the anti-siphon air valve is opened but otherwise the apex pressure remains remarkably constant throughout the test including the siphon break event. The siphon break is always taken to be the time when the water flow reverses and/or the water level in the upper tank starts to increase due to water in the upcomer draining back.

Figure 6 shows the downcomer differential pressure measured by a dp cell connected between the siphon apex and the siphon discharge. The low pressure side of the dp cell is connected across the siphon downcomer and the high pressure side is connected to a liquid full reference leg. There is a very small pressure drop before adjusted time zero due to friction but it starts to increase rapidly a few seconds after the anti-siphon air flow is started due to the accumulation of air in the downcomer and the attendant reduction in the average density over the downcomer length.

Figure 7 shows the discharge differential pressure measured by a dp cell connected between a point just upstream of the discharge orifice and the atmosphere. This differential pressure is caused by the effective height of the entire siphon and decreases only a little before adjusted time zero due to the decrease in the level in the upper tank. After the anti-siphon air flow starts, the discharge differential pressure decreases due to the decreasing water flow.

Figure 8 shows two differential pressures measured along 6-foot lengths of the vertical downcomer about midway of the downcomer length. The 6-foot length for the DC2 dp cell is located above and immediately adjacent to the 6-foot length for the DC1 dp cell. The high pressure side of each dp cell is connected to the downcomer and serves as the reference leg since it remains liquid full. The low pressure side of each dp cell is connected to the downcomer some 6-feet below the high pressure connection and responds to the average density of the water in its 6-foot high section of downcomer. Since the DC2 dp cell is located above the DC1 dp cell, the DC2 measurements start to increase before the DC1 measurements.

Figures 9 and 10 show calculated air void fractions which provide the simplest theoretical modeling and generally reveal the difficulty of predicting a siphon break without a much more sophisticated analysis. There will be Figure 8 and Figure 9 type plots for several representative tests from a series. 
Figure 9 shows four different calculated air void fractions; three are based on dp measurements and the fourth is a simple theoretical construct as described below. A pressure difference from friction is inherent in each dp measurement but it is generally small so no attempt was made to subtract it before calculating the air void fractions. The air void fractions described below are calculated by assuming all the pressure difference is due to air mixed homogeneously with water in the downcomer section.

DC1 and DC2 AVF points are based on the differential pressure measurements along 6-foot lengths of the downcomer as shown on Figure 8 . Since the DC2 dp cell is located above the DC1 dp cell, the DC2 AVF values "lead" the DC1 AVF values.

DC3 AVF points are based on the downcomer differential pressure measurements over its entire length as shown on Figure 6. Again, the air void fraction is calculated by assuming all the pressure difference is due to air nixed homogeneously over the full downcomer length.

TH SB AVF points are theoretical downcomer air void fraction values calculated for a non-fluwing or stagnant siphon condition and depend only on the elevation of the water level in the upper tank, the elevation of the siphon apex, and the elevation of the siphon discharge. The slow decrease in those values is due to the decrease of the water level in the upper tank as the test run progresses.

Figure 10 shows air void fractions calculated for different combinations of assumptions about conditions in the downcomer as described below.

APX_Z AVF points are calculated assuming zero sweep-out of air from the downcomer and that the density of all the air corresponds to the measured apex pressure.

MID_Z AVF points are calculated assuming zero sweep-out of air from the downcomer and that the density of all the air corresponds to the average of the apex and discharge pressures; a midpoint approximation.

APX_F AVF points are calculated assuming full sweep-out of air from the downcomer and that the density of all the air corresponds to the measured apex pressure. No provision is made for any air accumulation over time. In effect, the calculation is just the ratio of the volumetric air flow rate to the volumetric water flow rate at the apex pressure. Therefore, the calculated values jump-up as soon as anti-siphon air is introduced into the siphon apex. 
MID-F AVF points are the same as the APX F AVF points except the density of all the air corresponds to the average of the apex and discharge pressures.

DC12 AVG points are the air void fraction salculated for the average of the DC1 and DC2 dp measurements shcwn on Figure 8 and approximate the air void fraction over a 12-foot length of the downcomer. This result is included because of the extreme scatter in some of the DC1 and DC2 measurements; averaging the two yields a somewhat smoother plot. The values are plotted on Figure 10 to avoid too much interference with the points on Figure 9. 


\section{DATA PIOHB AND REBULTE DEBCRIPTIONB FOR WF2X.XXX TEBT 8ERIE8}

Figures 11-47 show the measurement data and calculated air void fractions for the WF2O, WF21 and WF22 series of test runs. These plots are all grouped in one section to make comparisons easy.

Figures 1:-15 show the data for three "water flow only" wF20 tests which were run early in the test program.

Figure 11 shows that the upper tank volume histories repeat very well and that drainirg the tank would require some five minutes.

Figure 12 shows that the water flow rates repeat very well and that they decreased only a small amount over the first 175 seconds.

Figure 13 shows that the apex pressures did not repeat so well. Calculated values of the friction $\mathrm{K}$-factor for the inlet section (upper tank to apex) for the 002 and 003 tests were very low; even going negative in the worst case. But the friction $k-$ factor values for the 001 test are reasonable and contribute to the recommended value given in Table 2. The large impact of small differences in the measurements are a problem during all the low flow tests.

Figure 14 shows the extreme scatter in the downcomer differential pressures. The dp cell used for these measurements has a range of $0-125 \mathrm{kPa}((0-500 \mathrm{in}$-water) so the readings are less than 1 percent of full scale. The readings do, however, indicate the inherent noise turbulent flow and in the data collection system and that the downcomer friction is low.

Figure 15 shows that the differential discharge pressures for the 002 and 003 runs are nearly equal while those for the 001 run are lower. The calculated friction $\mathrm{K}$-factors for these data show very low values for the 001 run and higher, reasonable values for the 002 and 003 runs; essentially the opposite of the results obtained from the apex pressure data.

Figures 16-28 show the plots for the WF21 series of tests; the first series which included anti-siphon air flow. Figures 16-24 may look familiar because they are duplicates of Figures 2-10 which were used in describing the common elements of all the plots.

Figure 16 shows an upward trend for ends points of the upper tank water volumes due to the siphon breaking. The 003 run lasted for some 30 seconds longer than the 005 run because the upper tank liquid level is lower for the 005 run and therefore required less air accumulation in the downcomer to break the siphon. The nearly linear locus of the ends of the water volume 
Figure Number 11

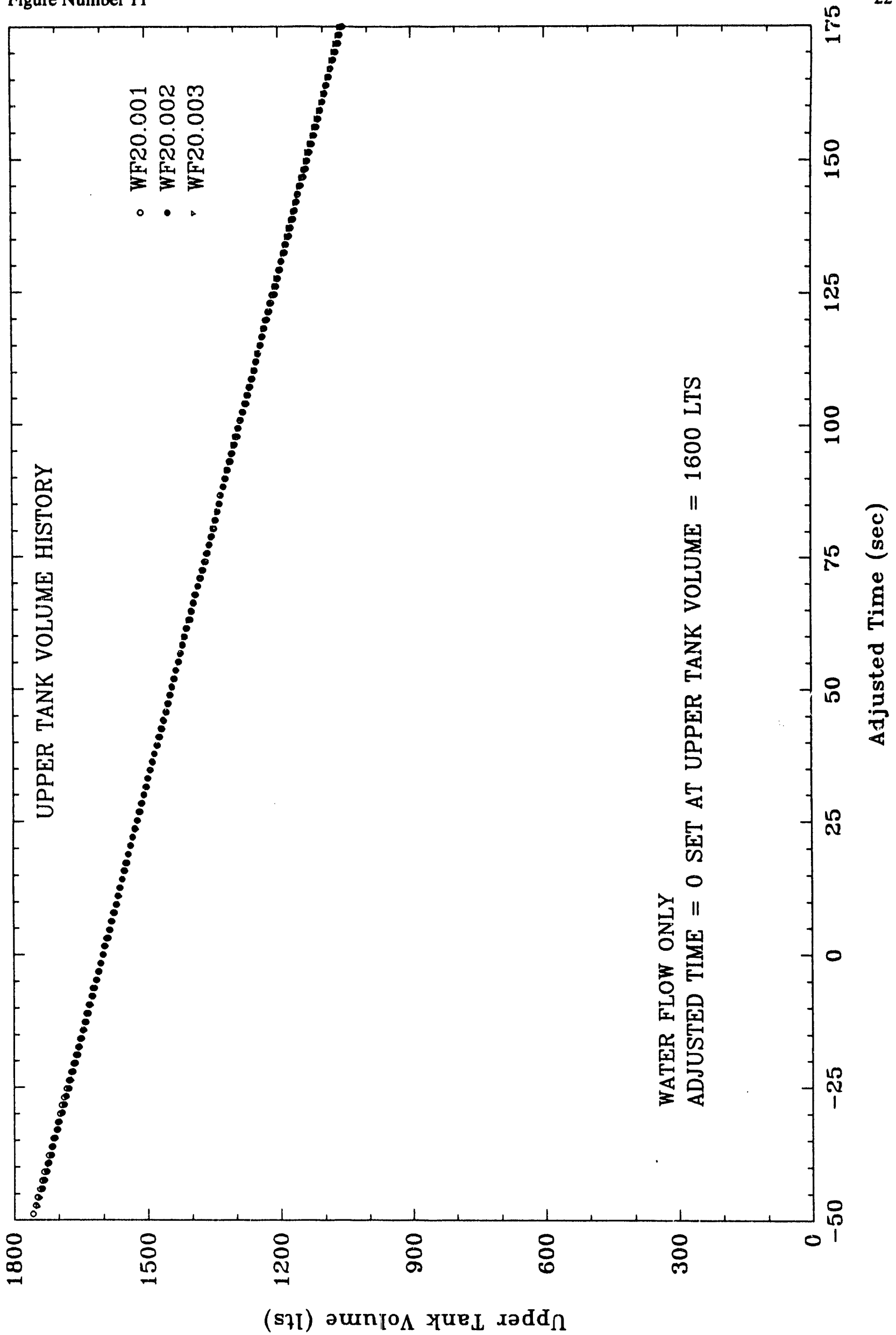




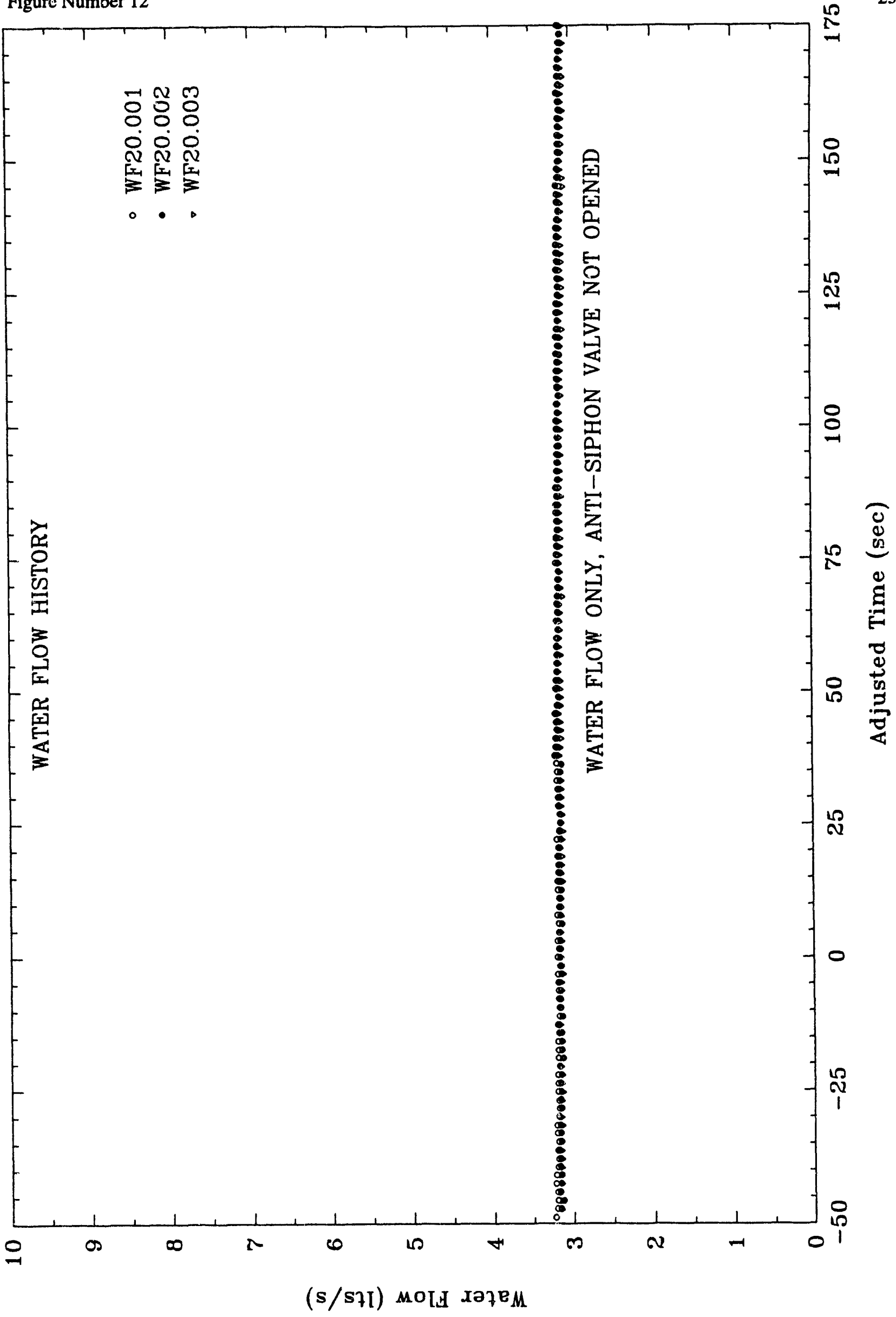


Figure Number 13

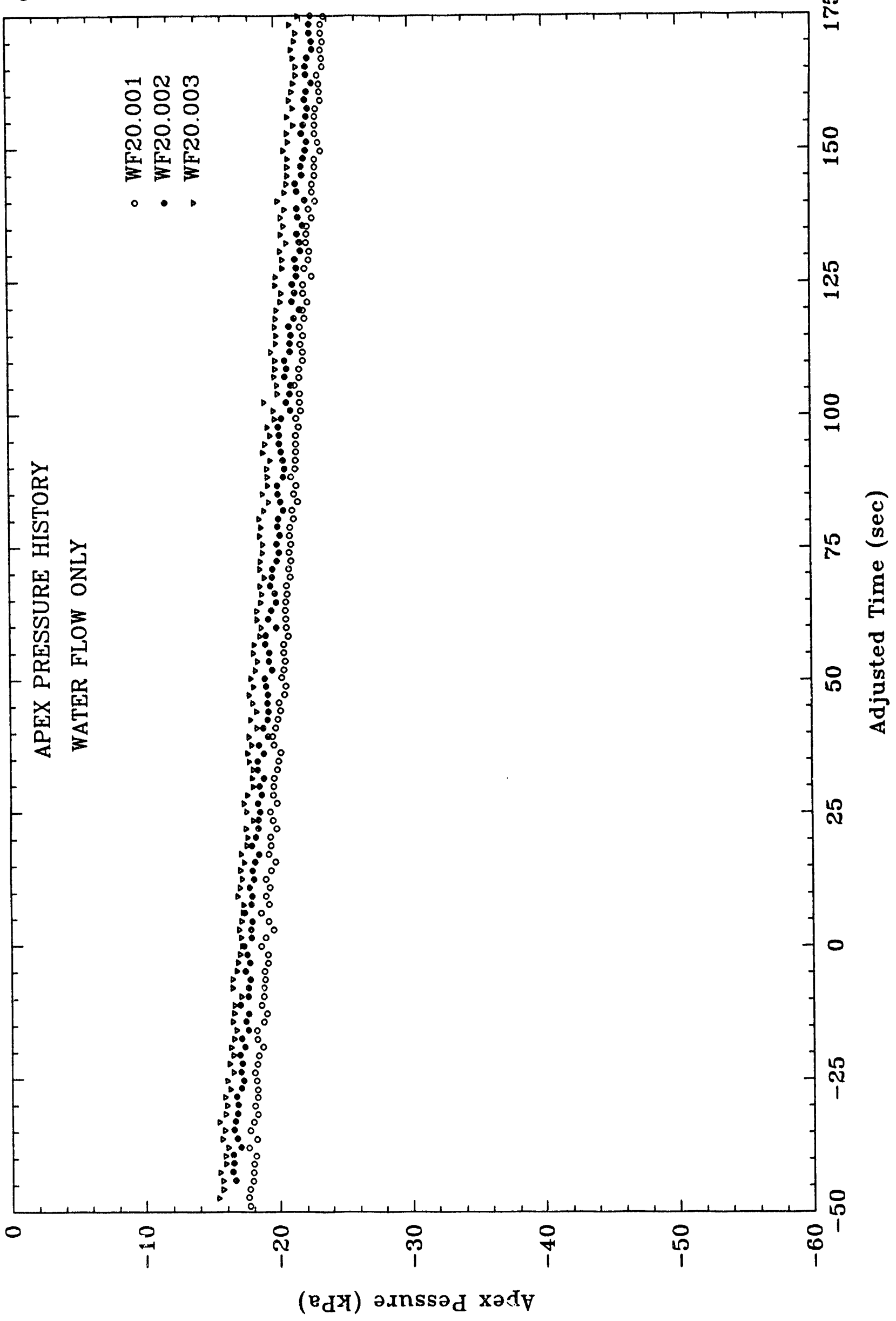


Figure Number 14

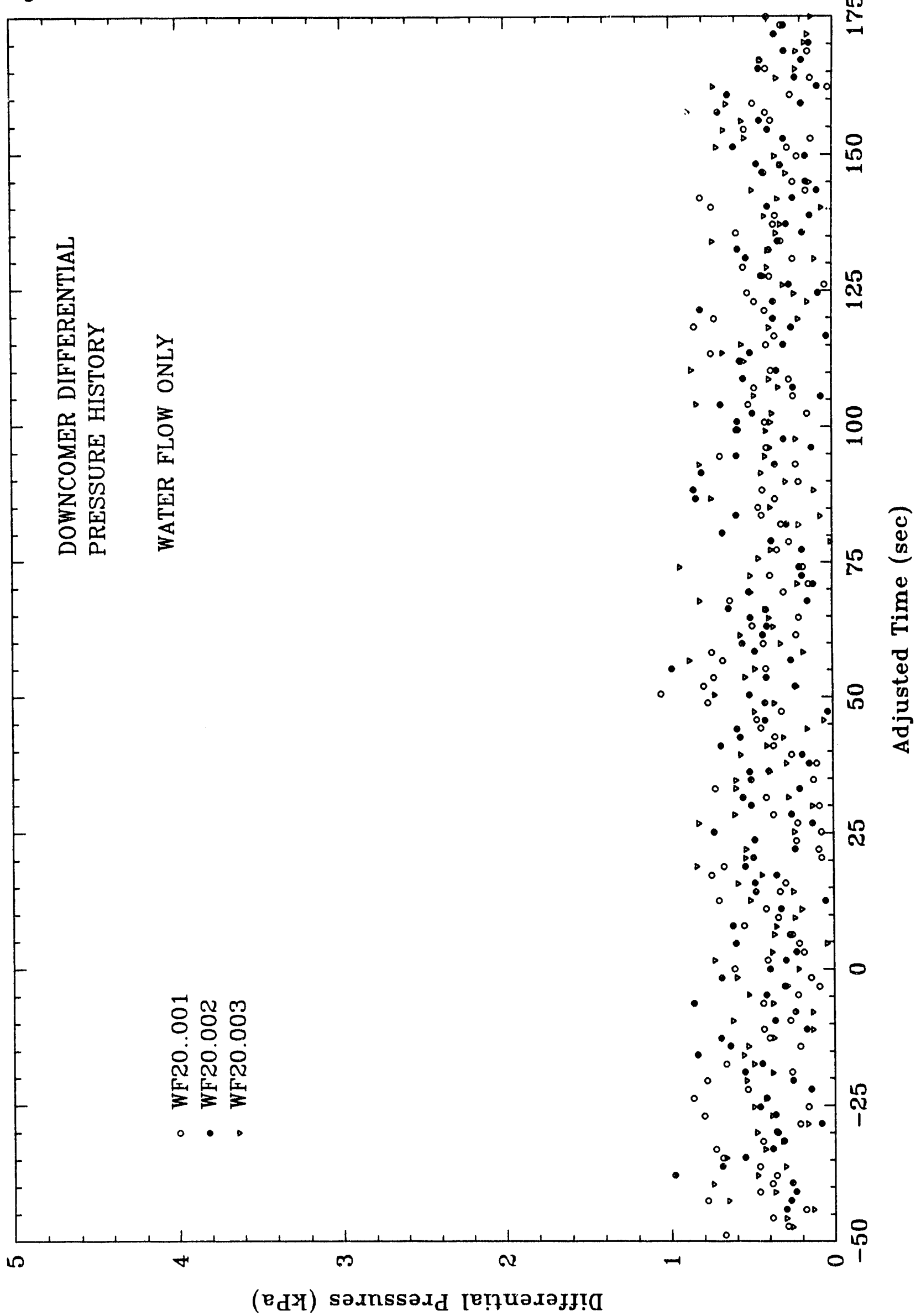


Figure Number 15

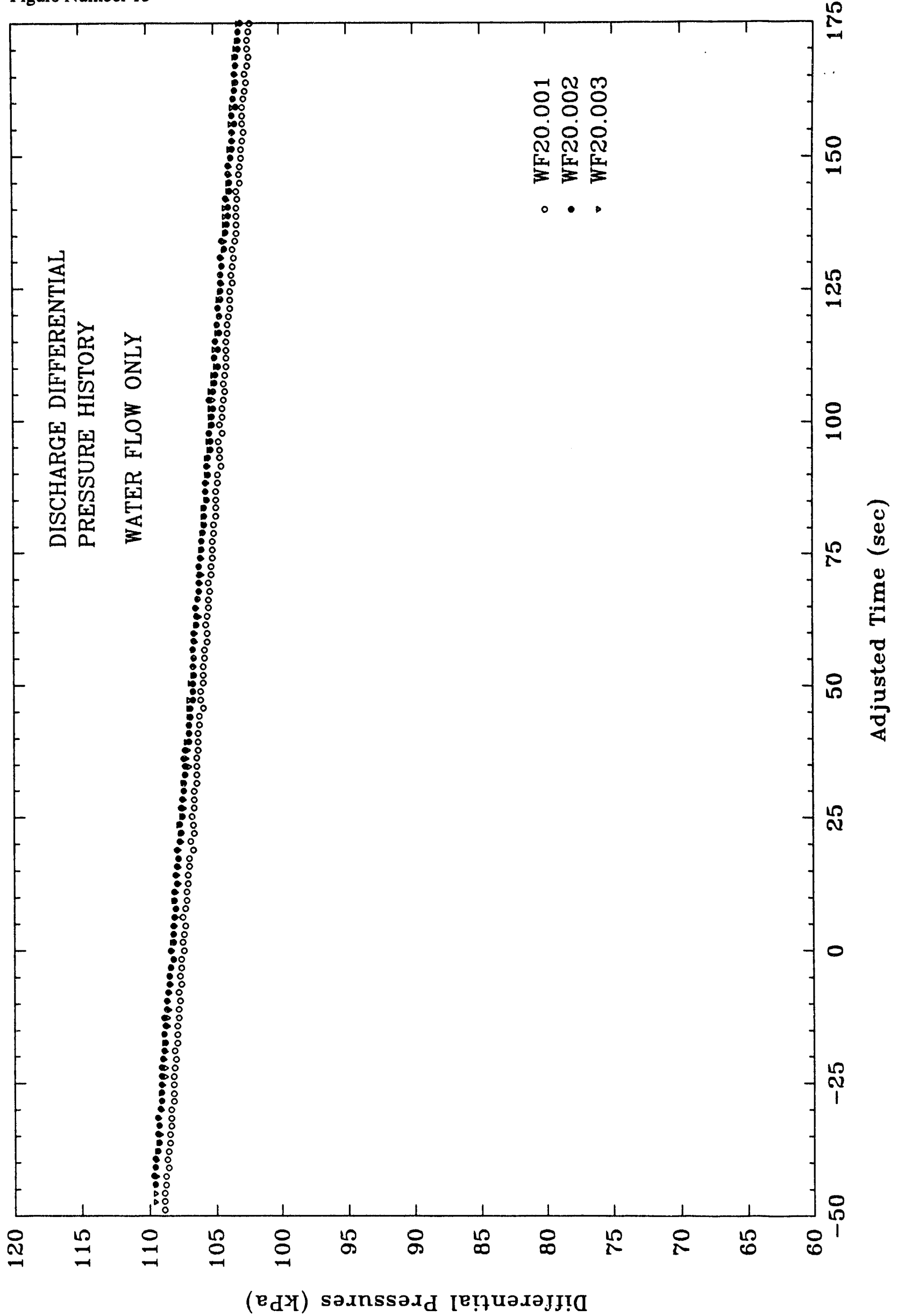




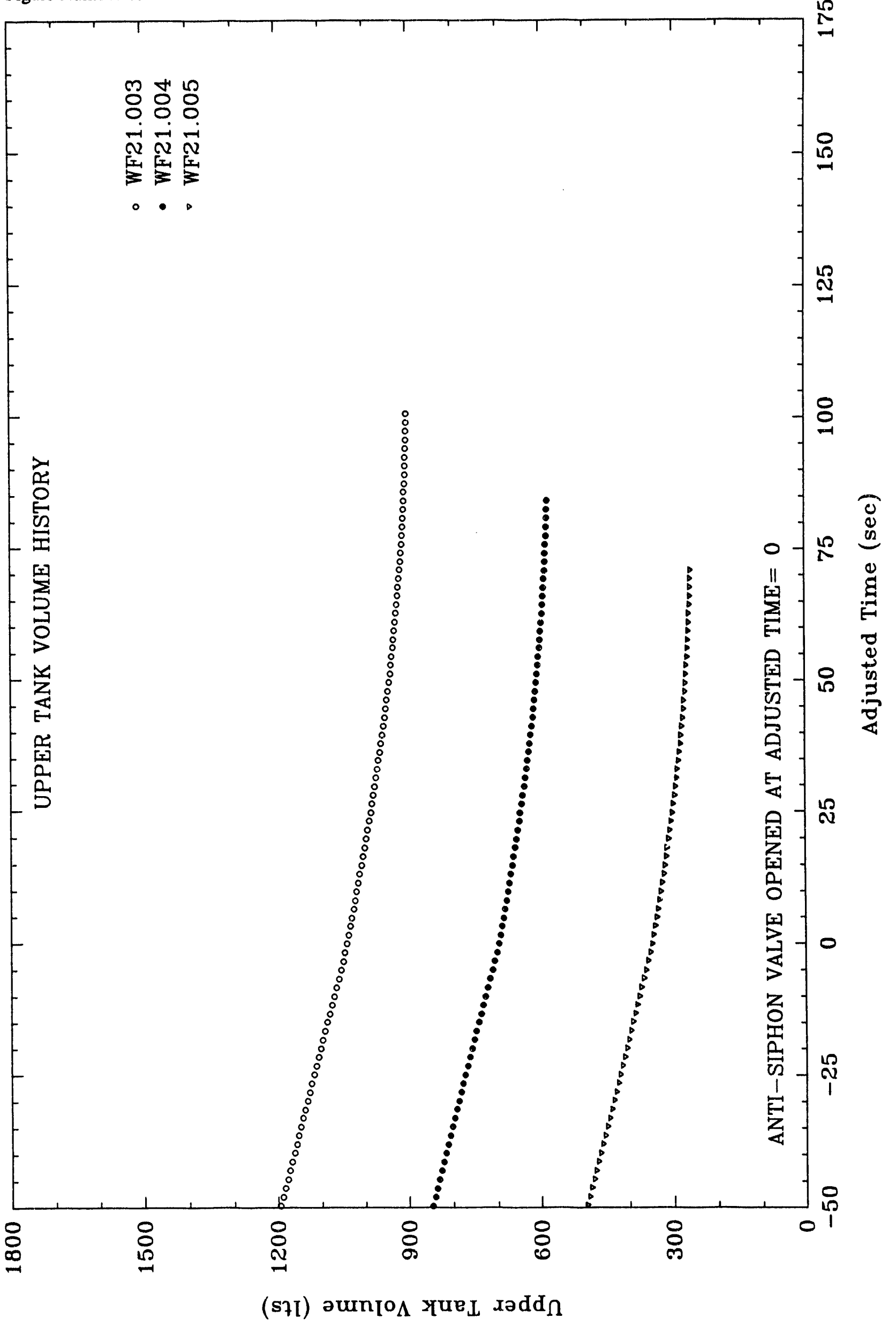


Figure Number 17

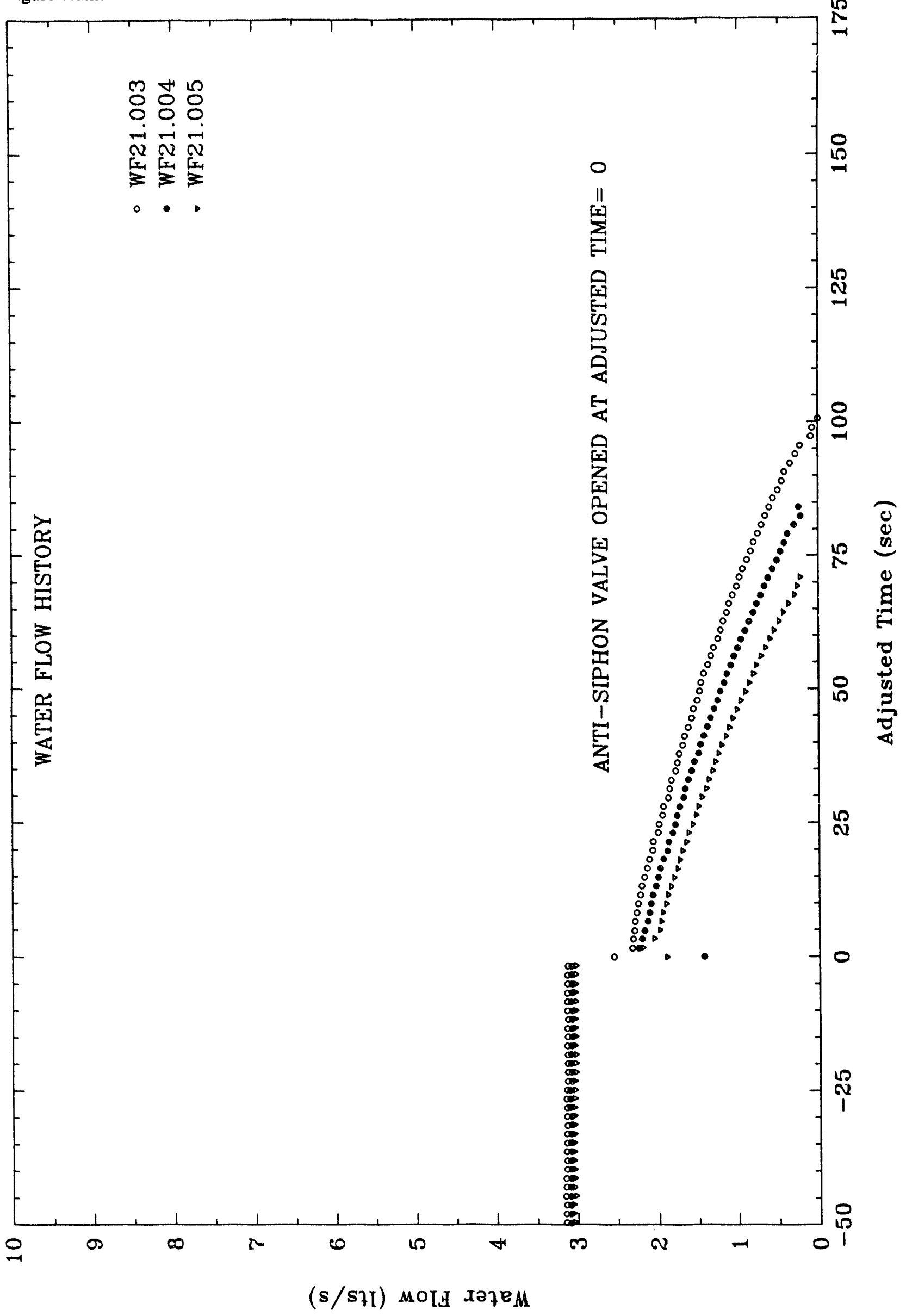




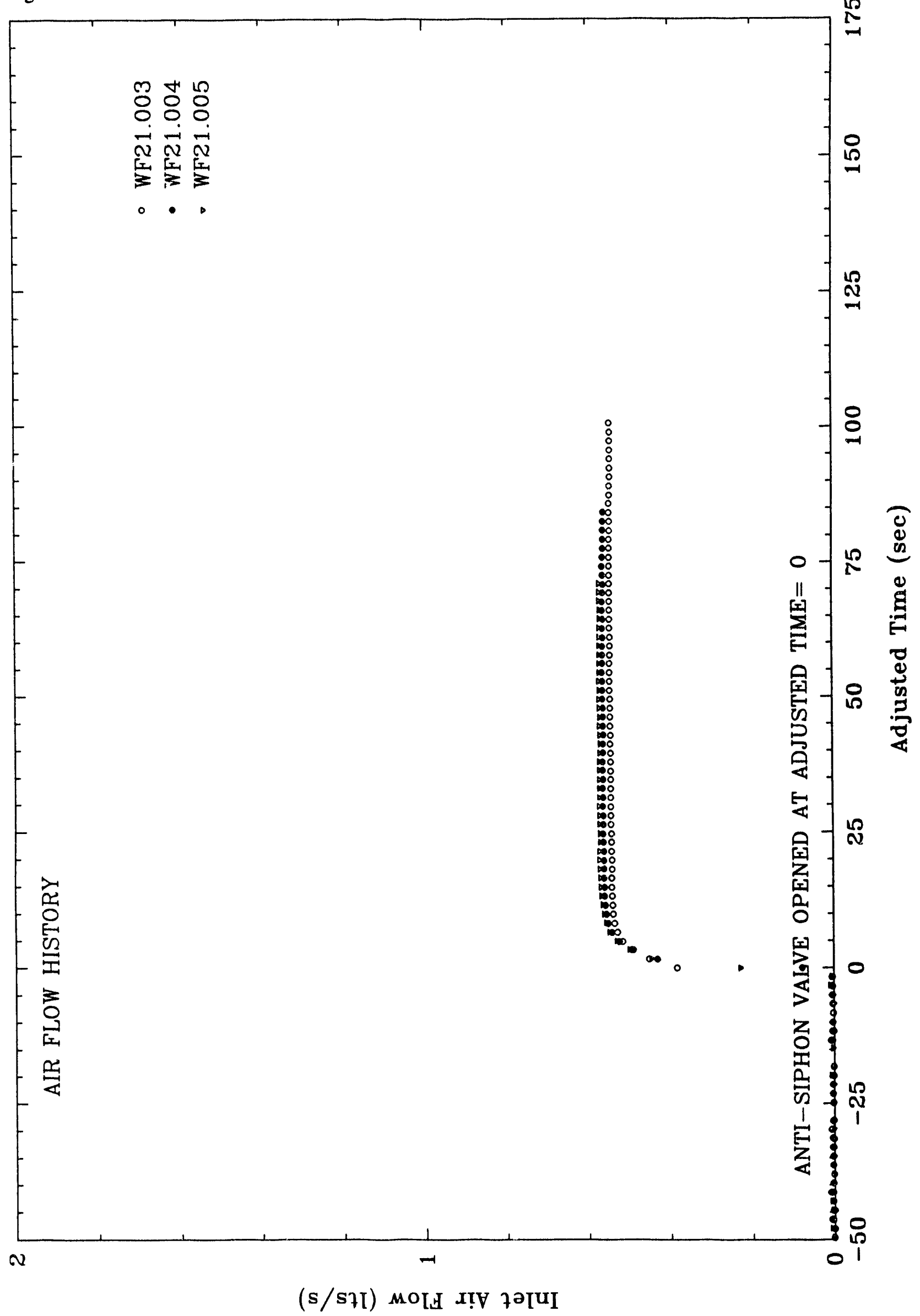


Figure Number 19

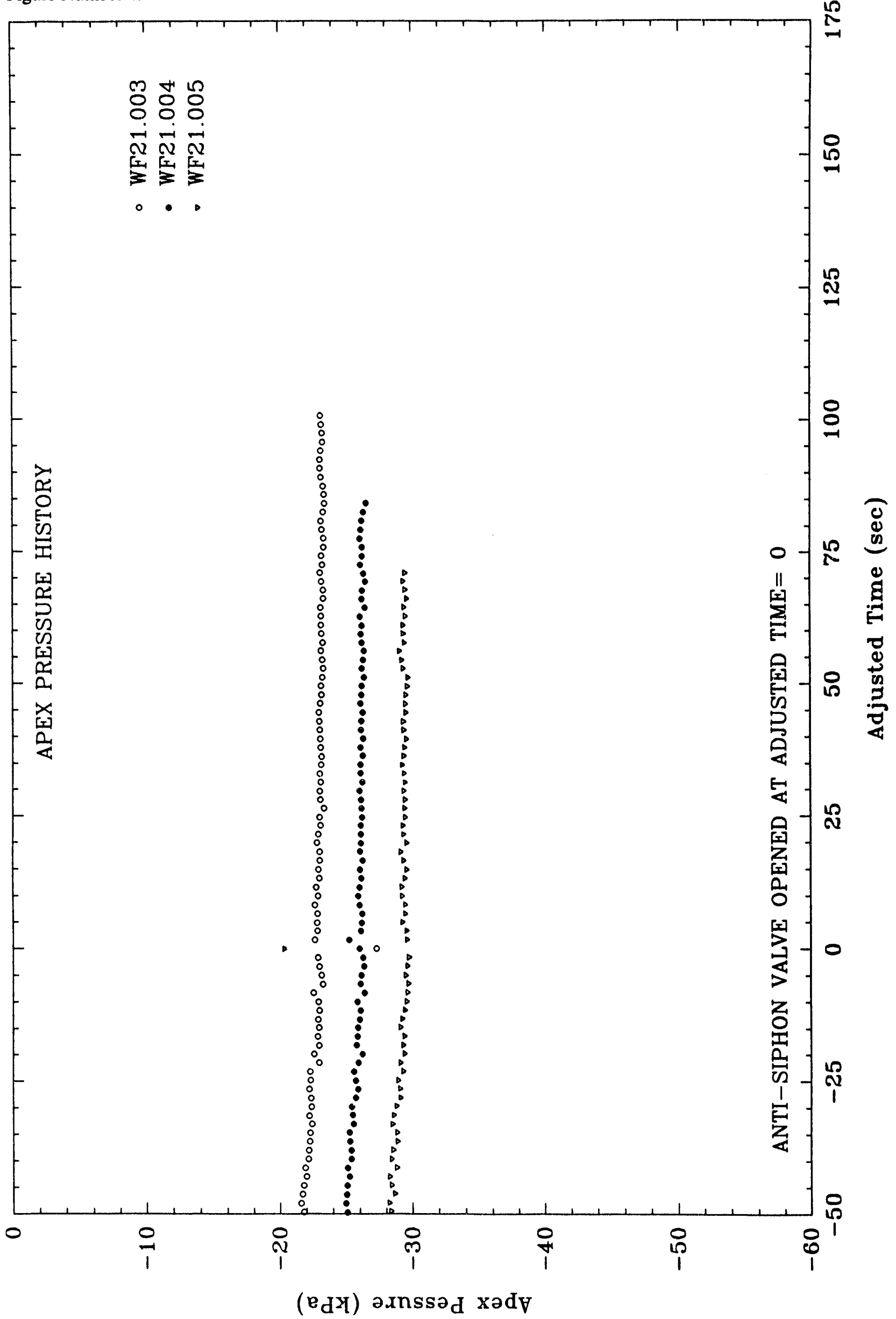




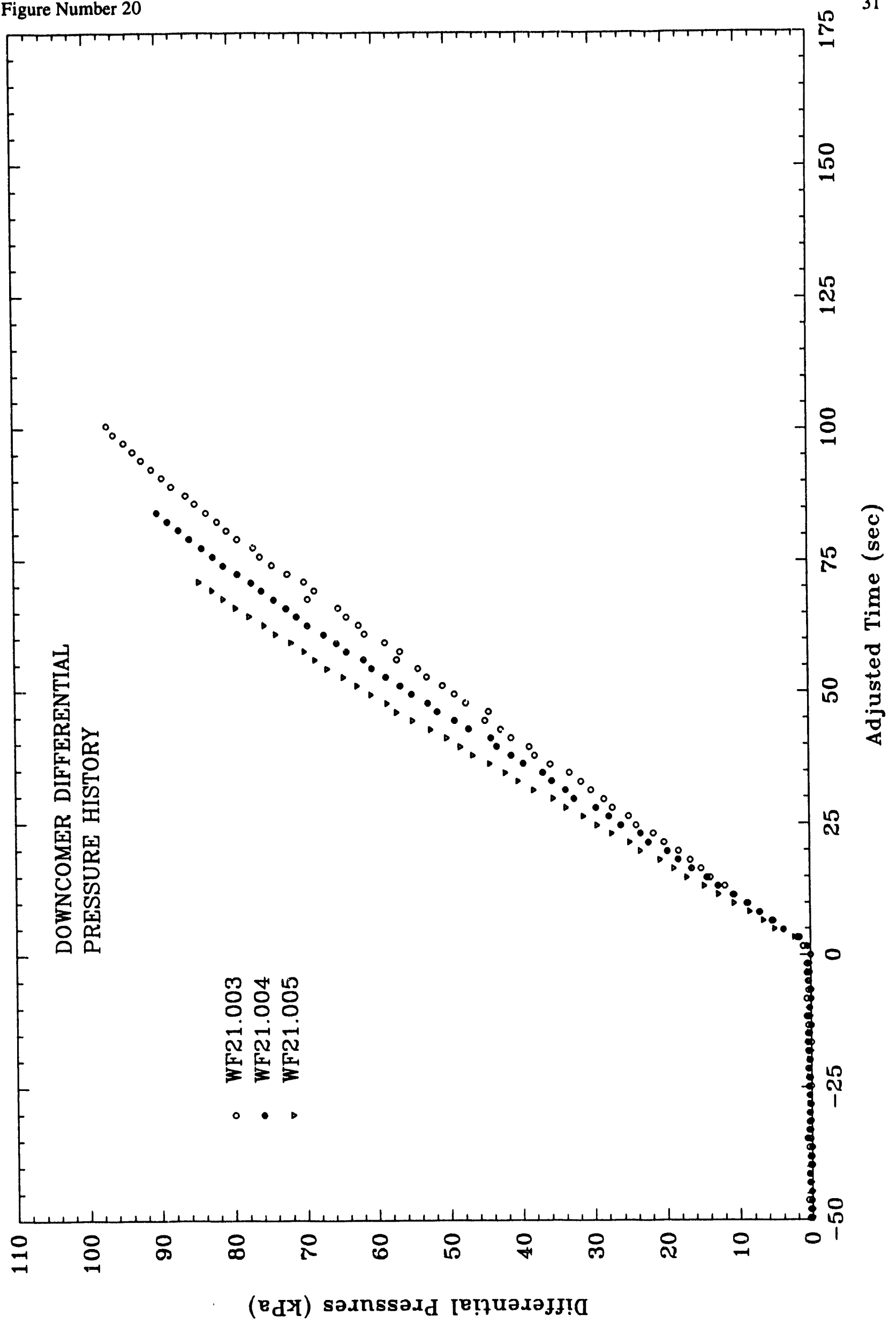


Figure Number 21

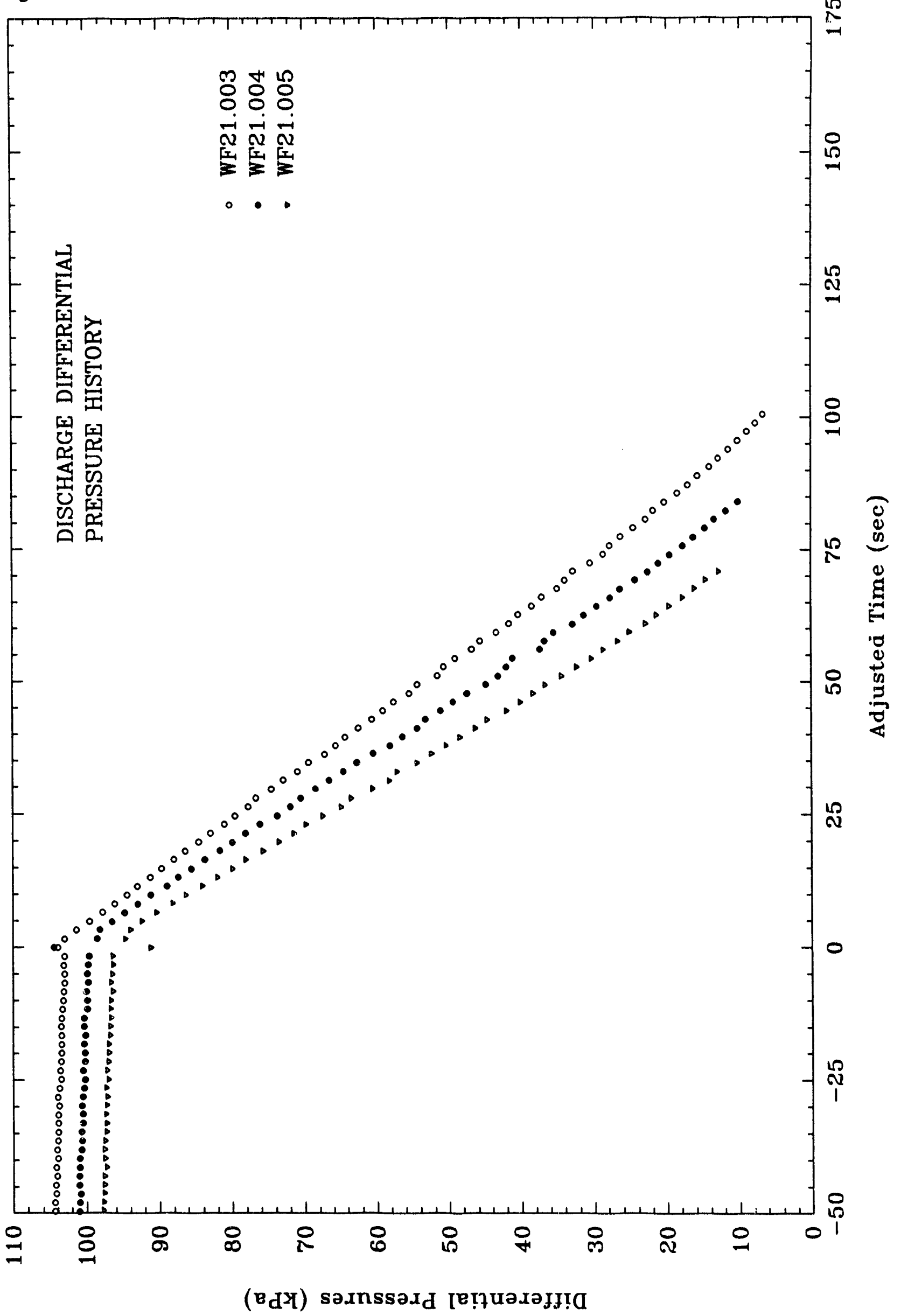


Figure Number 22

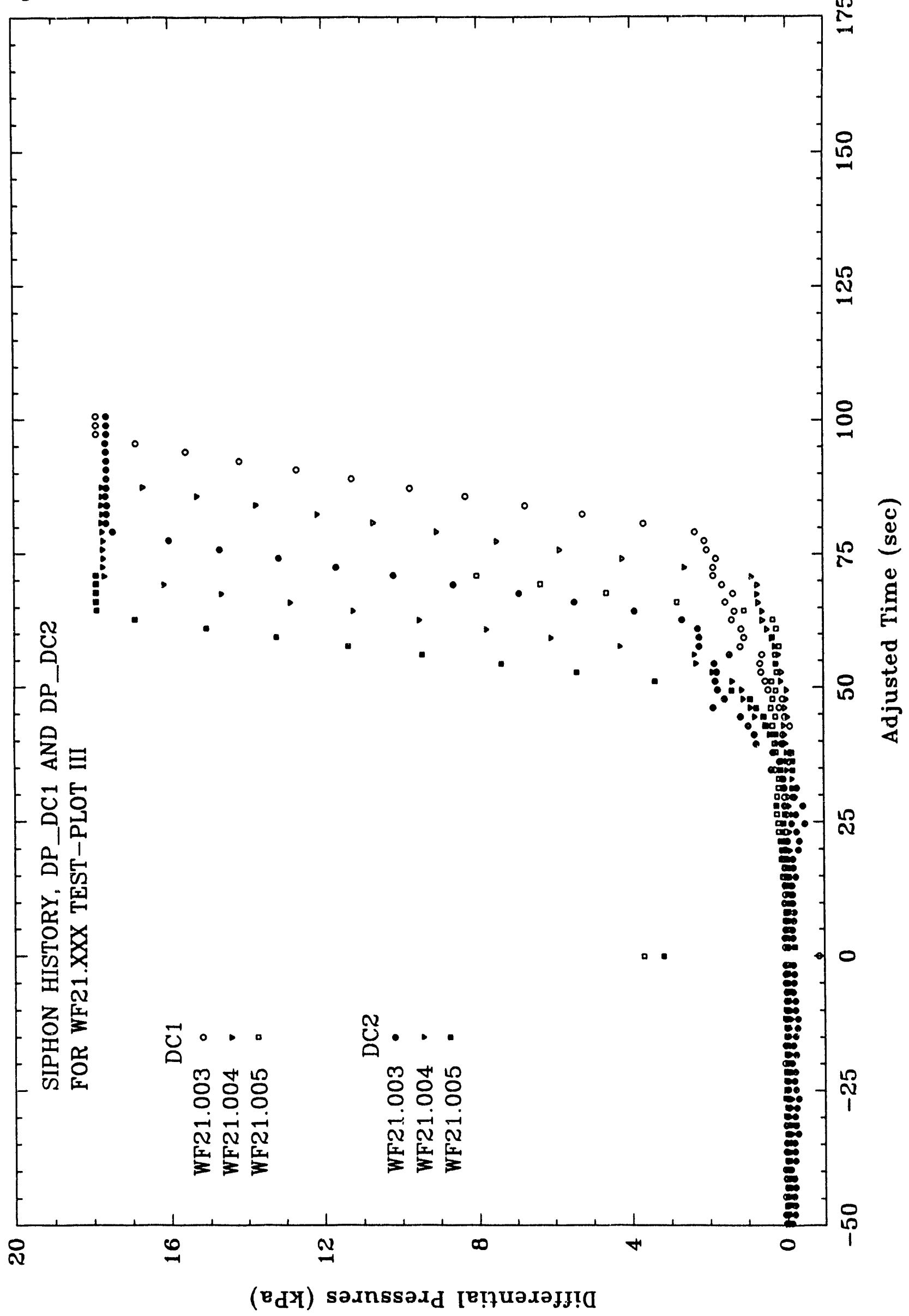




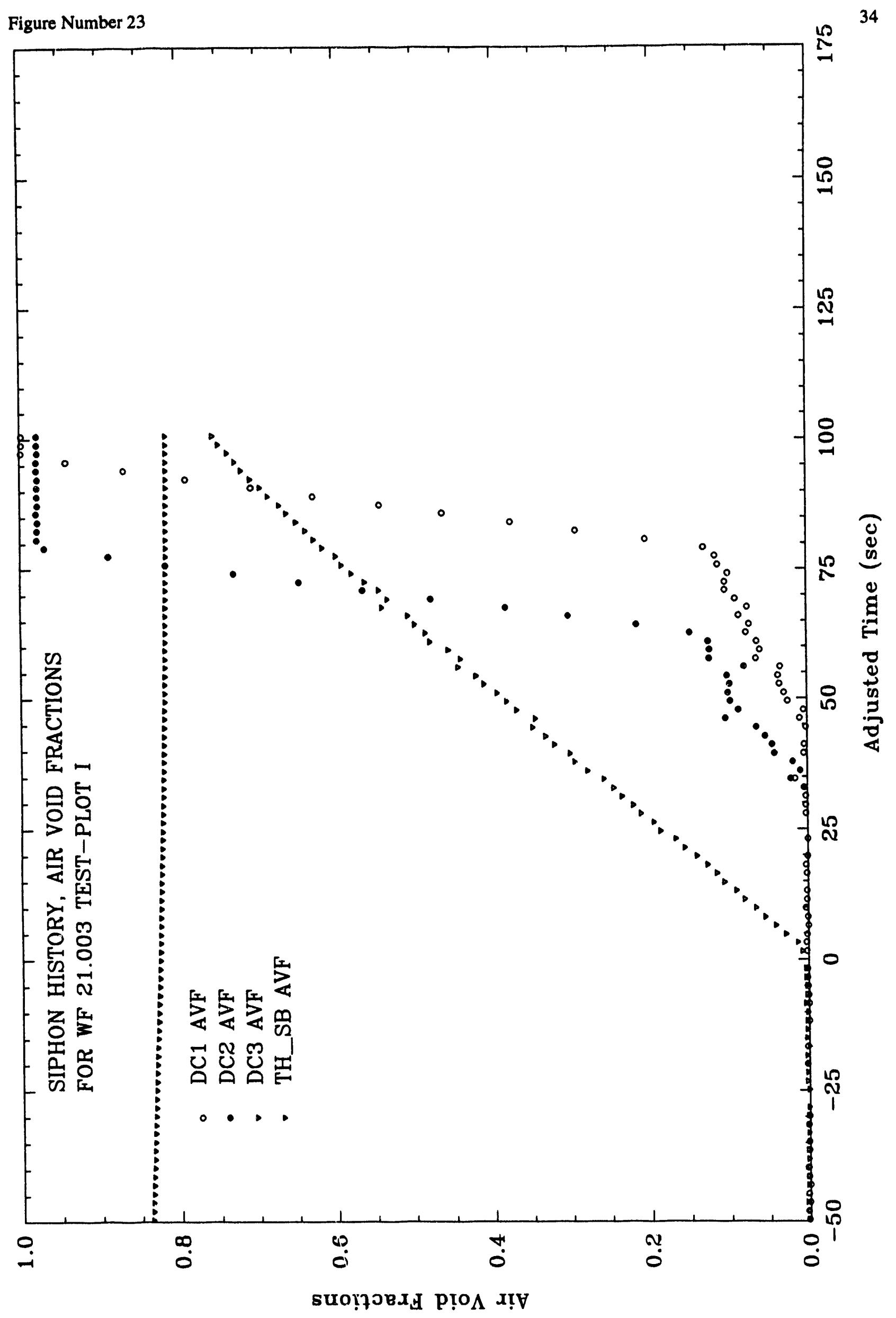




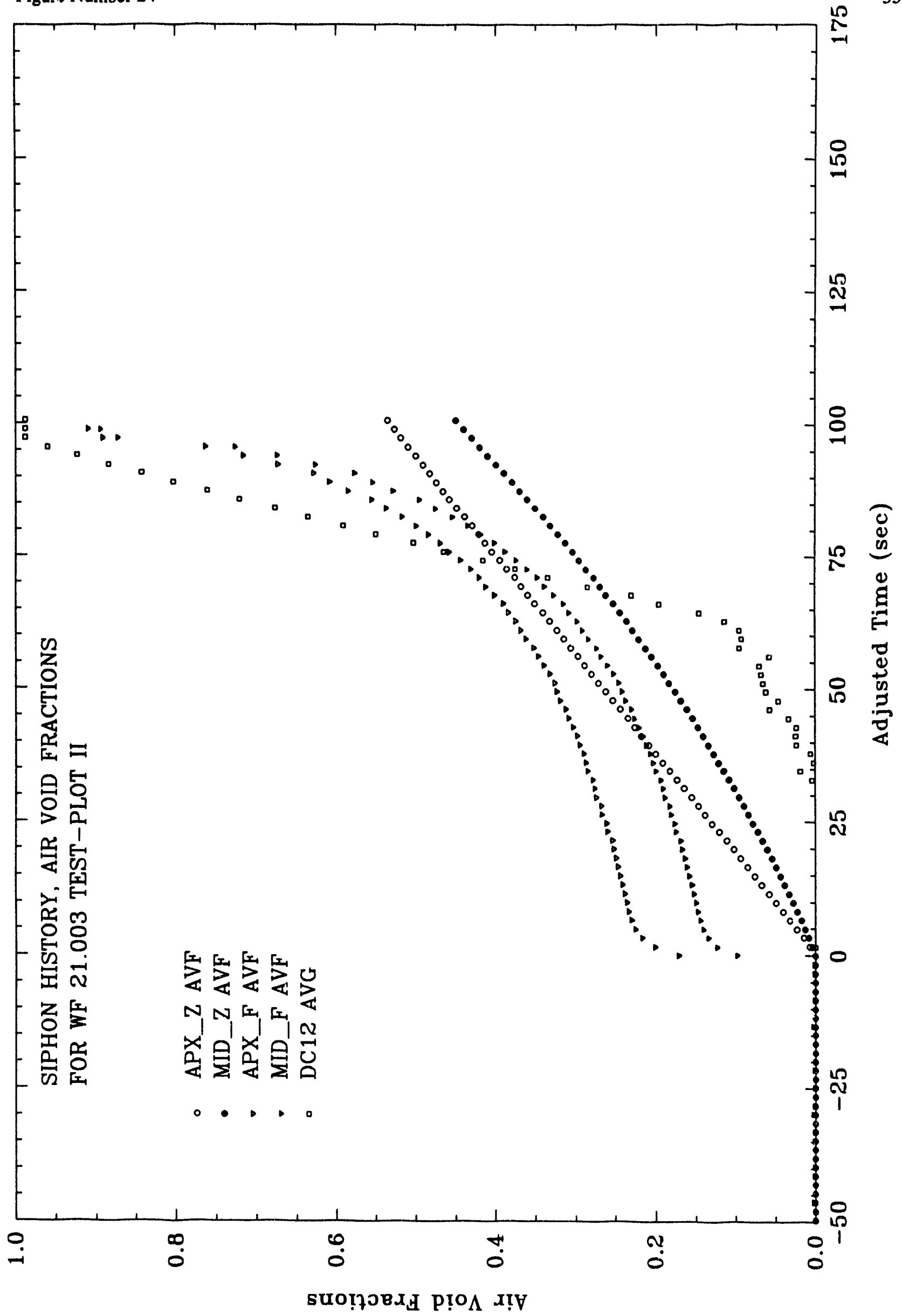




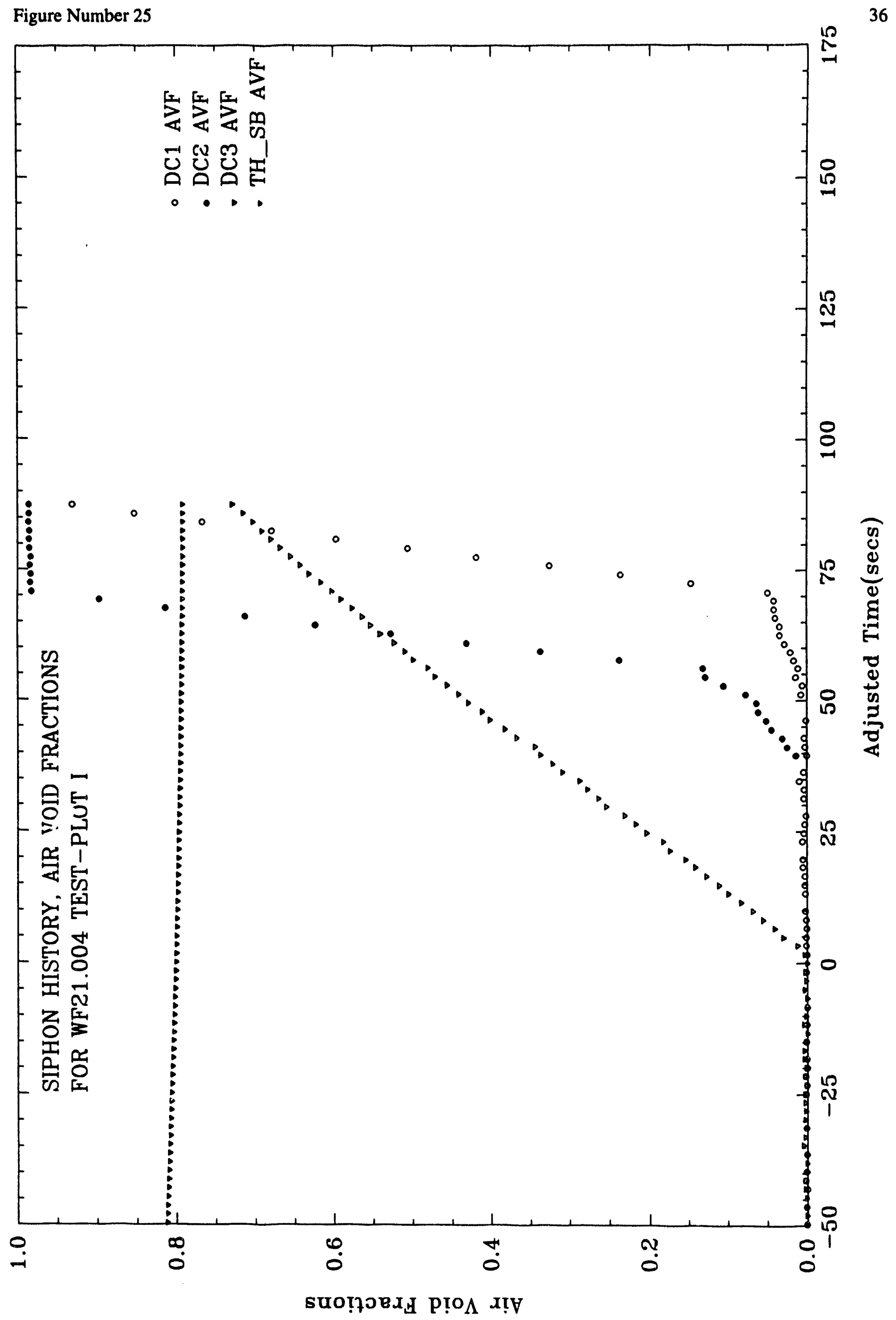


Figure Number 26

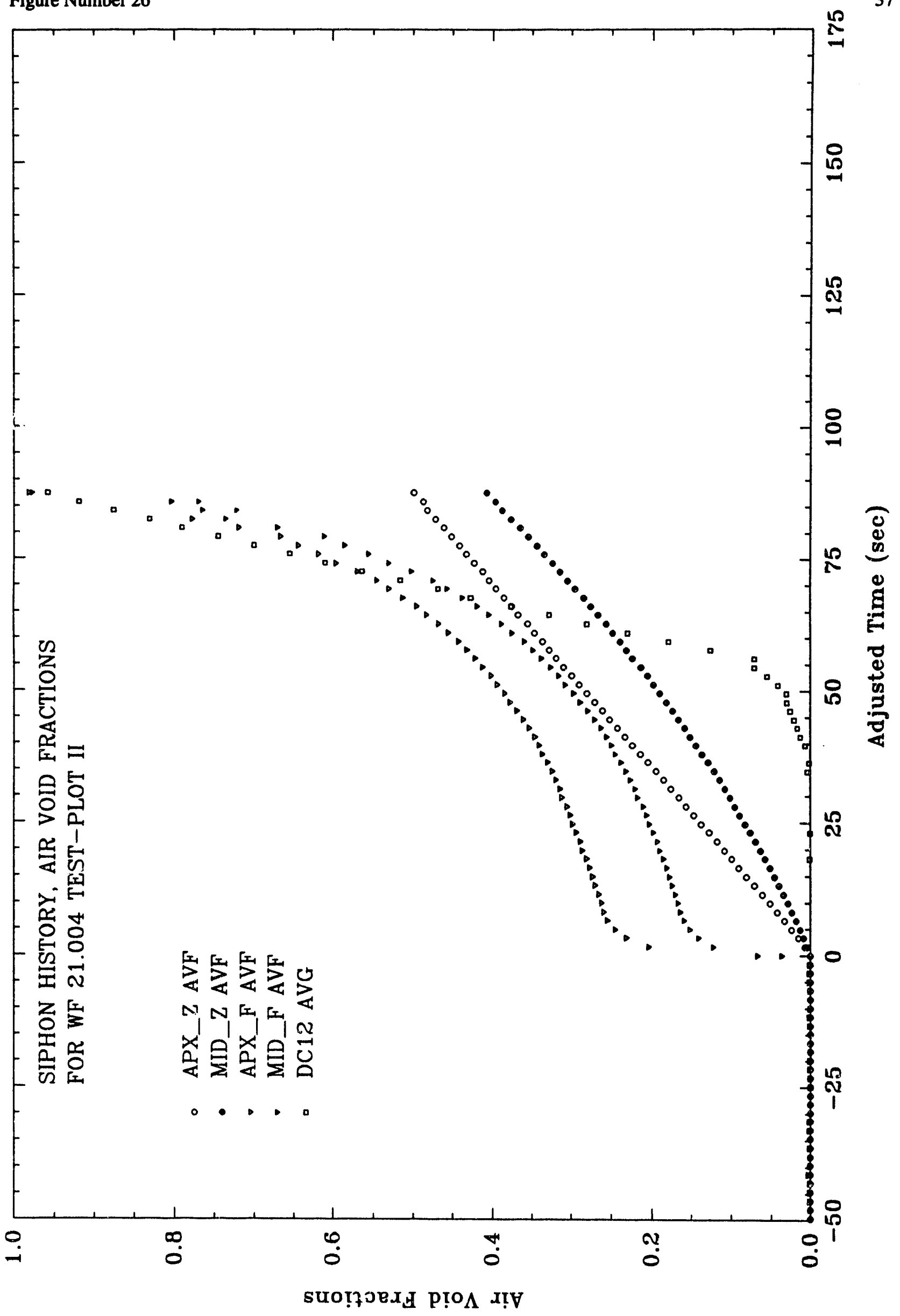




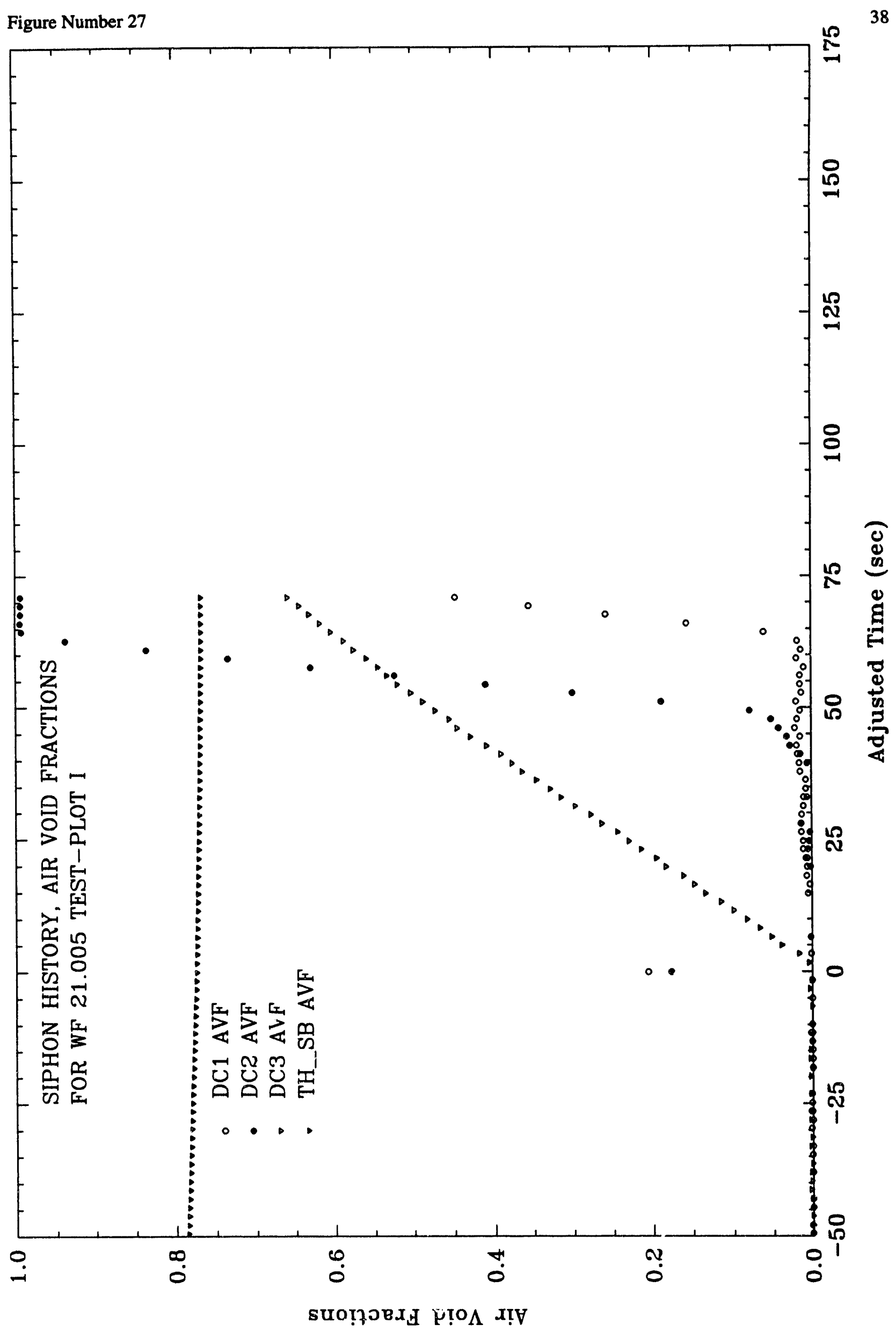




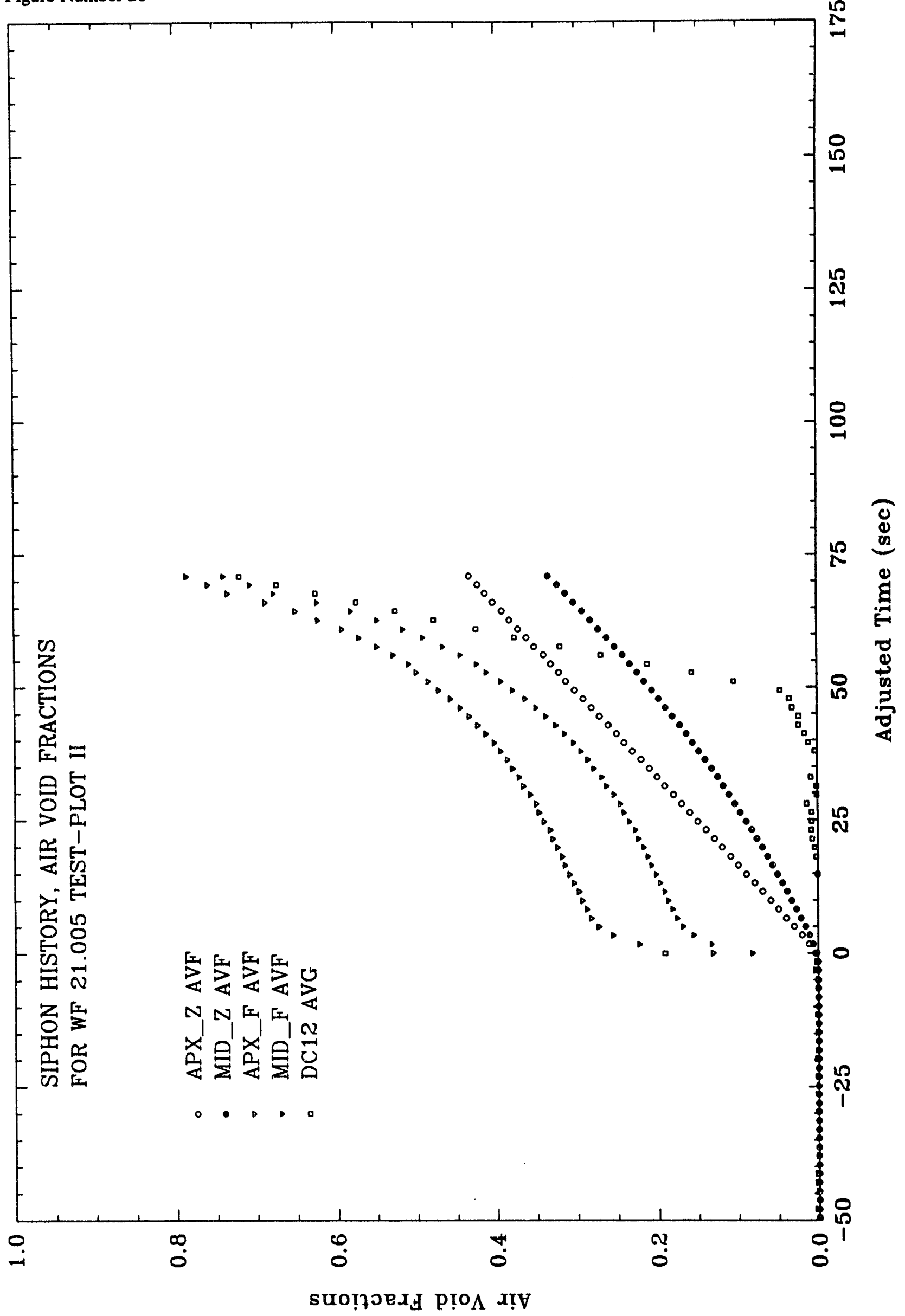




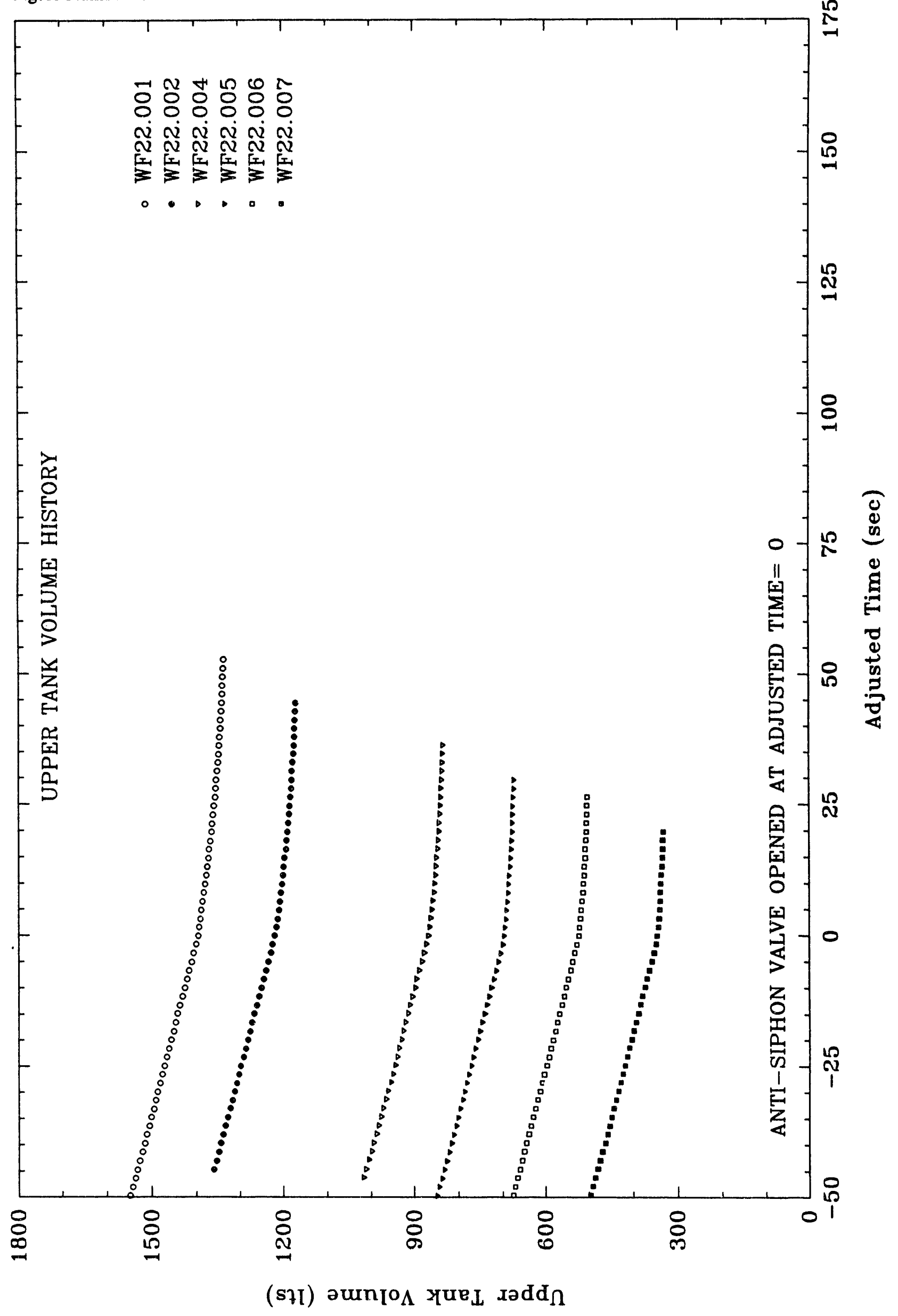




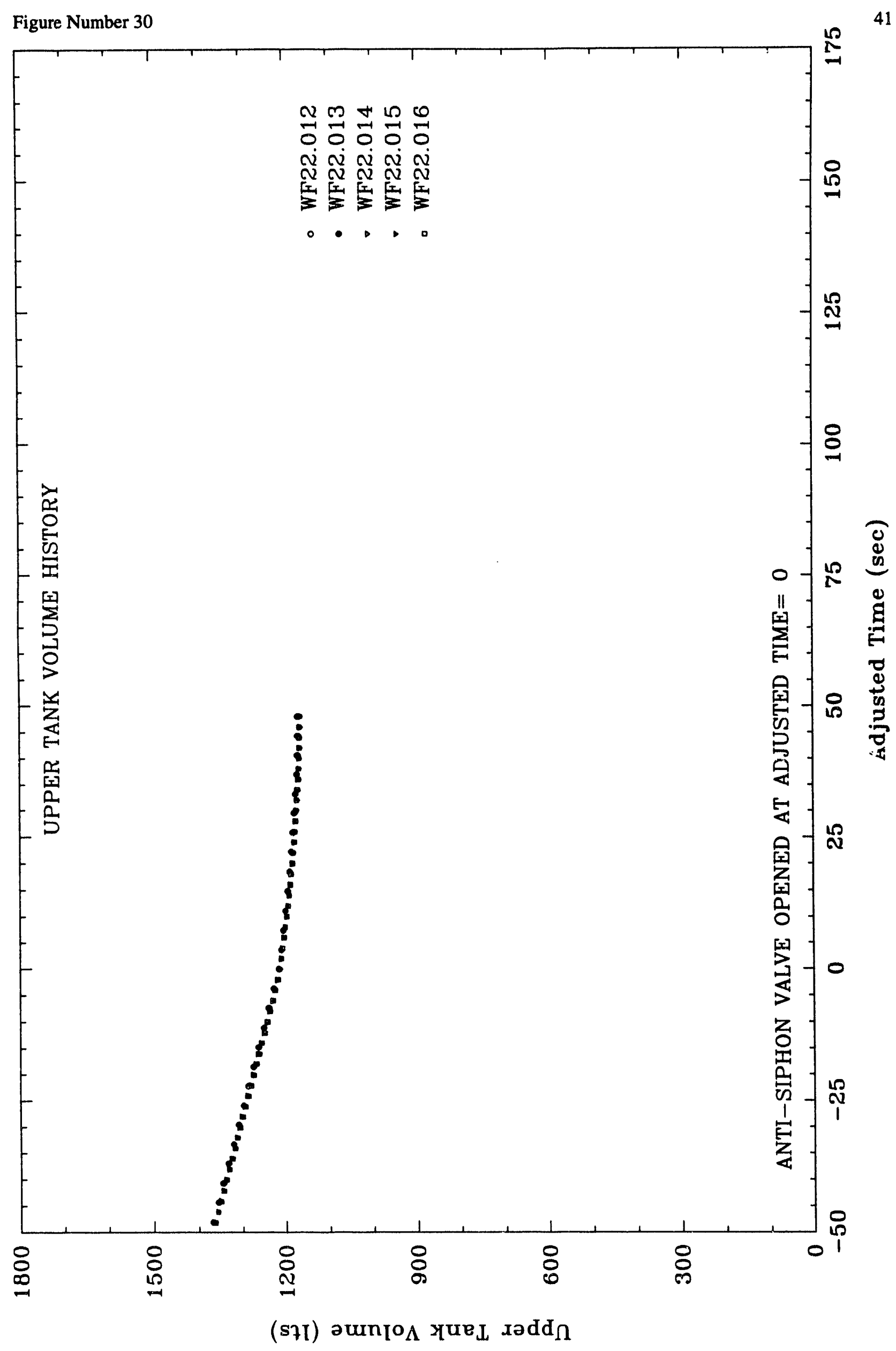


Figure Number 31

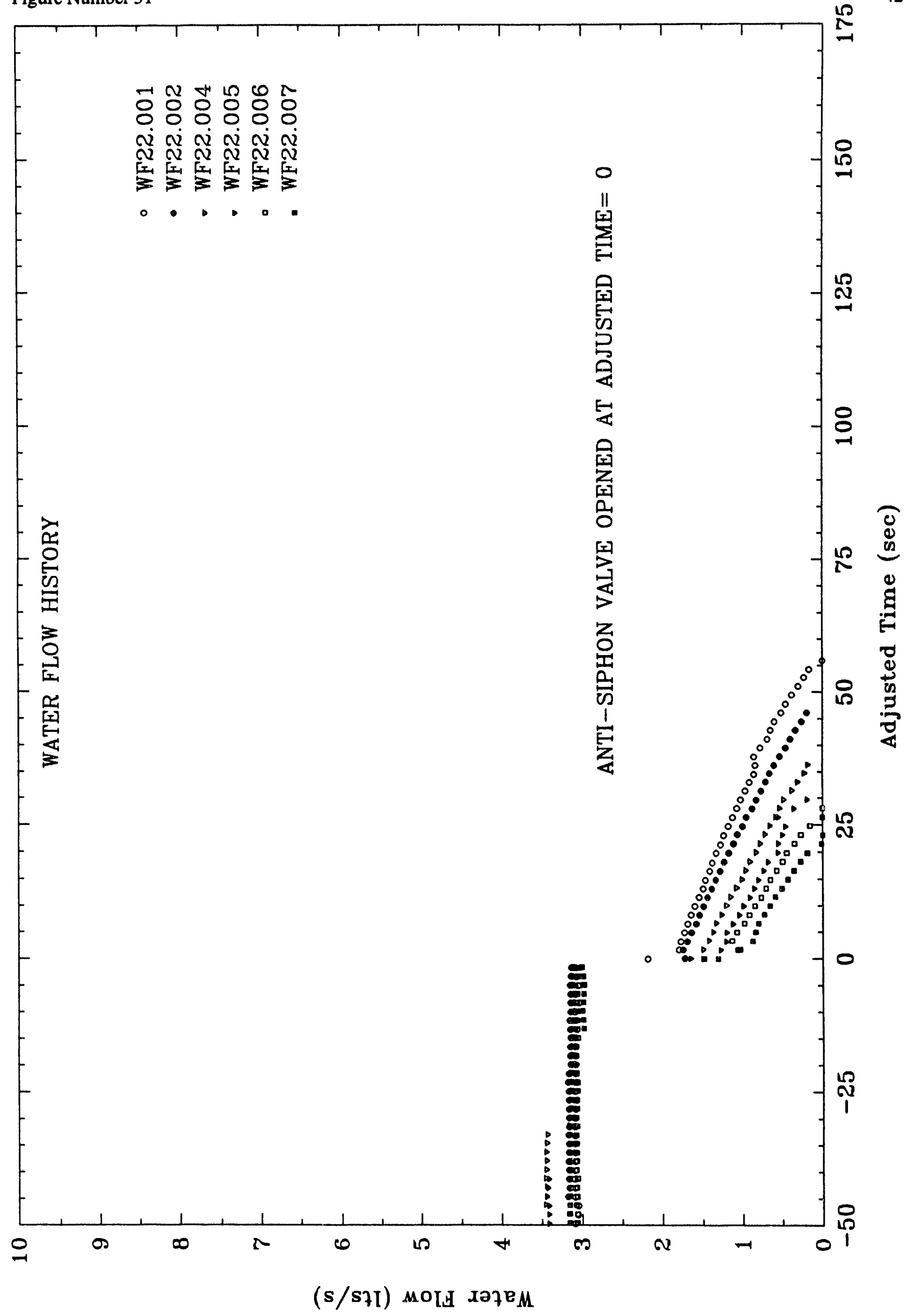


Figure Number 32

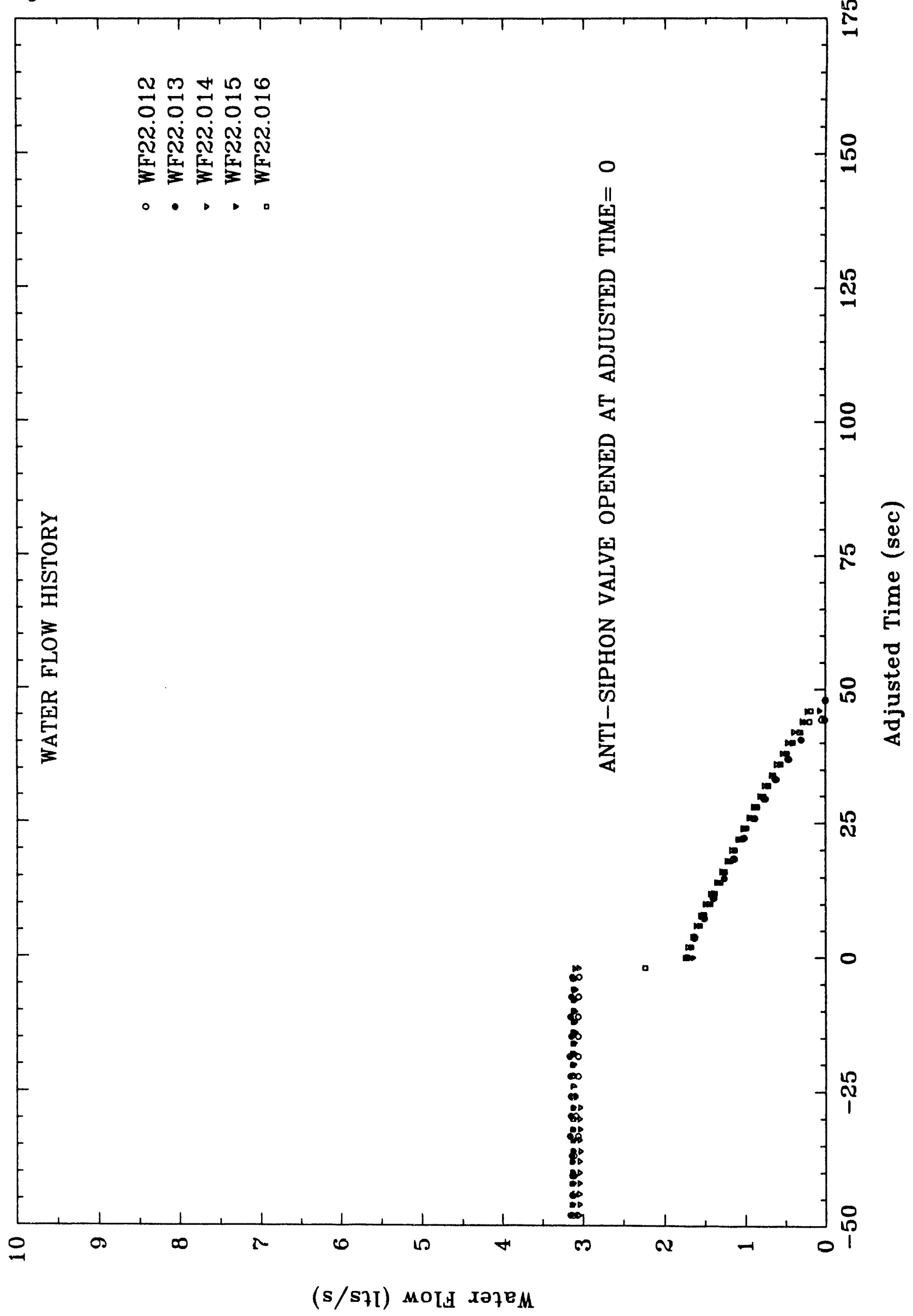




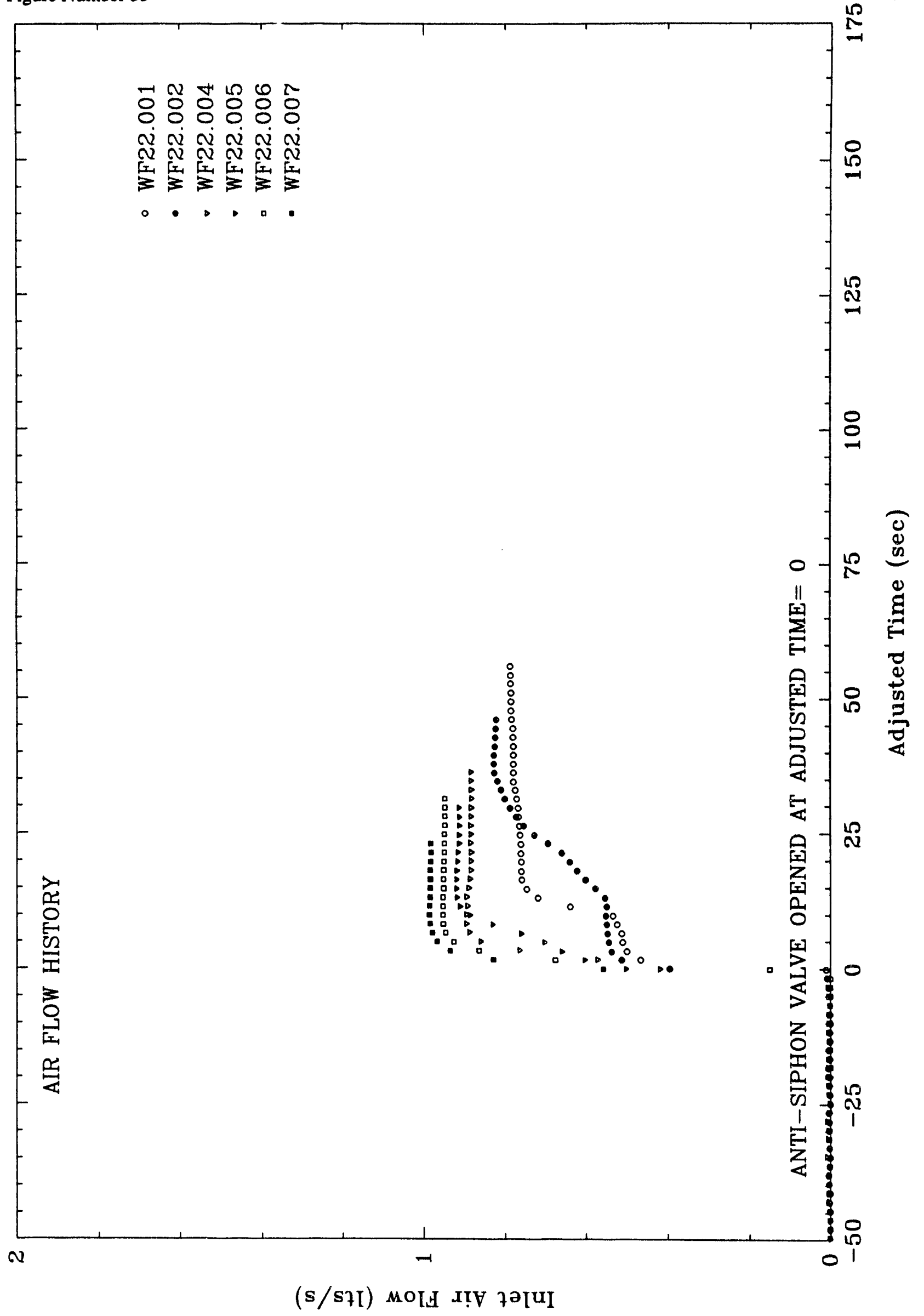




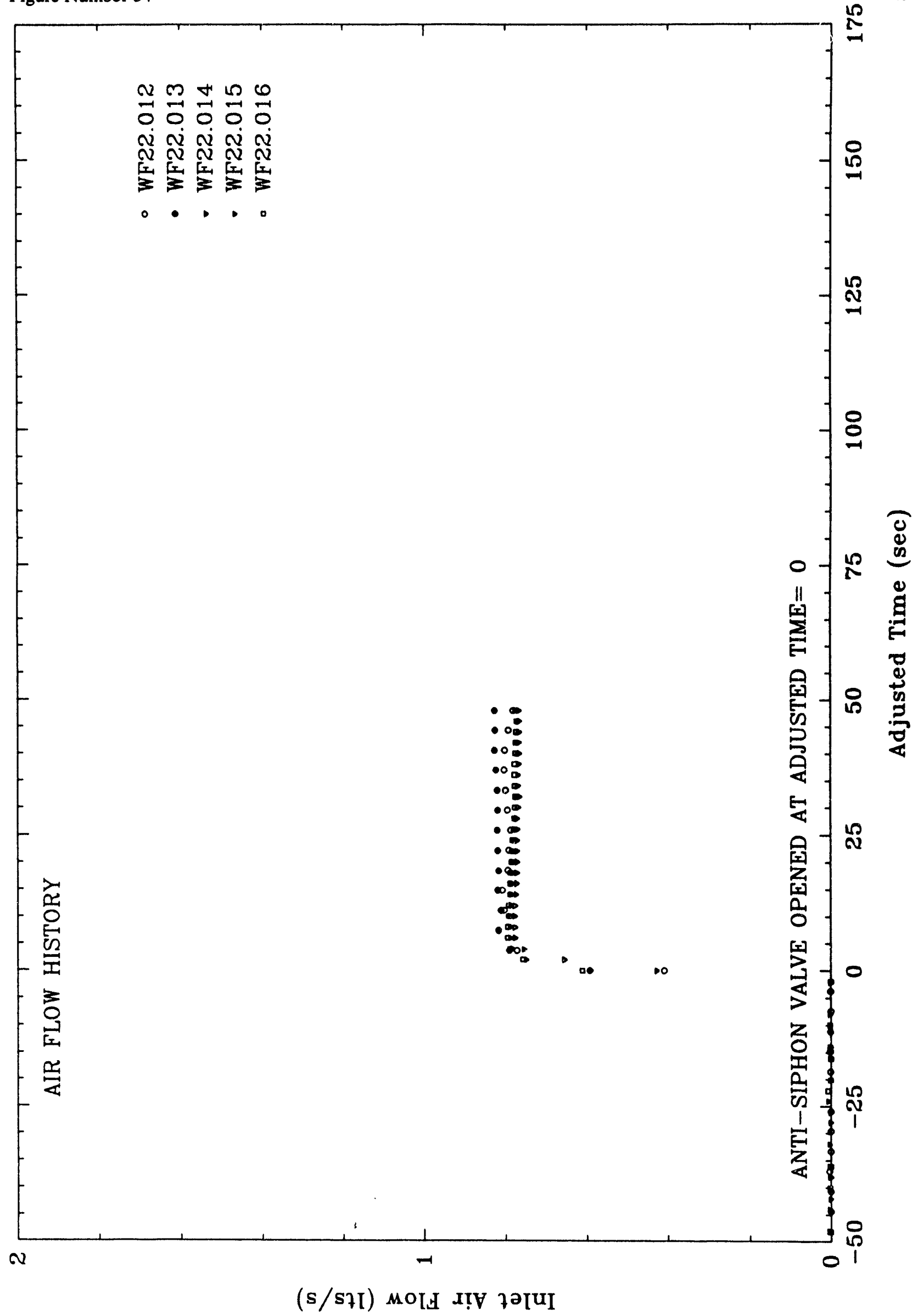




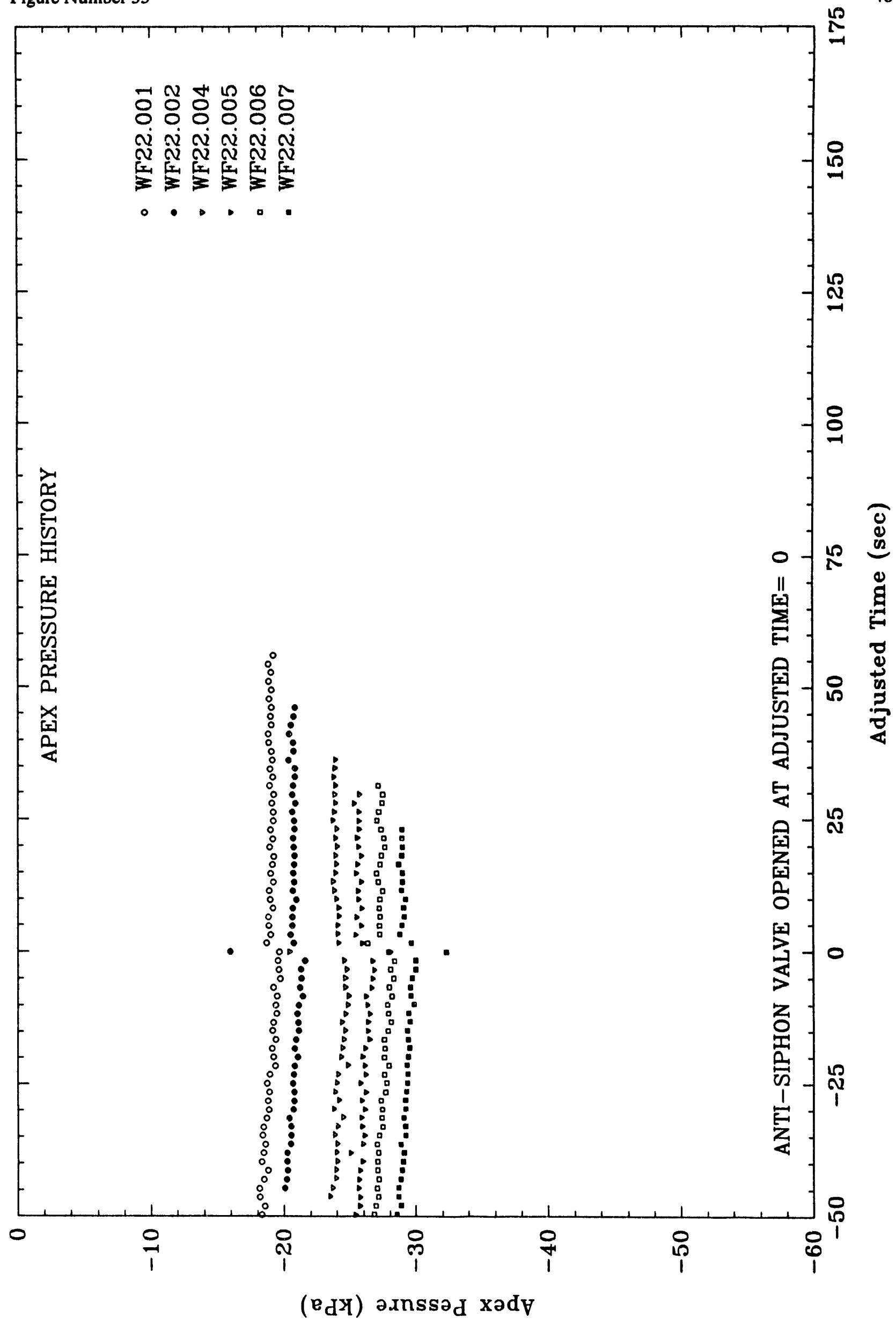




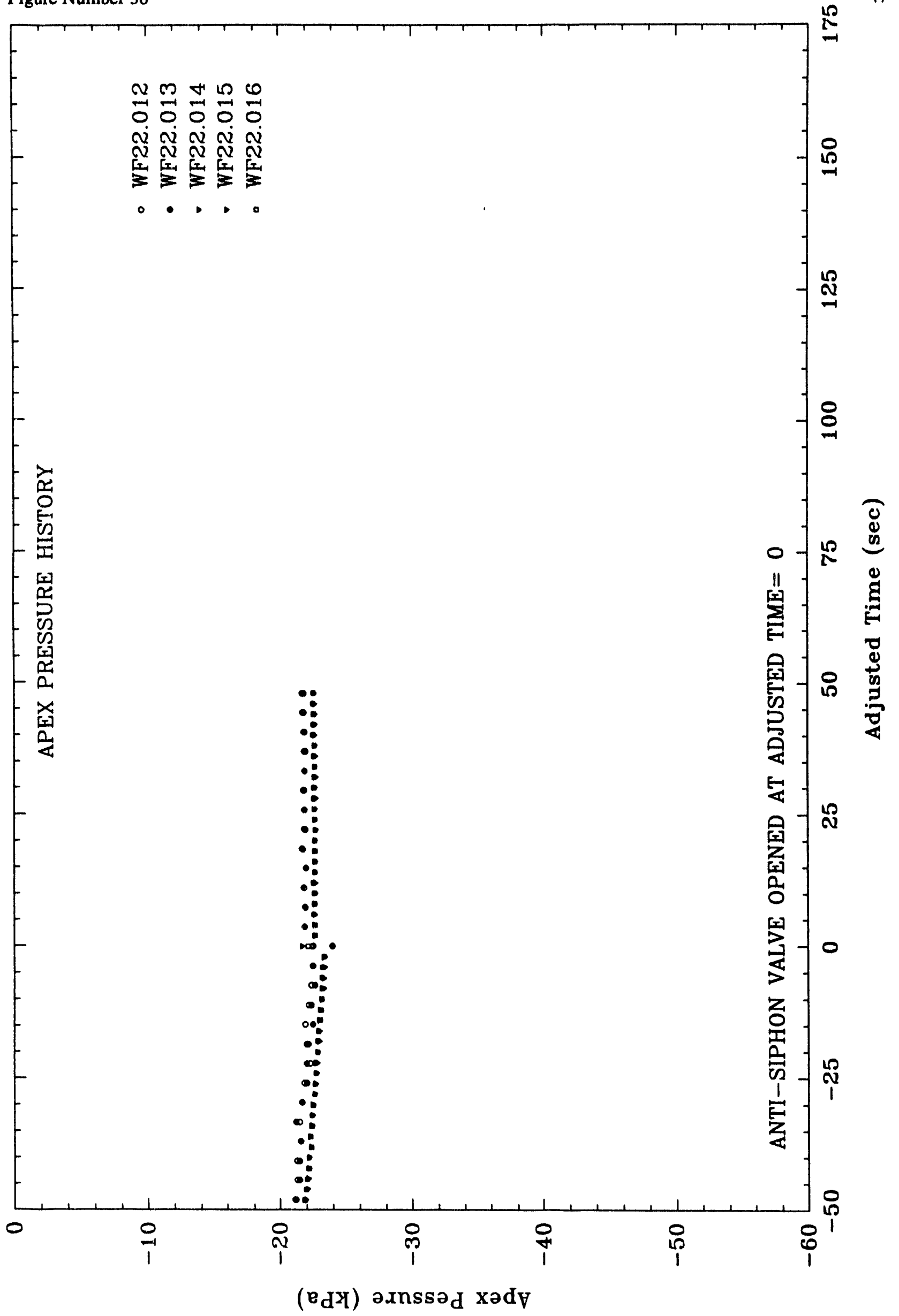


Figure Number 37

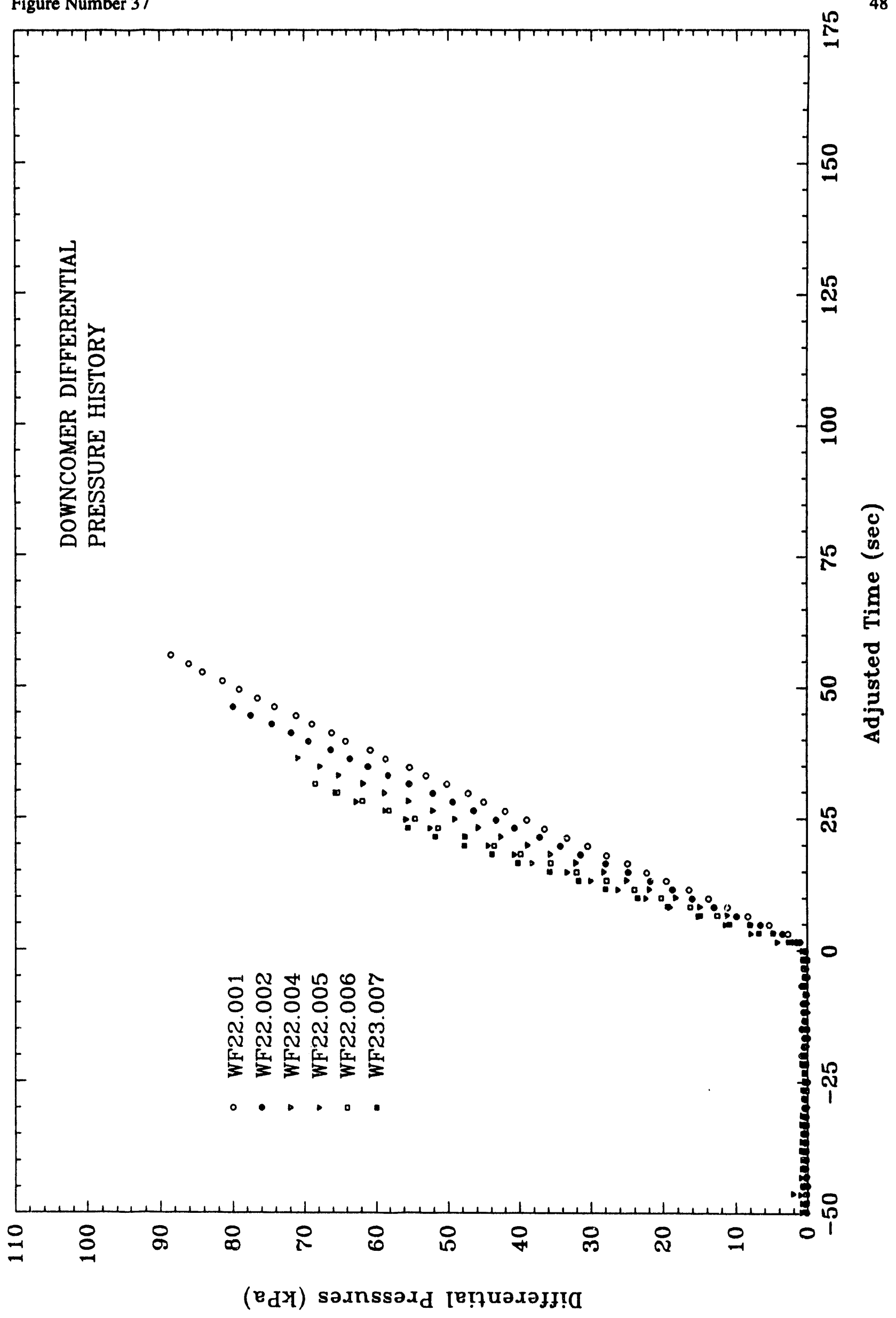




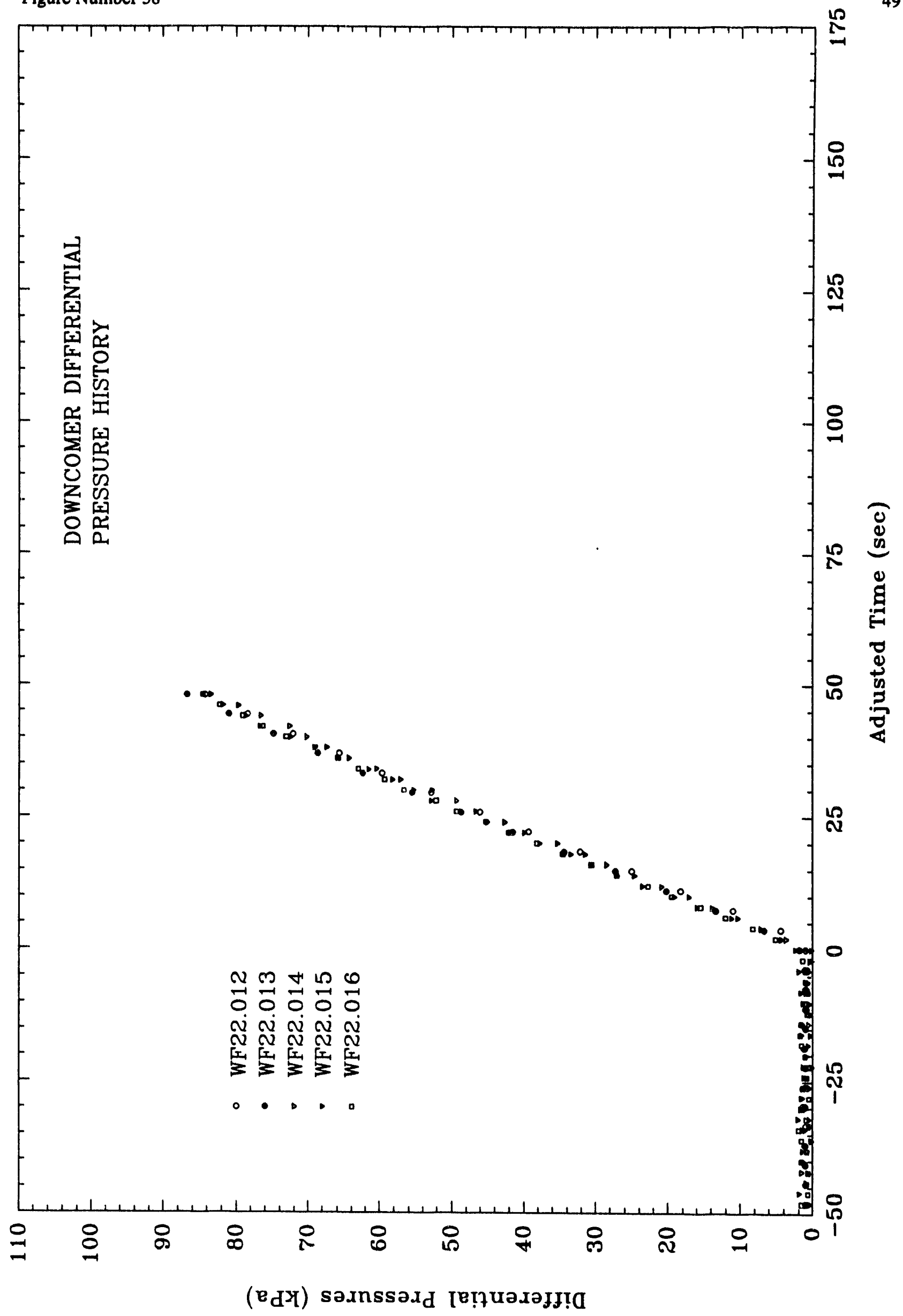




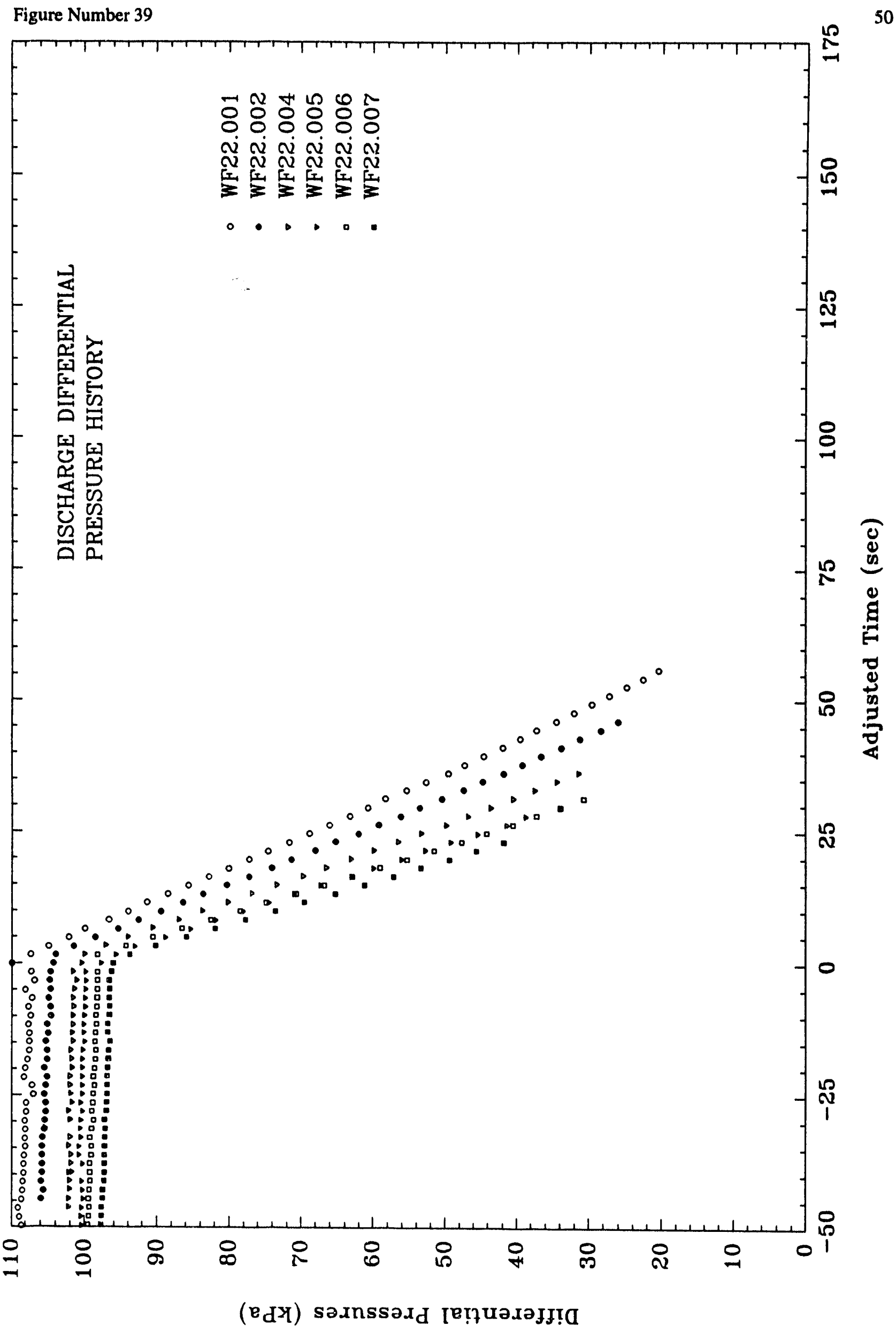




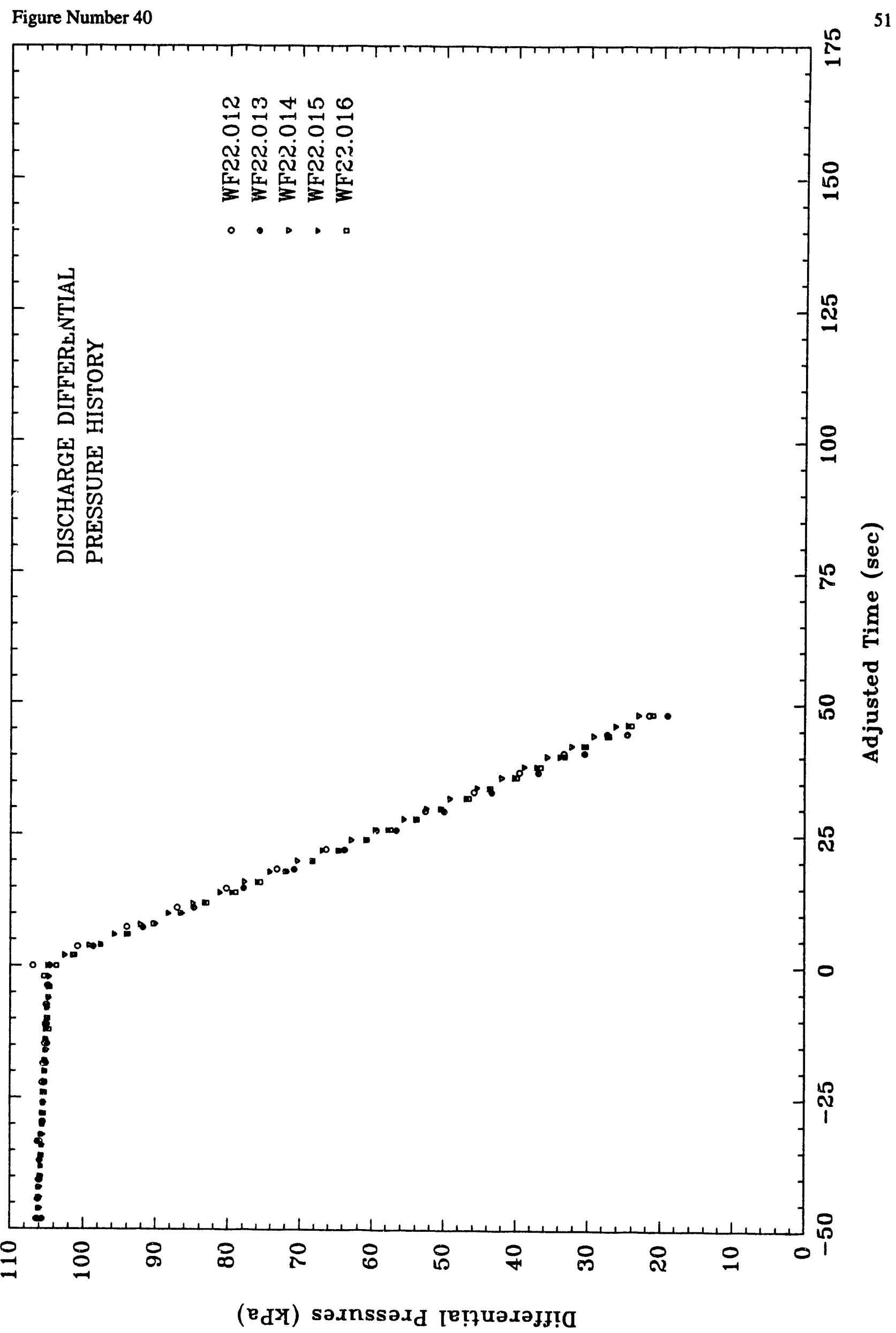


Figure Number 41

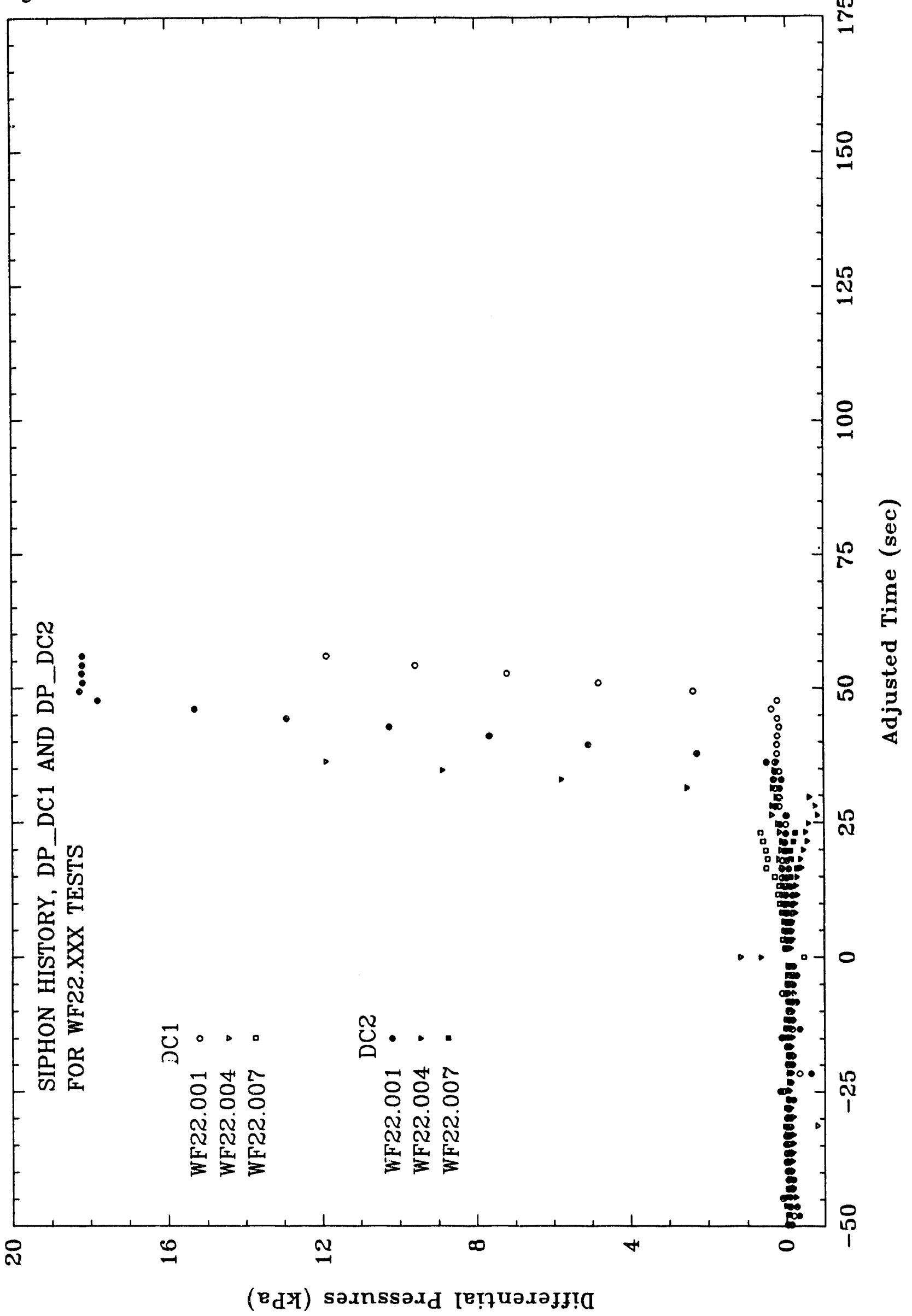


Figure Number 42

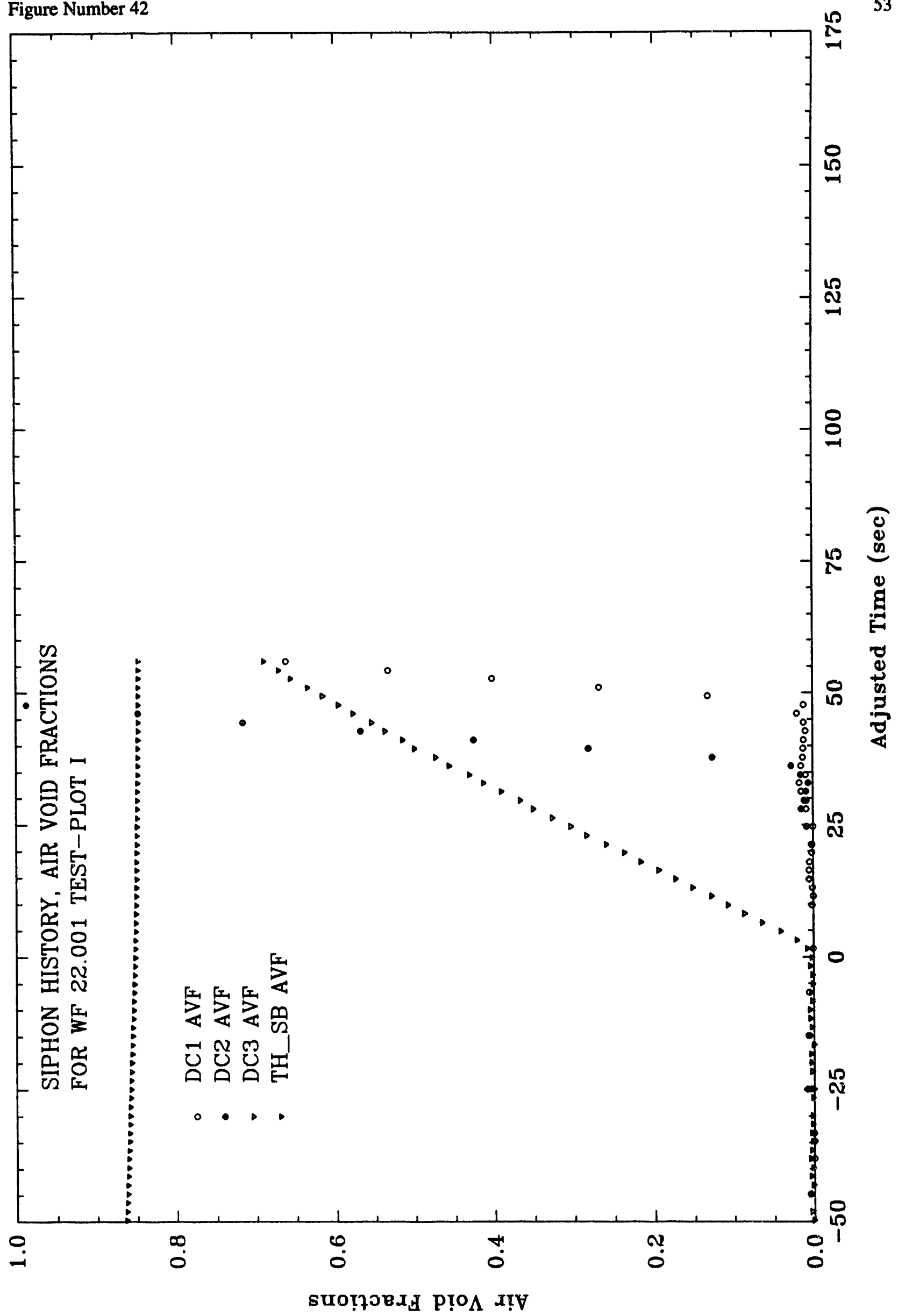




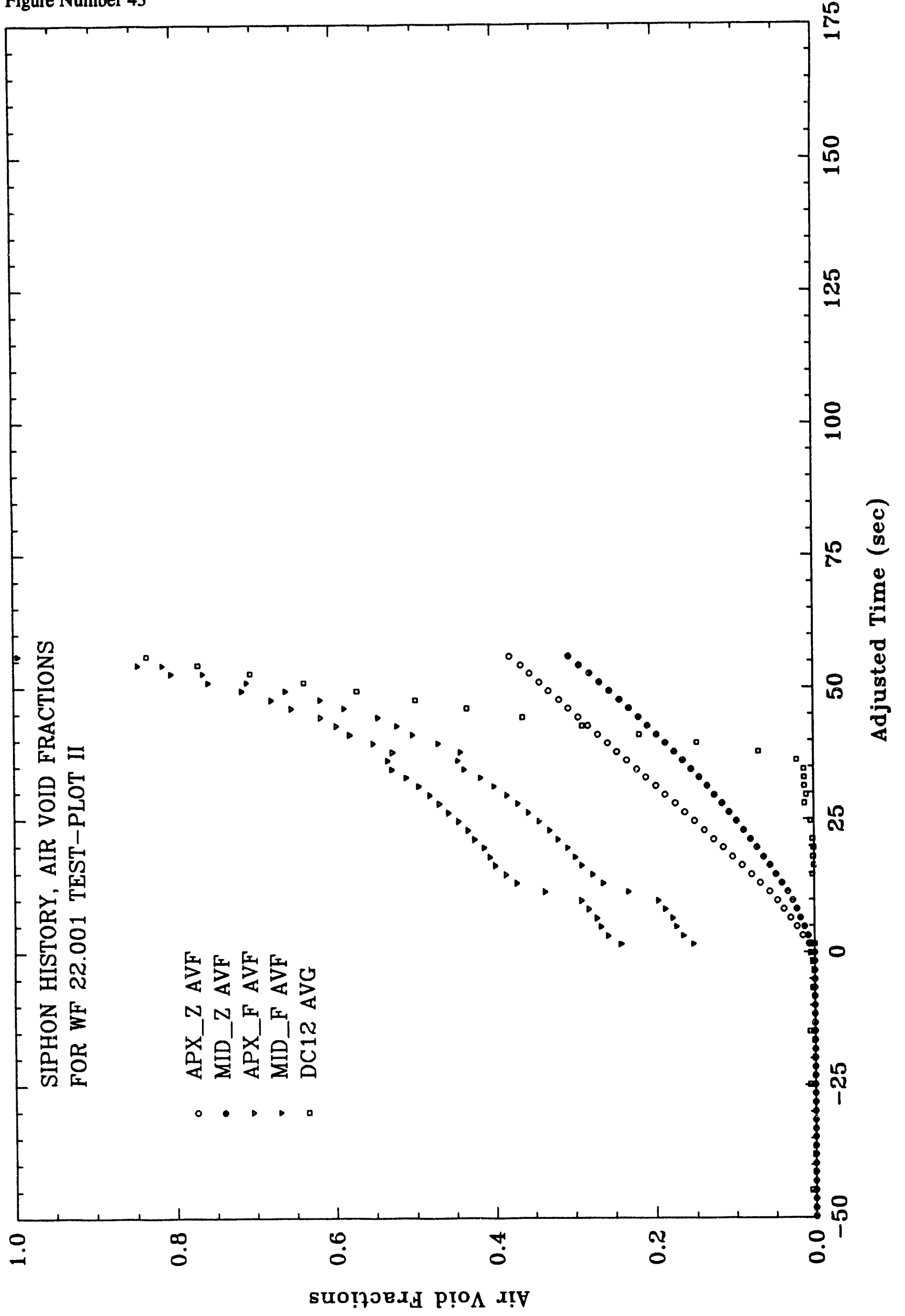


Figure Number 44

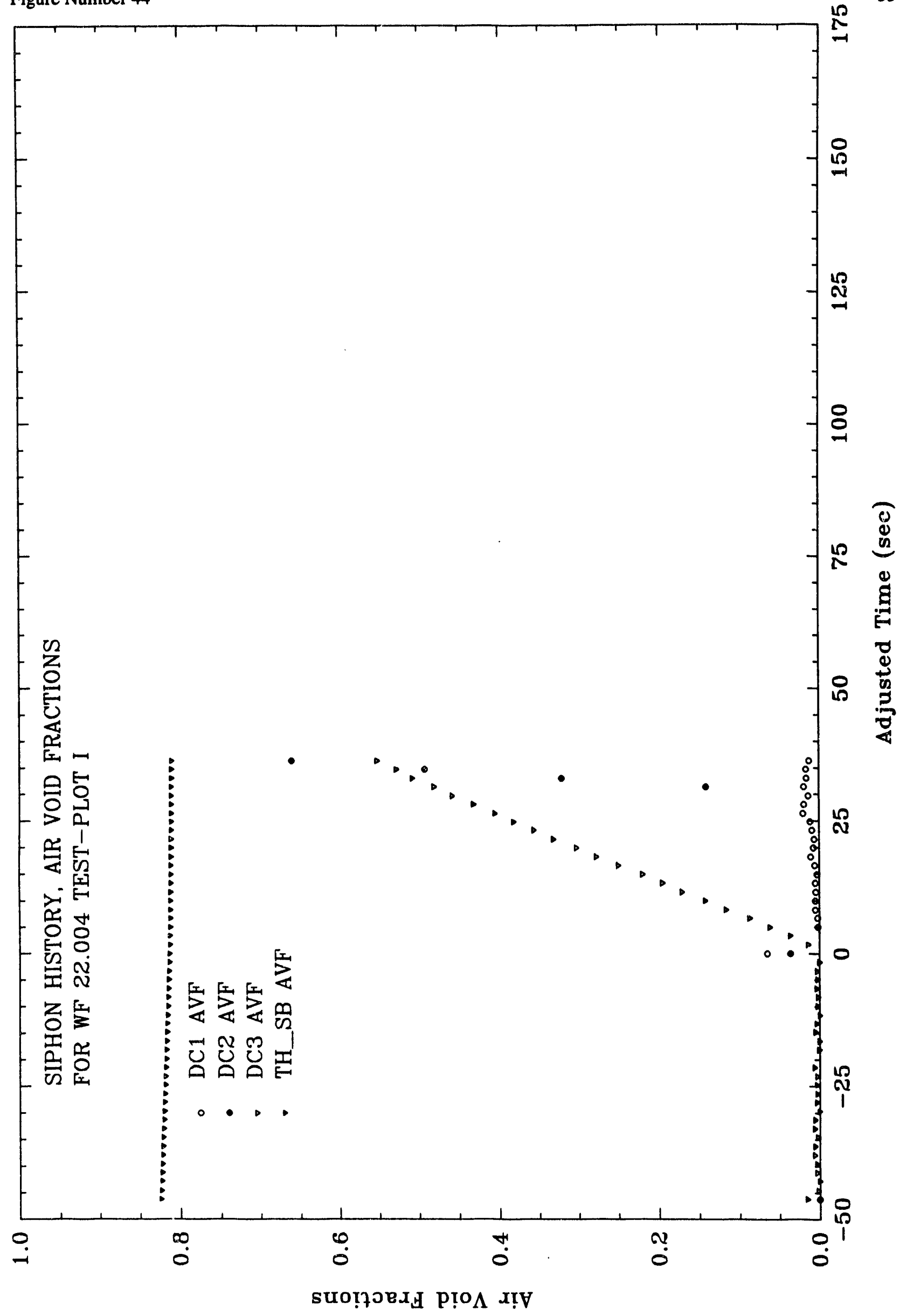




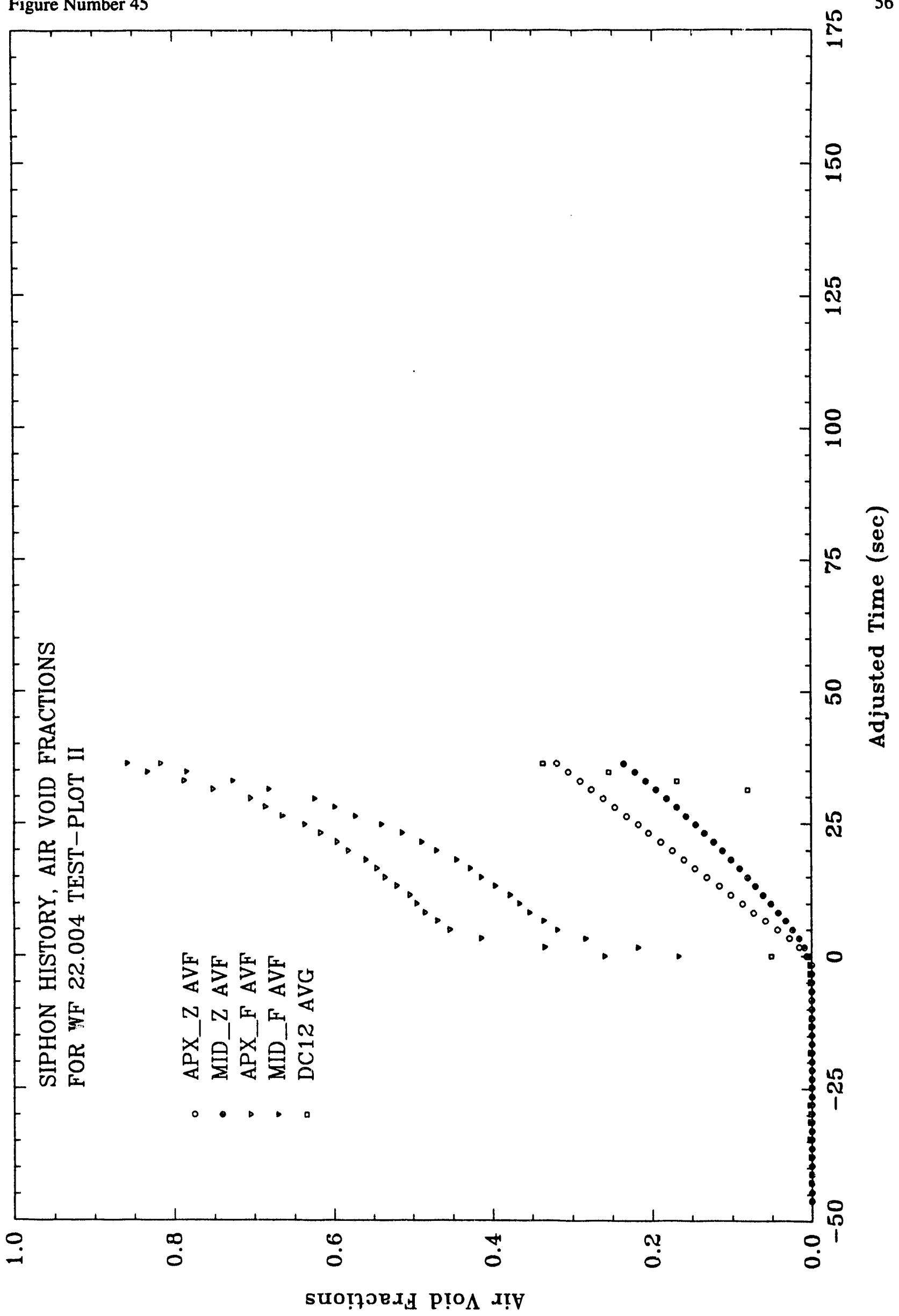




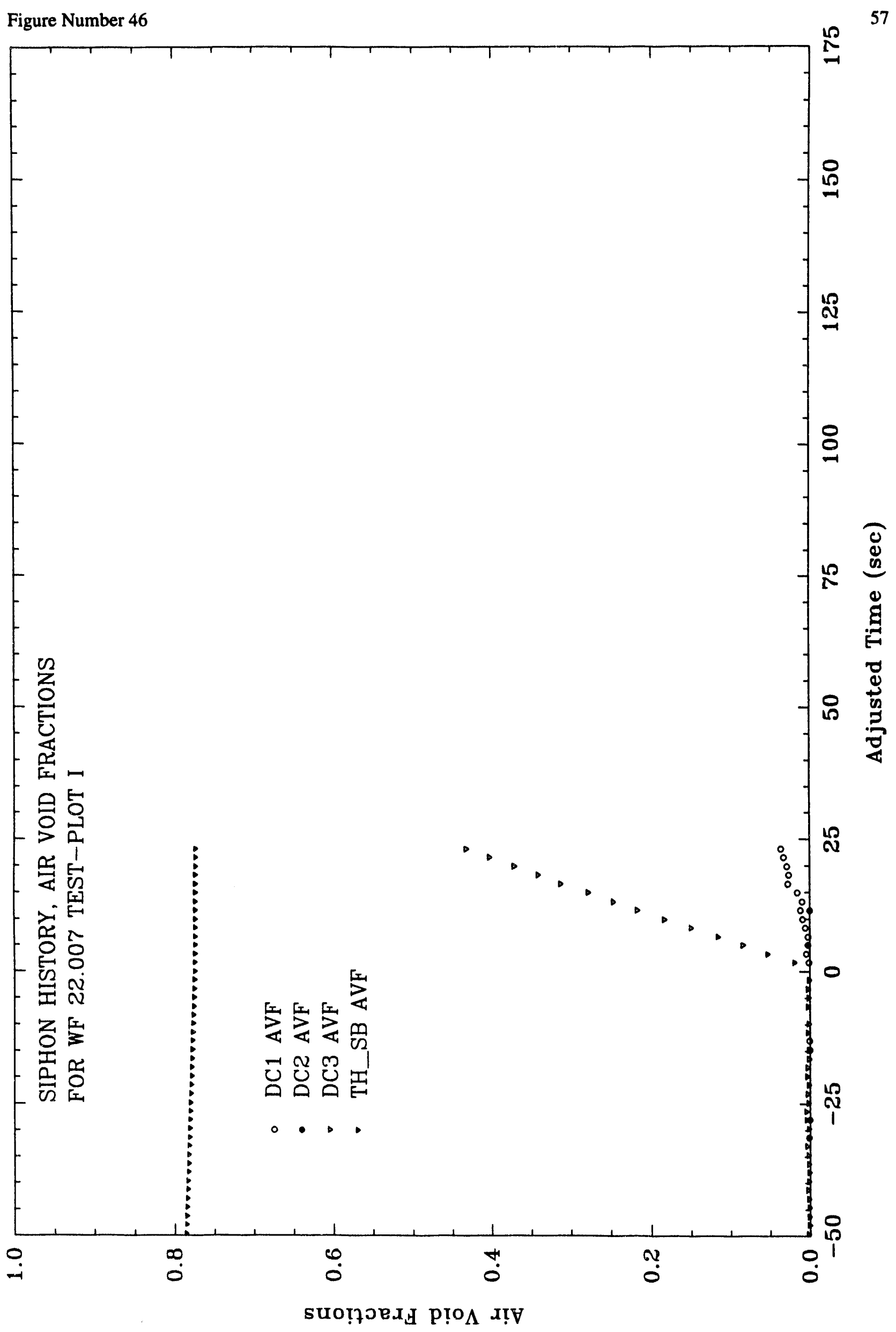




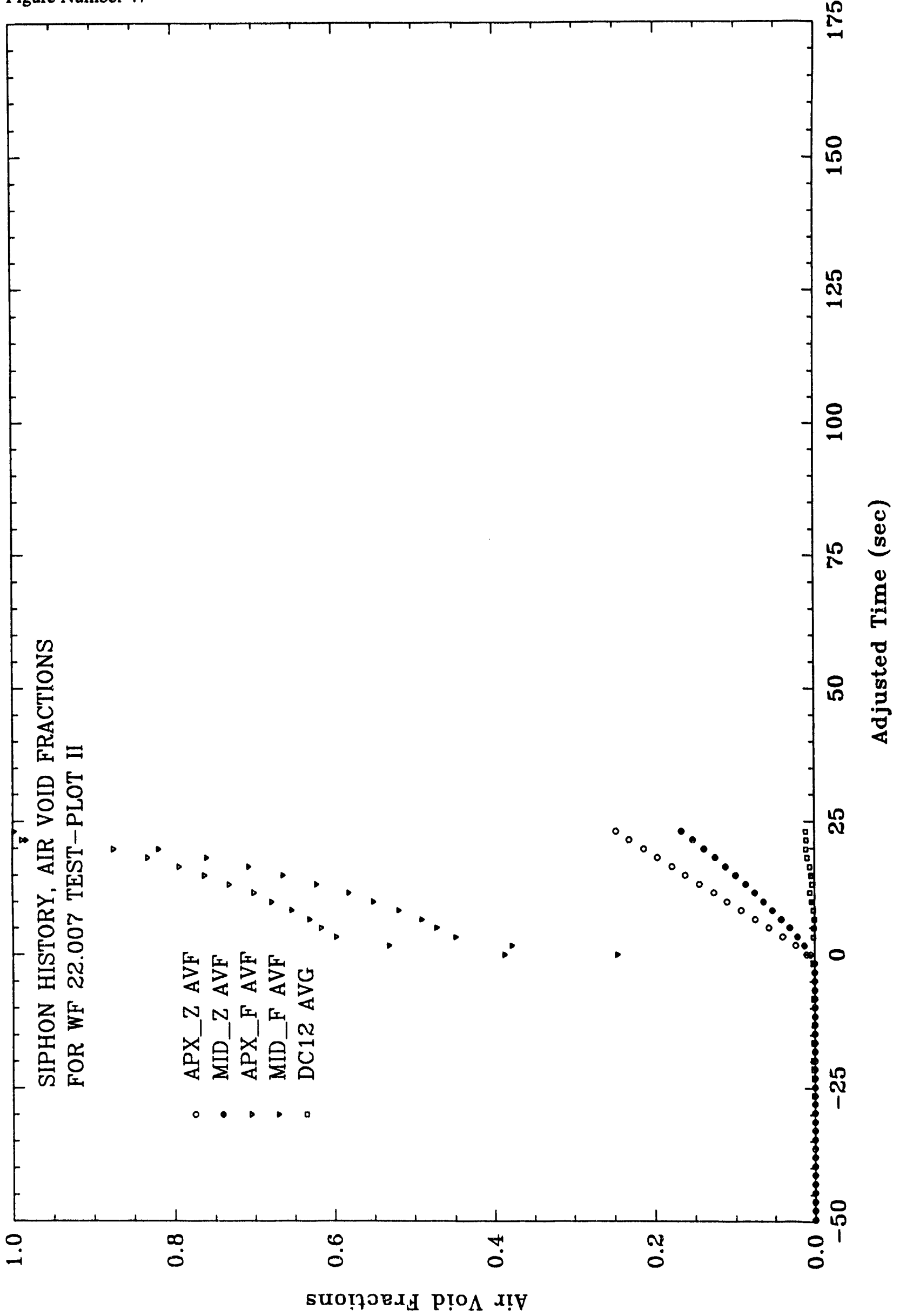


curves when the siphon breaks is a common characteristic of all the tests.

Figure 17 shows differences in the water flow rates due to the differences in the upper tank water levels for each run. The siphon broke by draining the upper tank for all three runs. The last three data points for the 003 run are indicative of "chugging flow" in the upcomer as air is sucked into it from the upper tank.

Figure 18 shows that the anti-siphon air flows are very slightly increased by the lower water level in the upper tank for each successive test. The lack of increase in the anti-siphon air flow as the upper tank water level decreases may be due to choking at the orifice in the air inlet line. About 3-feet of small tubing was installed in the air inlet line to prevent choking in later tests.

Figure 19 shows that the apex pressure becomes slightly more negative during the runs because of the decreasing upper tank water level even without the small tubing section in the air inlet line. These data plots are separated further than the air flows on the previous plot only because of differences in the vertical scale between the plots.

Figure 20 shows how the downcomer differential pressures spread due to the combined effects of less air flow and longer run times. At, say 50 seconds, the differential pressure is higher for the 005 run indicating that more air has been accumulated during the same time since the anti-siphon air valve was opened. The differential pressure for the 003 run eventually exceeds that for the 005 run because the upper tank water level is higher for the 003 run and therefore more air accumulation is required to break the siphon. The anti-siphon air accumulates in the downcomer as a giant bubble at the top of the downcomer. The water falls through the air bubble; rather like a contained water-fall. A short, frothy, turbulent air bubble region forms at the bottom of the water-fall and moves down the downcomer as the run progresses.

Figure 21 shows the decrease in the discharge differential pressure during a run due to both the decrease in the water flow and to the decrease in the overall density within the downcomer. None of the bubbles at the bottom of the water-fall reached the discharge section of the downcomer so these differential pressure measurements are all for single-phase flow. We should point out that the water flow measurement is made at the outlet of the upper tank; no water flow measurement was made at the discharge from the downcomer. At any time after adjusted time zero the discharge water flow should be a little greater than the water flow measured from the upper tank due to the accumulation of anti-siphon air in the downcomer. 
Figure 22 shows the differential pressures measured over the two 6-foot long sections near the middle of the downcomer. The DC2 dp cell is located above the DC1 dp cell so the DC2 dp cell sees the frothy region at the bottom of the water-fall first and hence its differential pressure increases first. Note that the DC1 differential pressure plotted points for the 005 run stop at about 70 seconds becuuse the siphon broke then and the waterfall interface didn't go any lower. If the bottom of the water fall goes below the lower connection of the dp cell, the dp cell output becomes constant as shown at the end of the plotted points for the test runs.

Figures 23-28 show the several calculated air void fractions based on the pressure measurements during the test runs. The overall air void fraction in the downcomer, DC3 AVF, is always below the theoretical siphon break air void fraction, TH SB AVF, at the actual siphon break for all runs. The magnitude of this difference increases as the upper tank level decreases. This increase is barely obvious on these plots because the water and air flow rates are rather low; however, it will be very pironounced for tests to be described later and will be discussed then. The full sweep-out air void fractions at both apex and mid downcomer pressures, APX_F AVF and MID_F AVF, respectively, always rise well above the theoretical siphon break air void fraction. At the same time the zero sweep-out air void fractions at both apex and mid downcomer pressures, APX_Z AVF and MID Z AVF, always stay well below the theoretical siphon break air void fraction. These results indicate that all four simple air void fraction models are poor predictors of when the siphon will break.

Figures 29-47 show the plots for the WF22 series of tests. These plots are presented as pairs for each variable. The first plot of a pair are for six test runs made from different upper tank water levels and the second plot of a pair are for five replicates of one of those test runs.

Figures 29 and 30 show the same upward trend of the end points of the upper tank water volume data when the siphon broke as with the previous test series. The water level at which the anti-siphon air valve is opened decreases about 1.1 meters over the six test runs since each 100 liters of tank volume is equal to about 0.1 meter of water level. These tests employ a 3.45-mm air orifice so the siphon broke much quicker than in the previous test series which employs a 2.39-mm air orifice. Figure 30 shows the upper tank volume history of five additional test runs which are replicates of the 002 test run.

Figures 31 and 32 show that the water flow rates are very nearly equal and decrease slowly until the anti-siphon air valve is opened. But after that event the flow rates separate and the time until the siphons break shortens as the upper tank water 
level at adjusted time zero decreases. Figure 31 has an interesting feature, the flow rates for the 004 and 005 runs over -50 to -25 seconds adjusted time are higher than for the other tests. We have no explanation for this difference; perhaps something "adjusted" in the water flow turbine meter.

Figures 33 and 34 show the measured anti-siphon inlet air flows. We have no explanation for the obvious delay in the build-up of the air flow during the 001 and 002 tests. The air flow data behave as expected; higher and shorter duration with lower upper tank water levels. The fact that the other measurements during the 001 and 002 tests are not upset by their "funny" air flows leads us to believe the apparent delays reflect problems in the air turbine rather than actual delays in the air flow itself. The increase in air flow rates with lower upper tank water levels means that the air flow is not choking in the inlet line. The air flows do not show any definite increase as the upper tank water level drops during any one test; however, the water level doesn't lower much during any one test.

Figures 35 and 36 show that the apex pressures behaved just as expected for all the test runs. The pressures become more negative as the upper tank water level lowers from run to run, become slightly more negative as the water drains out of the upper tank before adjusted time zero, and remain fairly constant after the anti-siphon air valve is opened.

Figures 37 and 38 show the progress of air accumulation in the downcomer. Note the very small pressure drop during the wateronly flow period before the anti-siphon air valve was opened.

Figures 39 and 40 show that the discharge differential pressures decrease prior to adjusted time zero as the upper tank water level decreases for each successive run. The discharge differential pressures then decrease rapidly after the antisiphon air valve is opened. This rapid decrease is due entirely to water flow rate decrease since the two-phase flow interface at the bottom of the water-fall does not reach the discharge orifice during these tests. The air accumulates as a growing bubble at the top of the downcomer. The water flows along the bottom of the apex and then falls as a water-fall through the air bubble.

Figure 41 shows the differential pressures measured over the two 6-foot long sections near the middle of the downcomer for three of the WF22 test runs. The increase in the differential pressures is indicative of the progress of the bottom of the water-fall down the downcomer. Notice that the water-fall bottom reached the lower dp cell, DCl, only during the 001 test and that it did not reach the upper dp cell, DC2, during the 007 test. 
Figures 42-47 show the various calculated air void fraction histories for the same three tests as plotted on Figure 41 . The major interesting features on these plots are that the siphon always breaks well before the overall downcomer air void fraction, DC3 AVF, which is based on the DC3 differential pressure measurements, reaches the simple theoretical air void fraction for breaking a "stagnant" siphon, Th SB AVF, and that the gap between these two plots gets larger for lower upper tank water levels as shown on Figures 42,44 , and 46. This increasing gap means the overall downcomer air void fraction required to break the siphon decreases faster than the theoretical air vold fraction. The lower water levels in the upper tank are the only cause for the decrease in the theoretical air void fraction plots for each test run; therefore, the lower water levels are not, at least simply, the reason for the increased gap.

These increasing gaps may be due to the fact that all of the kinetic energy in the water and air flowing through the apex is lost in the air bubble; principally at the bottom of the waterfall. In addition, the kinetic energy of the water flowing through the apex is higher than normal because the air bubble at the top of the apex forces the water to flow through a smaller cross-sectional area. That increase means that more of the siphon head is expended in accelerating the water from the upper tank through the apex and then lost to turbulence at the bottom of the waterfall. These two effects combine to reduce the apparent siphon head which means the air void fraction required to break the siphon is lower than a theoretical stagnant value. 


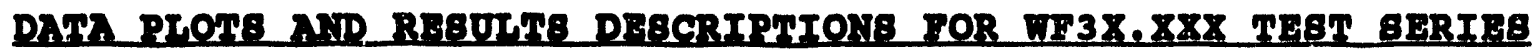

Figures 48-101 show the measured data and calculated air void fractions for the WF30, WF31, WF32 and WF33 series of test runs. These plots are all grouped in one section to make comparisons easy.

Figures 48-52 show the data for three "water flow only" WF30 tests which were run early in the test program.

Figure 48 shows that the upper tank volume histories repeat very well.

Figure 49 shows that the water flow rates repeat very well and that they decrease only a small amount over the first 175 seconds.

Figure 50 shows that the apex pressures did not repeat so well. The 003 run data are more negative than the 001 and 002 run data. We believe the 001 and 002 data are best because they agree better with the same measurements from the water flow only part of the other test runs in this series. However, these apex pressures are only some 20 percent greater than the same measurements in the WF2O test series while the water flow rate is about 1.5 times greater. That increase in water flow rate should have produced about 2.25 times greater pressure drop between the water surface and the apex.

Figure 51 shows that the downcomer differential pressure data plotted on Figure 50 are under 5 percent of the dp cell's 0-125 $\mathrm{kPa}$ full range but are in reasonable agreement with the same measurements for the water flow only part of the other test runs in this series.

Figure 52 shows that the discharge differential pressure data agree well with each other and with same measurements from the water flow only part of the other test runs in this series.

The discharge differential pressure data cannot be compared to that from other test series since the orifice sizes are different.

Figures 53-65 show the plots for the WF31 series of tests. since the five tests in this series are run from the same initial level in the upper tank, the data on each plot should fall along single line. Tests in this series run from lower upper tank water levels all have serious inconsistencies in one measurement or another.

Figure 53 shows that the siphon broke at about 170 seconds after the anti-siphon air valve was opened. The differences in siphon break time are due to experimental variation and the difficulty 
Figure Number 48

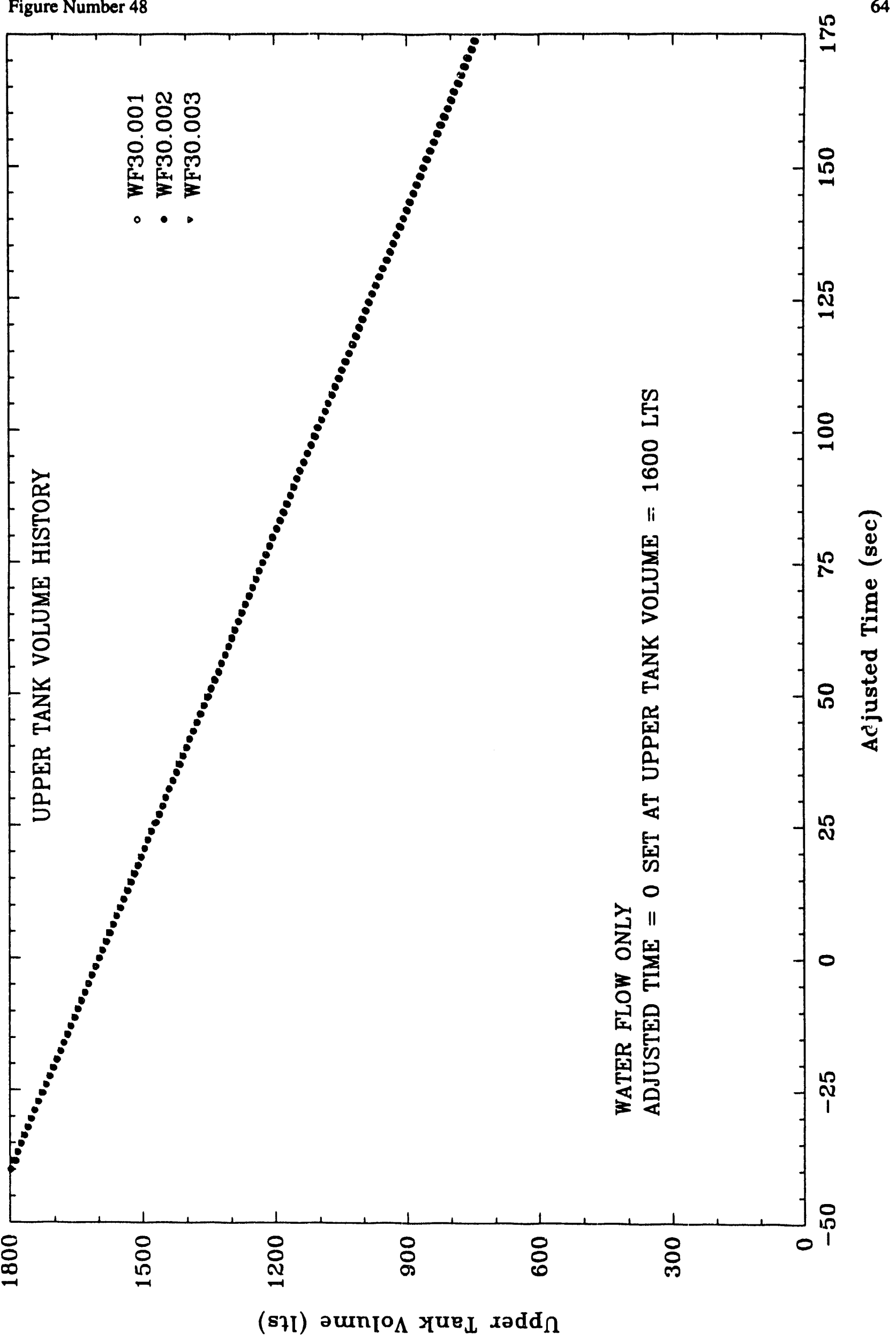




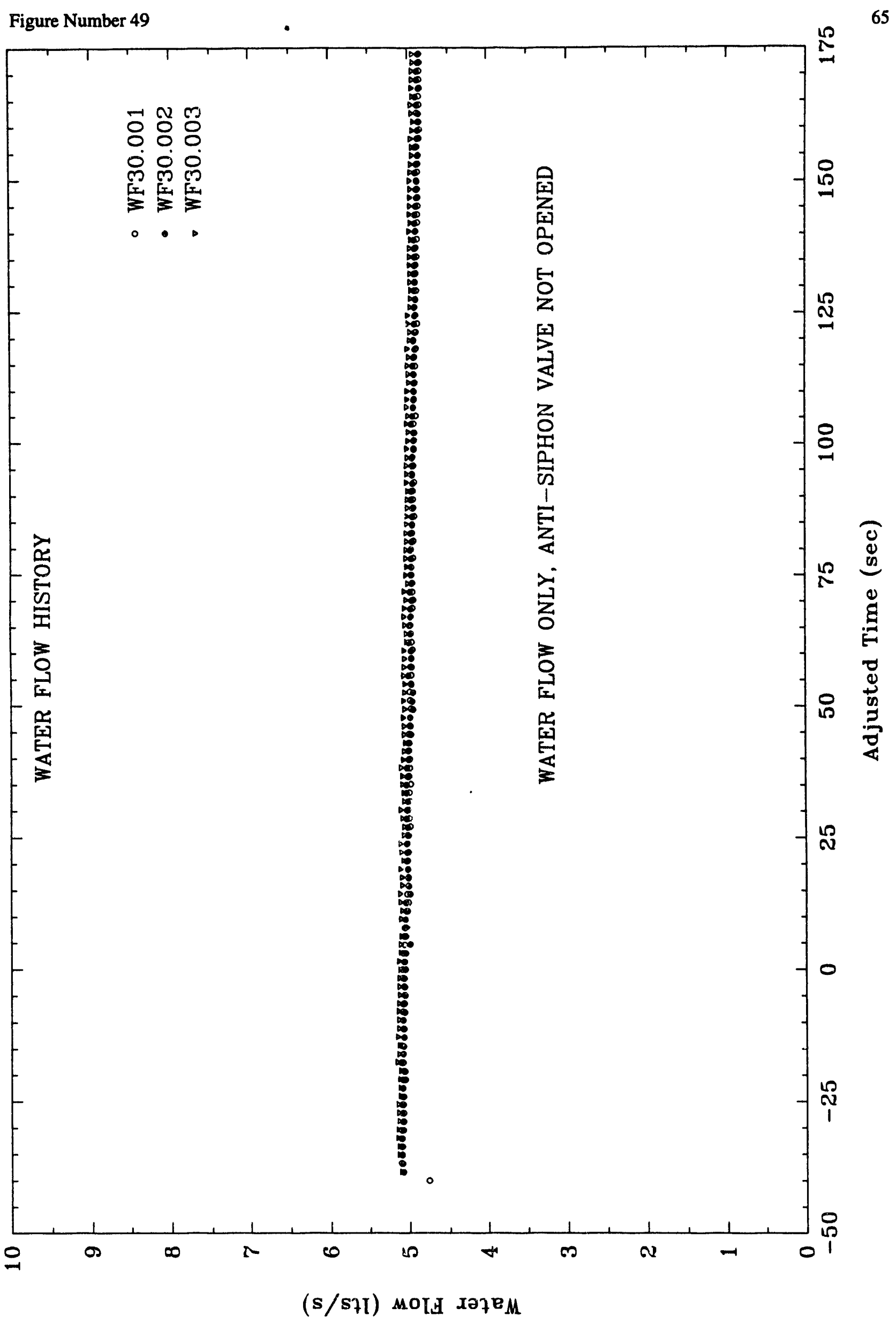


Figure Number 50

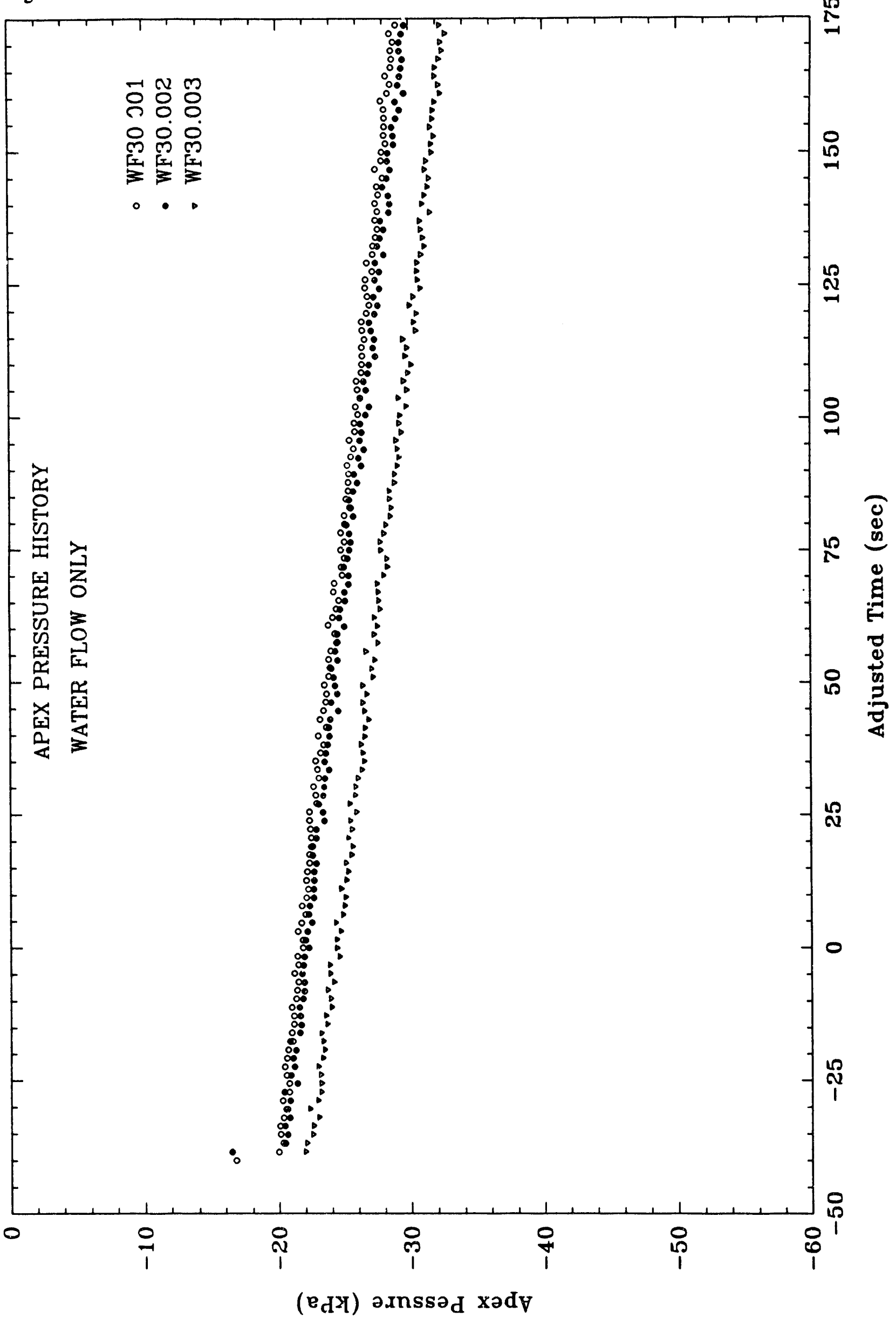


Figure Number 51

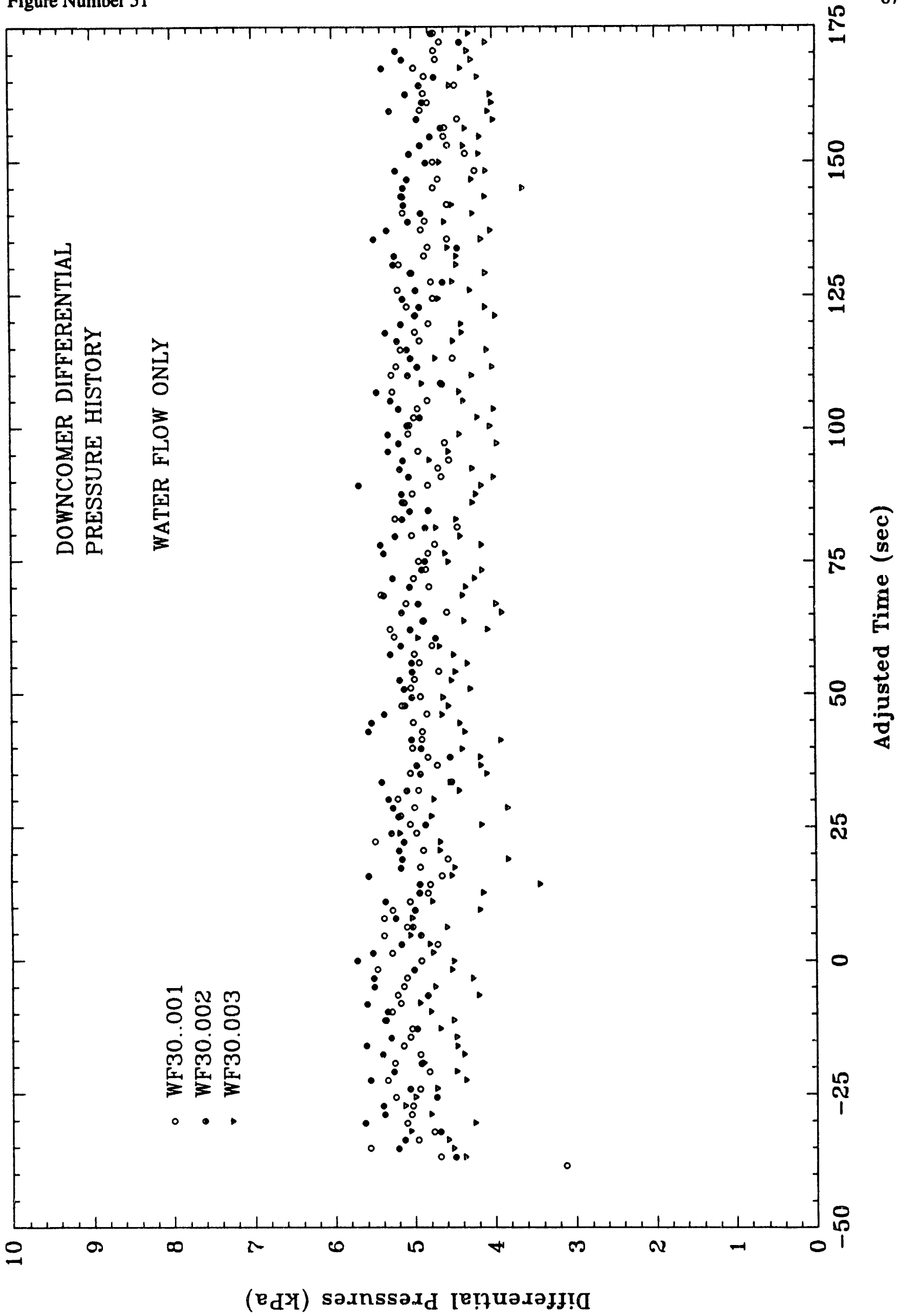


Figure Number 52

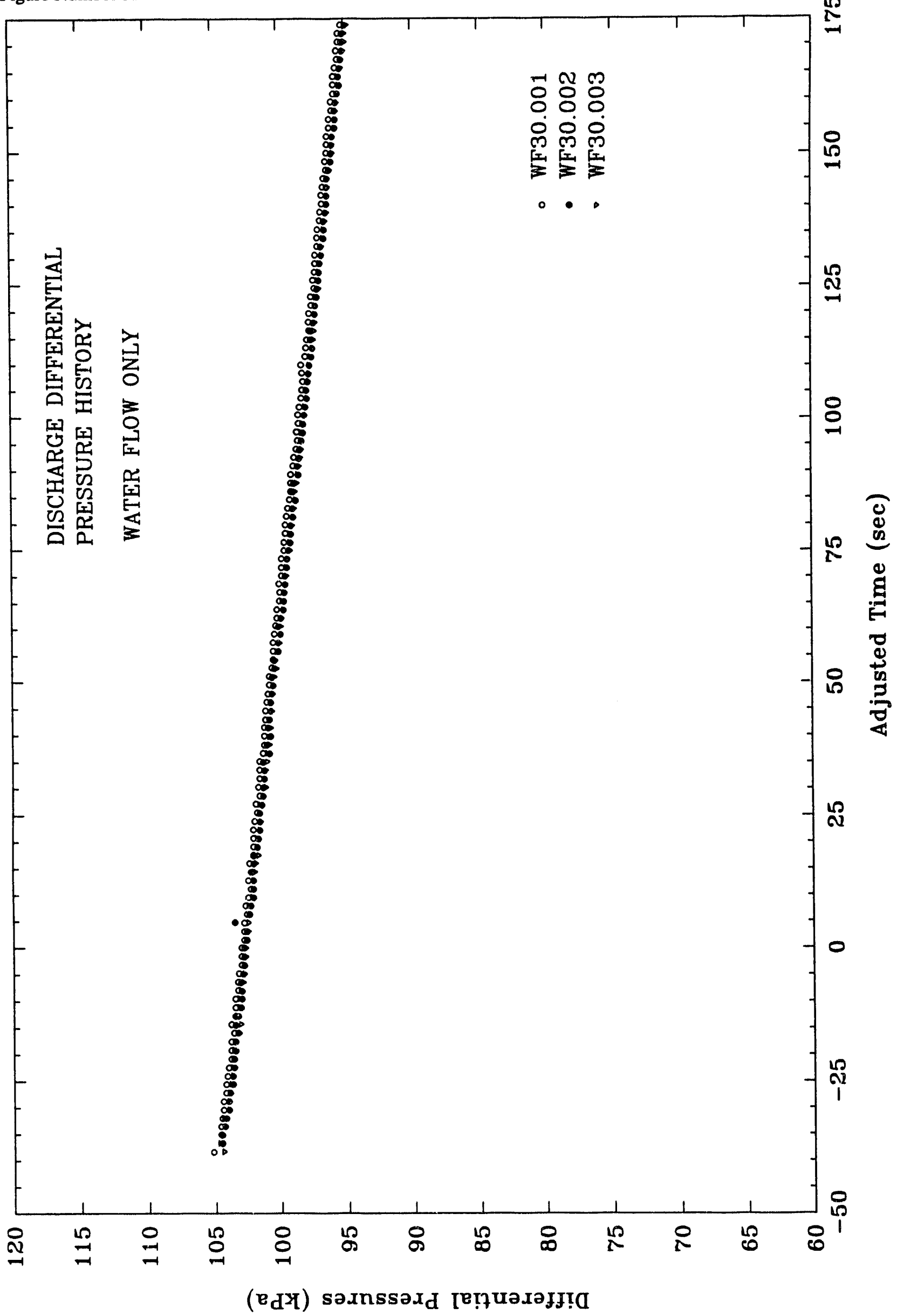




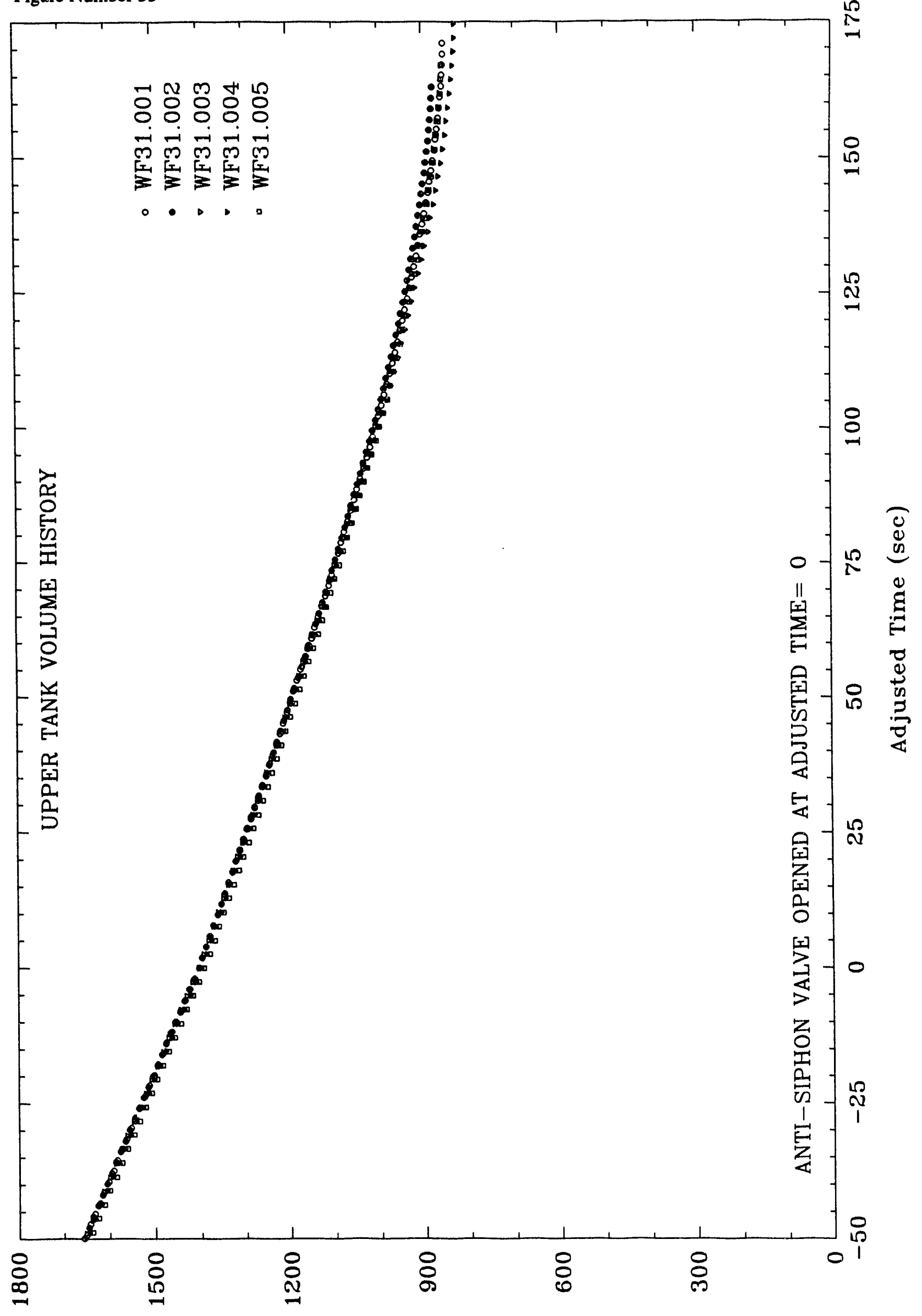

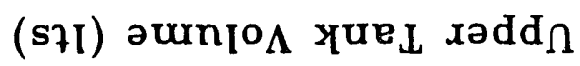


Figure Number 54

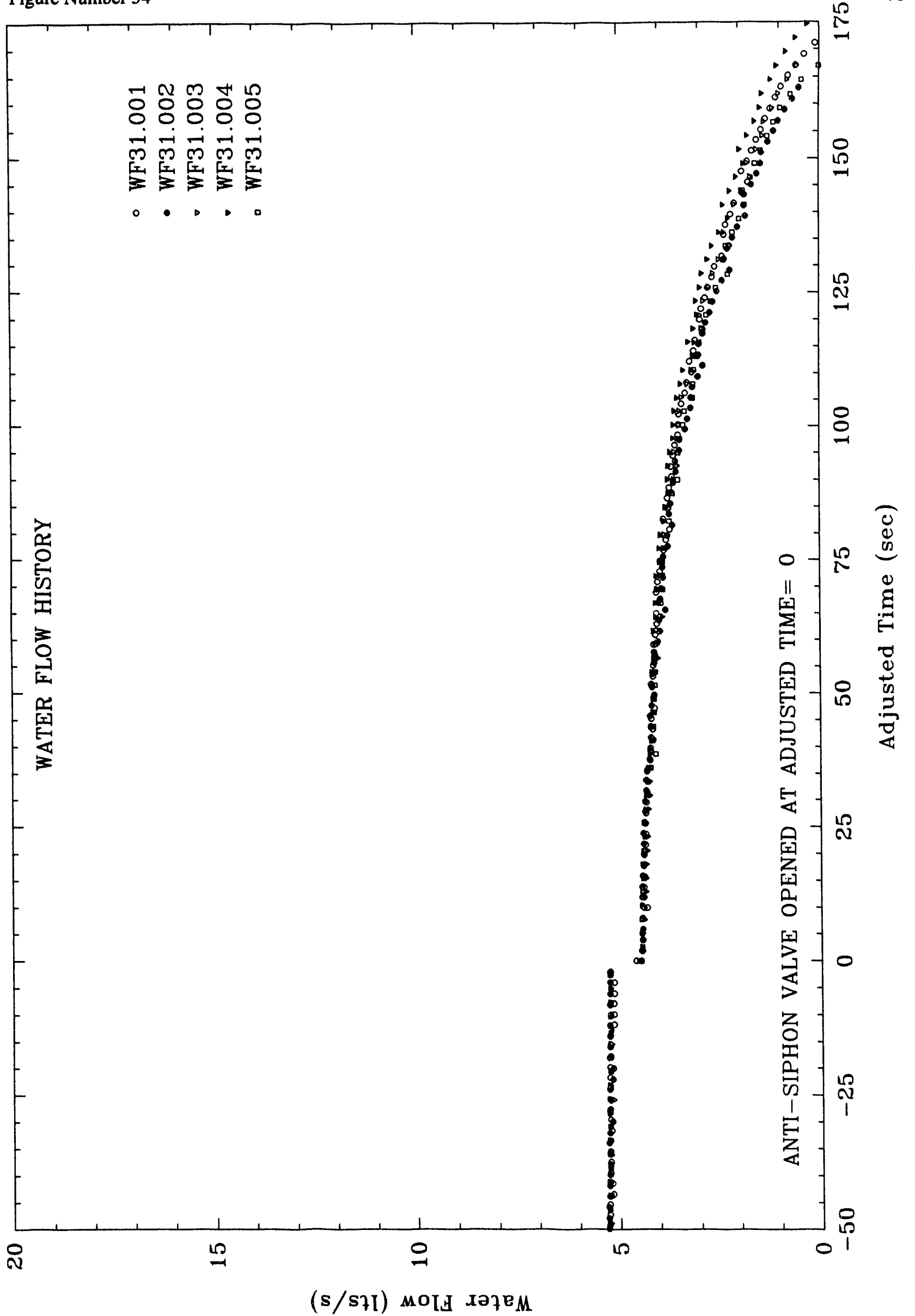




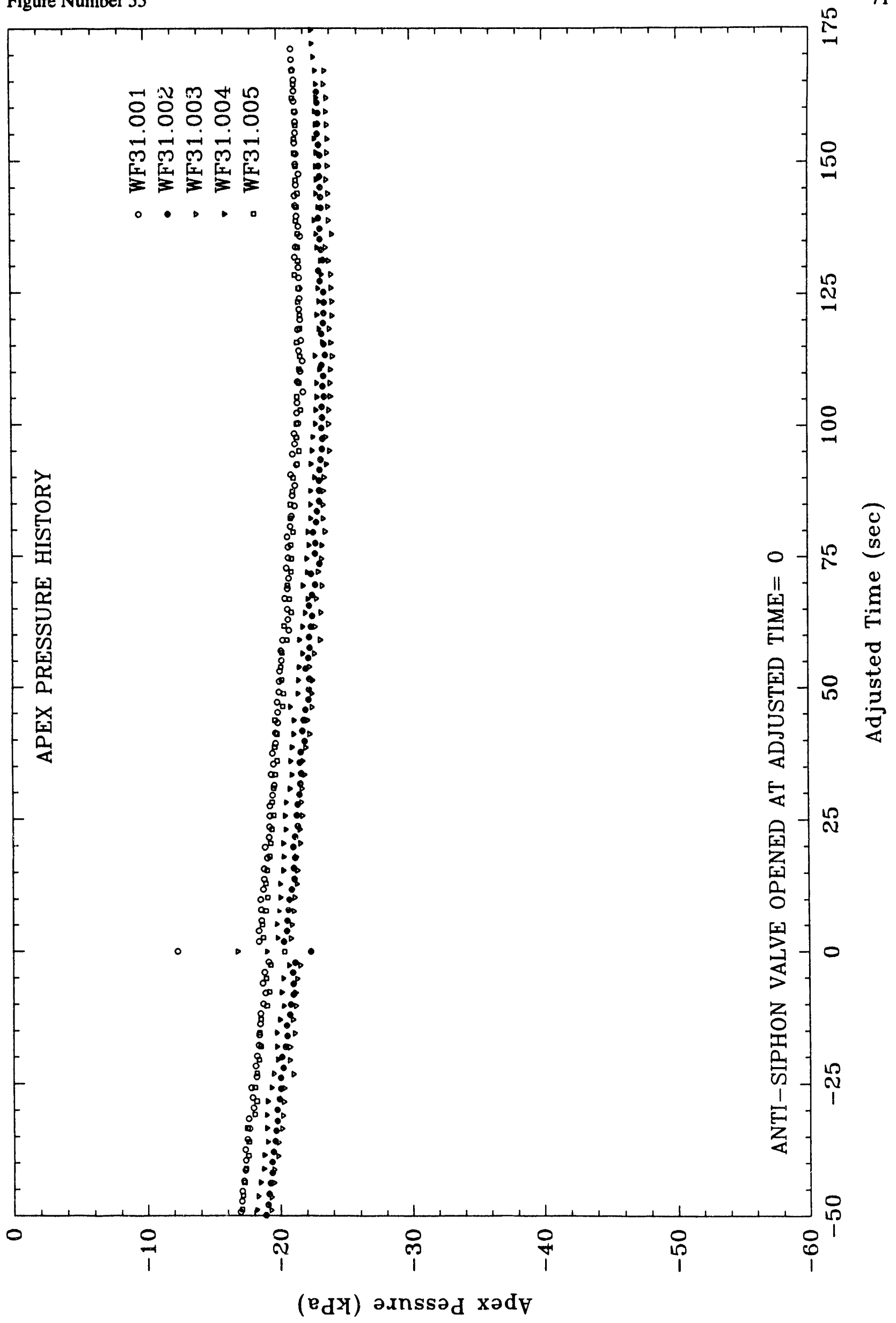




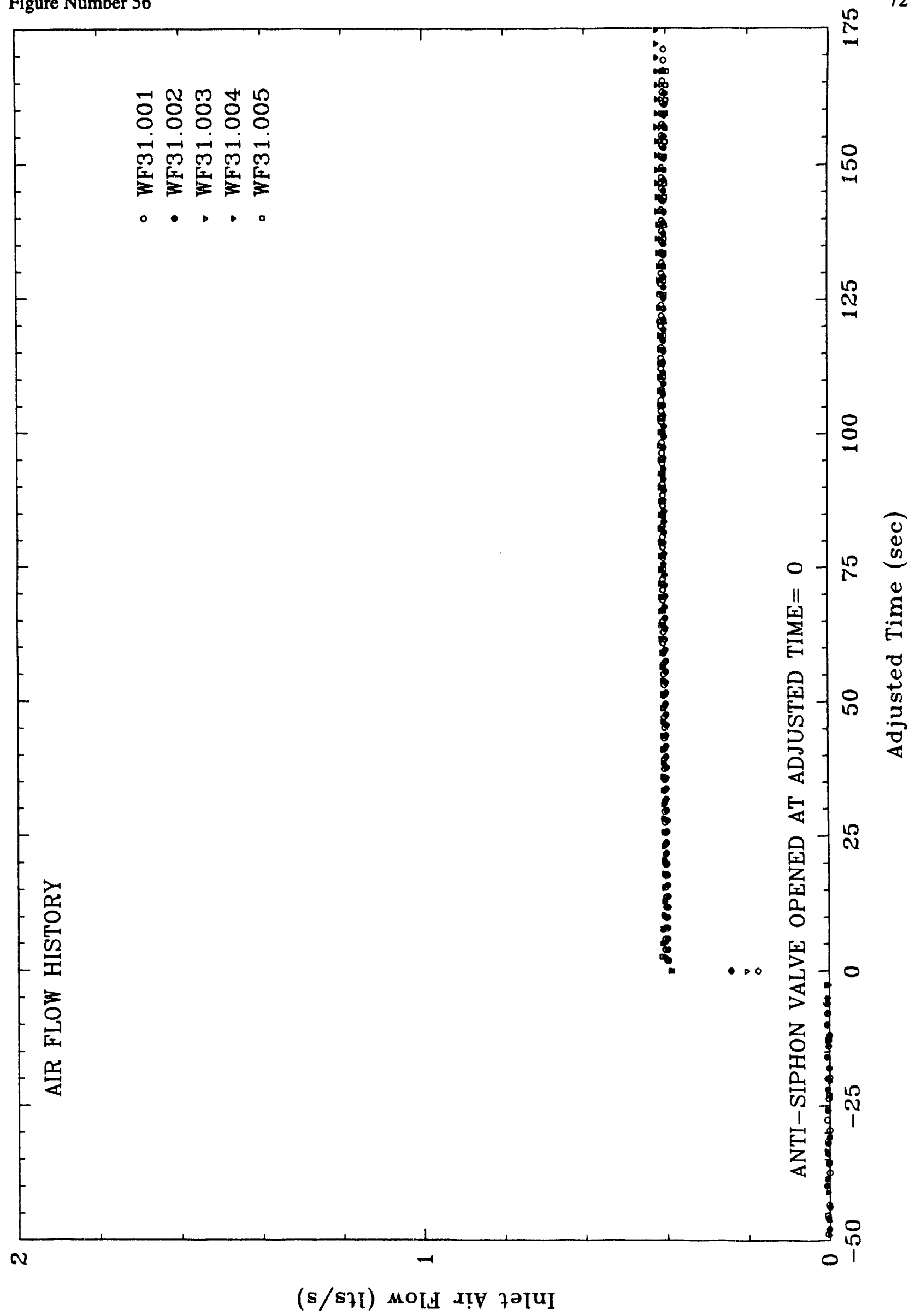




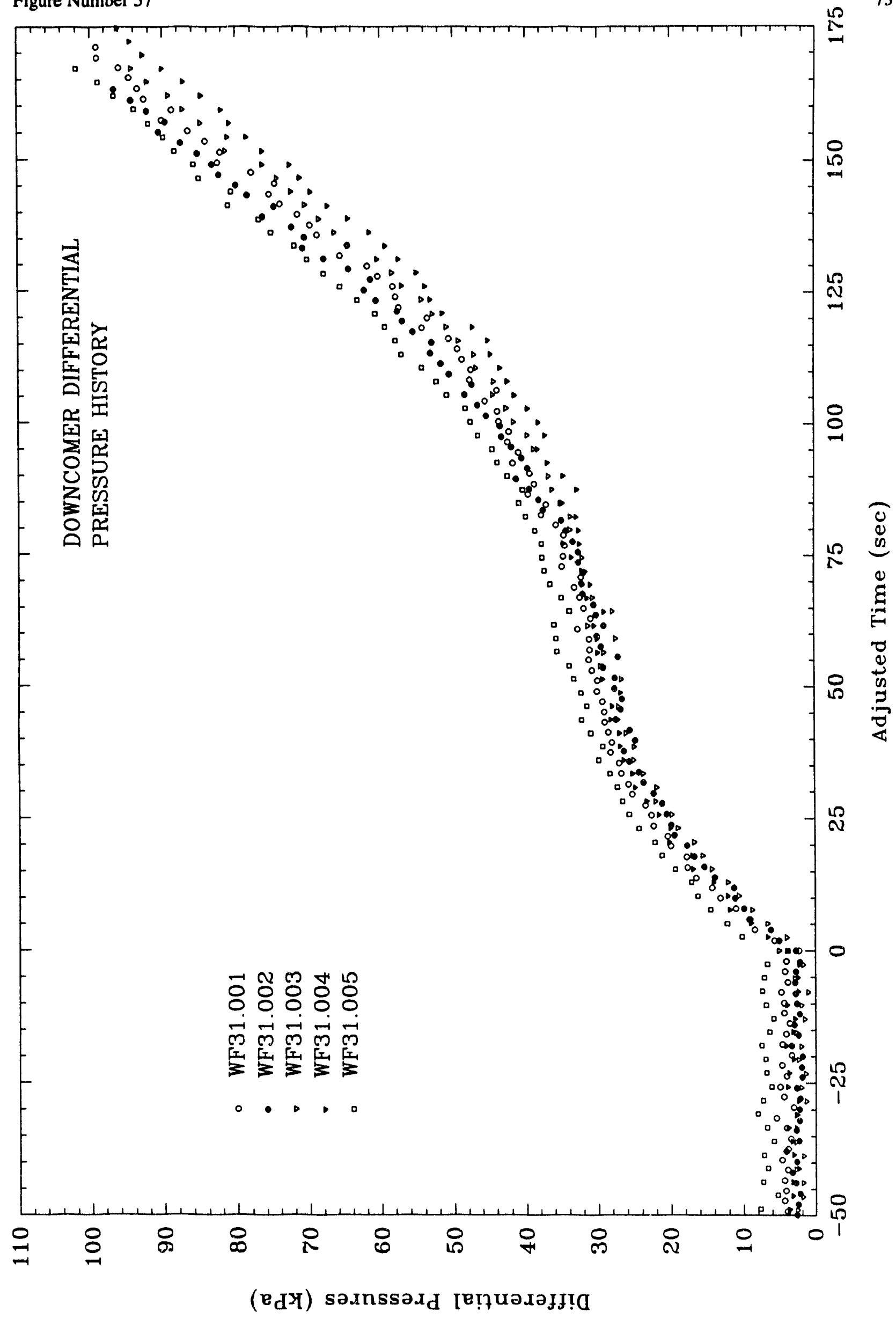


Figure Number 58

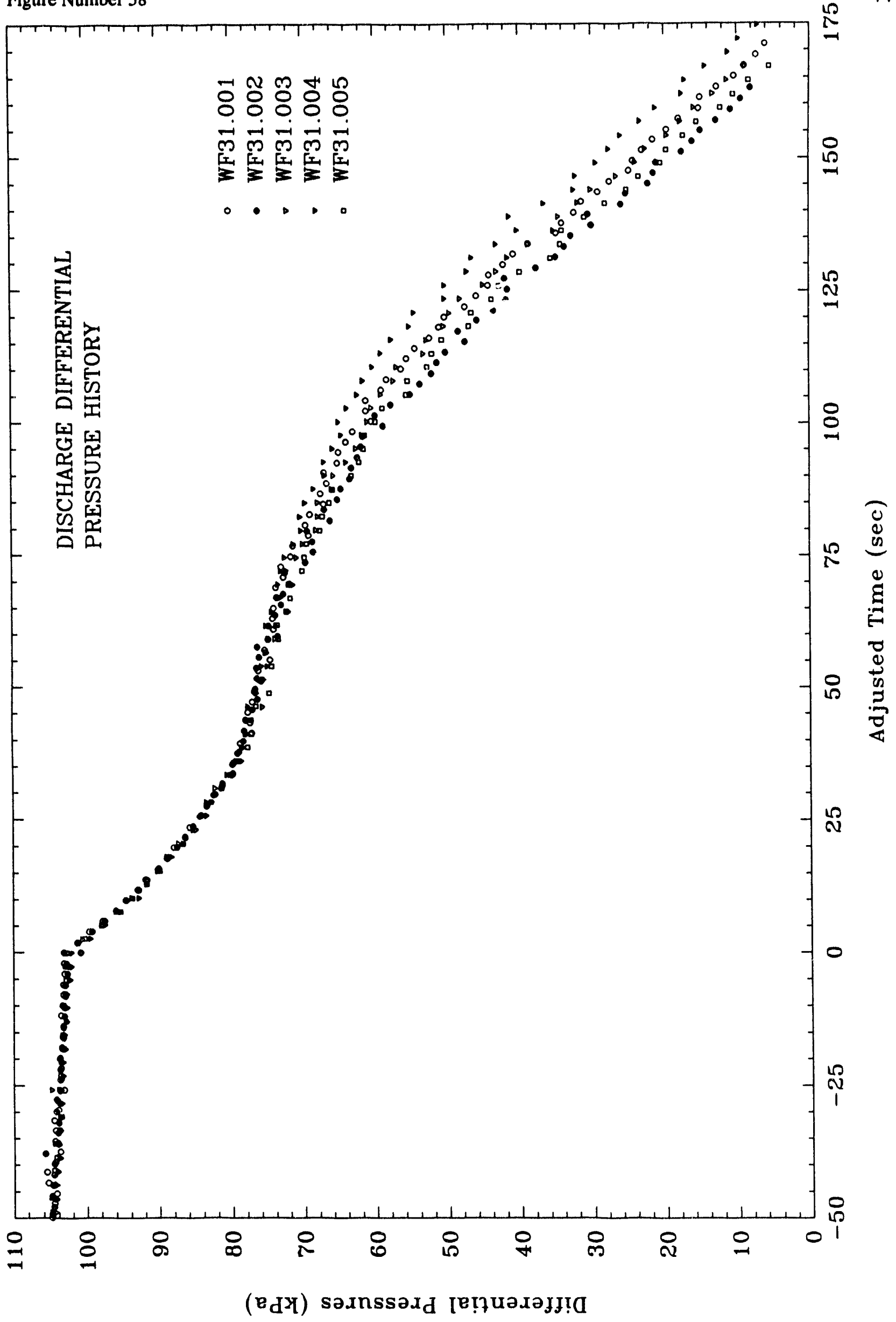


Figure Number 59

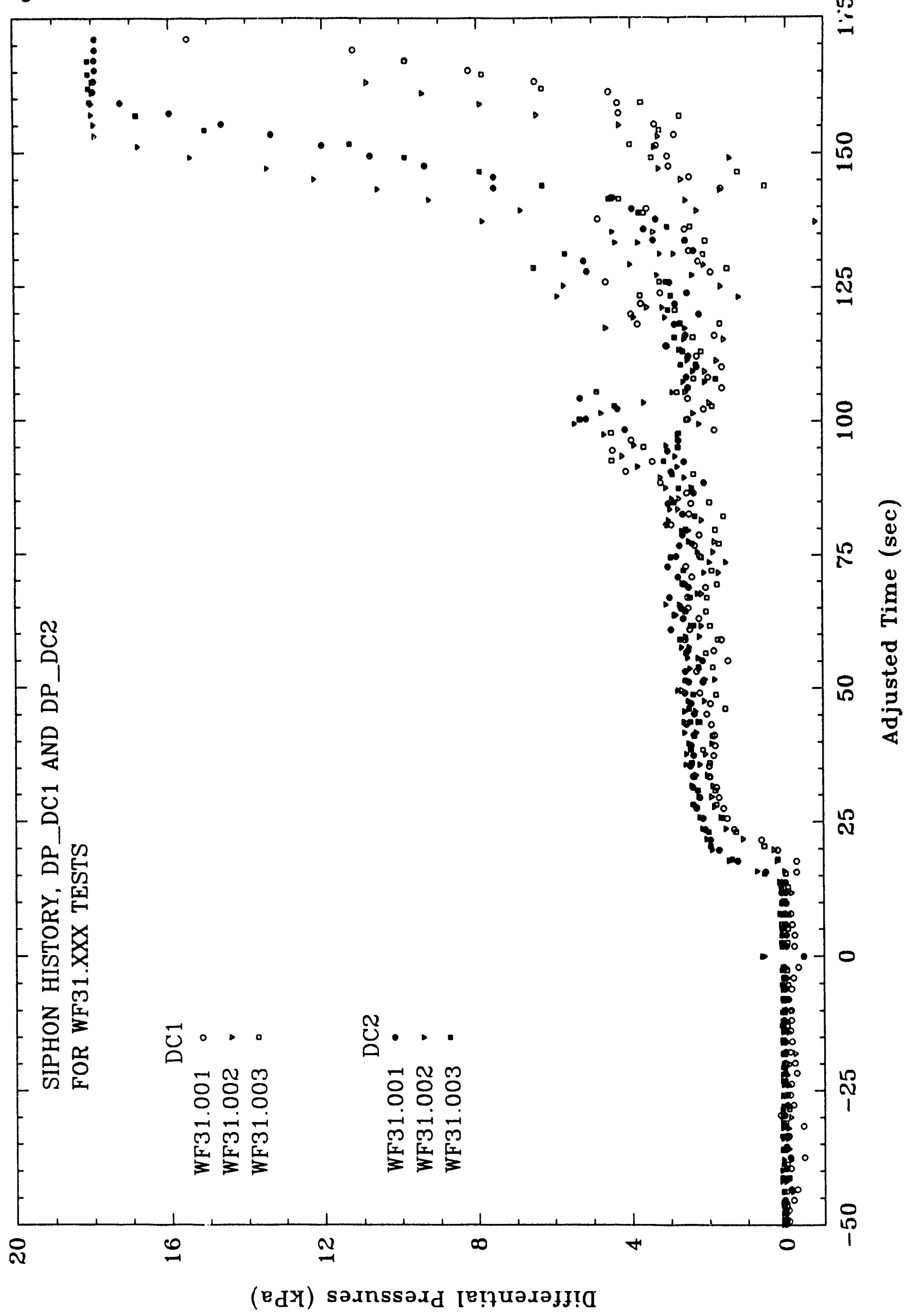




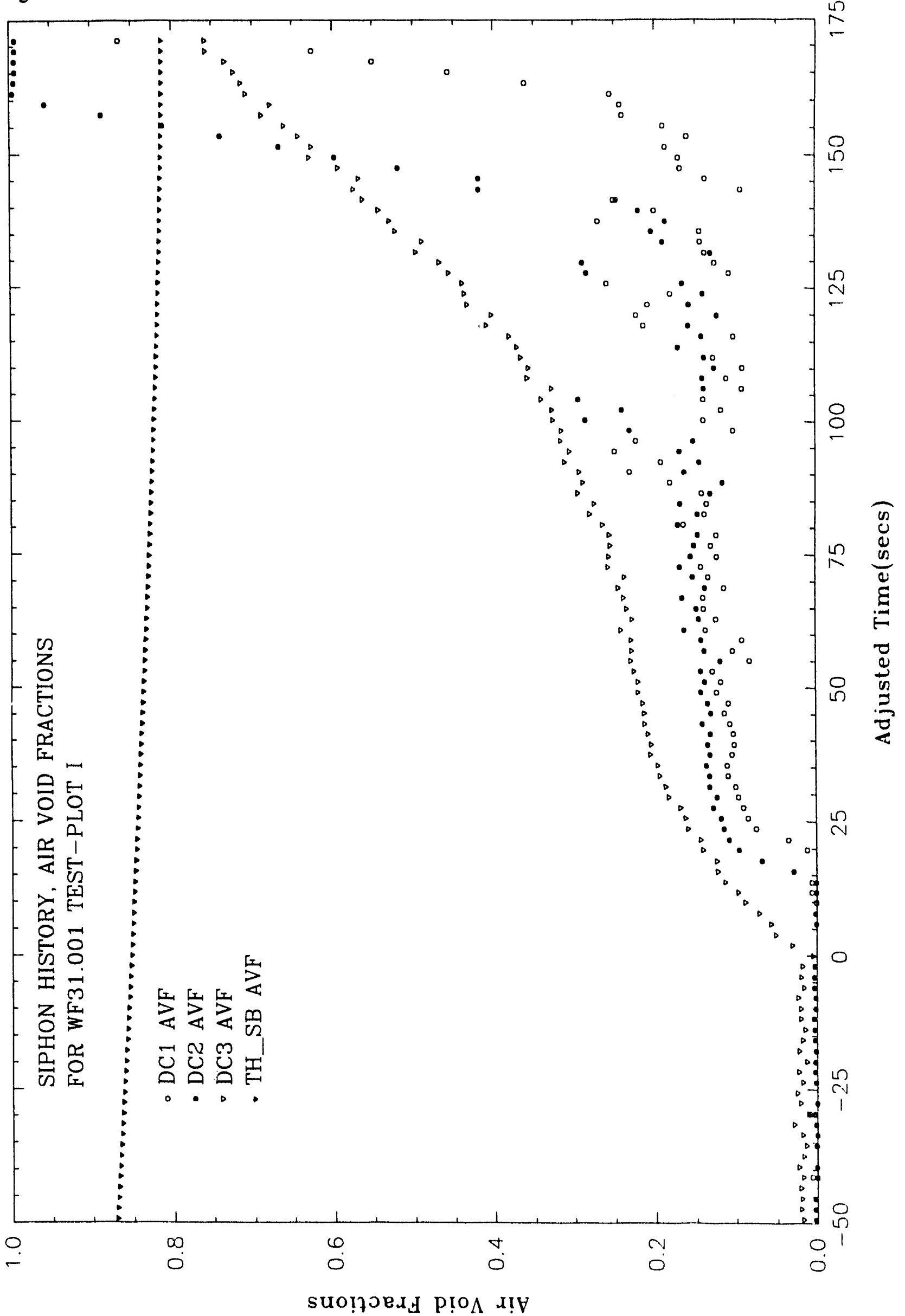




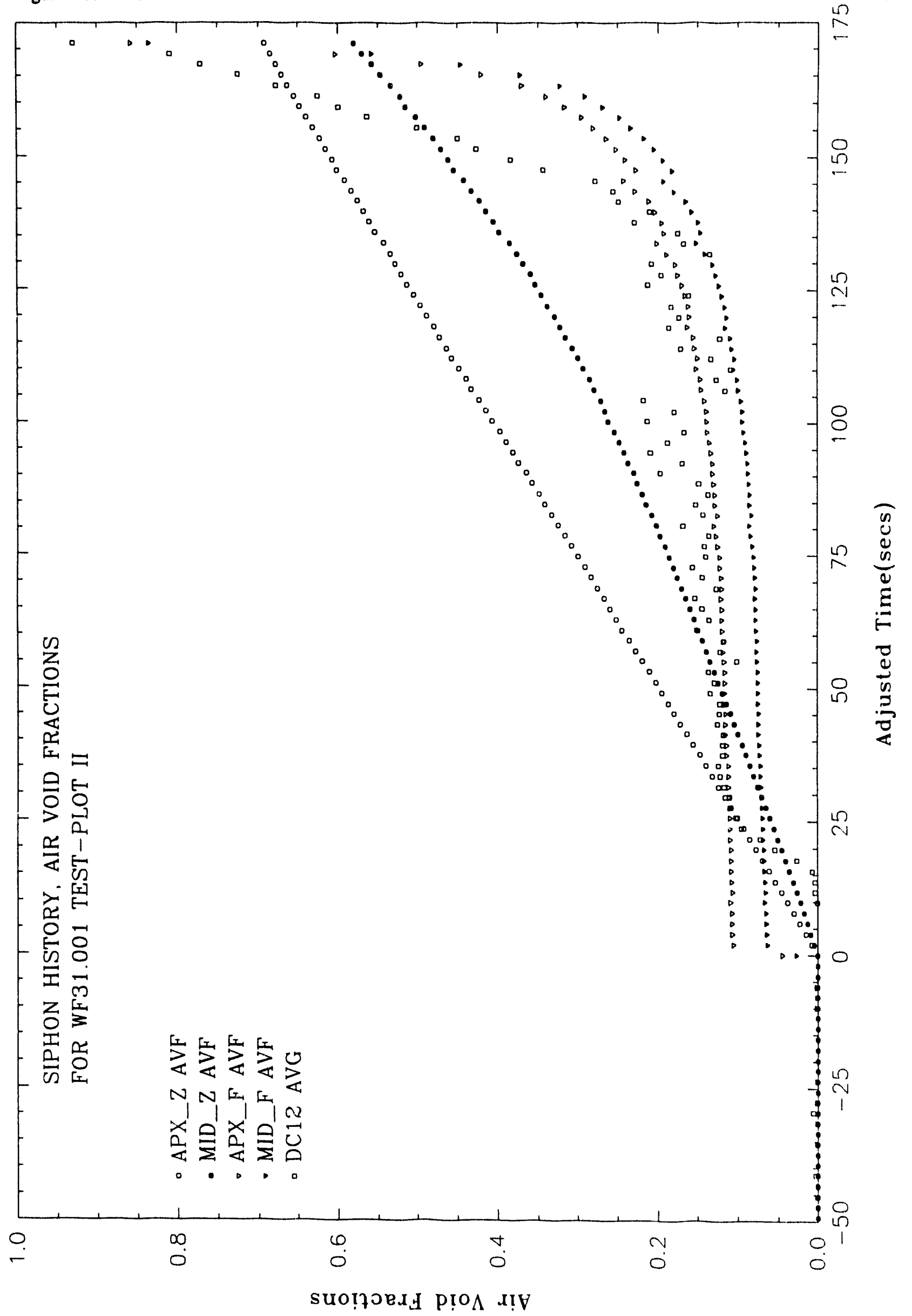




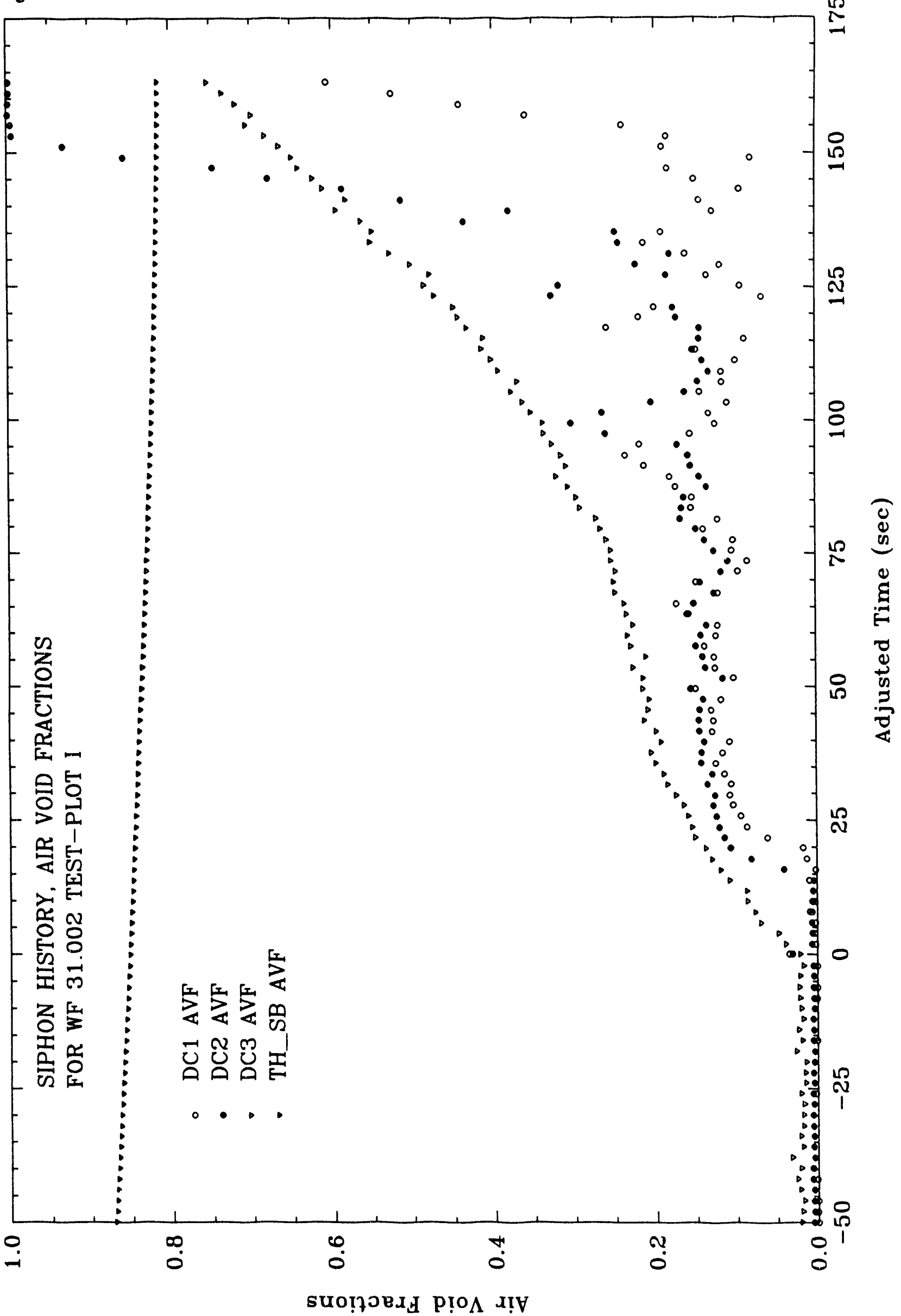




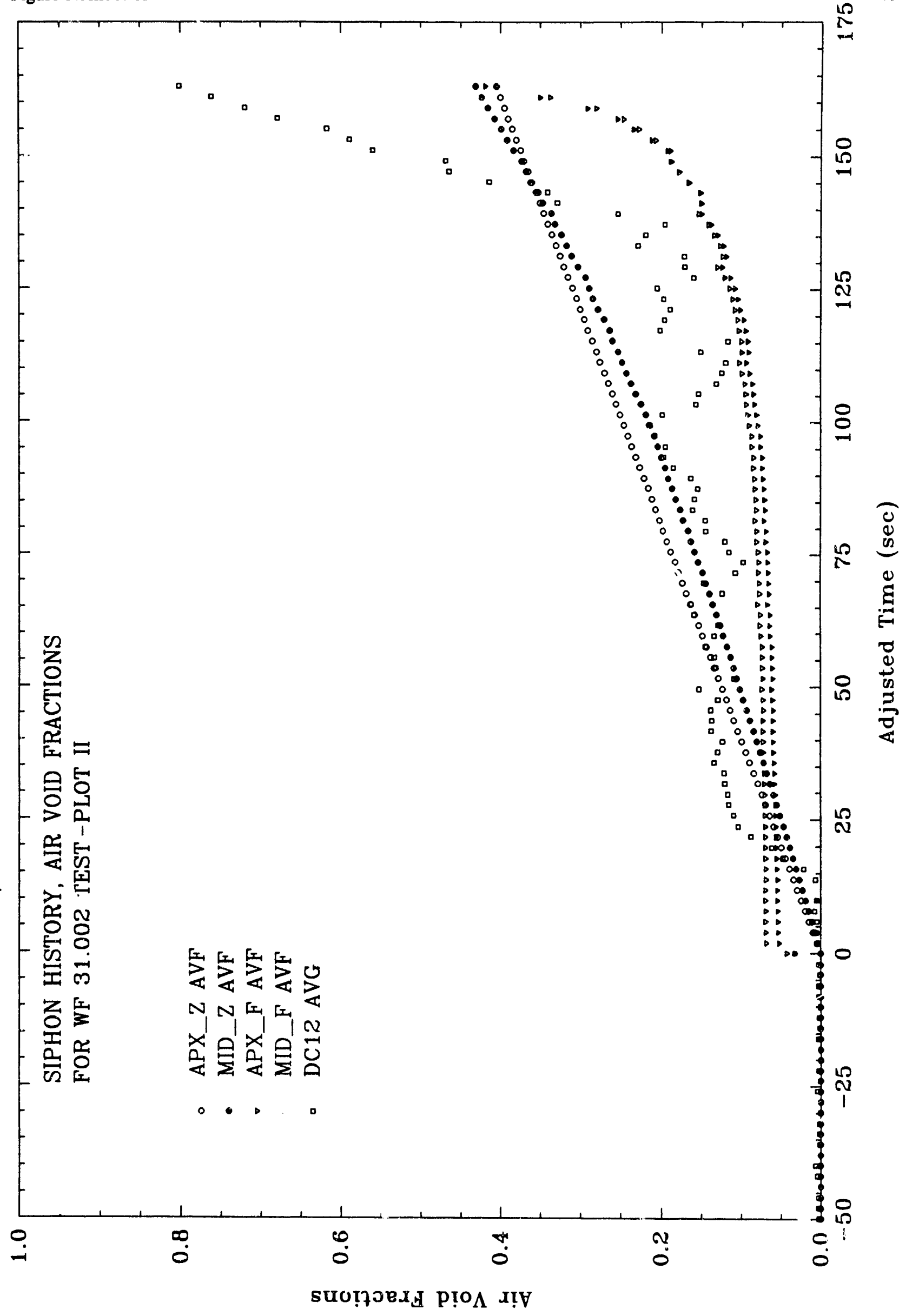




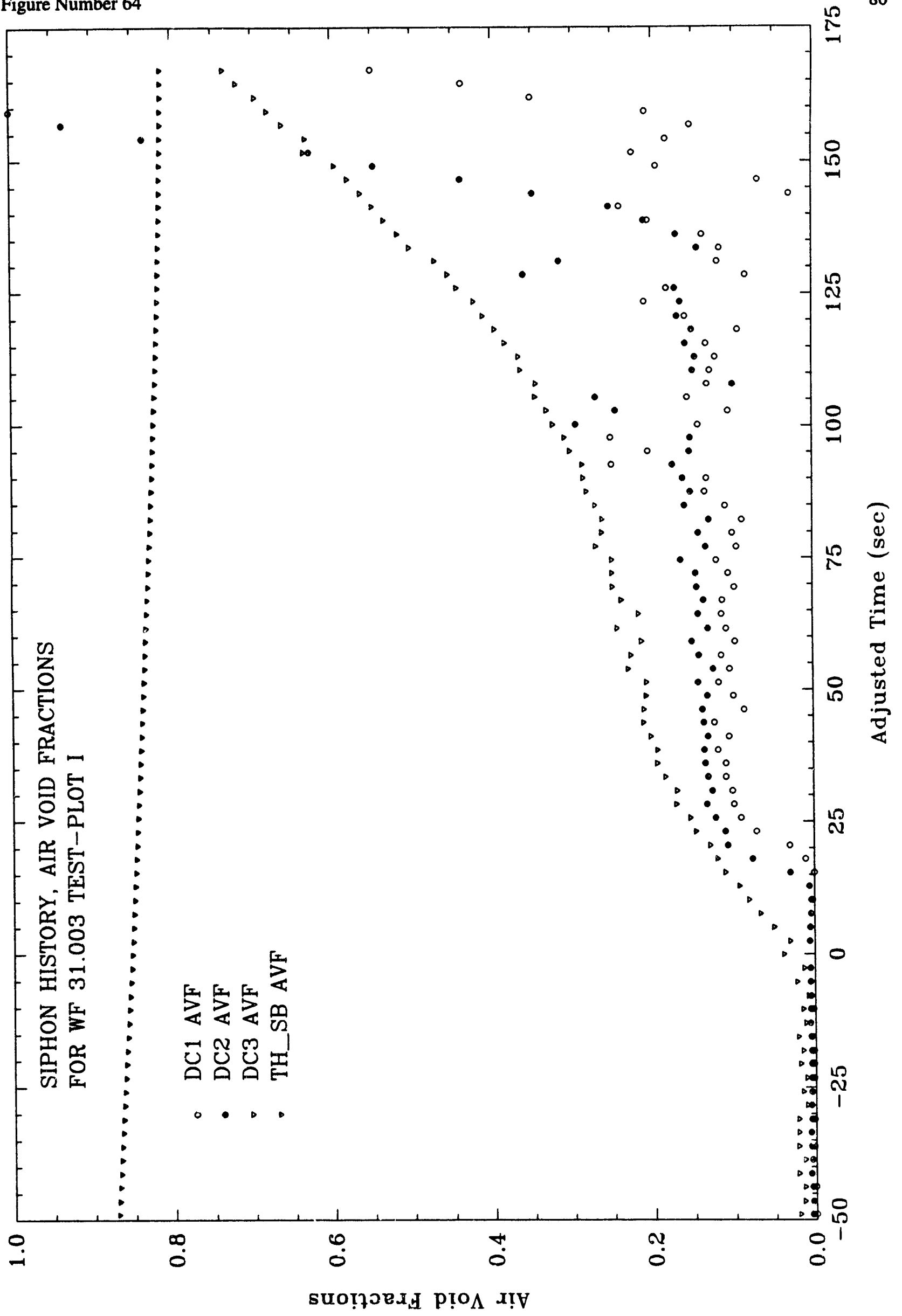




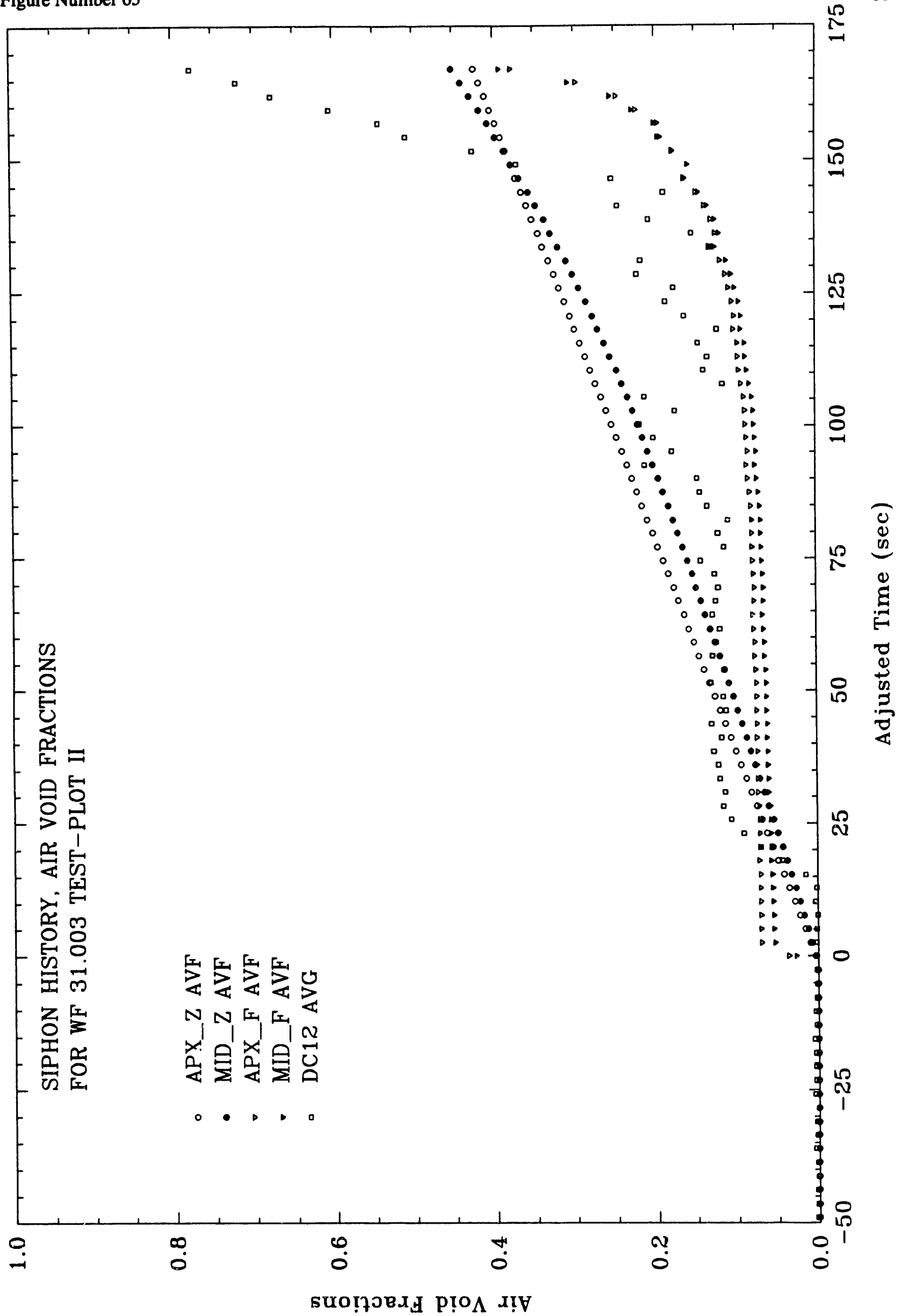




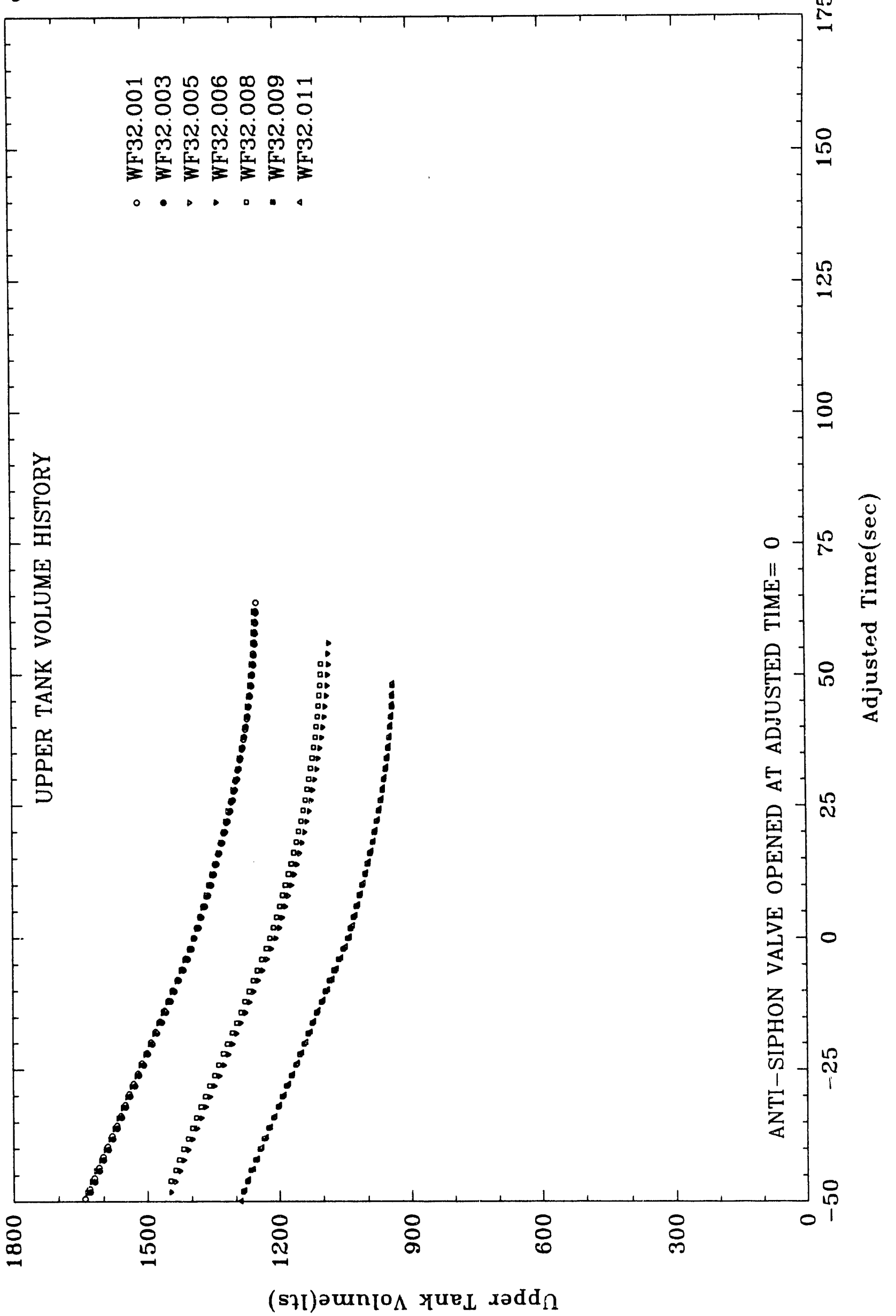




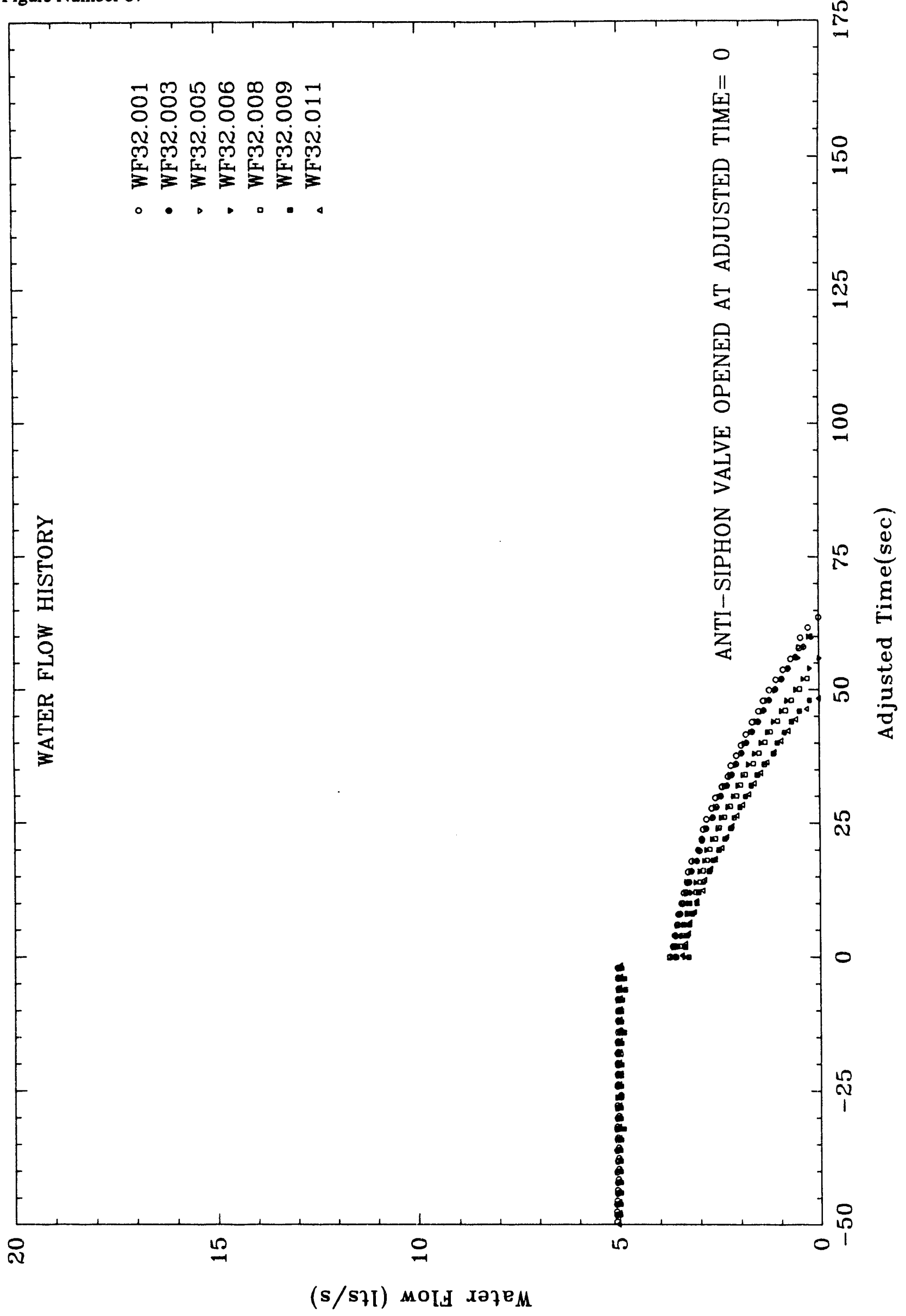




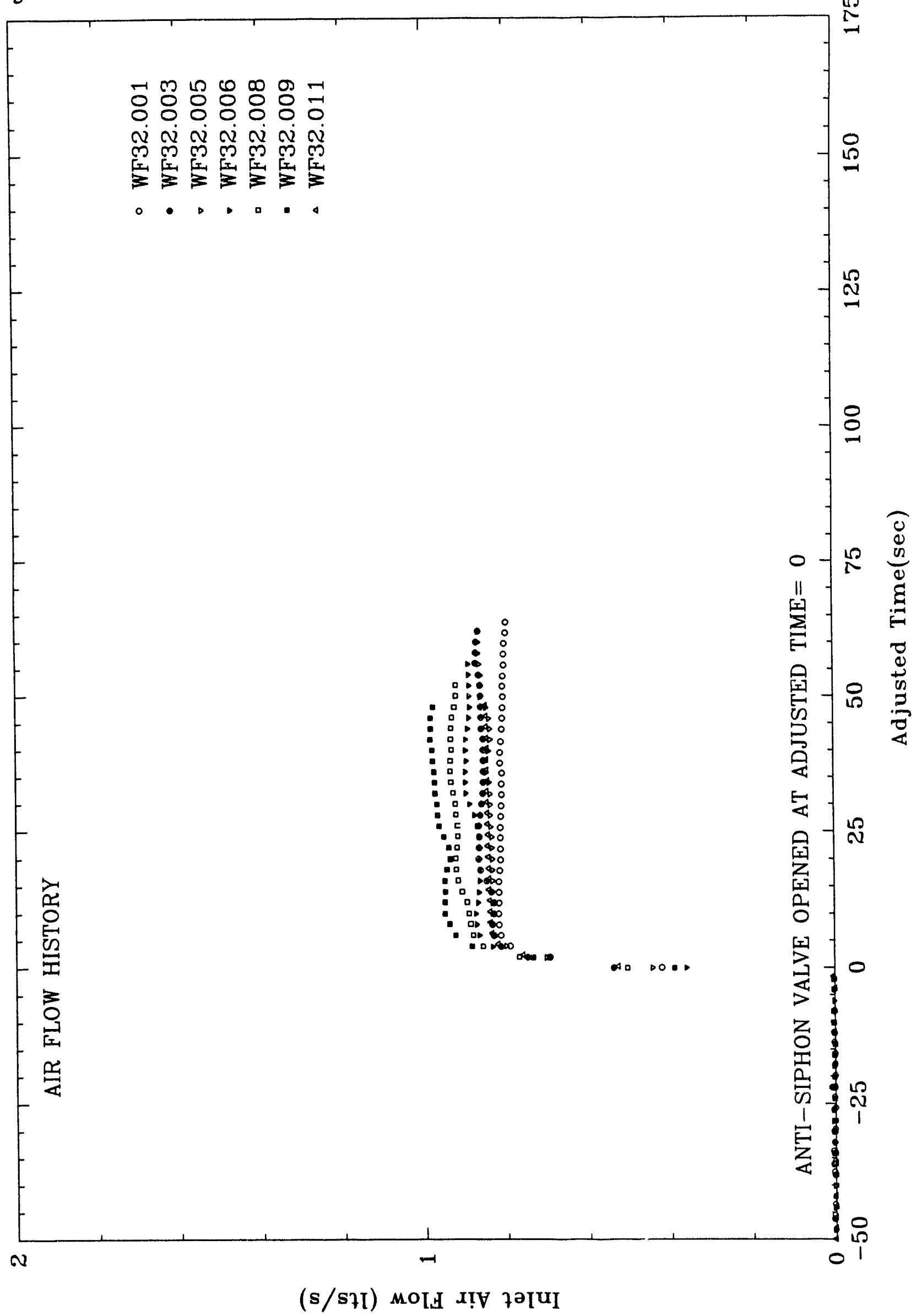




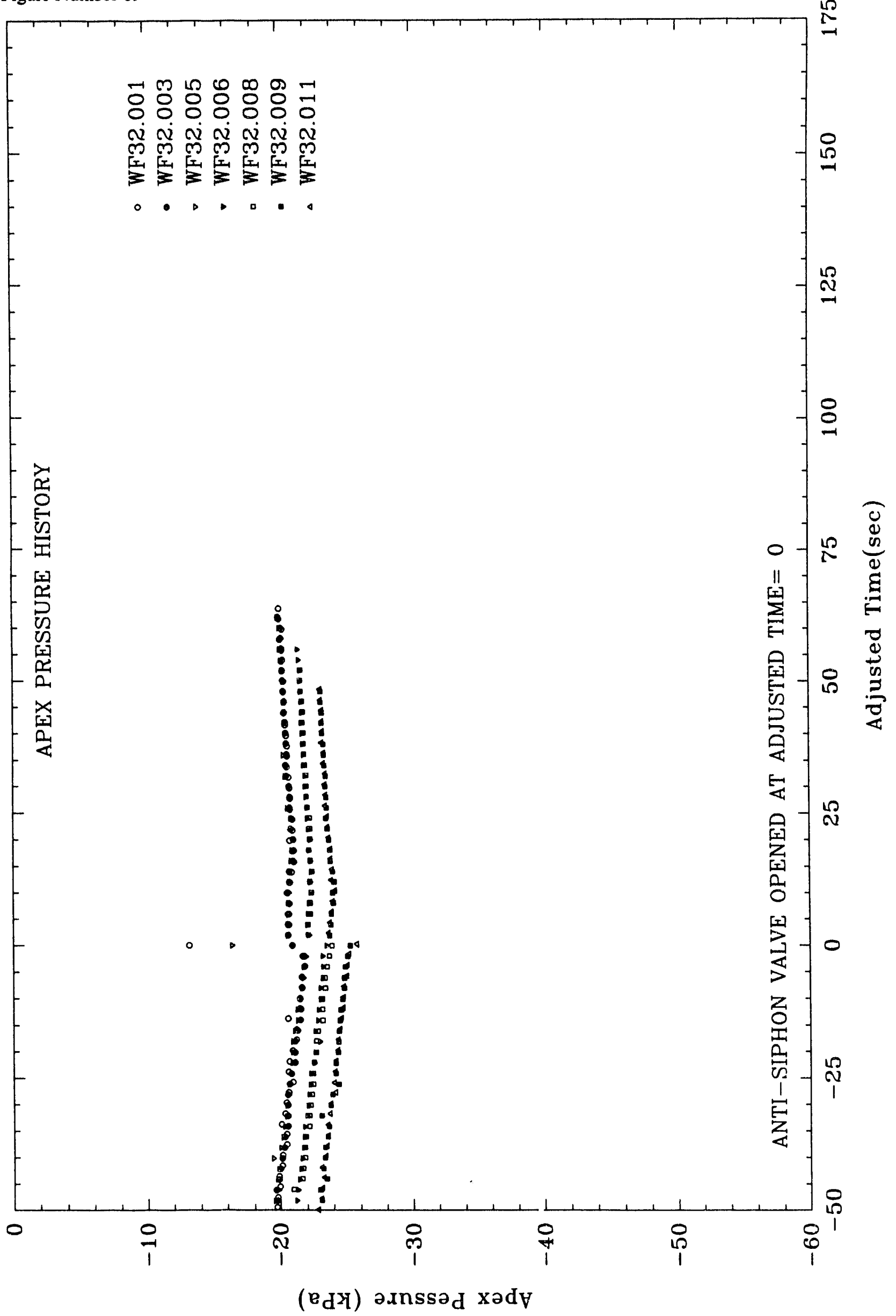


Figure Number 70

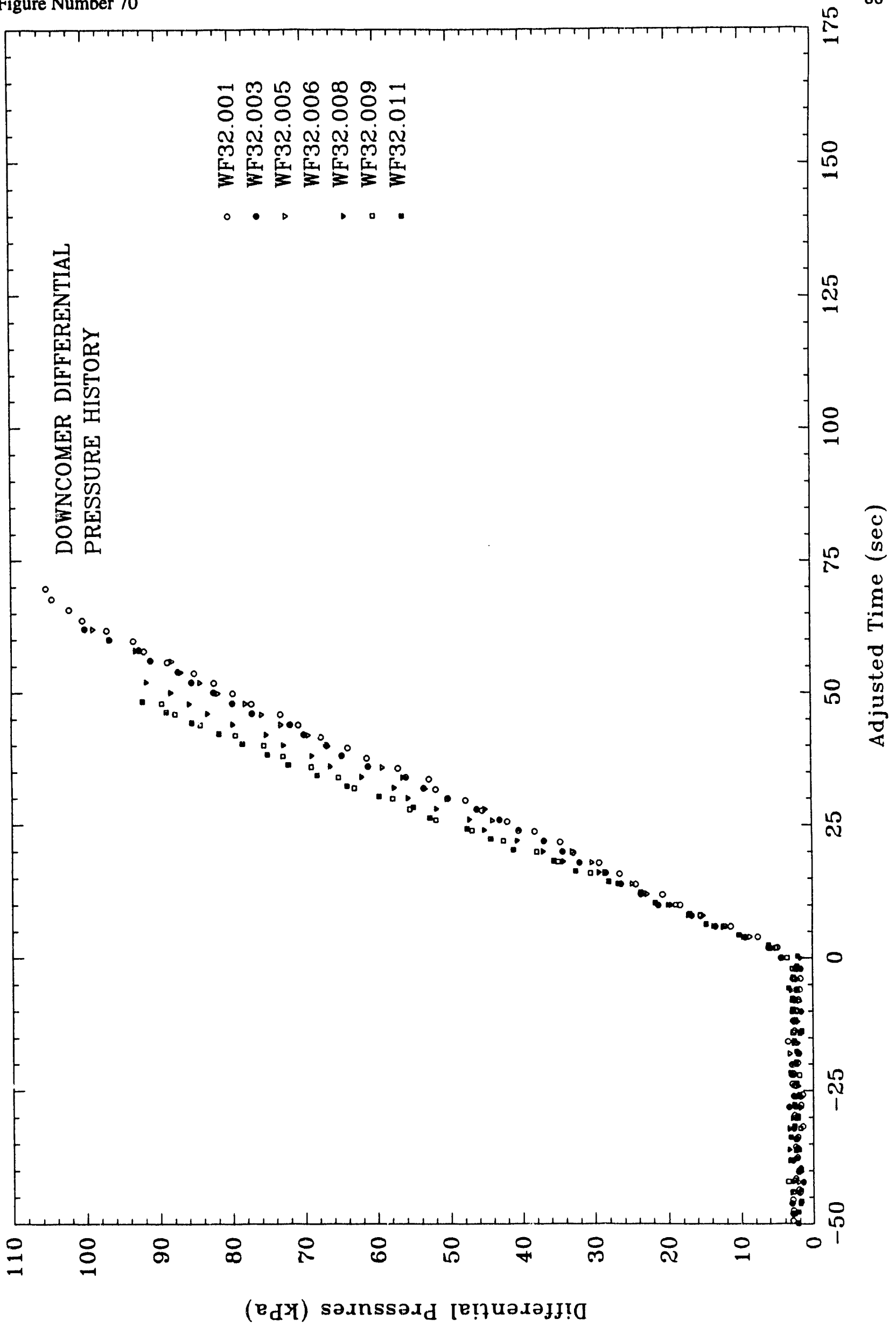


Figure Number 71

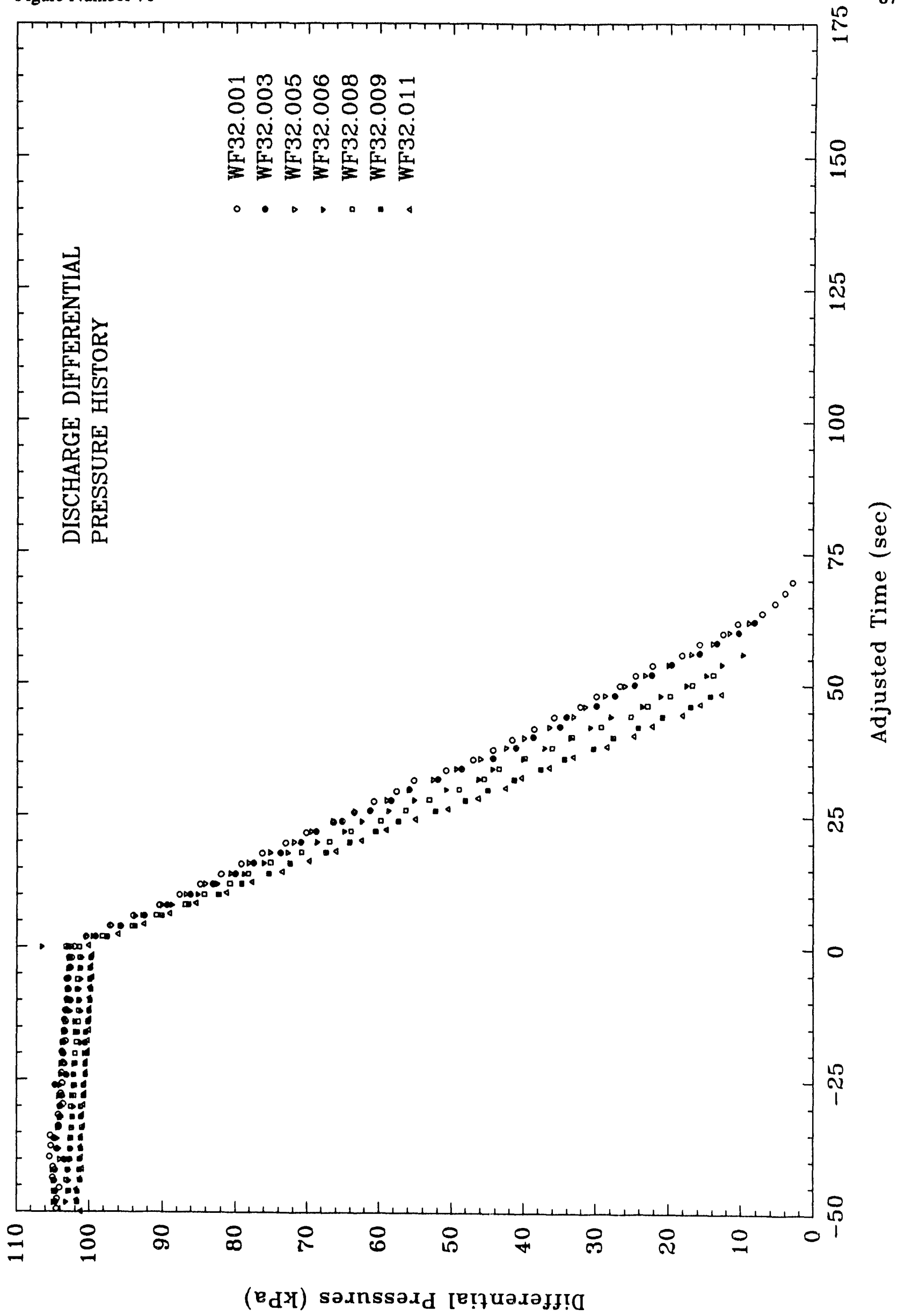


Figure Number 72

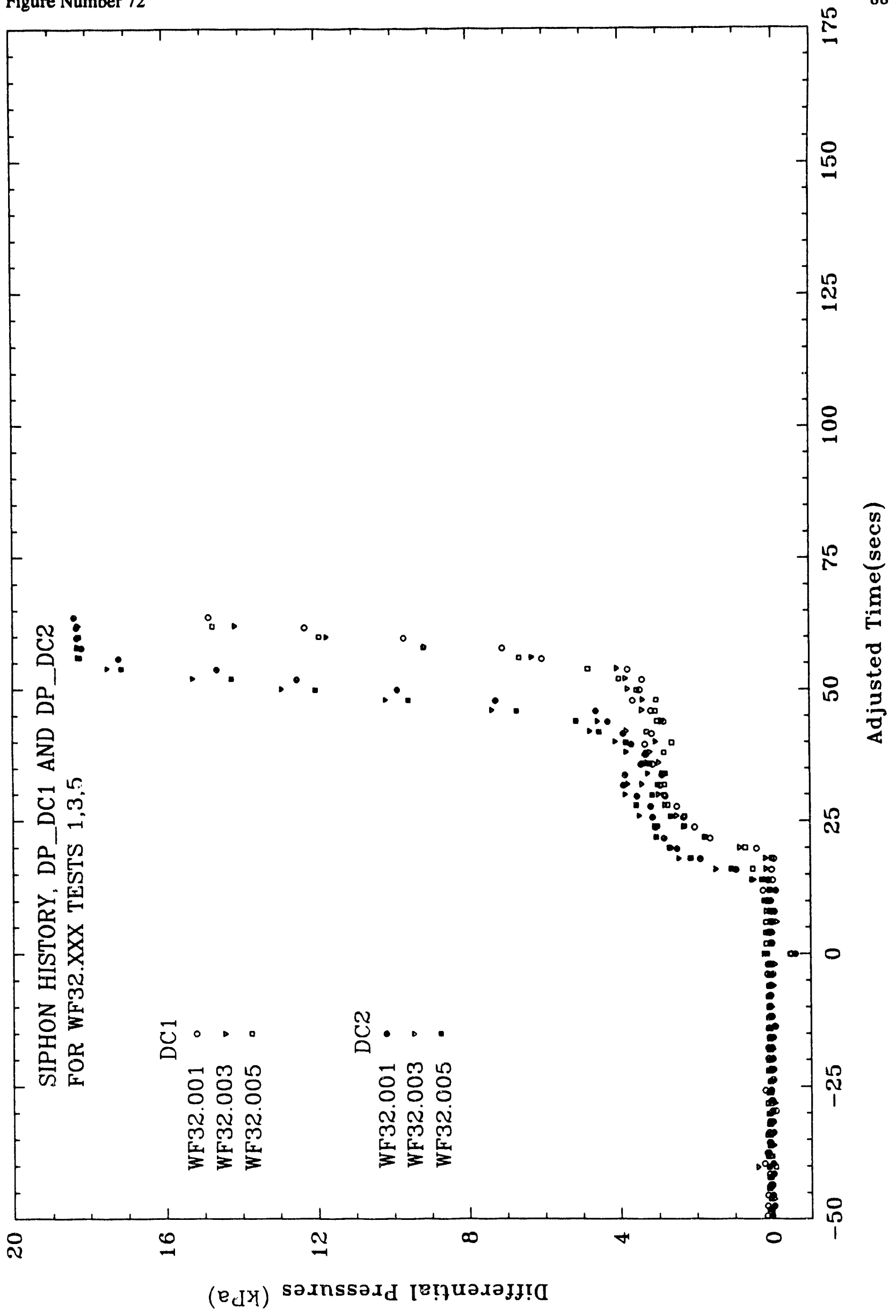


Figure Number 73

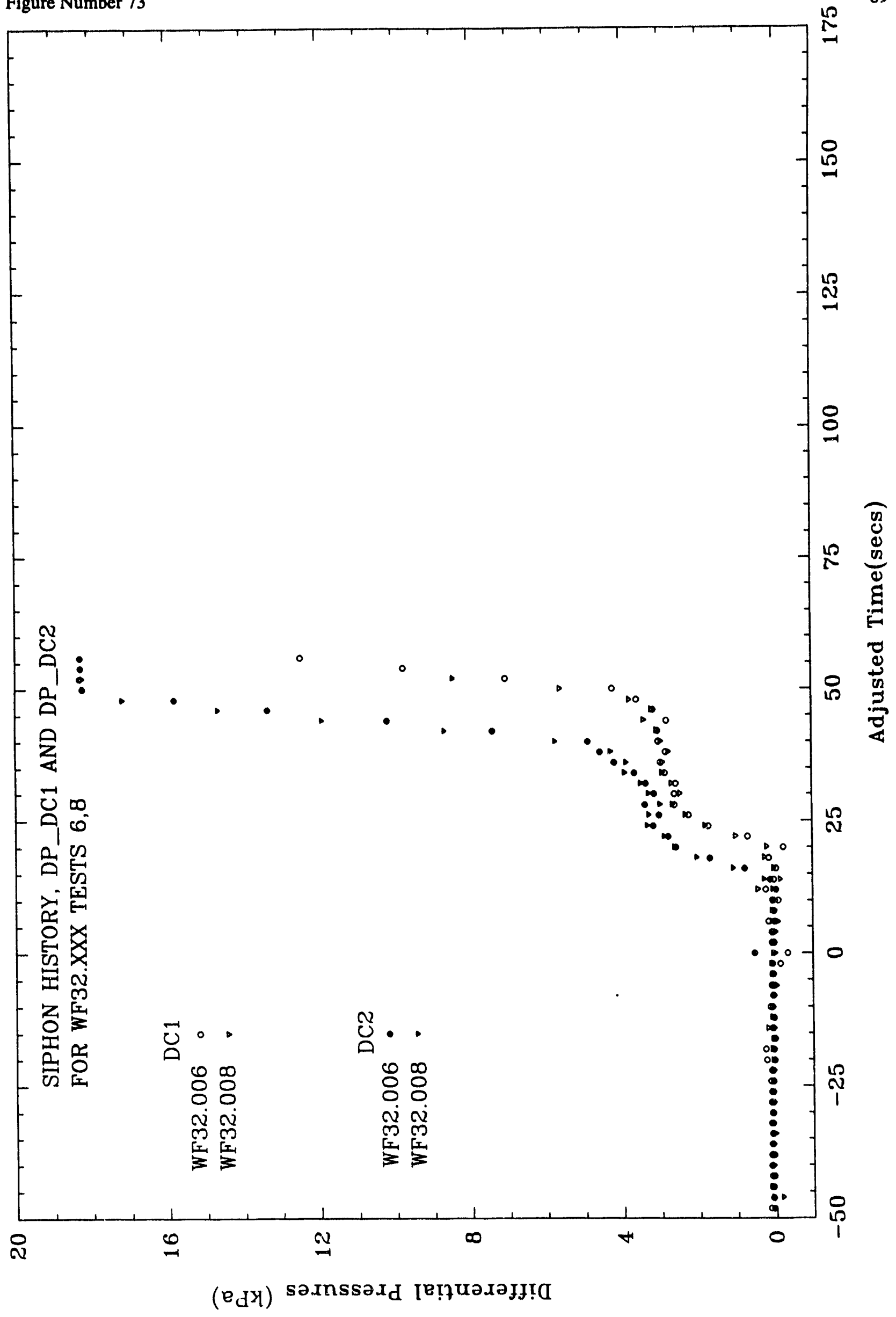




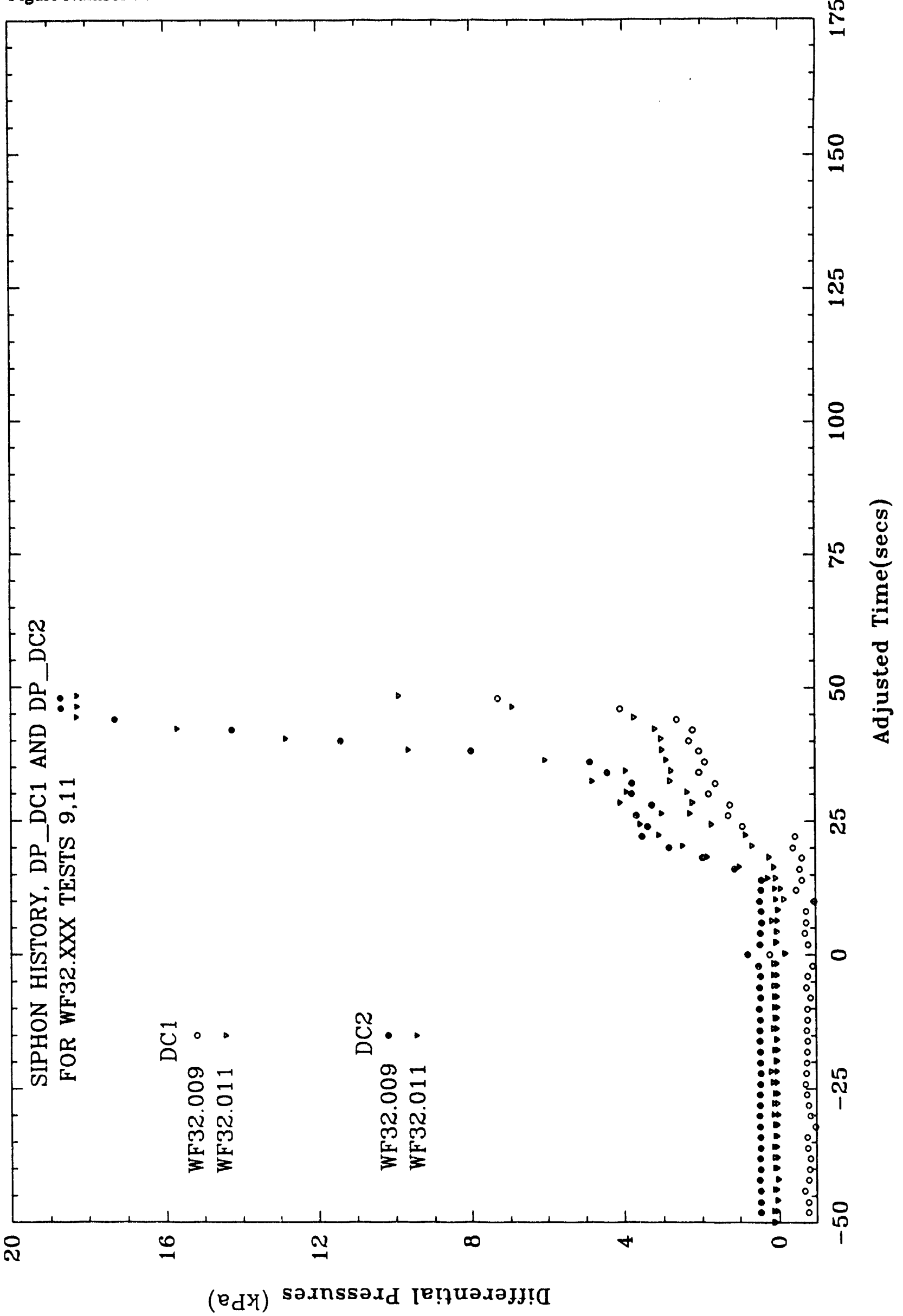


Figure Number 75

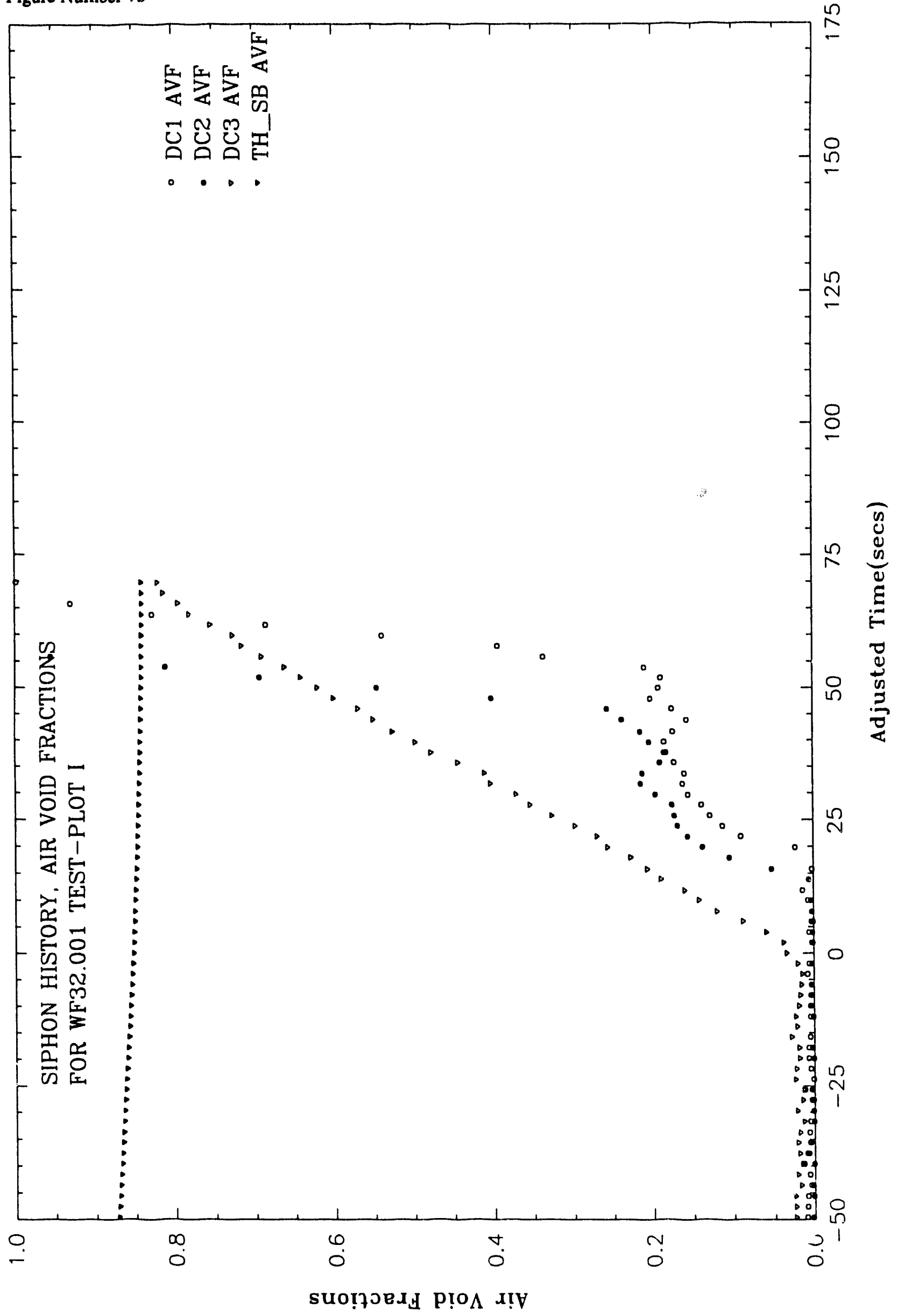




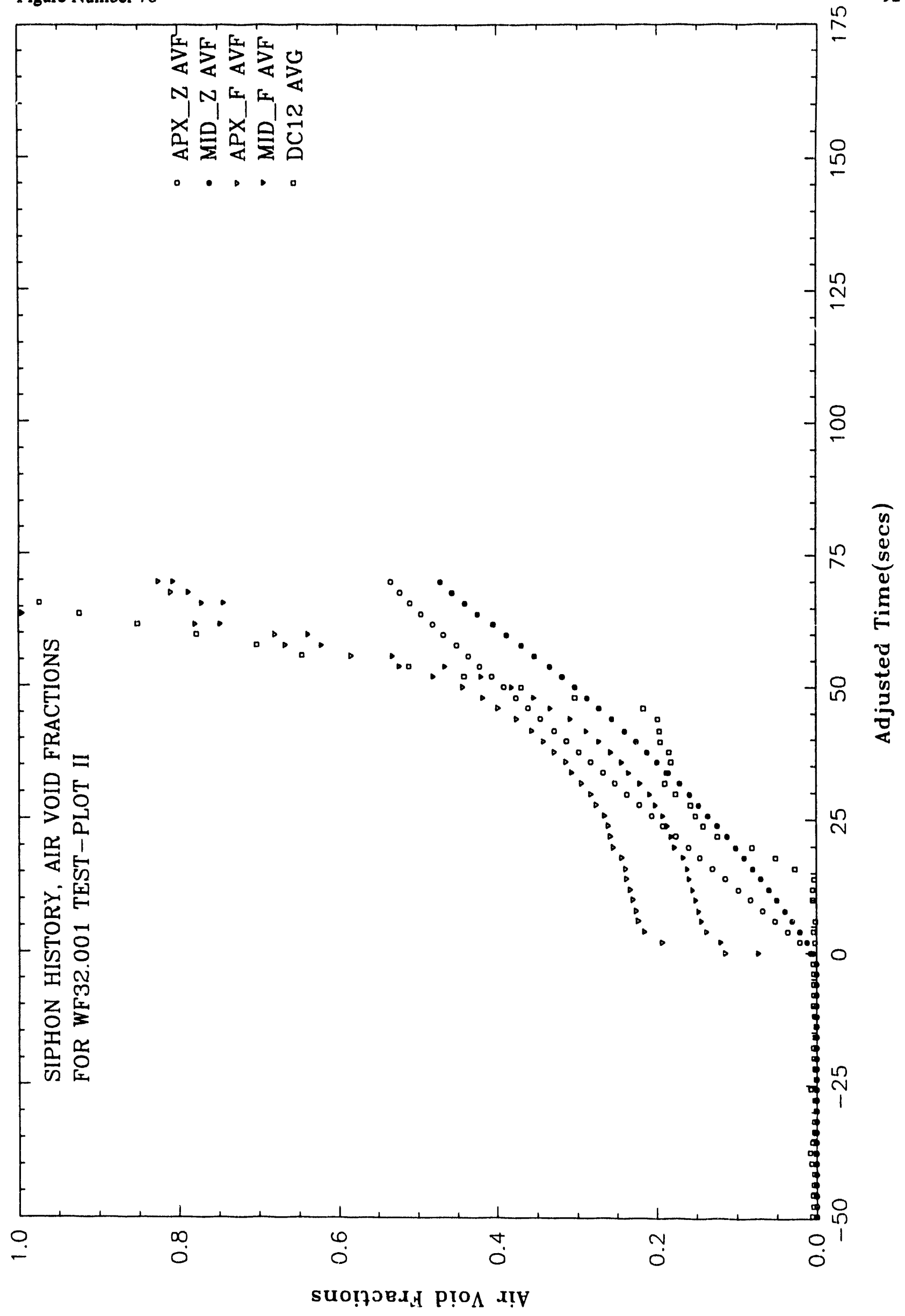


Figure Number 77

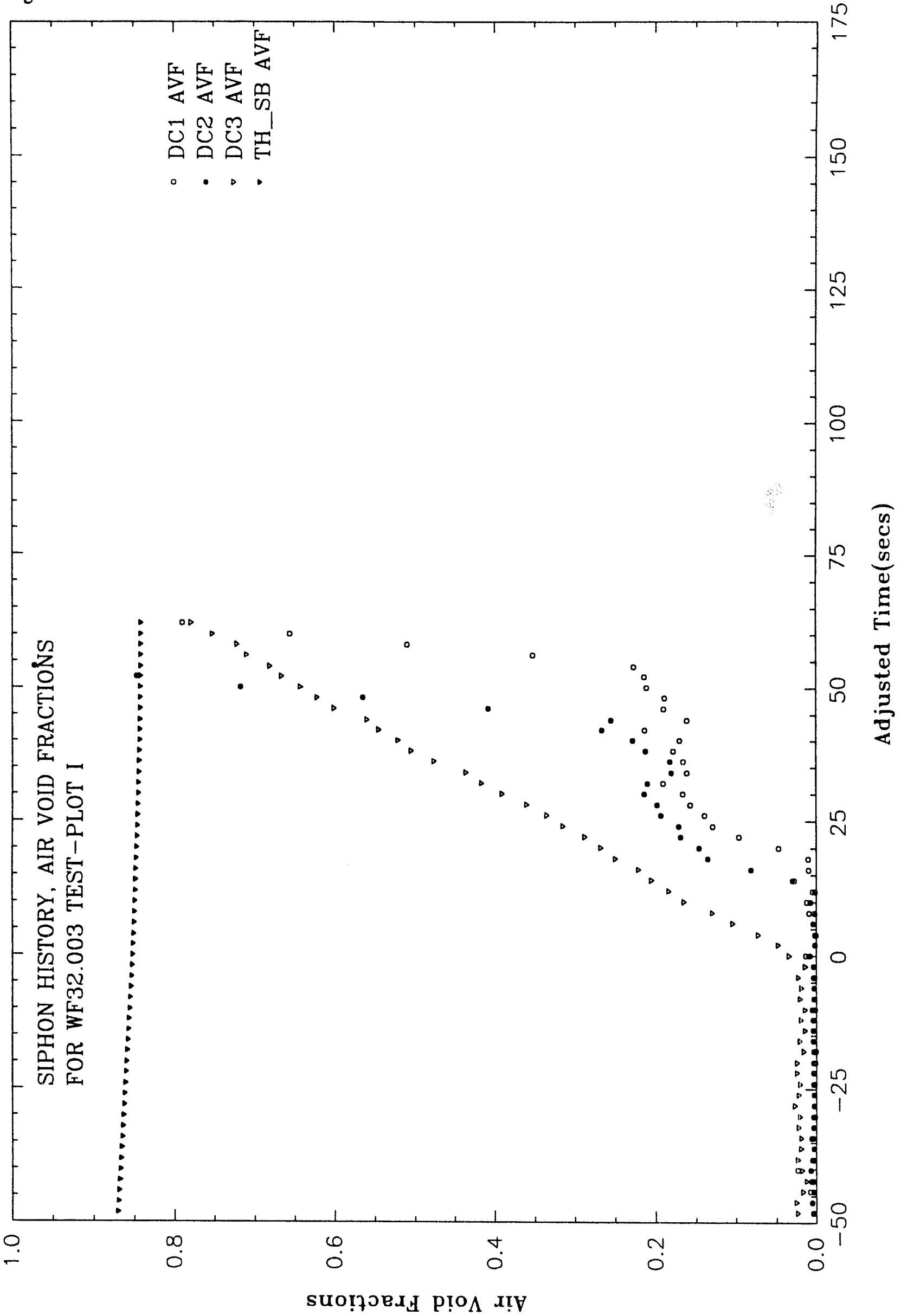




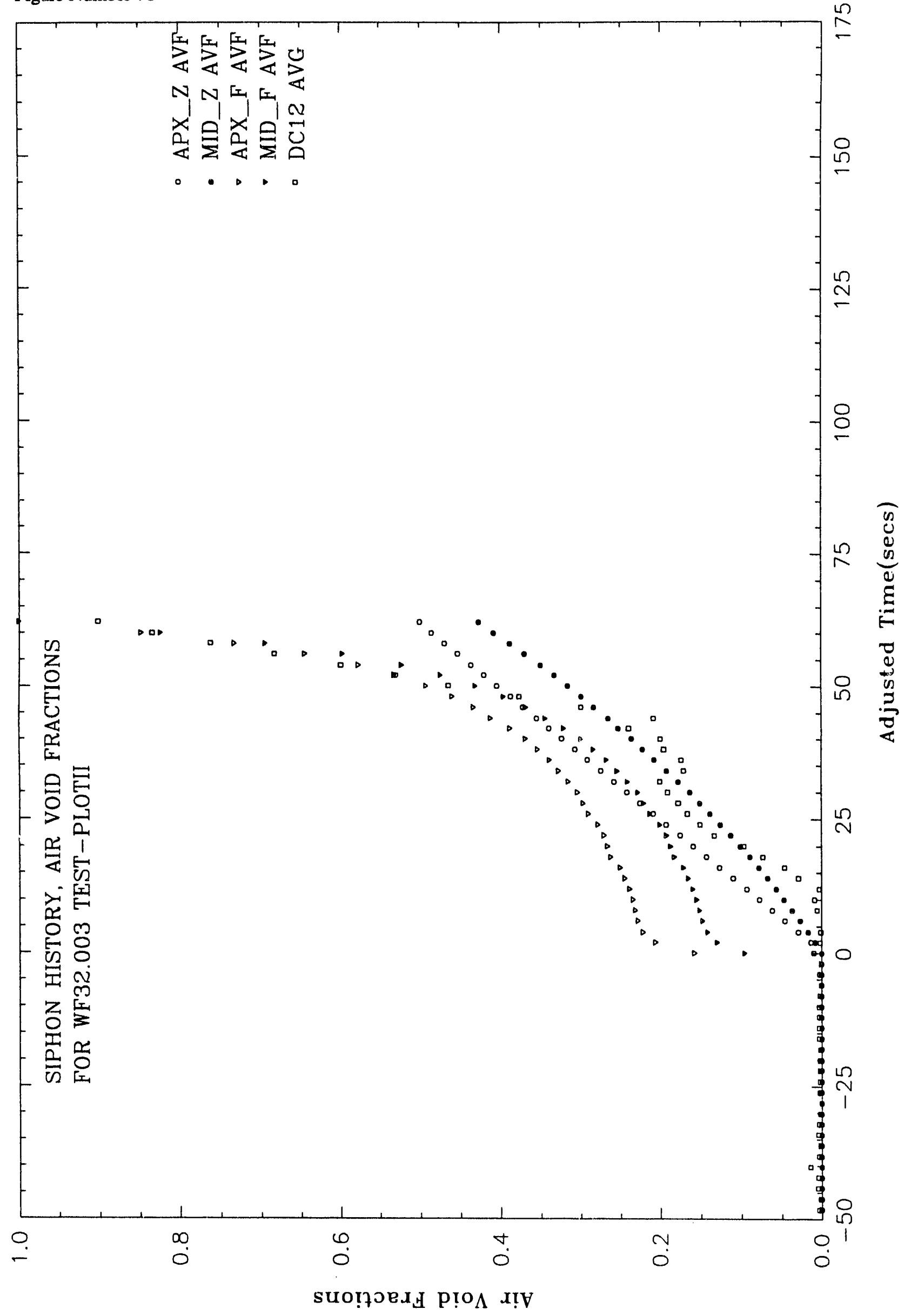




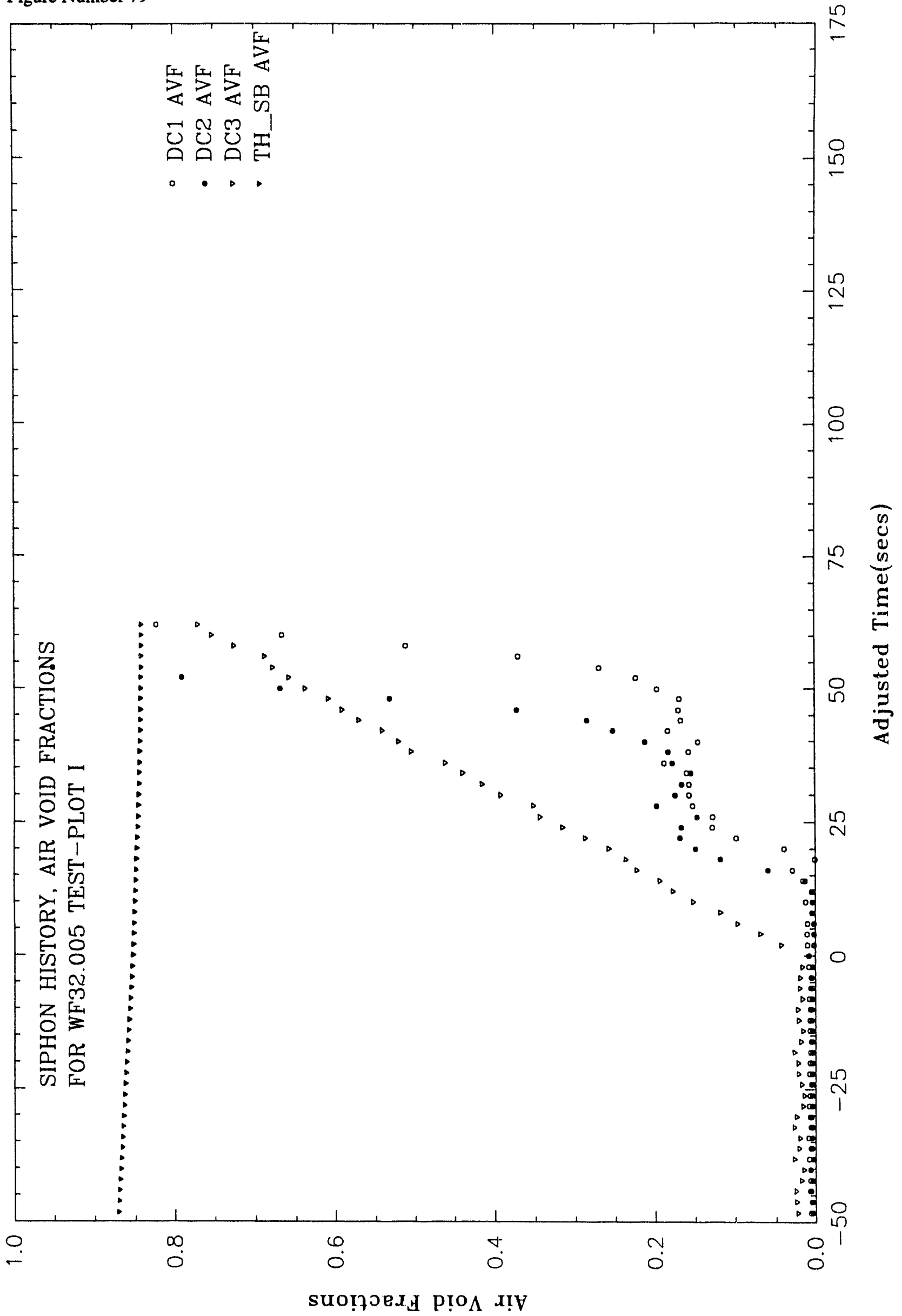


Figure Number 80

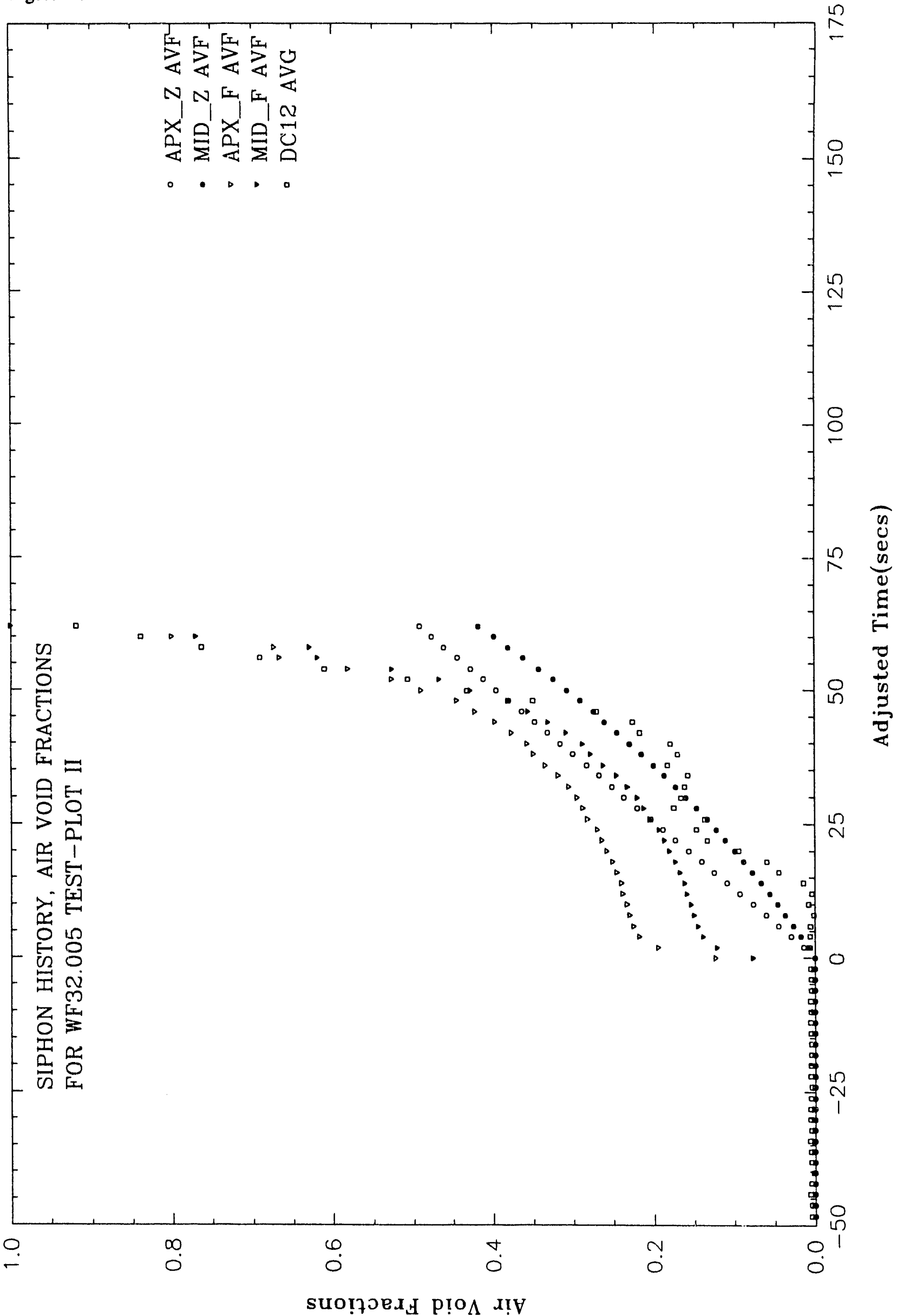




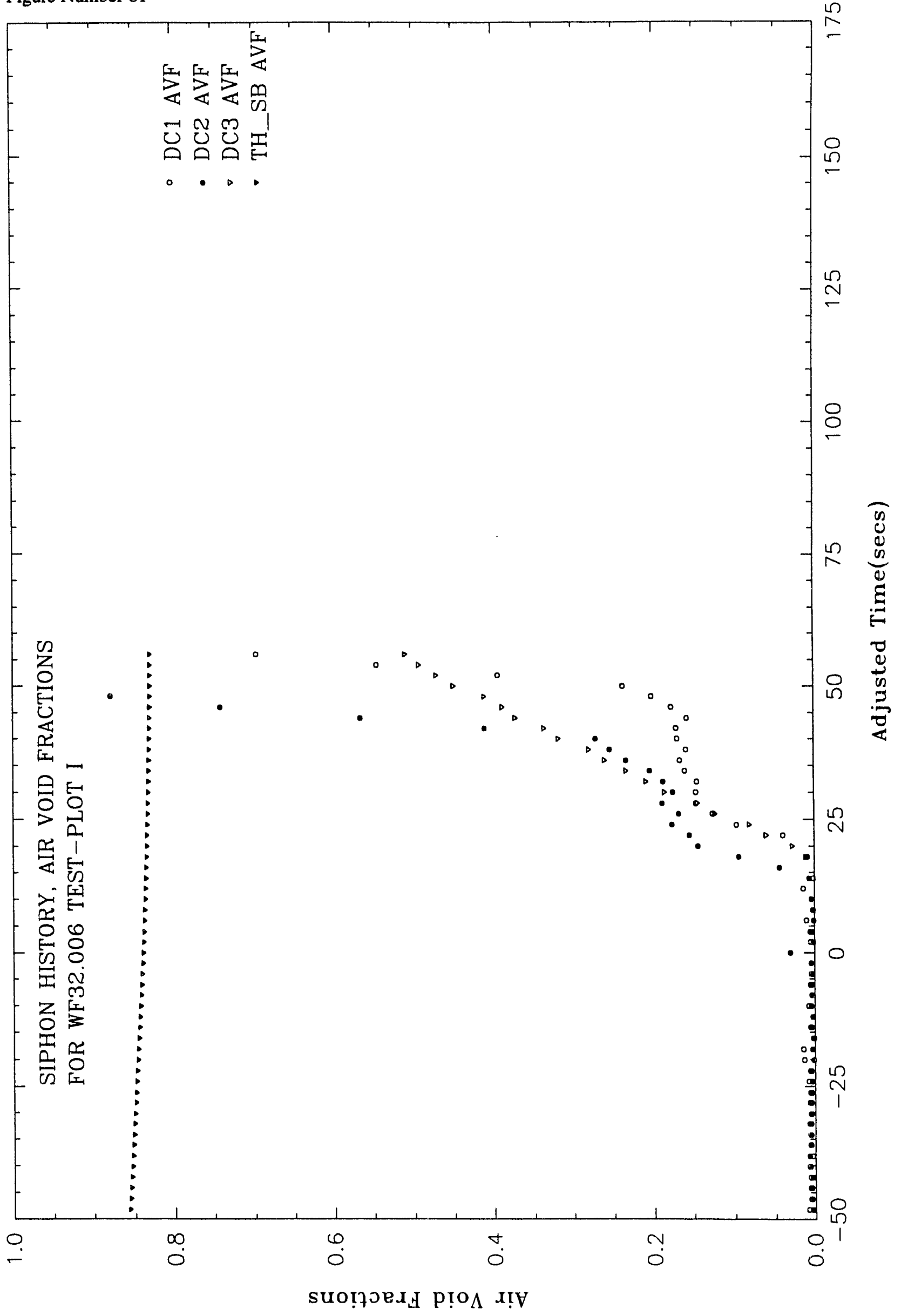


Figure Number 82

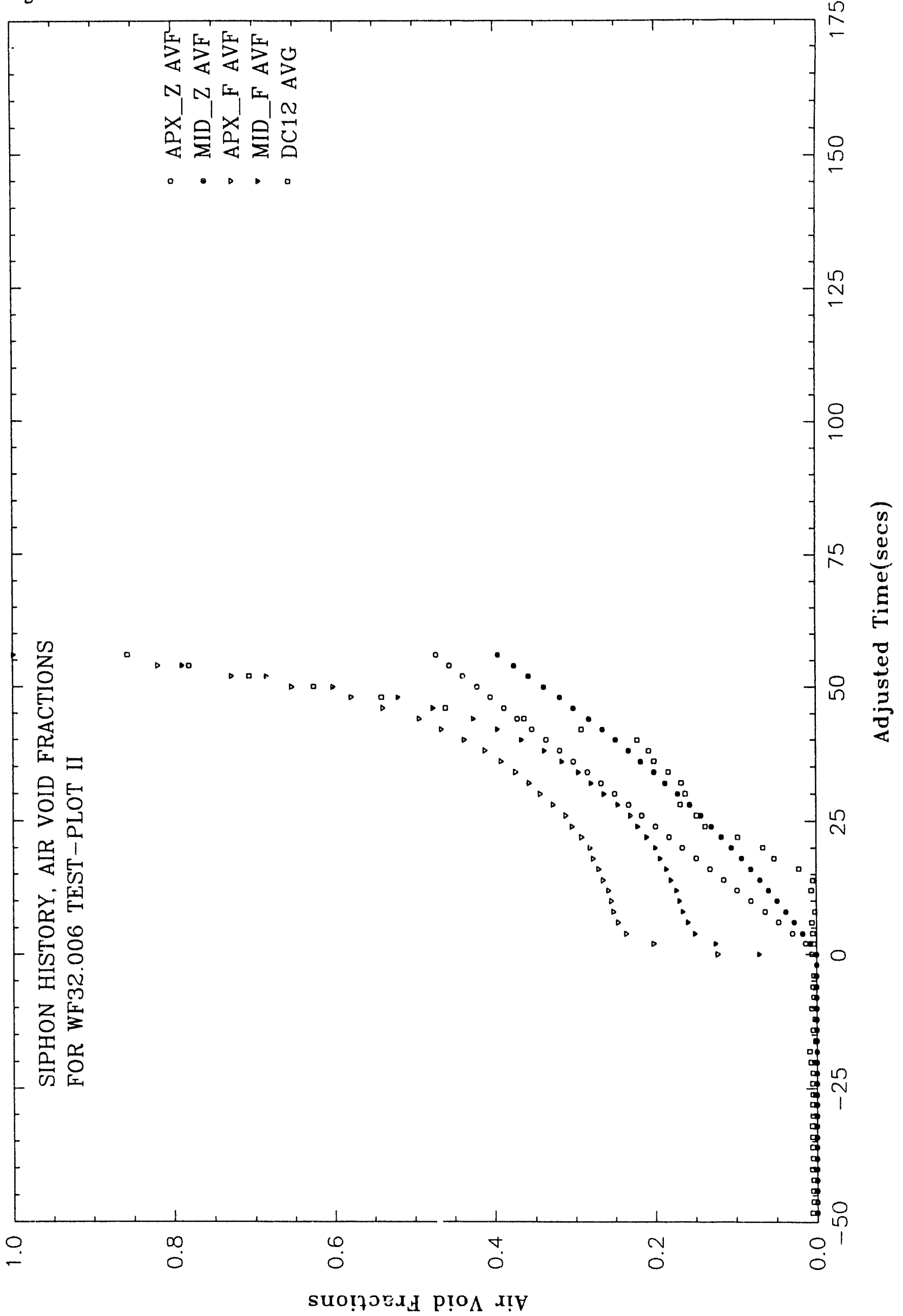




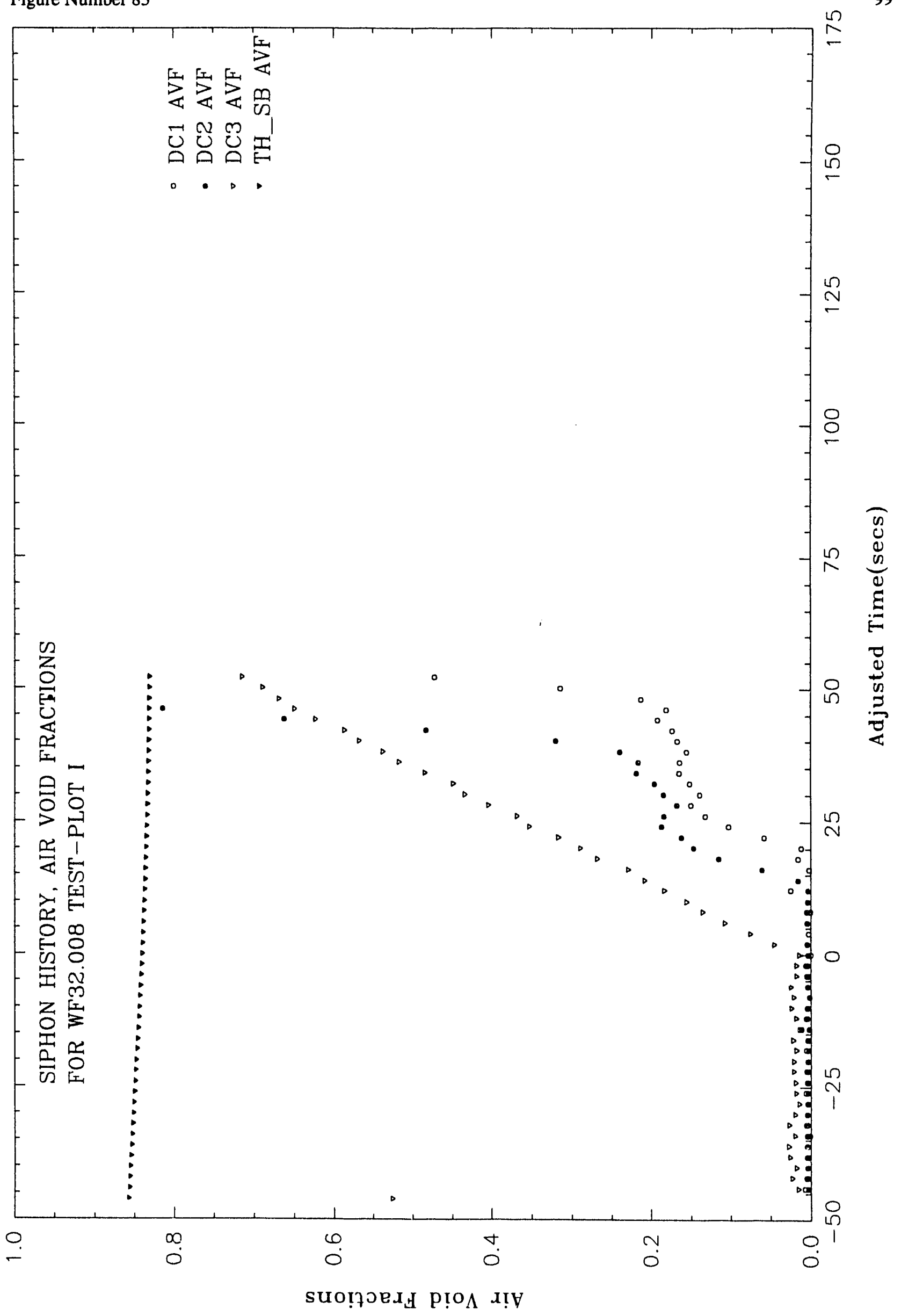




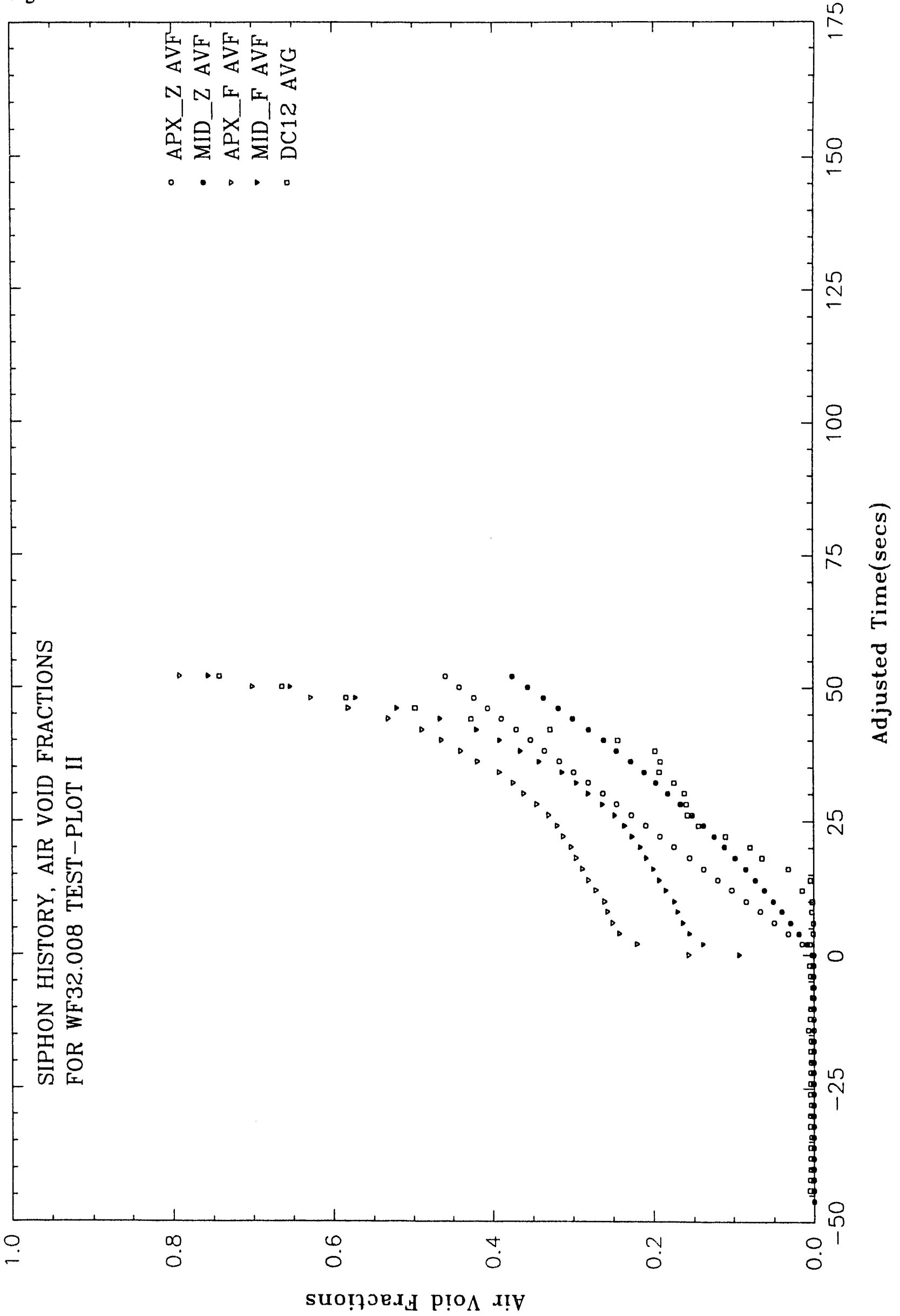




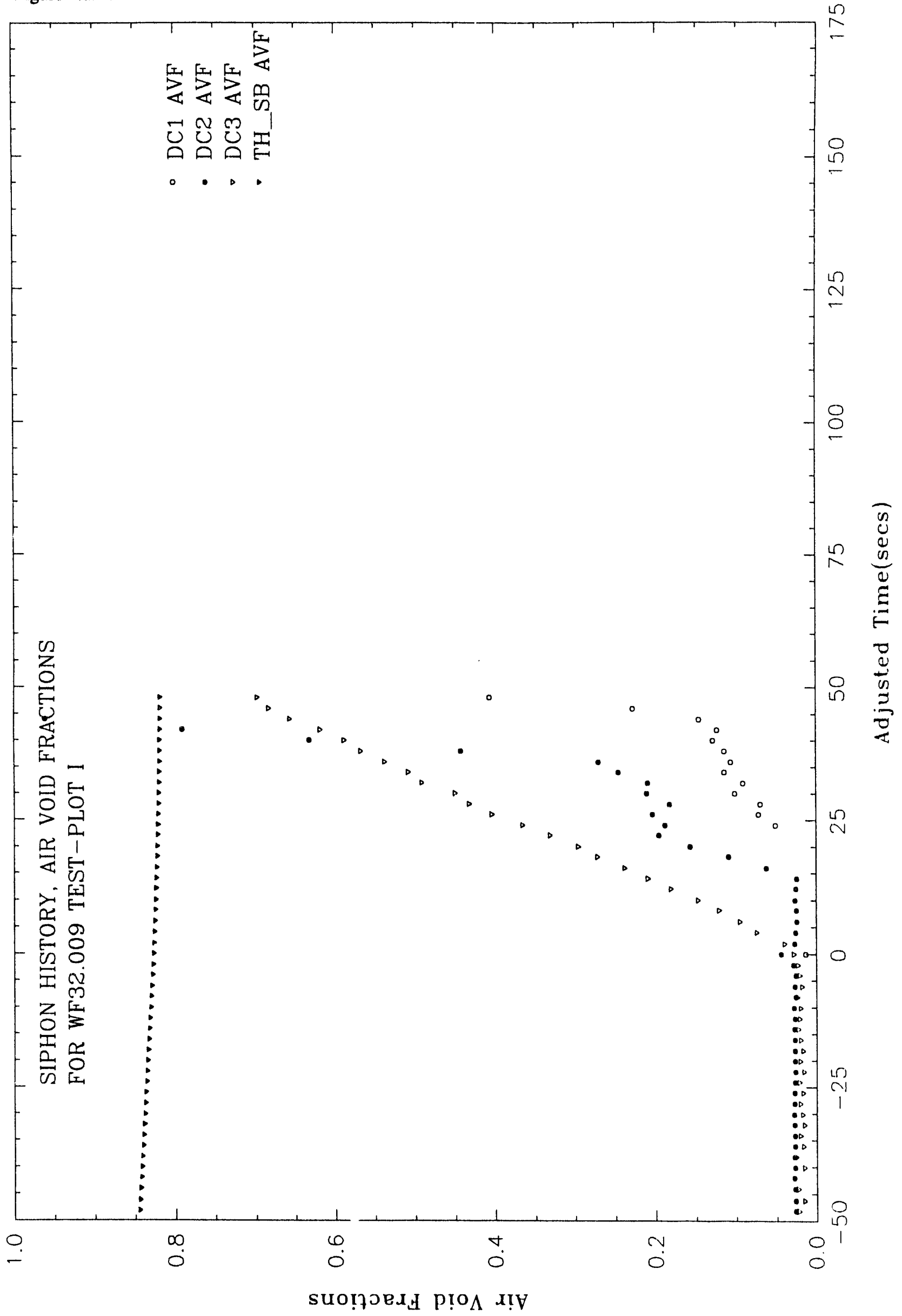




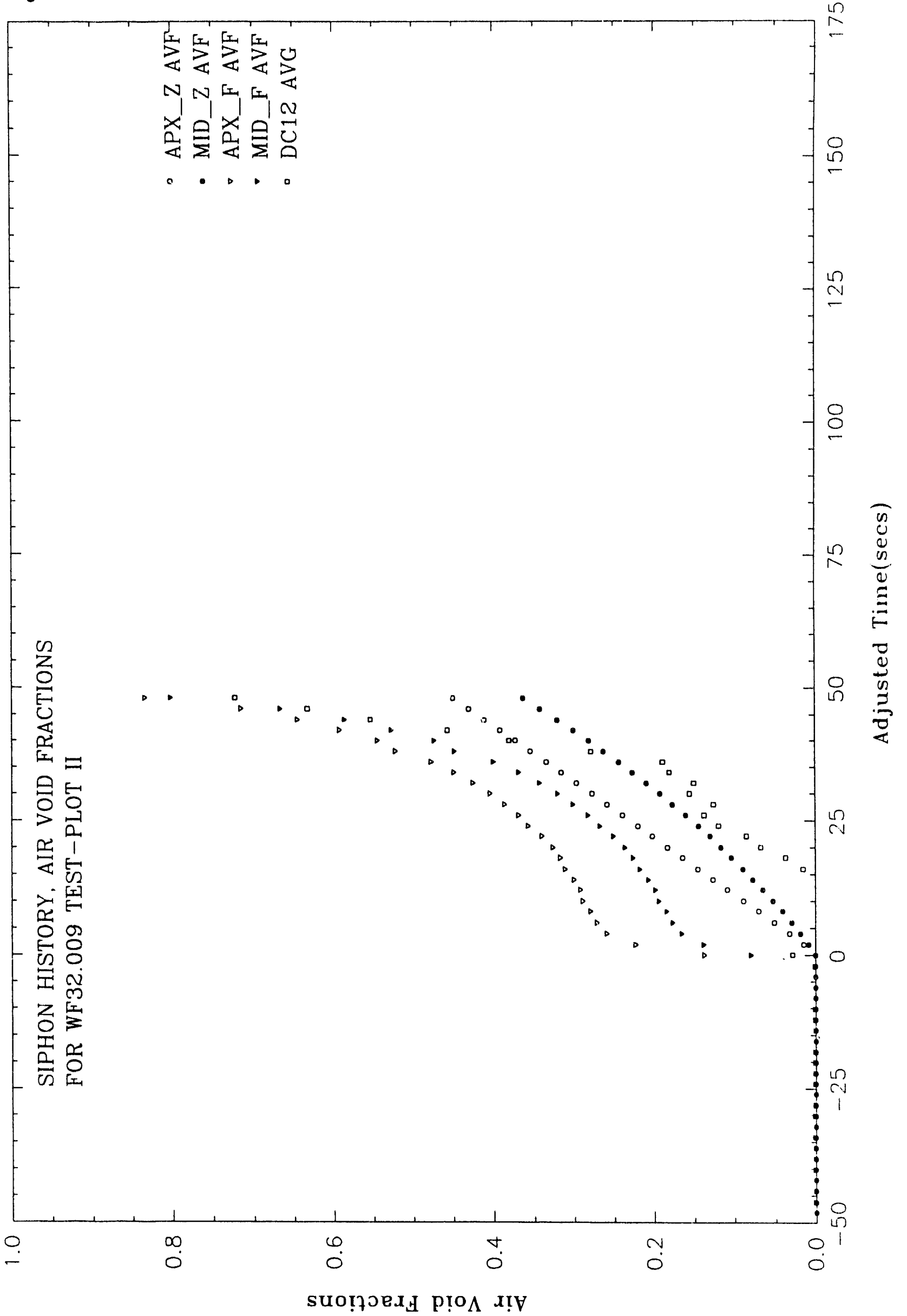


Figure Number 87

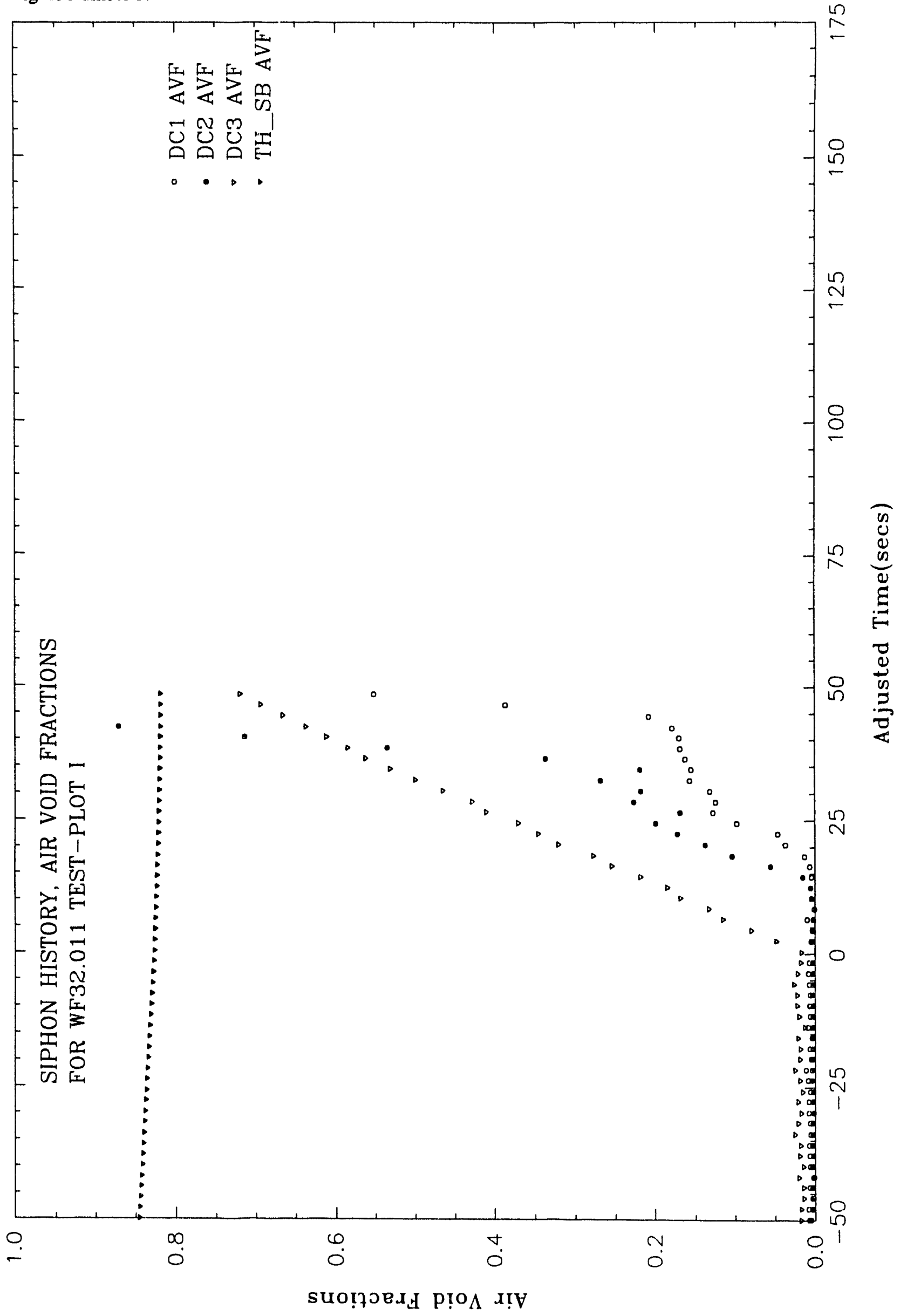




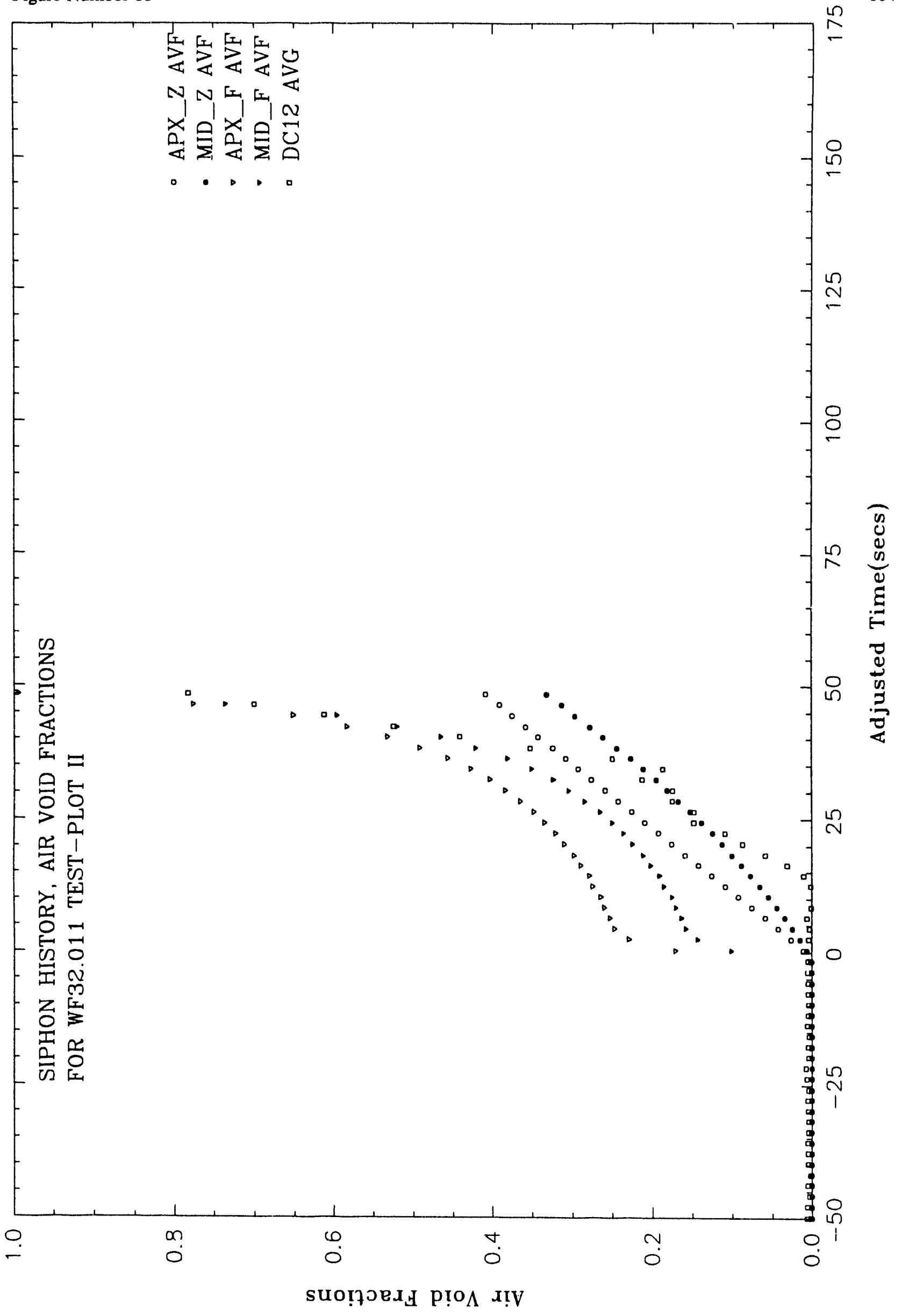


(

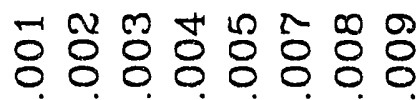

மं $\dot{~ m ं ~}$

$m m \infty m$

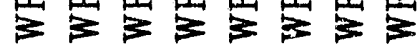

0

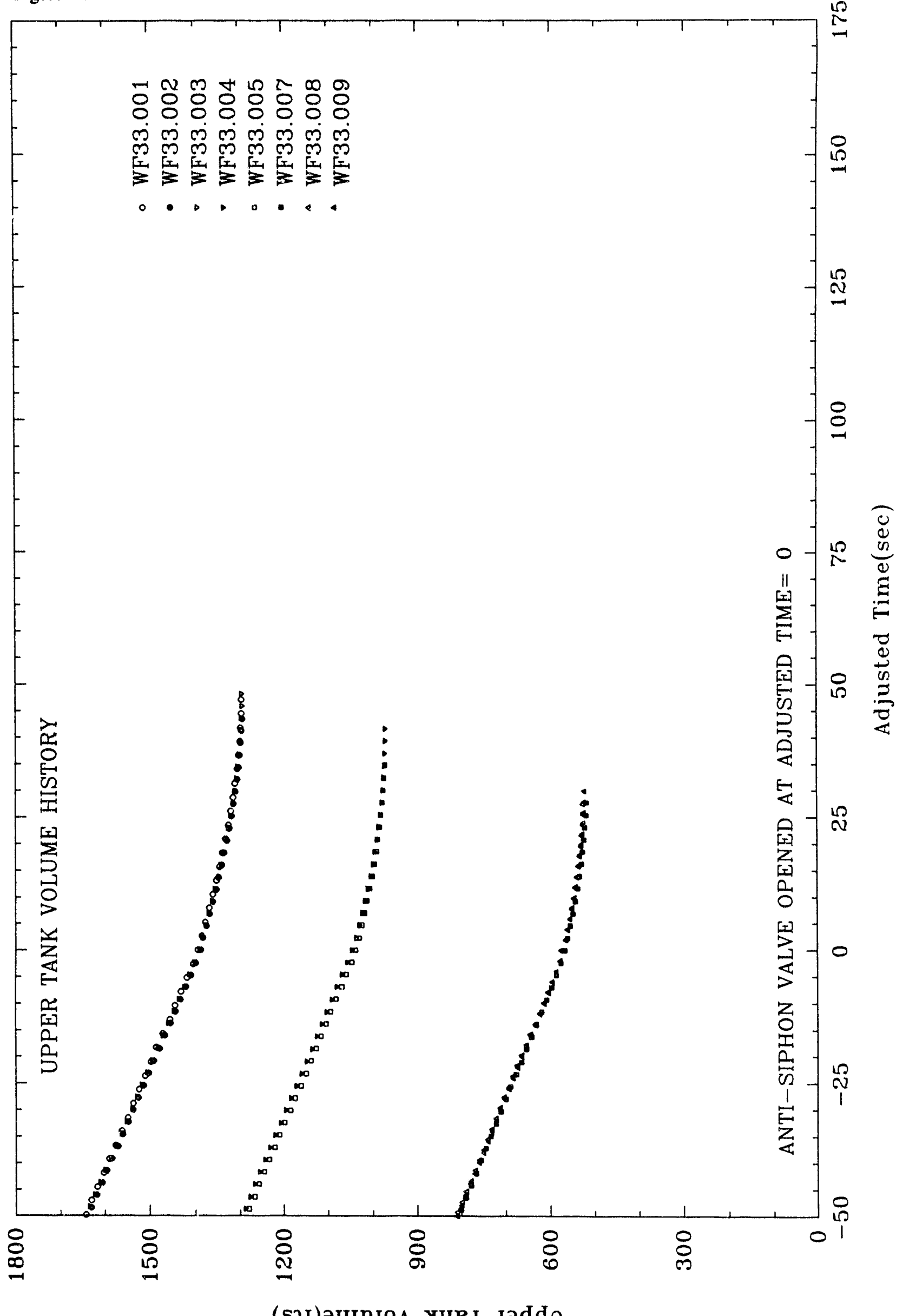

-

-

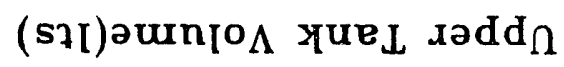




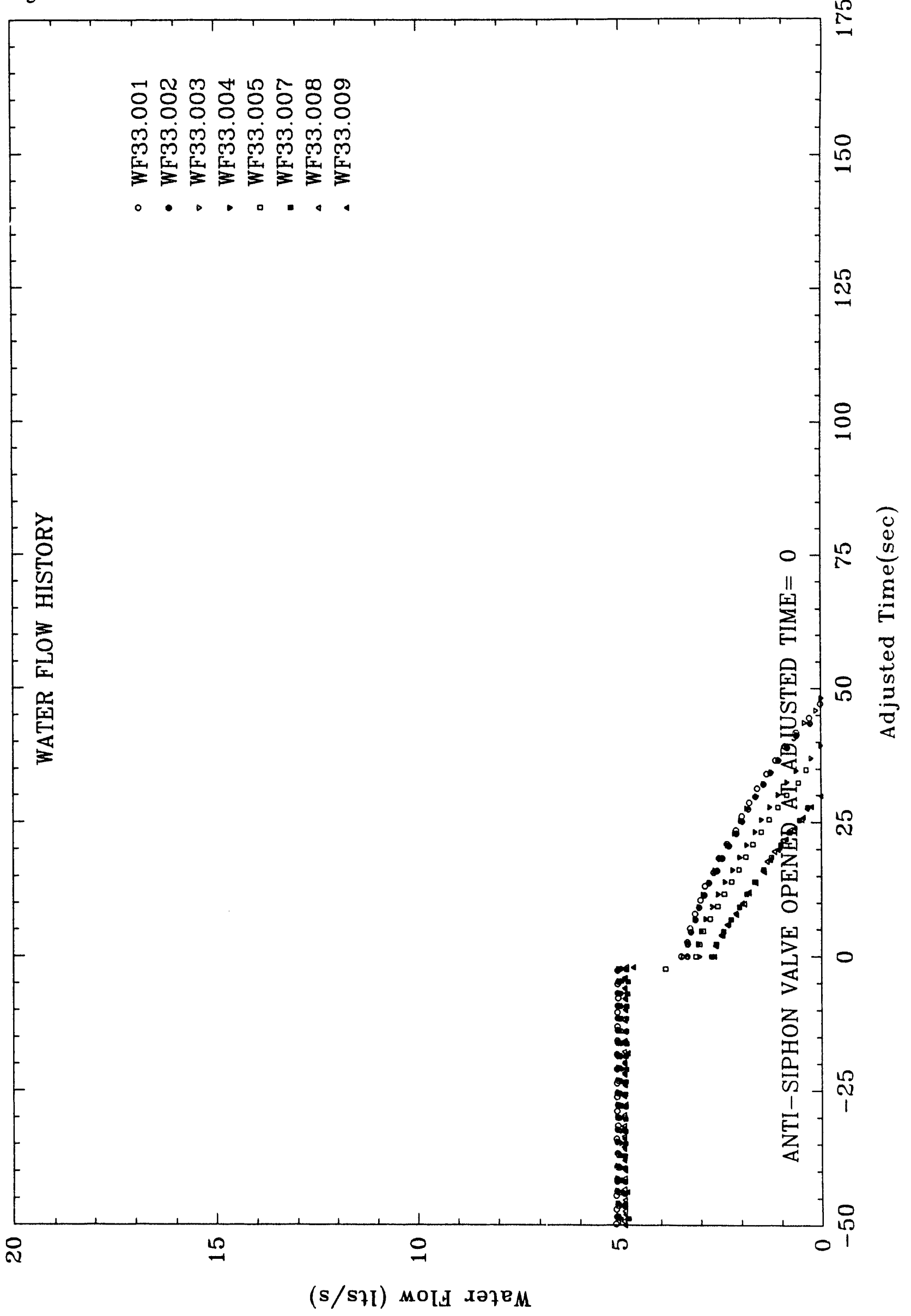




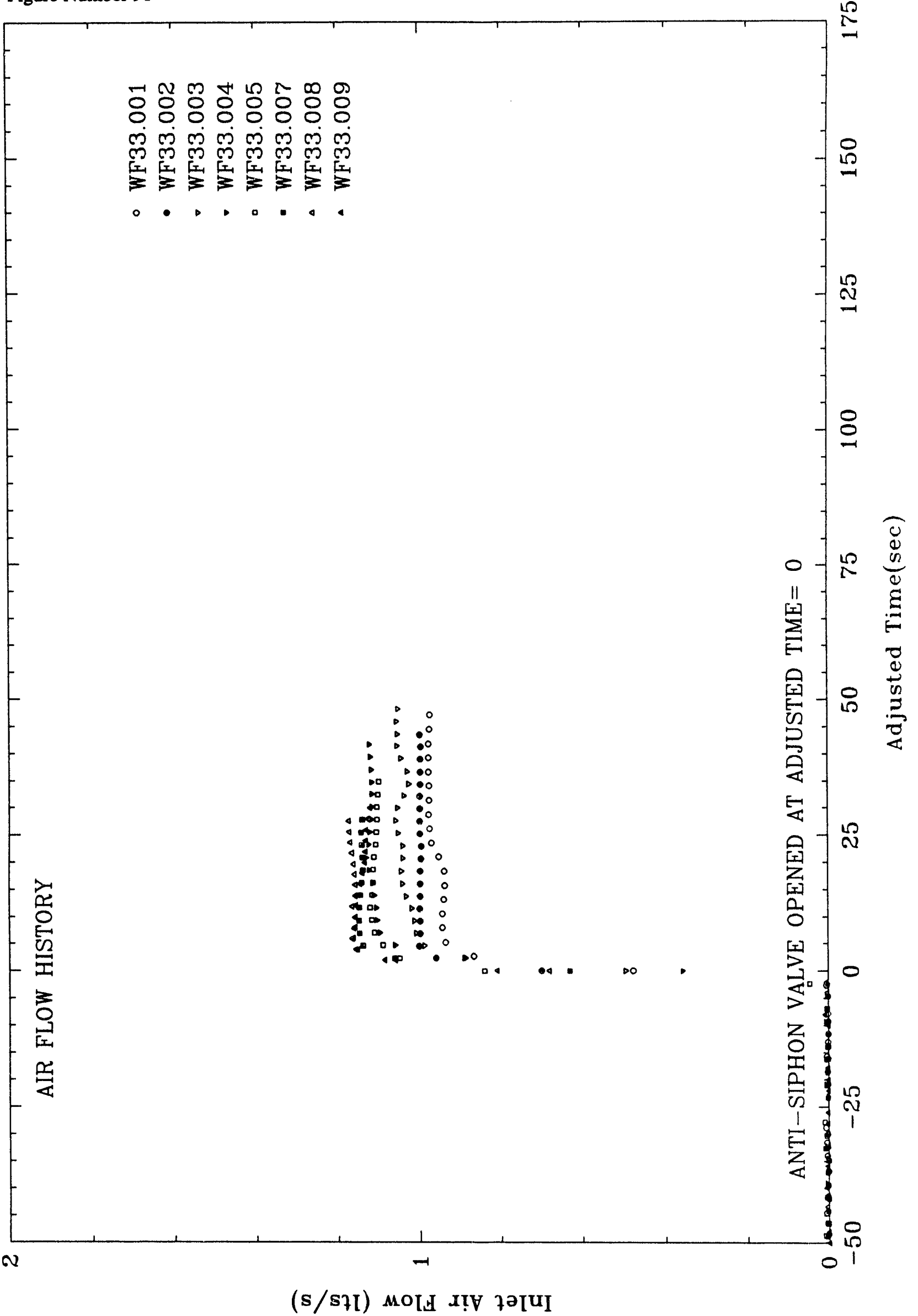




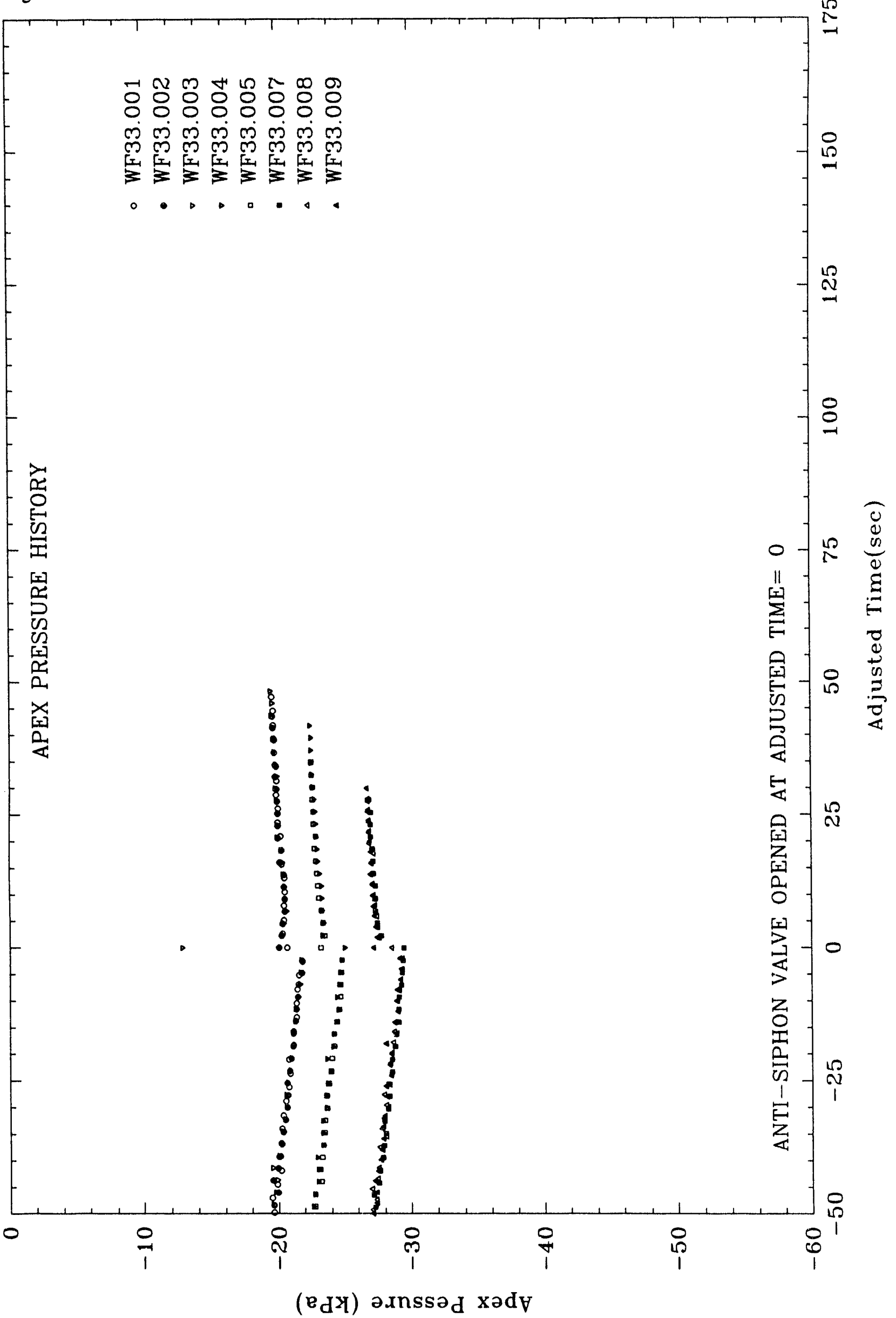




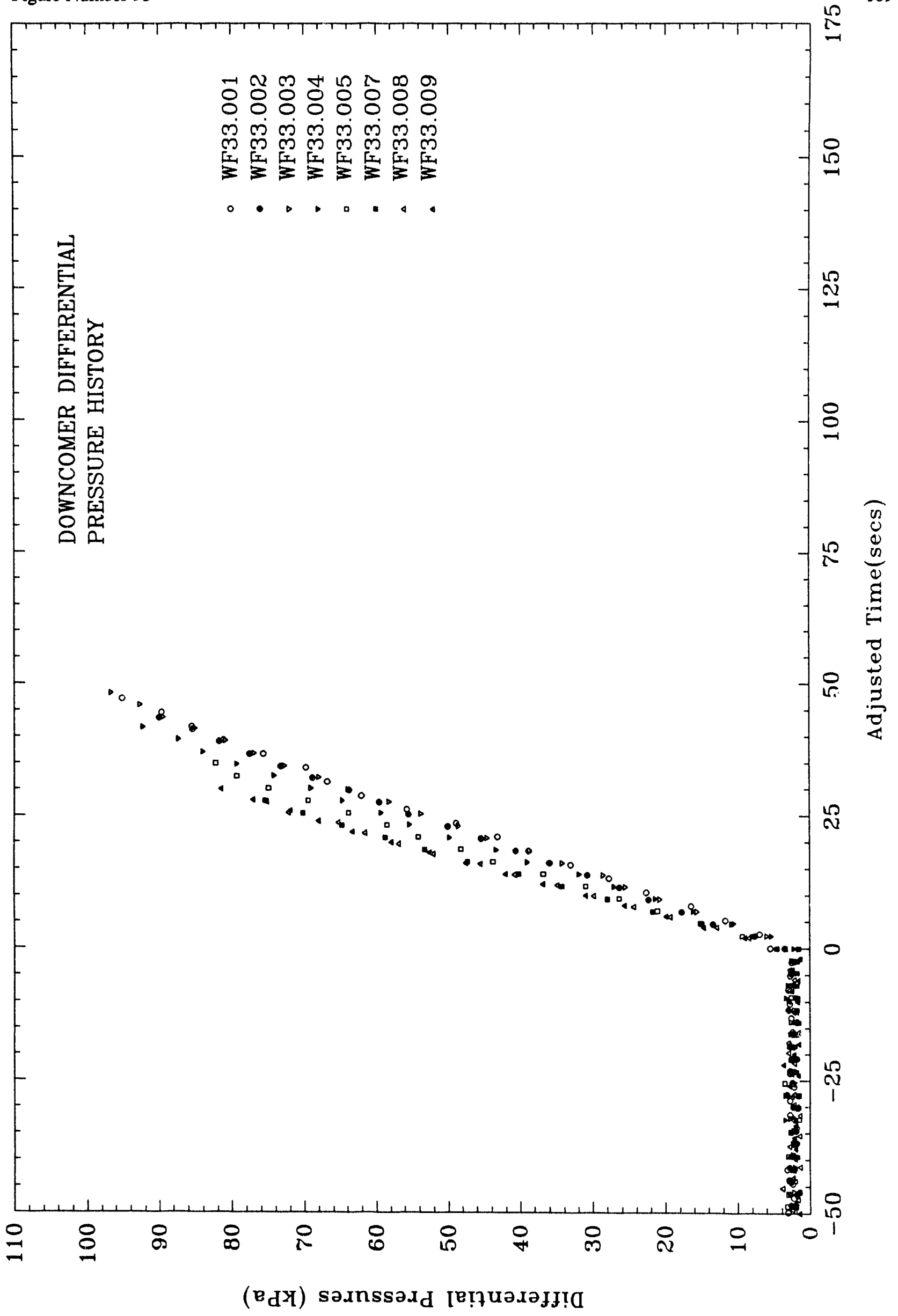


Figure Number 94

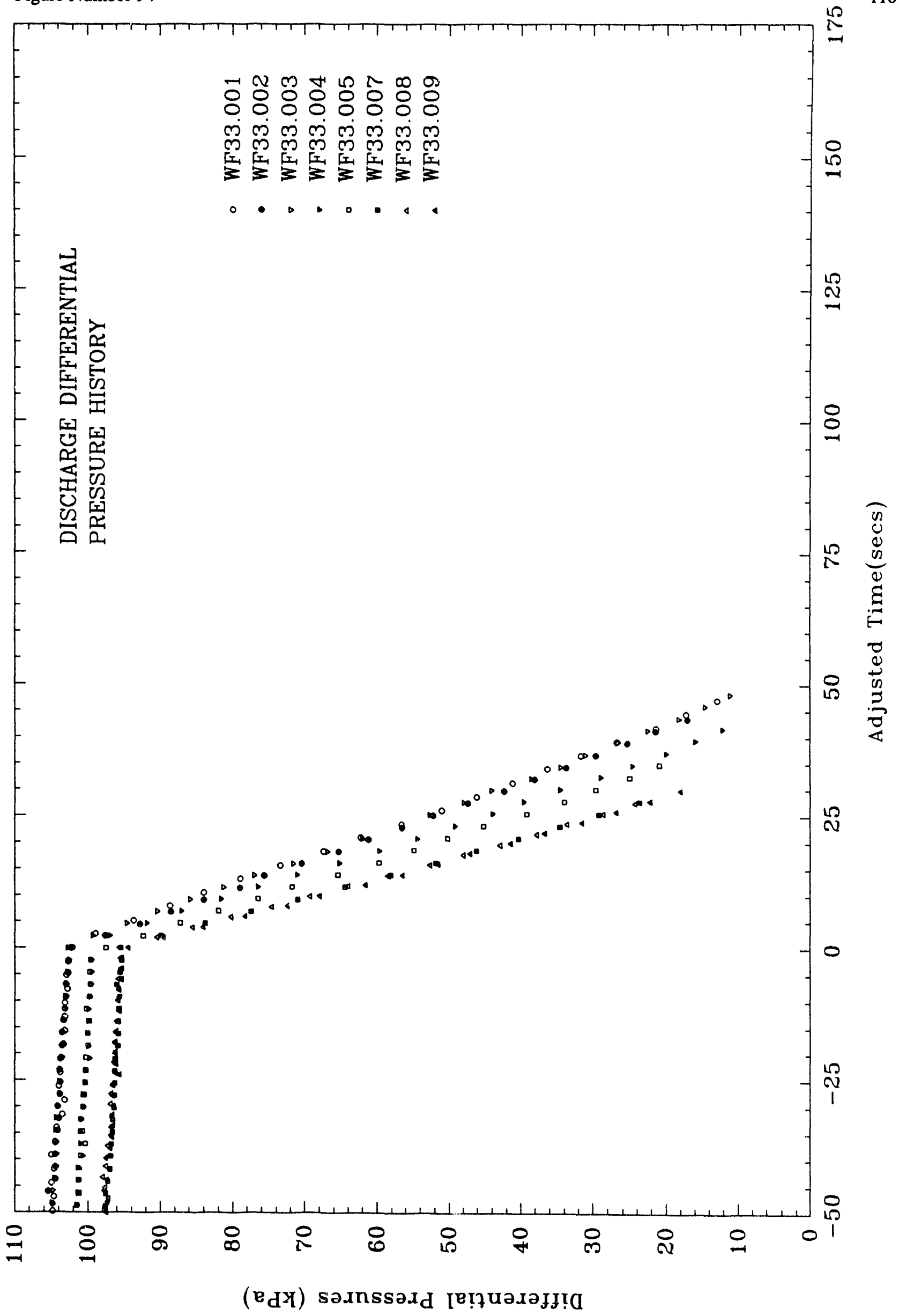




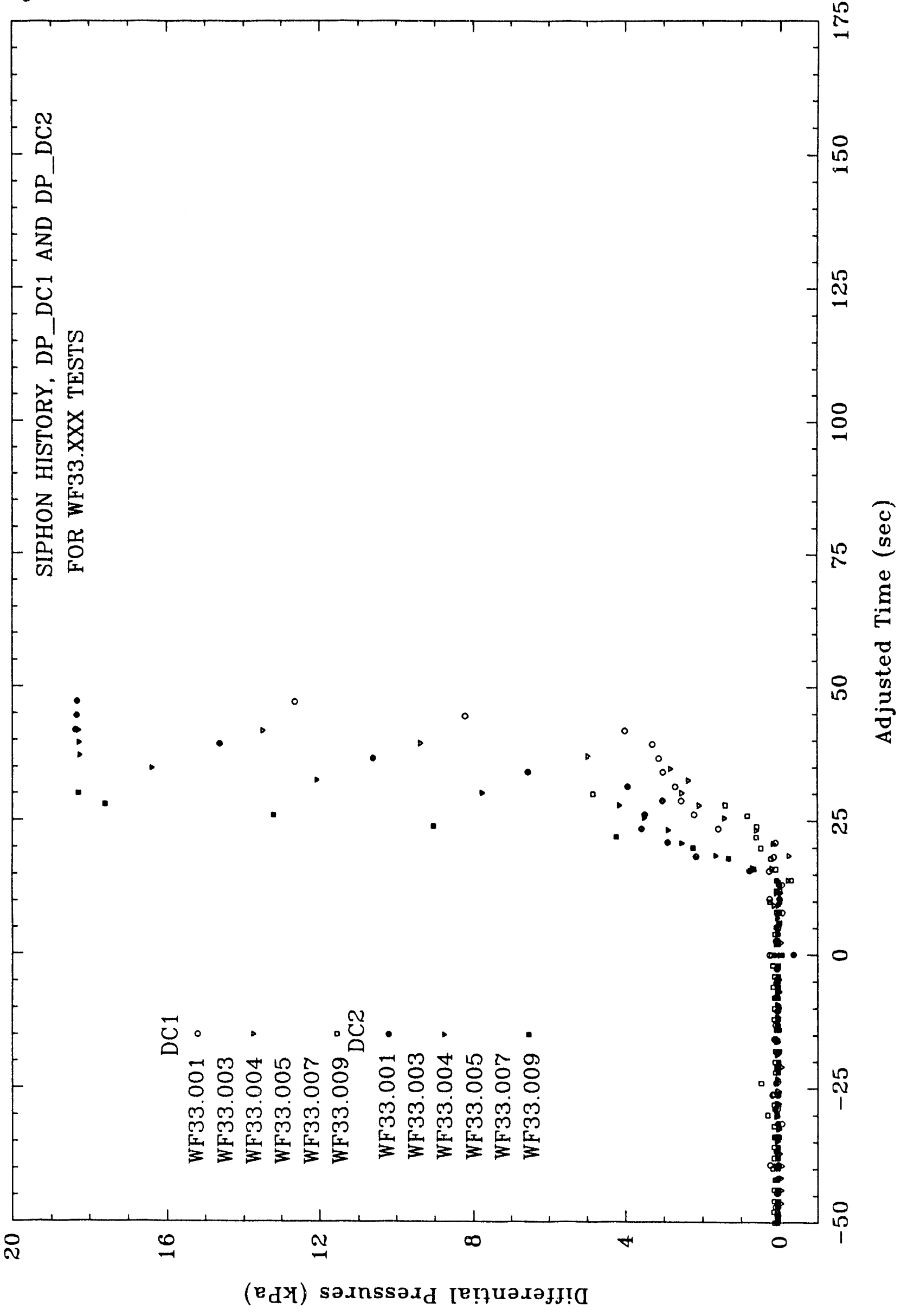




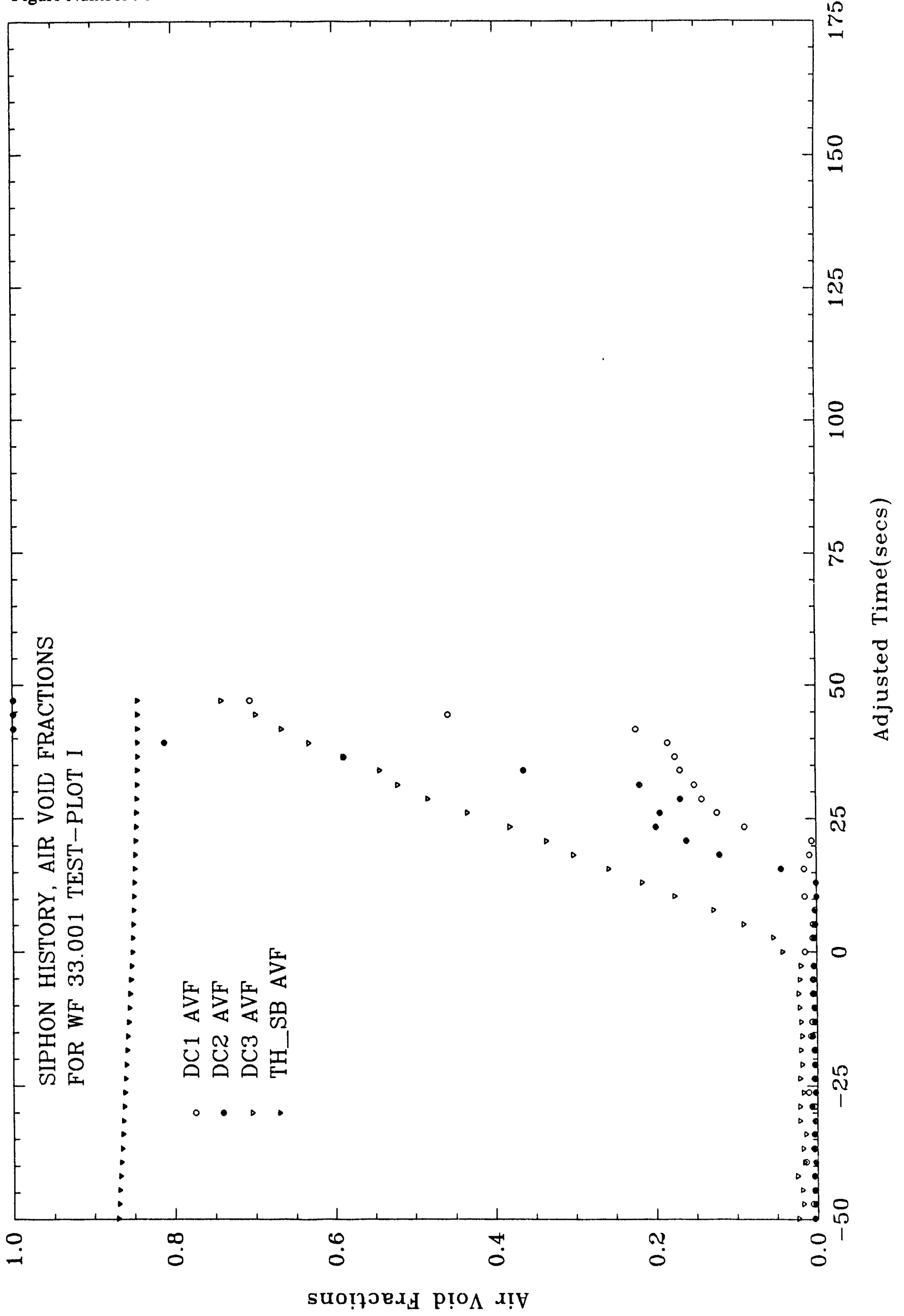


Figure Number 97

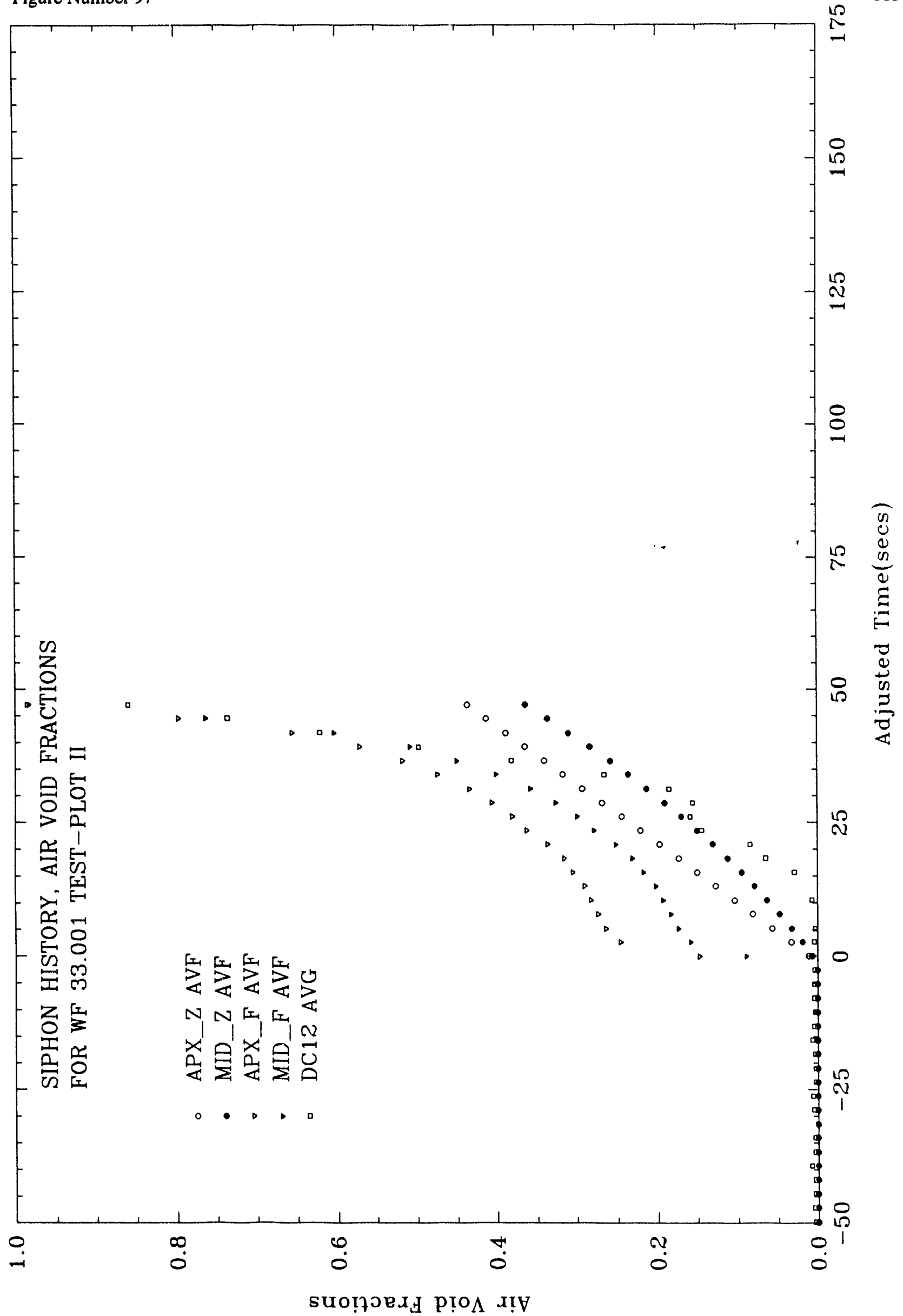




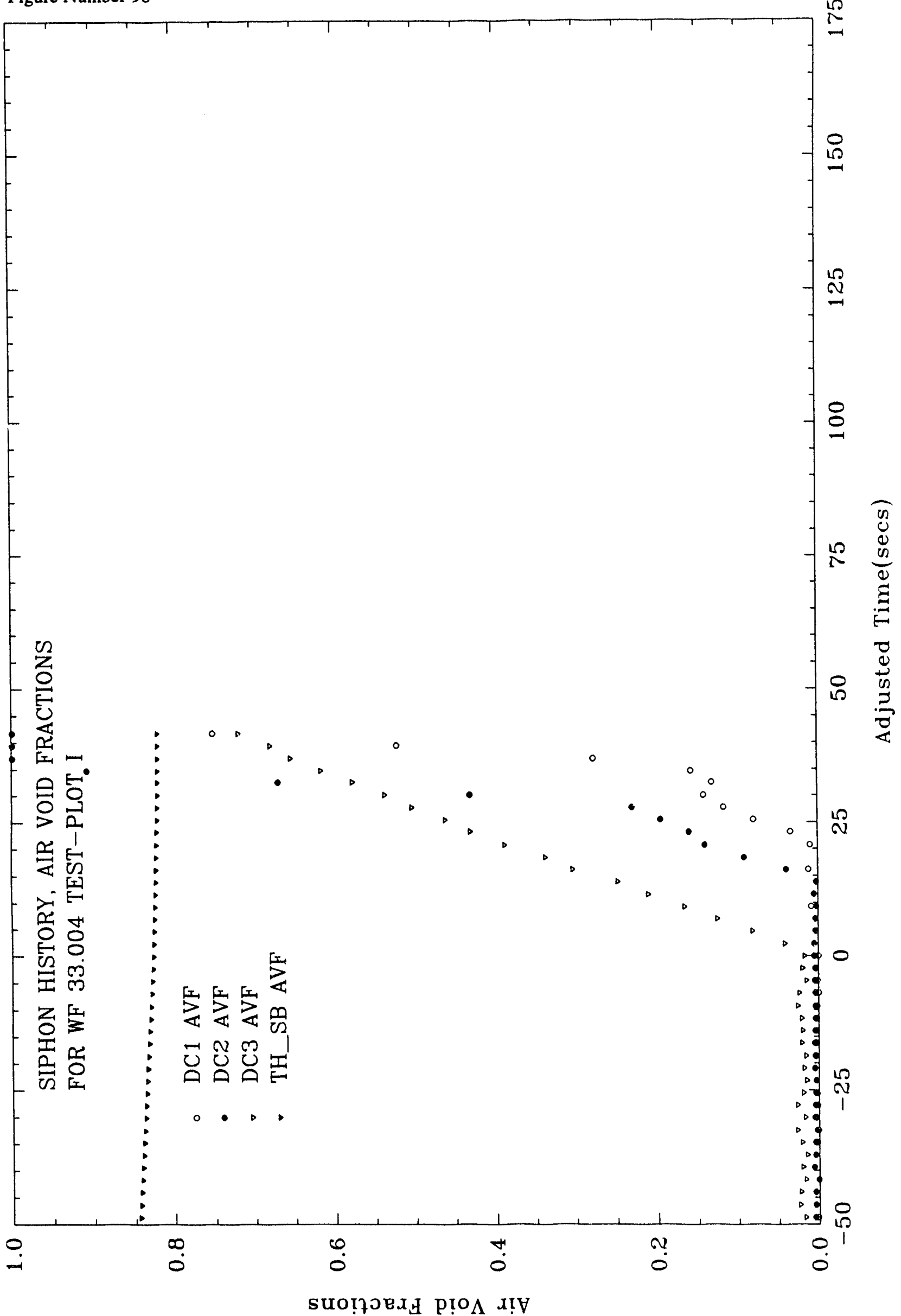




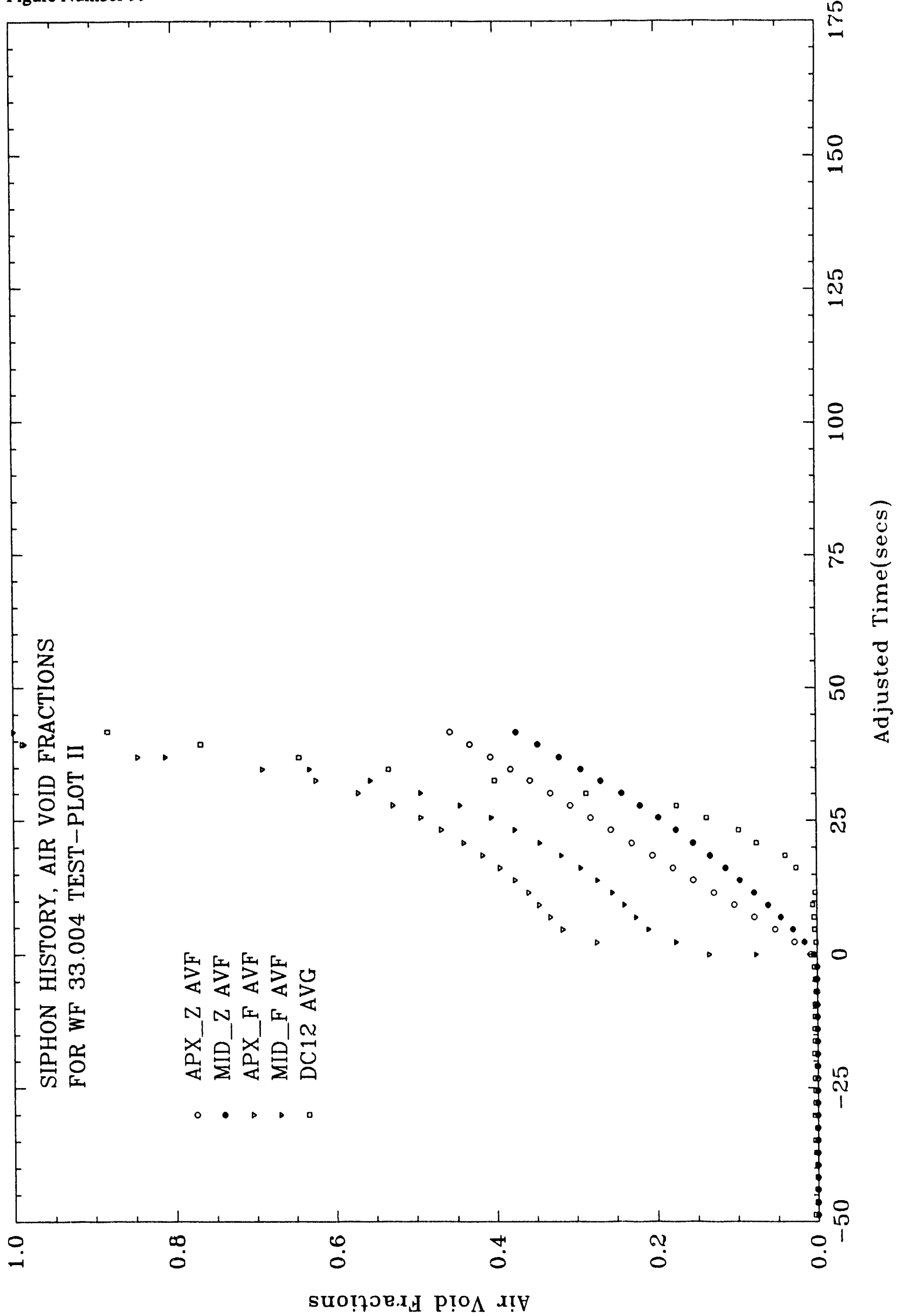




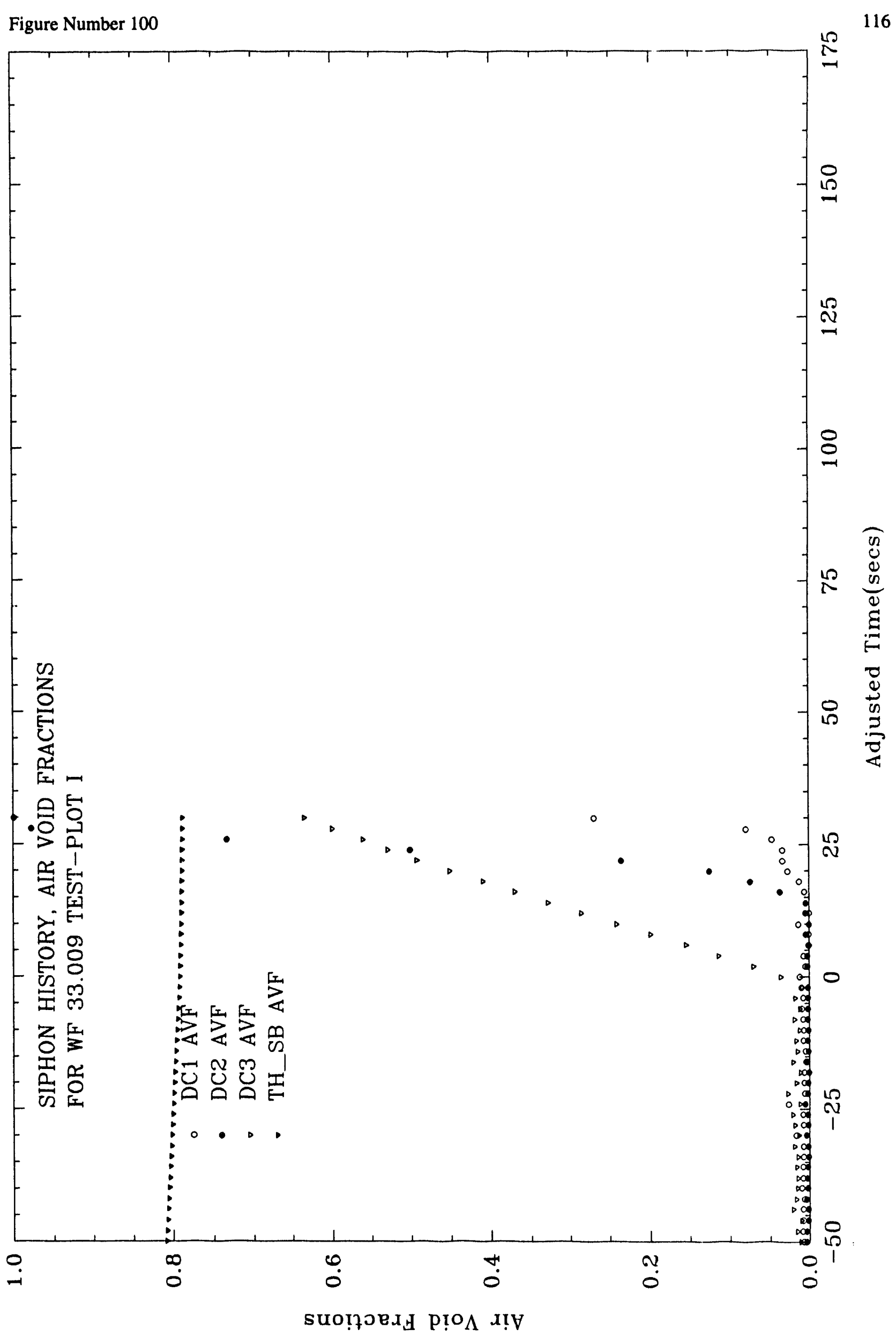




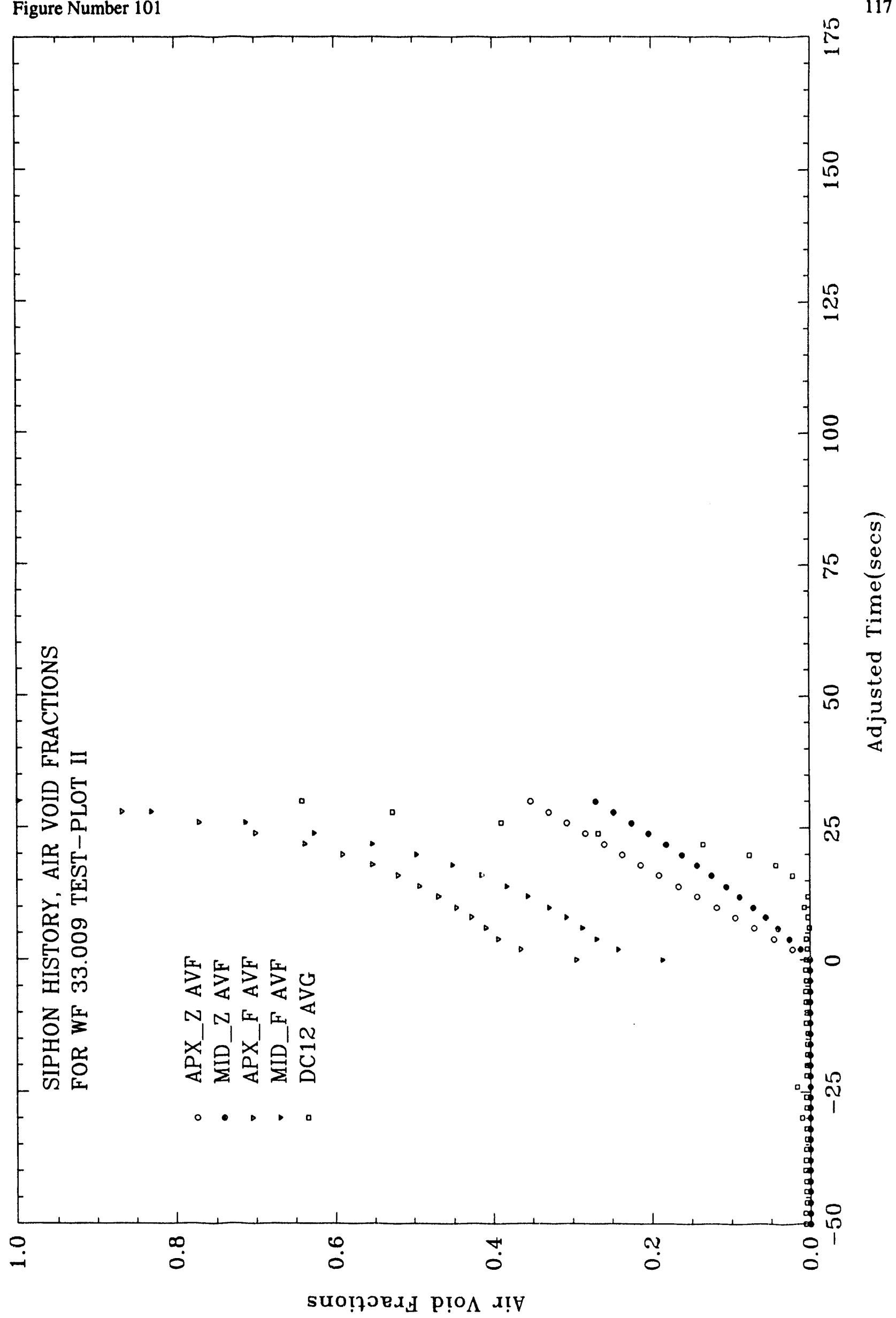


of determining exactly when the siphon flow stopped and reversed itself to drain the upcomer back into the upper tank. The data do not show the slope of decreasing siphon break times which are so evident on the WF21 test series because these tests were all run from the same upper tank water level.

Figure 54 shows that the water flow data started to scatter at an adjusted time of about 60 seconds; we believe that is when the bubbly, two-phase flow front reached the discharge orifice. Such scatter is not evident during the wF2X test serjes. These data appear to be diverging over the last 50 seconds of the test. The data should not be diverging since the tests were all run with the same upper tank level at adjusted time zero and are nominally identical. The divergence must be the result of some two-phase flow phenomenon.

Figure 55 shows the apex pressure data to be significantly different for several of the otherwise identical runs. The apex pressures jump to less negative values when the anti-siphon air flow starts and gradually become nearly constant near the end of the test run.

Figure 56 shows that the anti-siphon air flows remain nearly constant over the test duration but diverge just a bit near the end.

Figure 57 shows a lot of scatter in the downcomer differential pressure data even during the water flow only portion of the test run. Nevertheless, the inflection region over the 40 to 90 second adjusted time is interesting. We believe it is caused by the bubbly, two-phase flow being swept out the discharge orifice. Apparently full sweep-out is not achieved since the differential pressure continues to rise slowly over this time period. After about 90 seconds the slope of the data starts to increase and by about 125 seconds it has returned to nearly equal the slope of the data over the 0 to 40 second range. These two steep slope regions correspond to a zero sweep-out condition. The first zero sweep-out period occurs because the bubbly, two-phase flow front has not reached the downcomer discharge. The second zero sweep-out period occurs when the water flow has slowed so that air is not swept into the discharge ragion of the downcomer and all the air is accumulated in the downcomer.

Figure 58 shows an inflection in the discharge differential pressure data similar to that in the downcomer differential pressure data but at slightly different adjusted times. The increased scatter in the data caused by two-phase flow through the discharge orifice is very apparent on this plot. Again there is clear evidence of a divergence in the data even though the test runs are nominally identical. 
Figure 59 shows the differential pressures measured over the two 6-foot long sections near the middle of the downcomer. The data are constant until an adjusted time of about 15 seconds and then increase suddenly as the bubble front passes the upper connection of the dp cell. The upper dp cell, DC2, data start to increase about five seconds before the data from the lower dp cell, DC1. The measurements remain rather constant and smooth until an adjusted time of about 50 seconds; then they begin to scatter 'out remain nearly constant until about 90 seconds when they take some large jumps which last for about 10 seconds. We believe these jumps are due to the passage of large air bubbles of about 20-40 cm length. These air bubbles resemble mini-water falls when seen on the video tape because water appears to be falling though them as they move down the downcomer. At about 140 seconds the bottom of the large water-fall, which extends from the top of the downcomer, passes the dp cell connections causing a large, permanent increase in the readings.

Figures 60-65 show the calculated air void fractions for three of the tests. Since all three tests were nominally identical, Figures 60,62 and 64 should be nominally identical also and they are; at least until the mini-water falls appear. The large jumps due to the passage of the mini-water falls are even more pronounced on these plots since each plot is for a single test run. Likewise, Figures 61,63 and 65 should be nominally identical but Figure 61 is different, particularly the air void fractions calculated for zero sweepout, $\operatorname{APX} \mathrm{Z}$ and MID $\mathrm{Z}$. We believe this difference is due to the difference between the apex pressure measured for the 001 run and the measurements for the 002 and 003 runs. The apex pressure is the major variable in determining the air density and hence the calculated air void fractions.

Figures 66-88 show the plots for the WF32 series of tests. Data is shown for seven tests with at least two from each of three different upper tank levels; therefore, the data comparisons are very useful.

Figure 66 shows upper tank volume history for the tests. Tests 001,003 and 005 are all run from the highest water level, tests 006 and 008 from the intermediate level and tests 009 and 011 from the lowest level. There is a definite upward slope of the ends of the upper tank volume data where the siphon broke.

Fisure 67 shows that the water flows are virtually identical until the anti-siphon valve is opened; then they separate. The separation is caused by the difference in the anti-siphon air flow rates due to the different apex pressures caused by the different water levels in the upper tank.

Figure 68 shows the difficulty we had in getting reliable, repeatable air flow measurements during this test series. The 
data are pretty well separated into bands depending on the upper tank water level at adjusted time zero; however the 011 data are near the bottom rather than near the top with the 009 test data. since both of those tests were run from the lowest upper tank water level their air flow rates should be at the top. Again, we believe this problem is with the air flow meter since the water flow rates shown on Figure 67 group logically.

Figure 69 shows the apex pressure data. These data separate into bands depending on the upper tank water level as they should. The apex pressures become more negative before adjusted time zero and then actually turn upward after the anti-siphon air valve is opened.

Figure 70 shows that the downcomer differential pressure measurements increase smoothly without the inflection so apparent on Figure 57 for the WF31 series of tests. This difference is due to the siphon breaking before any two-phase flow reached the discharge of the downcomer in this test series. No 006 test data are plotted on this figure because the dp cell was bypassed during the test.

Figure 71 shows that the discharge differential pressure measurements decrease equally smoothly over the test duration without the inflection so apparent on Figure 58 for the WF31 series of tests.

Figures 72-74 show the differential pressures measured over the two 6-foot long sections near the middle of the downcomer. Three figures are used to avoid too much conflict in the data points. Each figure is for a different upper tank water level at adjusted time zero. The data remain constant for 15-20 seconds after the anti-siphon air valve is opened until the bubbly, two-phase front passes. Then the data rise rapidly before becoming constant for about 15 seconds on Figurs 72 , about 10 seconds on Figure 73 and less than 5 seconds on Figure 74. Finally the data increase rapidly as the bottom of the water-fall air bubble passes. The water-fall air bubble passed the upper dp cell, DC2, but didn't get completely past the lower dp cell, DC1, before the siphon broke for all the tests in the series.

Figures 75-80 show the calculated air void fractions for the three tests run from the highest upper tank water level. The theoretical air void fraction to break a stagnant siphon, $T H$ AVF, was almost reached by the overall downcomer air void fraction, DC3 AVF.

Figures 81-84 show the calculated air void fractions for the two tests run from the middle water level in the upper tank. 
Figures 85-88 show the calculated air void fractions for the two tests run from the lowest upper tank water level. There is little difference in the relationship between the theoretical air void fraction to break a stagnant siphon and the overall downcomer air void fraction for any of these test runs.

Figures 89-101 show the plots for the WF33 series of tests. Data are shown for eight tests with at least two at each of three different upper tank water levels. The spread of upper tank water levels is significantly larger than that in the WF32 test series.

Figure 89 shows the large differences in the upper tank water volume at adjusted time zero for each group of tests. There is a clear upward slope to the locus of siphon break times and those times are shorter than for the previous WF31 and WF 32 test series.

Figure 90 shows that the water flows were only slightly reduced during the water flow only portion of the test runs by the large differences in upper tank water level. But the water flows separate immediately at adjusted time zero and diverge thereafter.

Figure 91 shows again the difficulty we had in getting consistent, reproducible anti-siphon air flow measurements. However, the pattern is as expected; tests run from high upper tank water levels have lower air flows and vice versa. The bumps and dips in the data must be due to rotor bearing friction and/or water in the air line.

Figure 92 shows that the apex pressures become more negative as the upper tank water level decreases before adjusted time zero but become less negative as the water flow slows due to the accumulation of anti-siphon air in the downcomer.

Figure 93 shows that the downcomer differential pressures increase linearly and spread slightly due to the different antisiphon aix flow accumulations. Again, there are no inflections or other strange effects since the two-phase flow did not reach the downcomer discharge.

Figure 94 shows that the discharge differential pressures are separated before adjusted time zero due to differences in the upper tank water level and decrease smoothly thereafter due to the decreasing discharge water flow.

Figure 95 shows the differential pressures measured over the two 6-foot long sections near the middle of the downcomer for only one test run from each upper tank water level. The water fall passed the upper dp cell, DC2, but did not pass the lower dp cell, DC1, during all test runs. 
Figures 96-101 show the calculated air void fractions for one test run from each upper tank water level. The pattern is just about the same as for the other test runs; the overall downcomer air void fraction is always short of the theoretical air void fraction to break a stagnant siphon. 


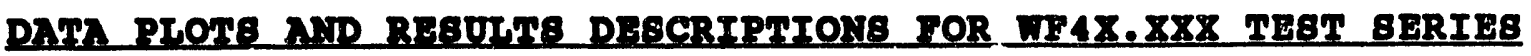

Figures 102-128 show the measured data and calculated air void fractions for the WF40, WF42 and WF43 series of test runs. These plots are all grouped in one section to make comparisons easy.

Figures 102-106 show the data for three "water flow only" WF40 tests which were run early in the test program.

Figure 102 shows that the upper tank volume histories repeat very well and that the tank emptied at an adjusted time of about 150 seconds.

Figure 103 shows that the water flow rates were identical for all three tests.

Figure 104 shows that the apex pressures diverge as the tests progress. We believe this divergence is due to instrument drift rather than some random phenomena in the siphon process since the downcomer differential pressure data and the discharge differential pressure data shown in the next two figures remain parallel during the tests.

Figure 105 shows that the downcomer differential pressures remain close together and parallel for all three runs and decrease slowly in keeping with the decrease in the water flow rate.

Figure 106 shows that the discharge differential pressures were a bit different over the test durations but they did not diverge appreciably. The discharge differential pressures appear to be decreasing much faster than the downcomer differential pressures shown on Figure 105; while that is true, the appearance is enhanced by the scale change between the differential pressure axes on the two plots.

Figures 107-117 show the plots for the wF42 series of tests. only the two tests for which data are plotted gave useable results for the full test duration.

Figure 107 shows the upper tank volume history for the two tests. There is a definite slope break when the anti-siphon air valve is opened at adjusted time zero. After that event the slope steadily decreases until the upper tank empties.

Figure 108 shows several interesting bumps in the water flow histories. There is a step decrease in the flow during the water flow only period. Such step changes during the water flow only period occur for many of the tests; we do not have any explanation for them. The only moving part in the siphon besides the water is the siphon block valve. Perhaps its position adjusted somehow under the influence of the water flow. 


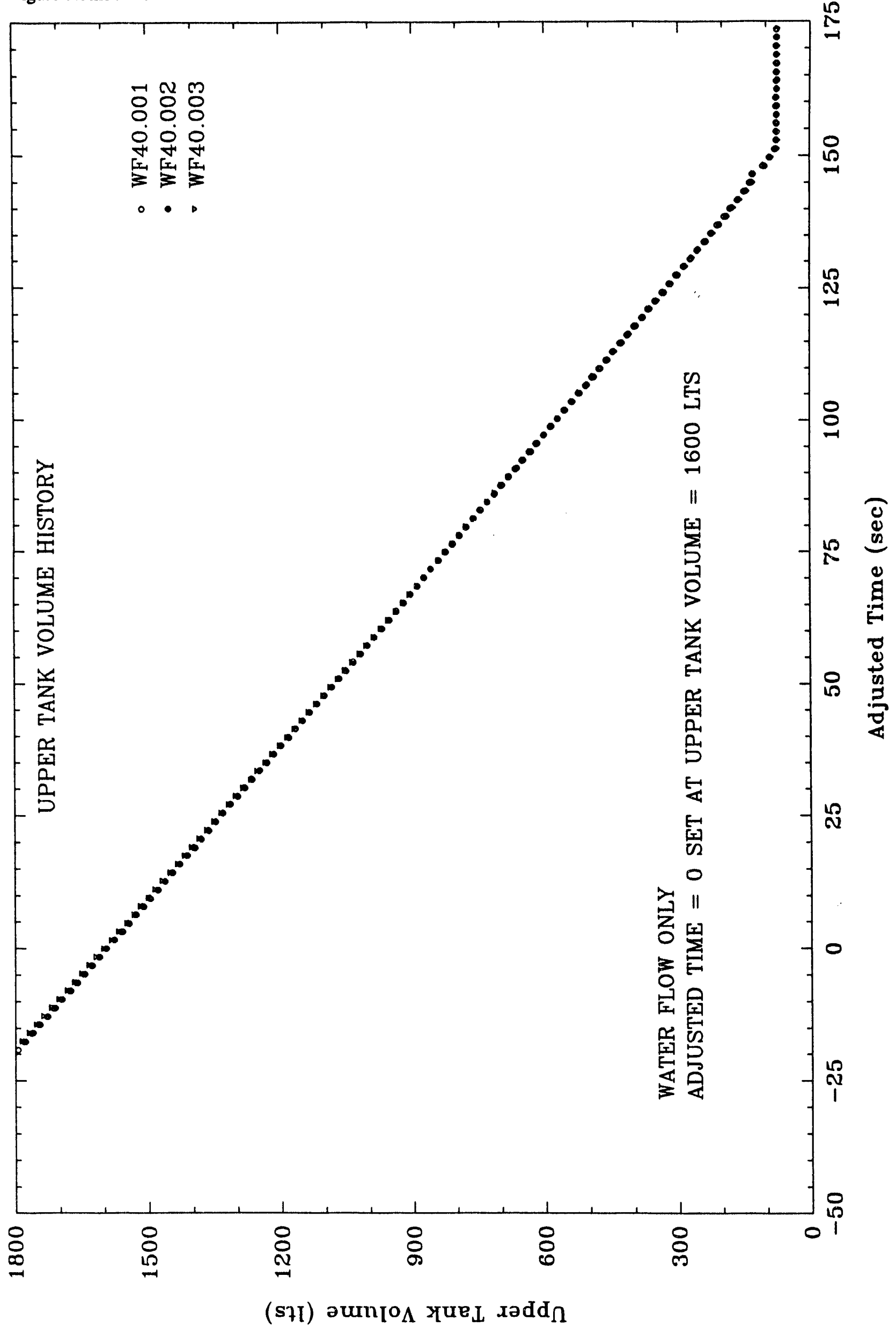




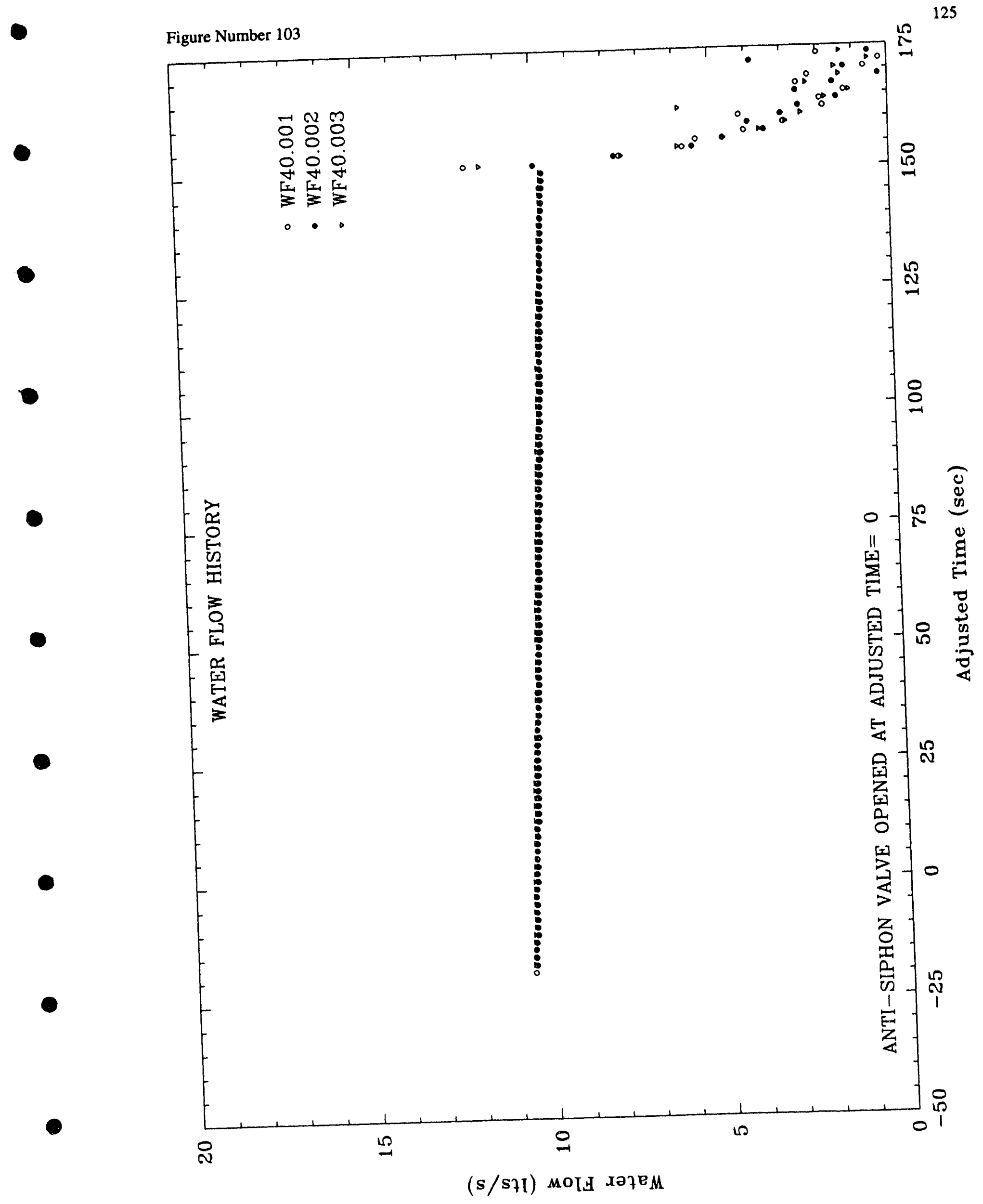




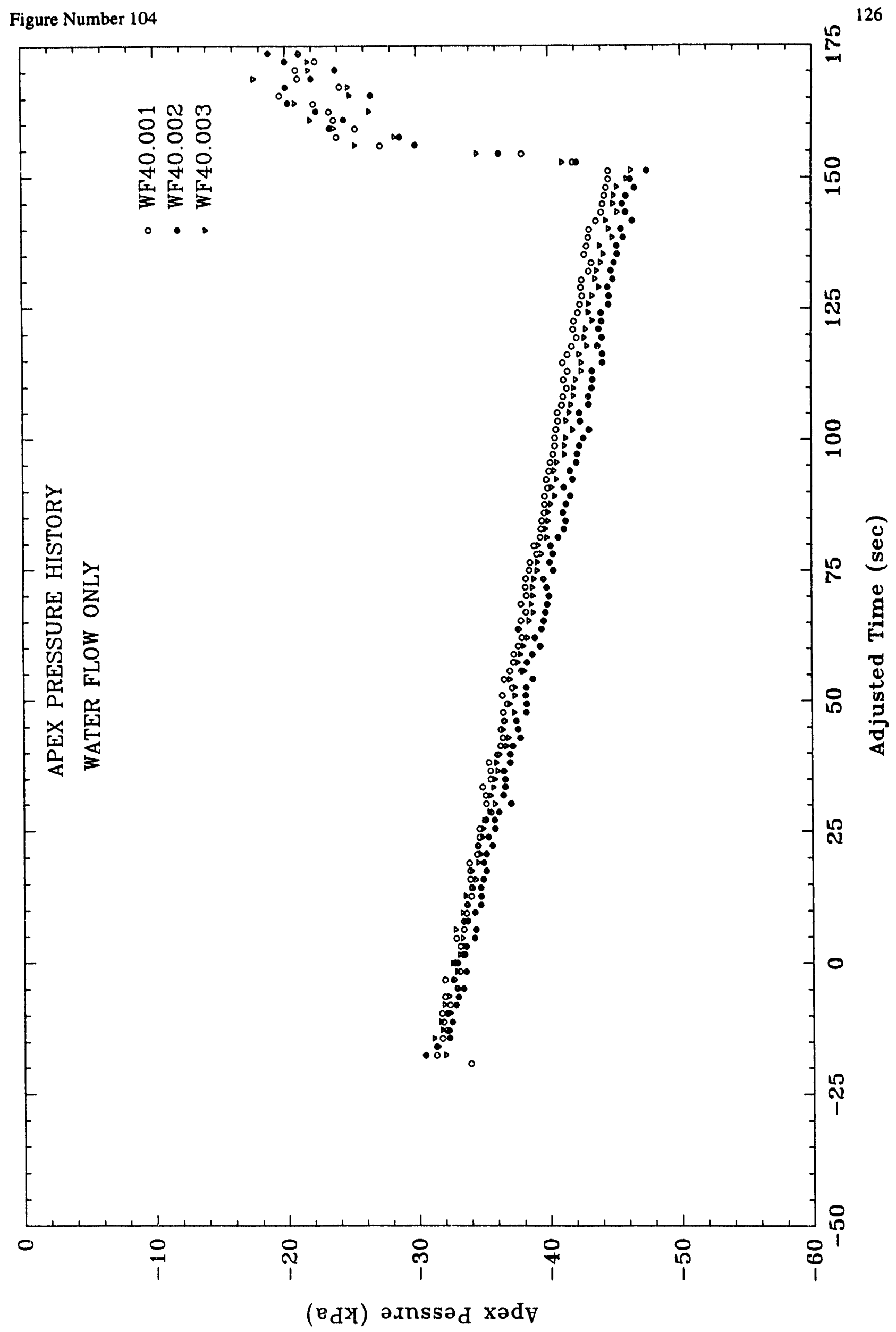


Figure Number 105

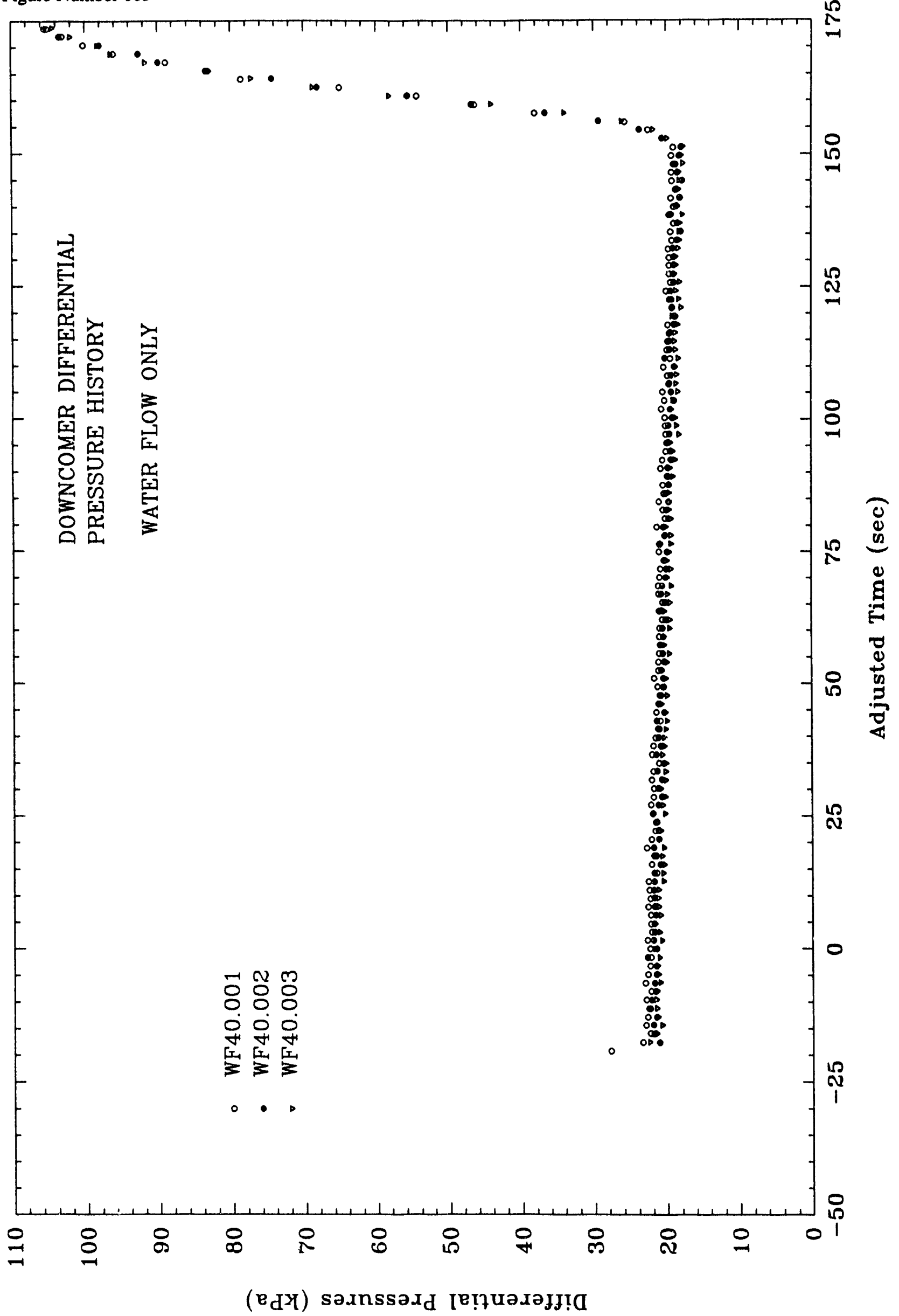


Figure Number 106

$\stackrel{n}{1}$

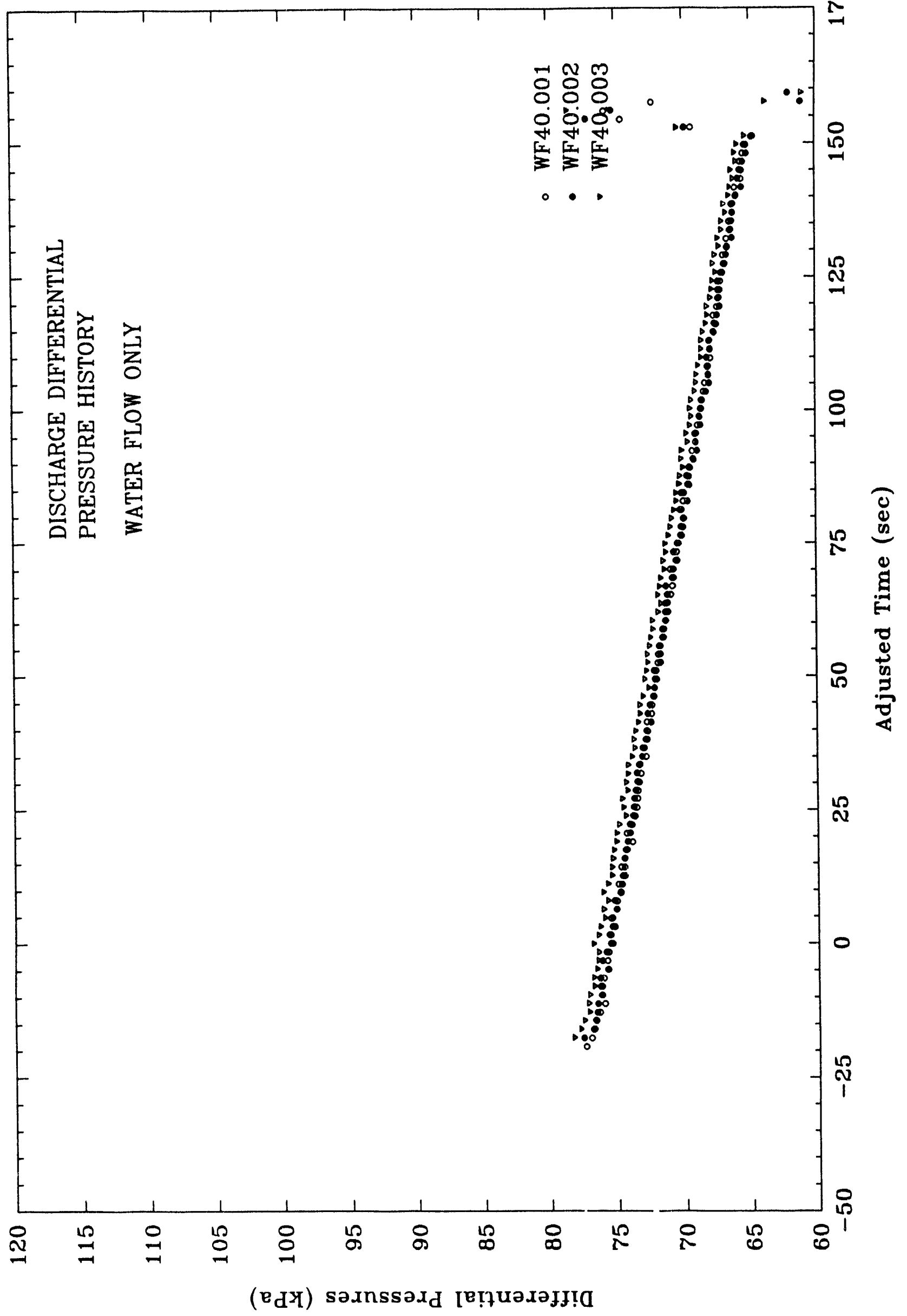


Figure Number 107

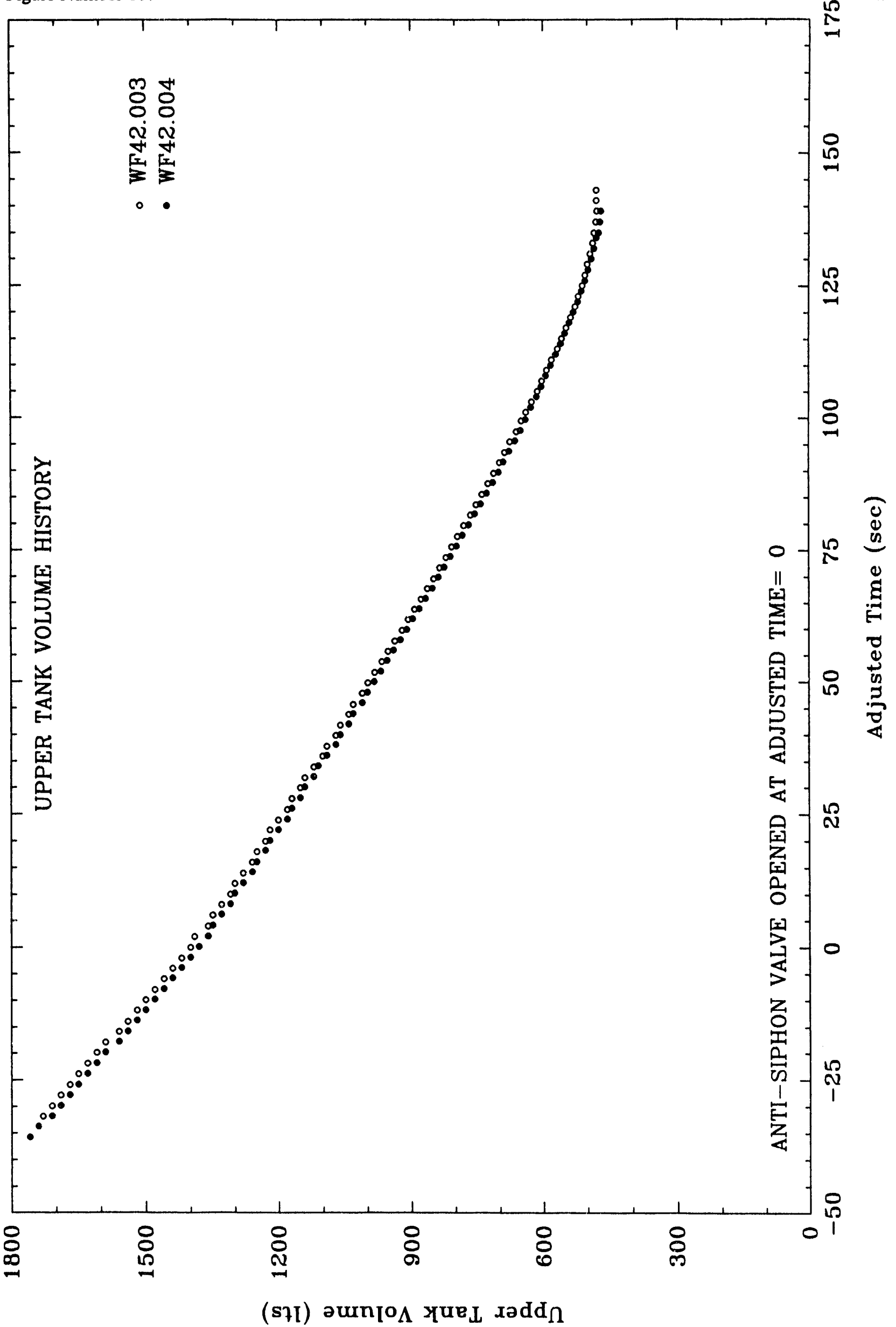




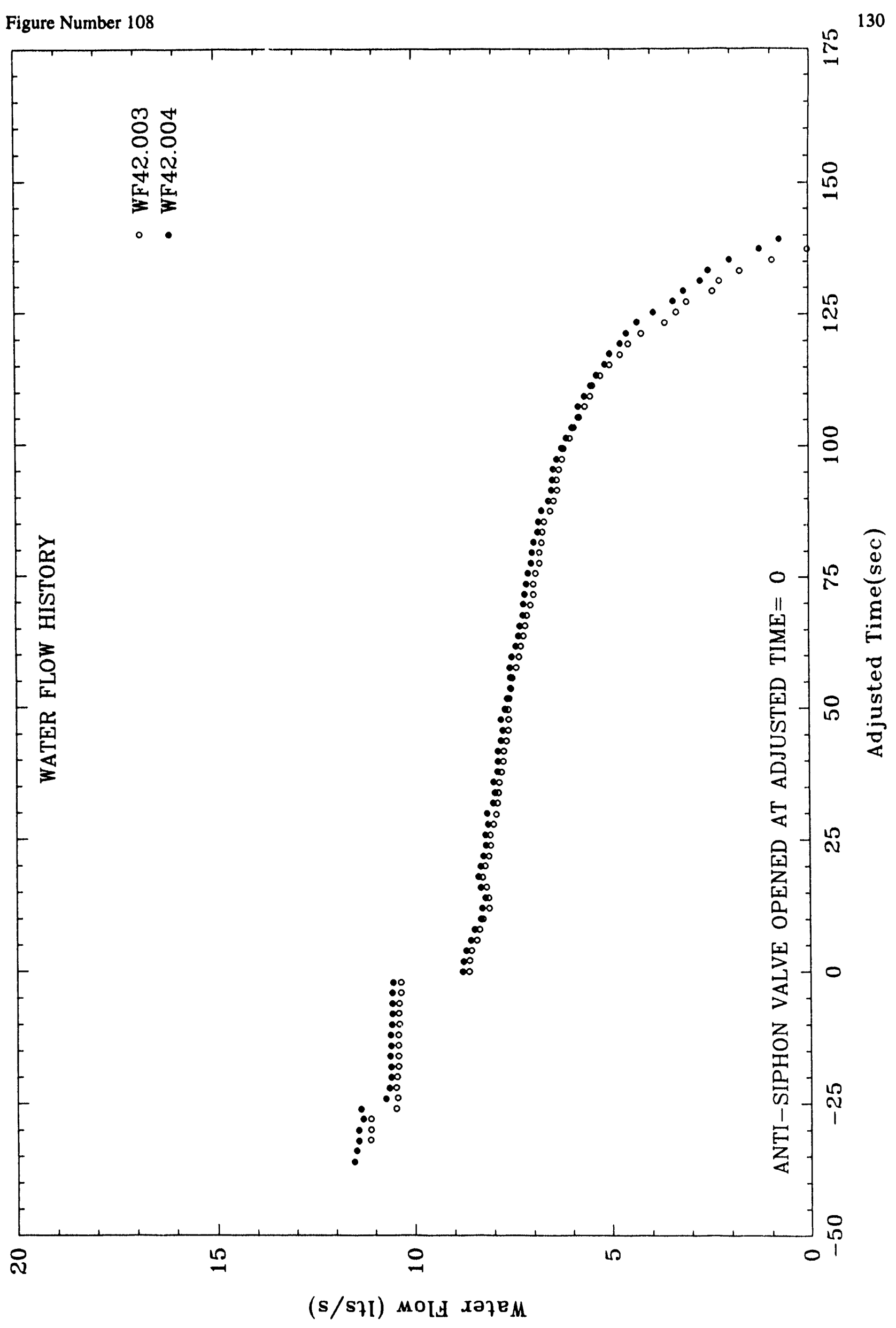




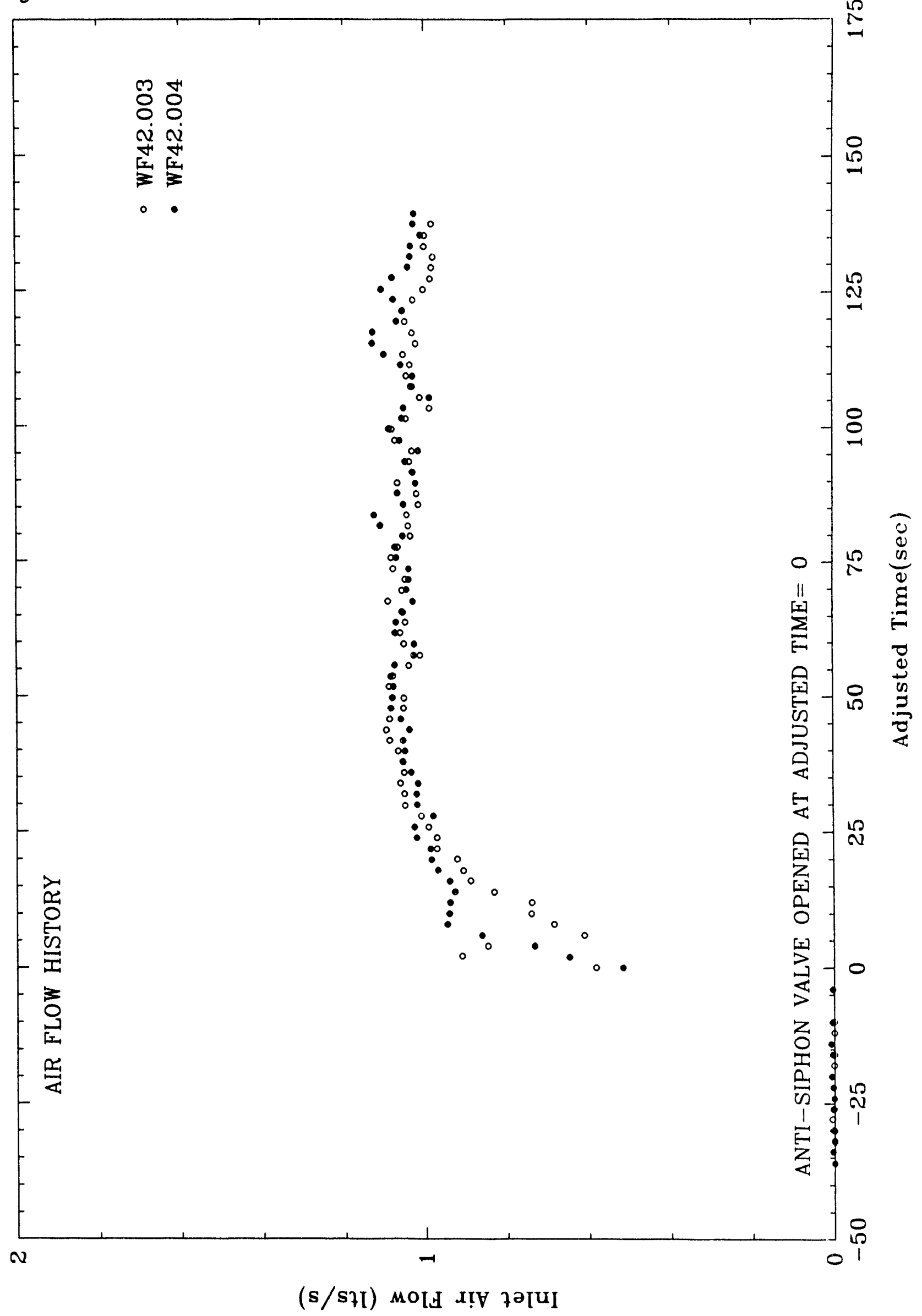




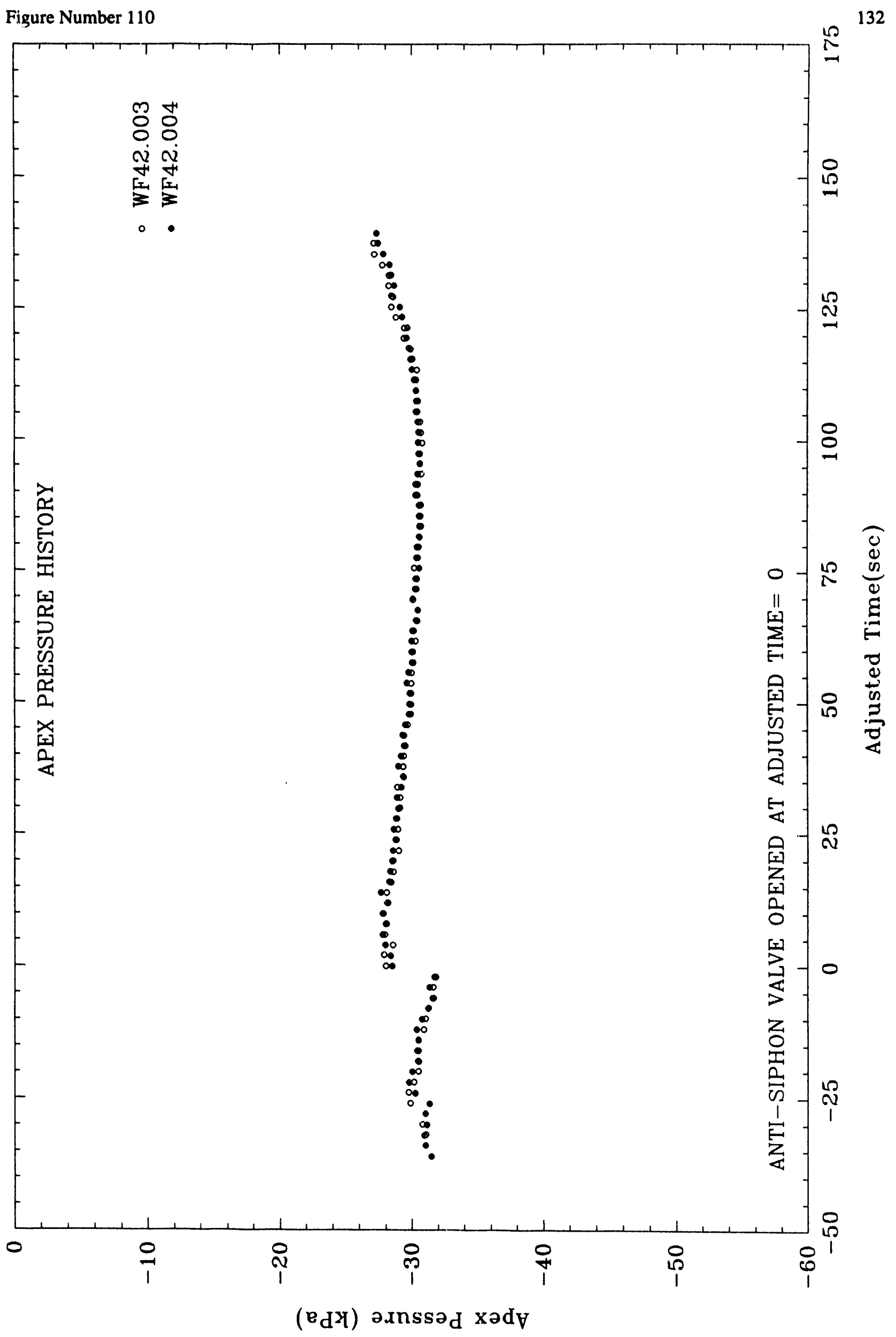


Figure Number 111

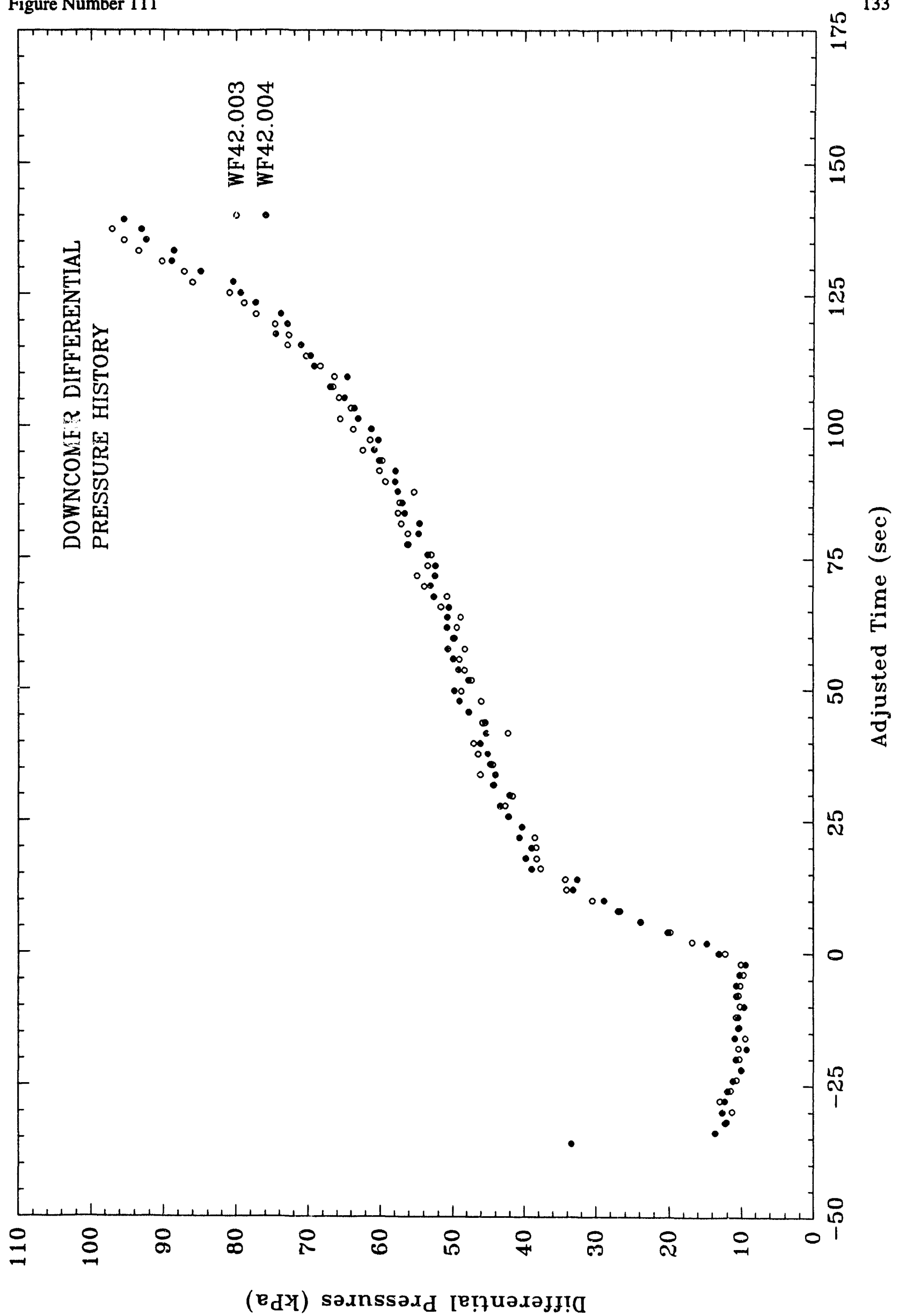


Figure Number 112

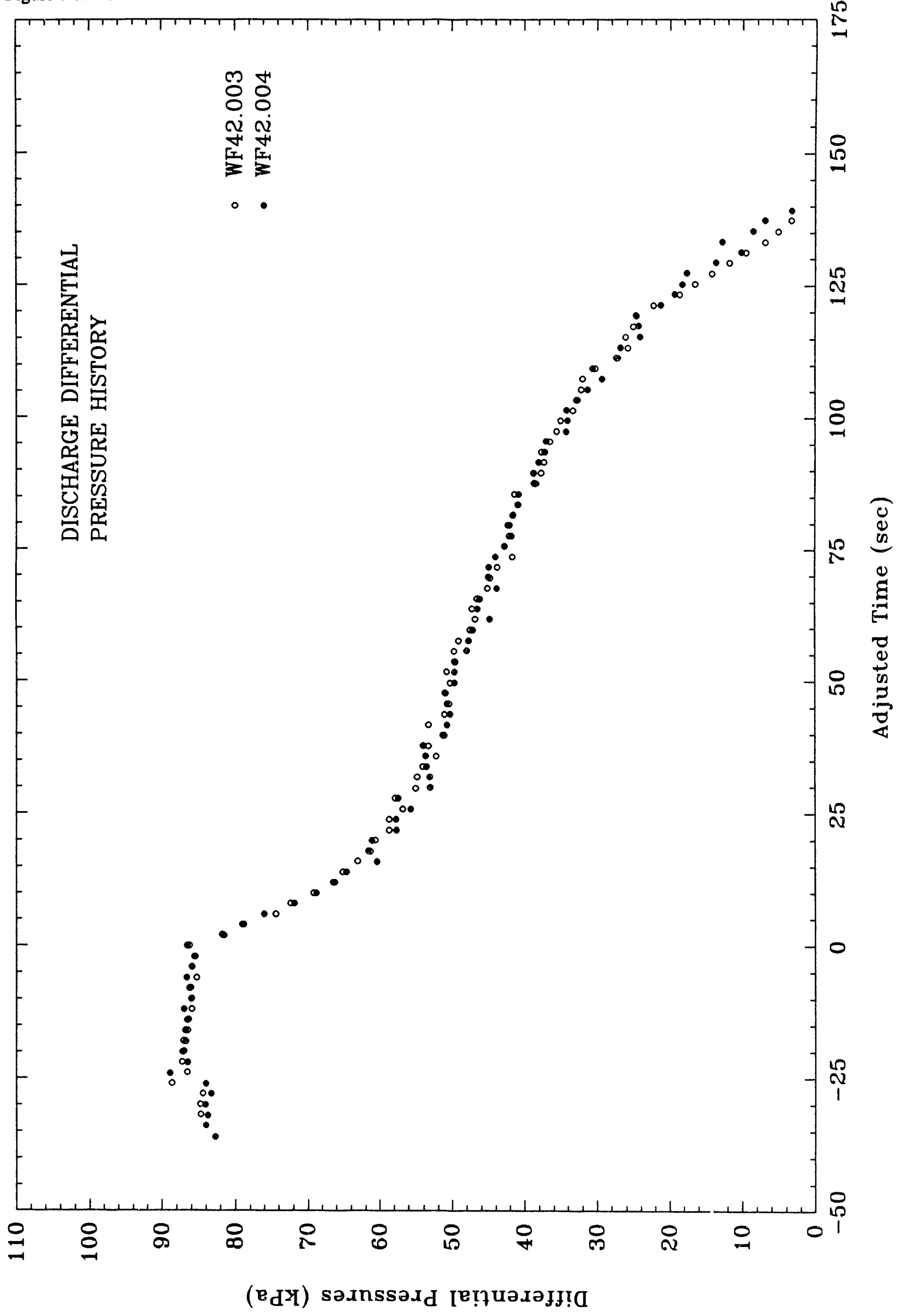




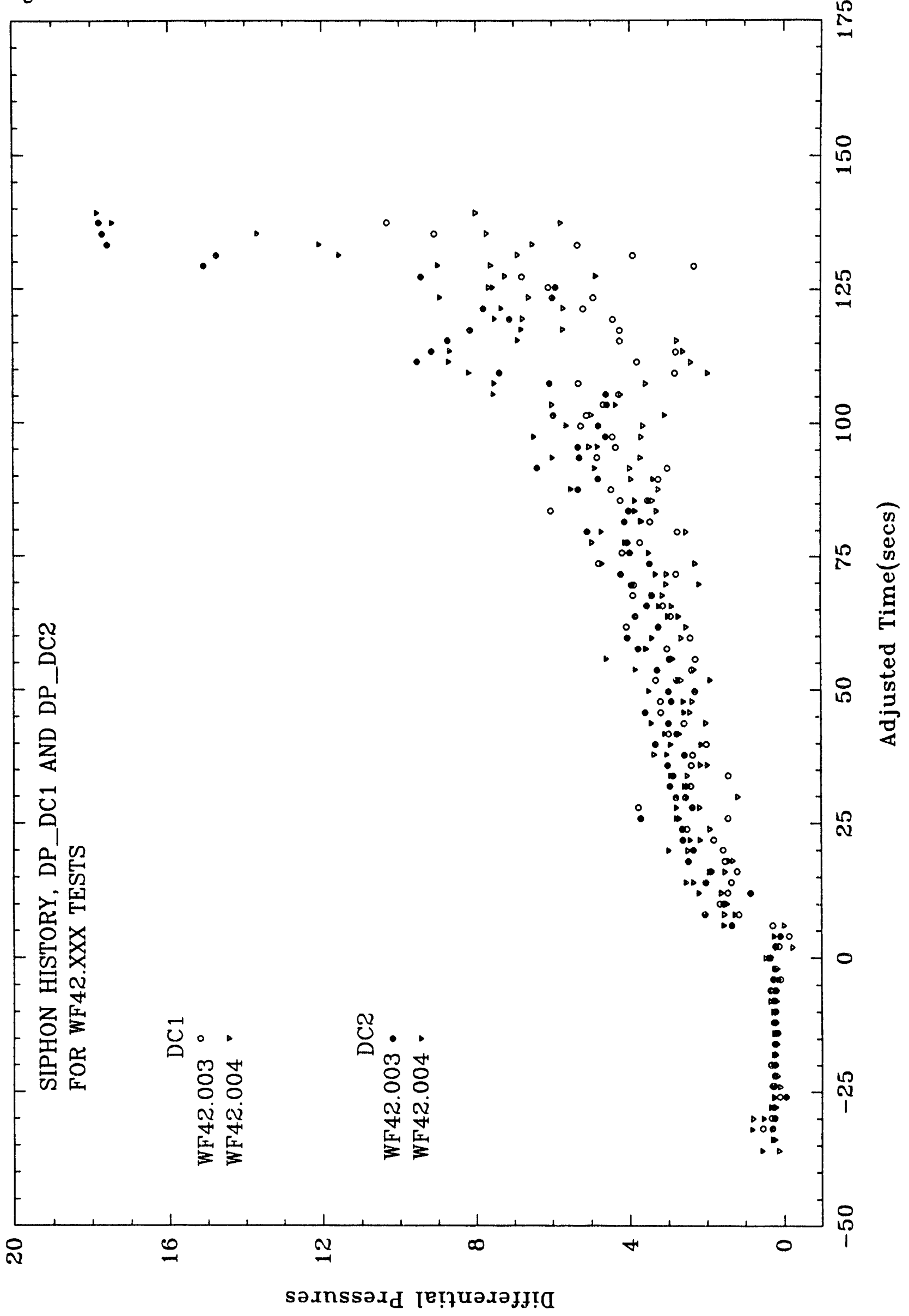




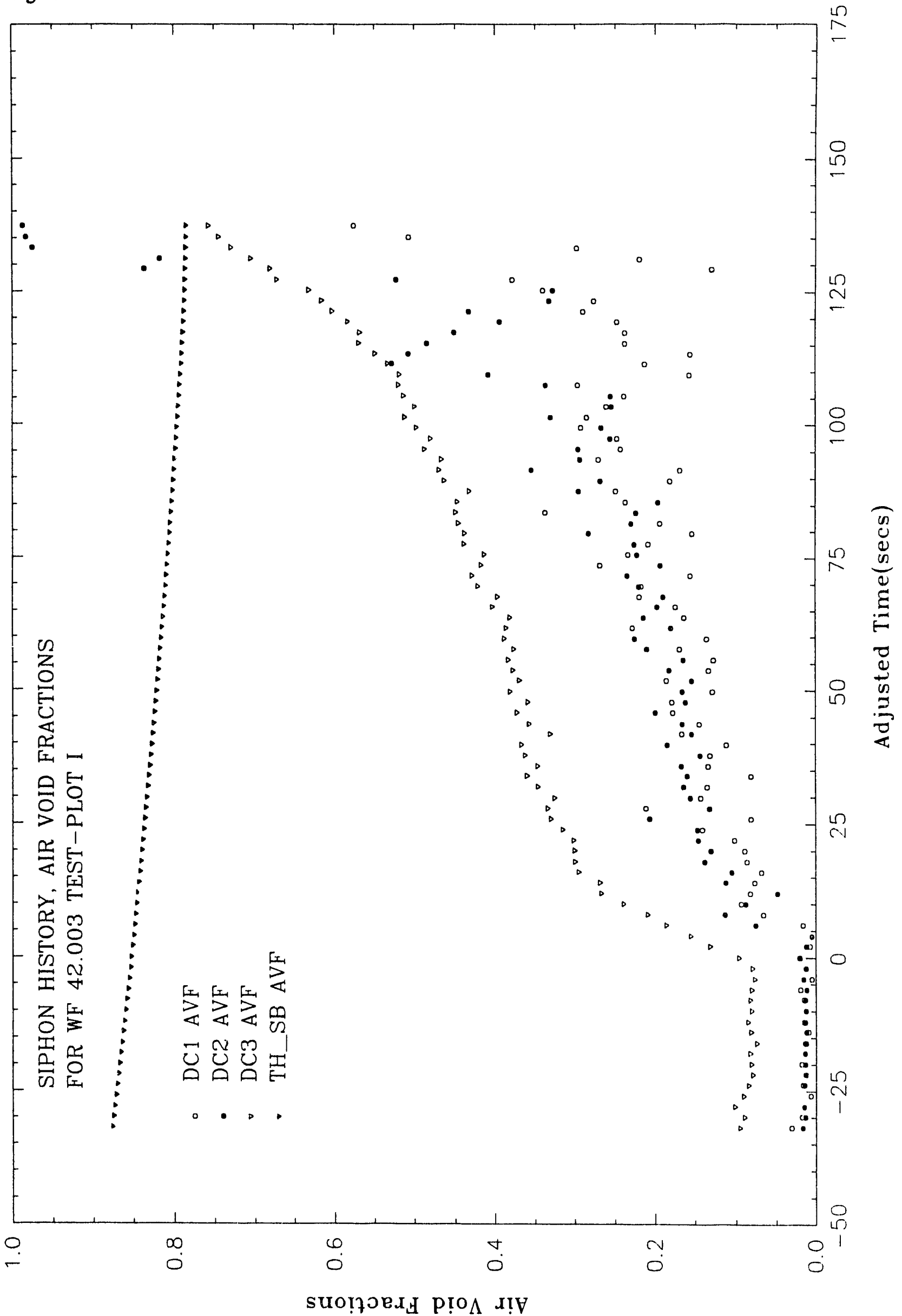




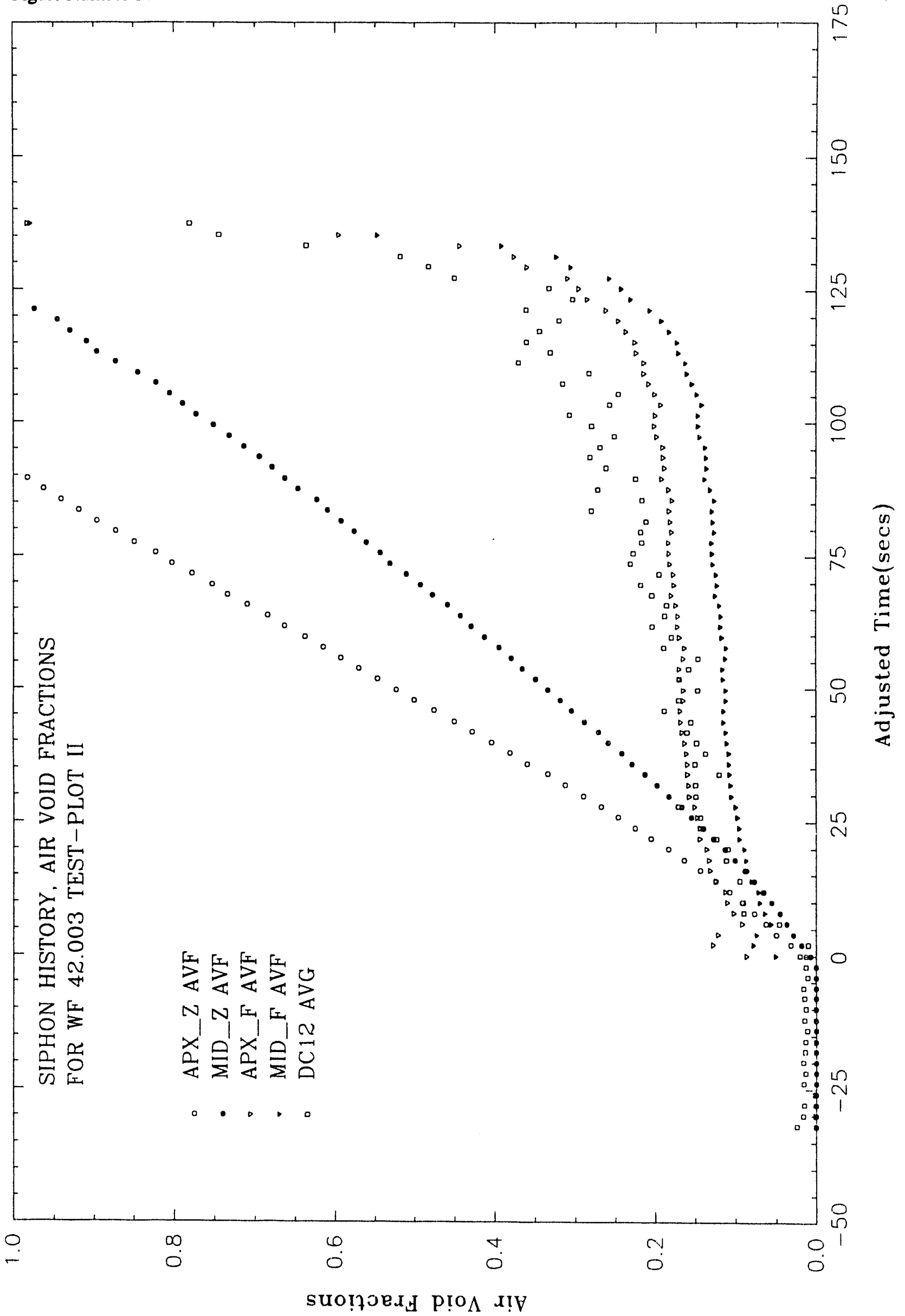




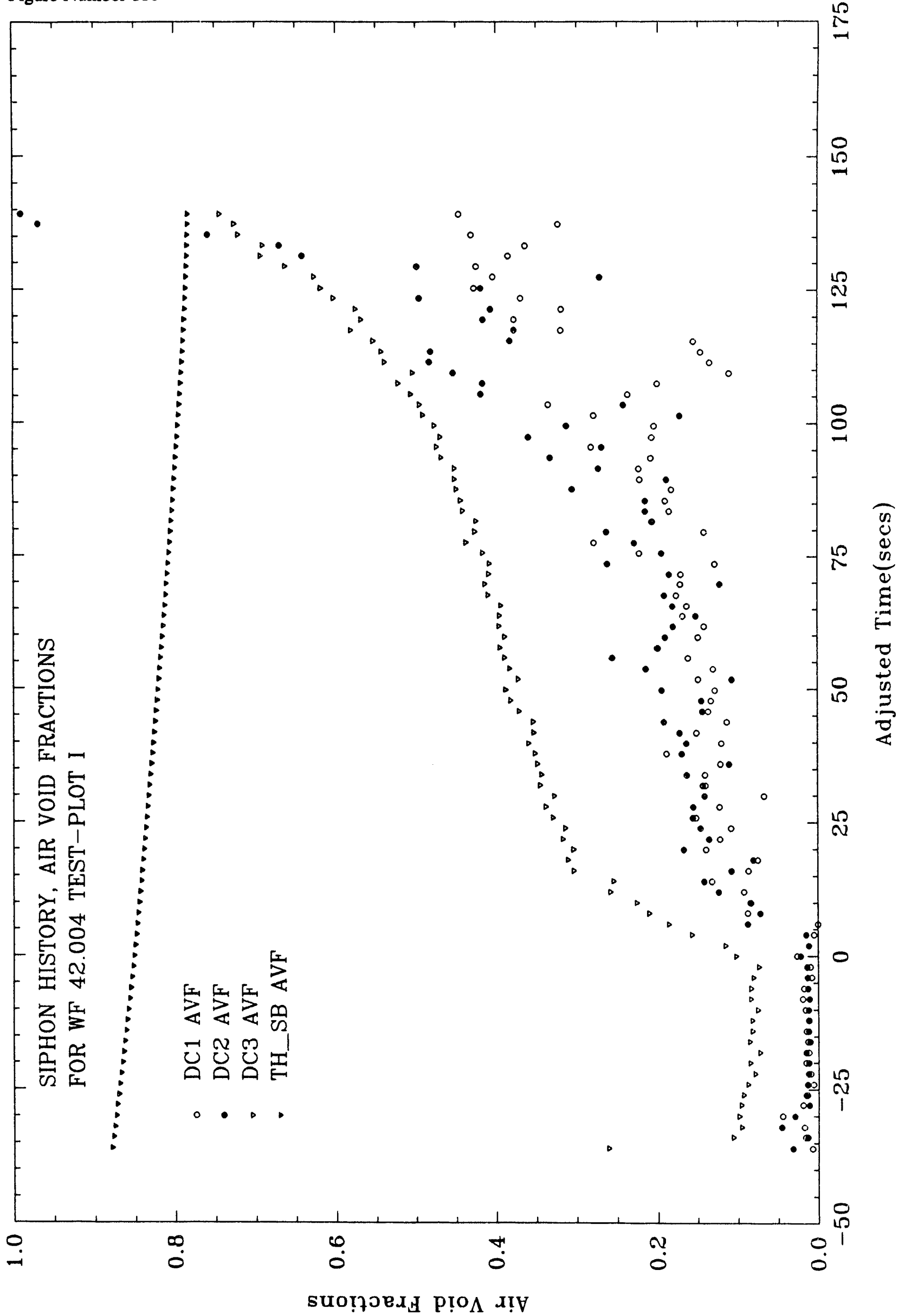




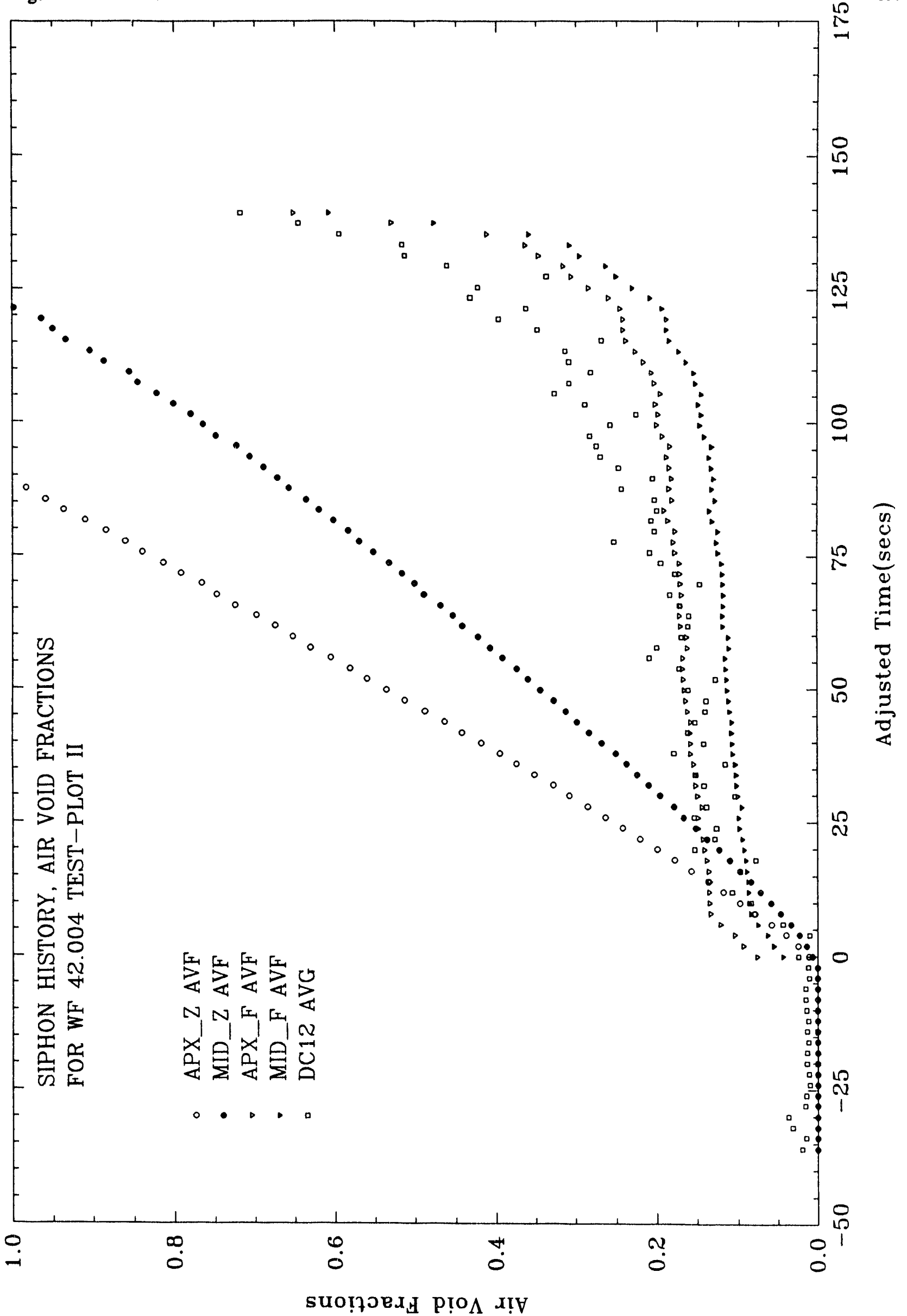




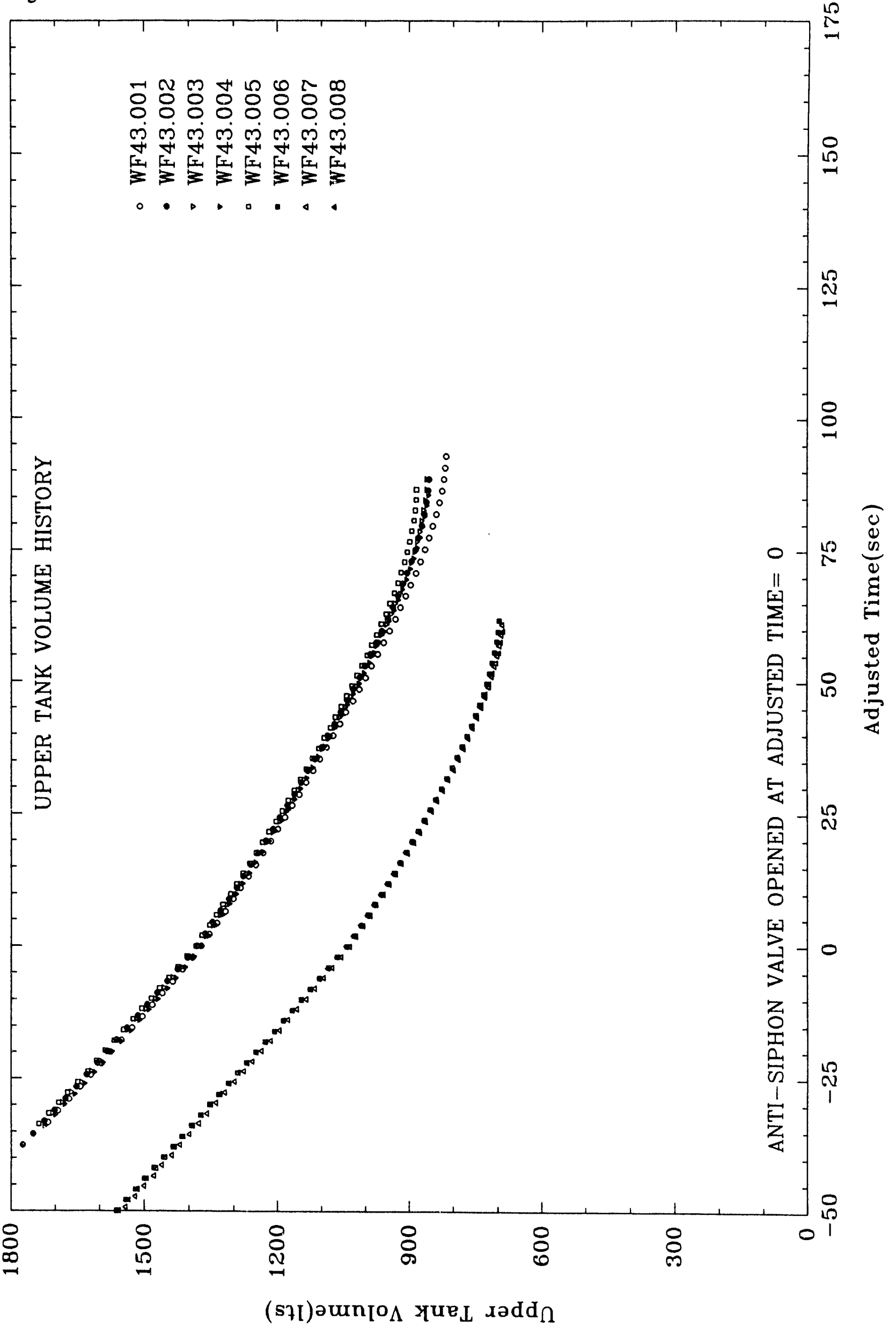




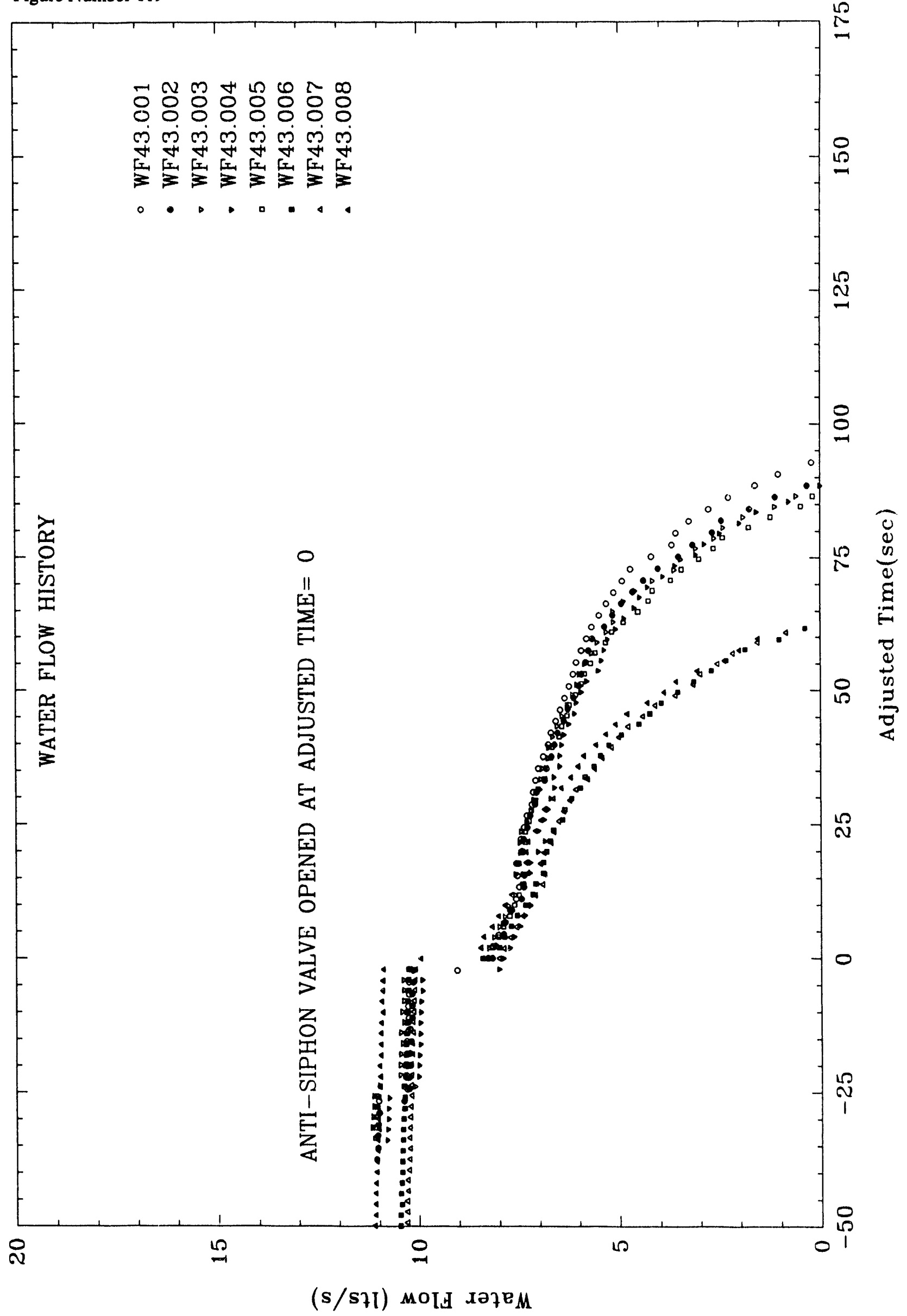




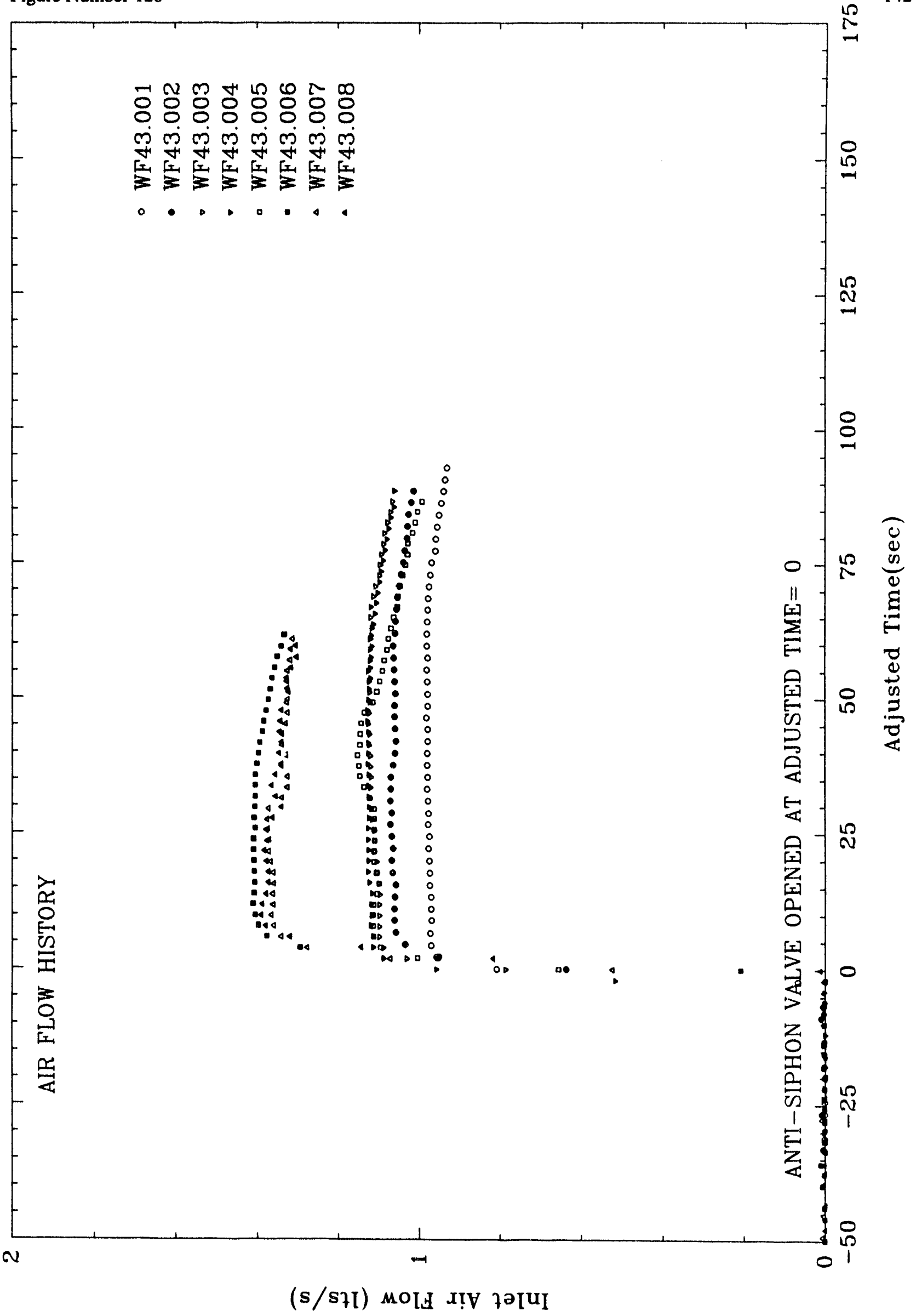




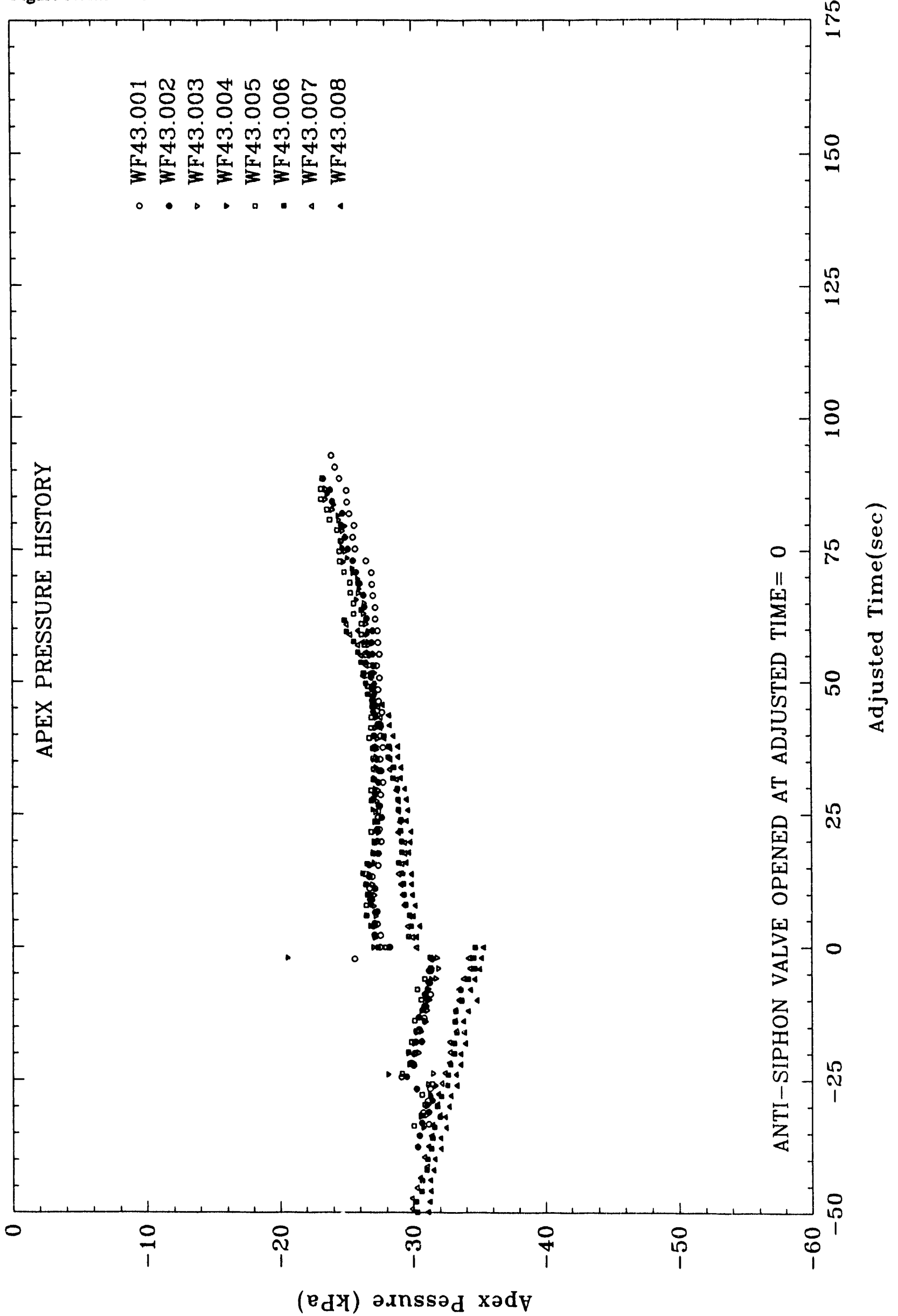




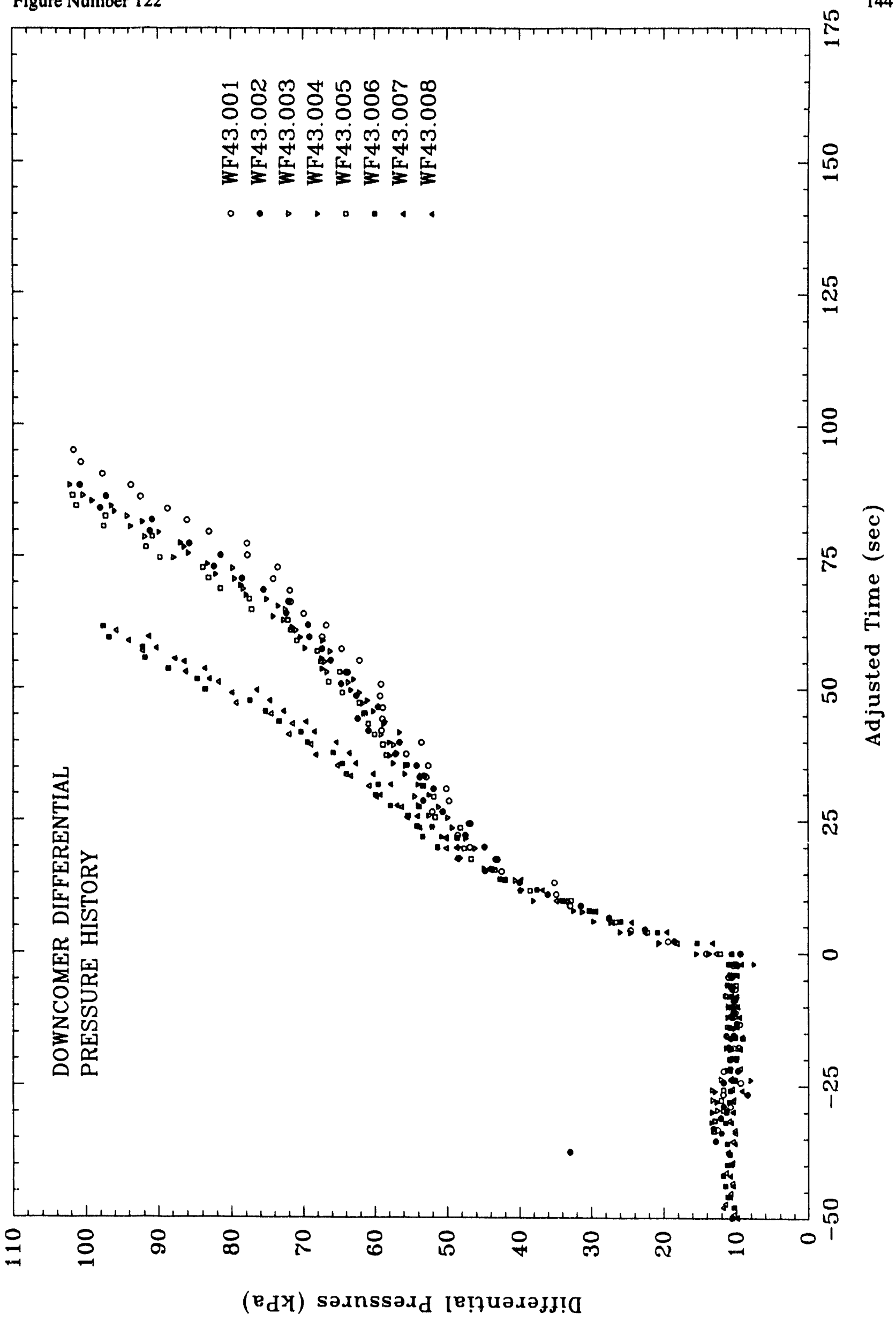


Figure Number 123

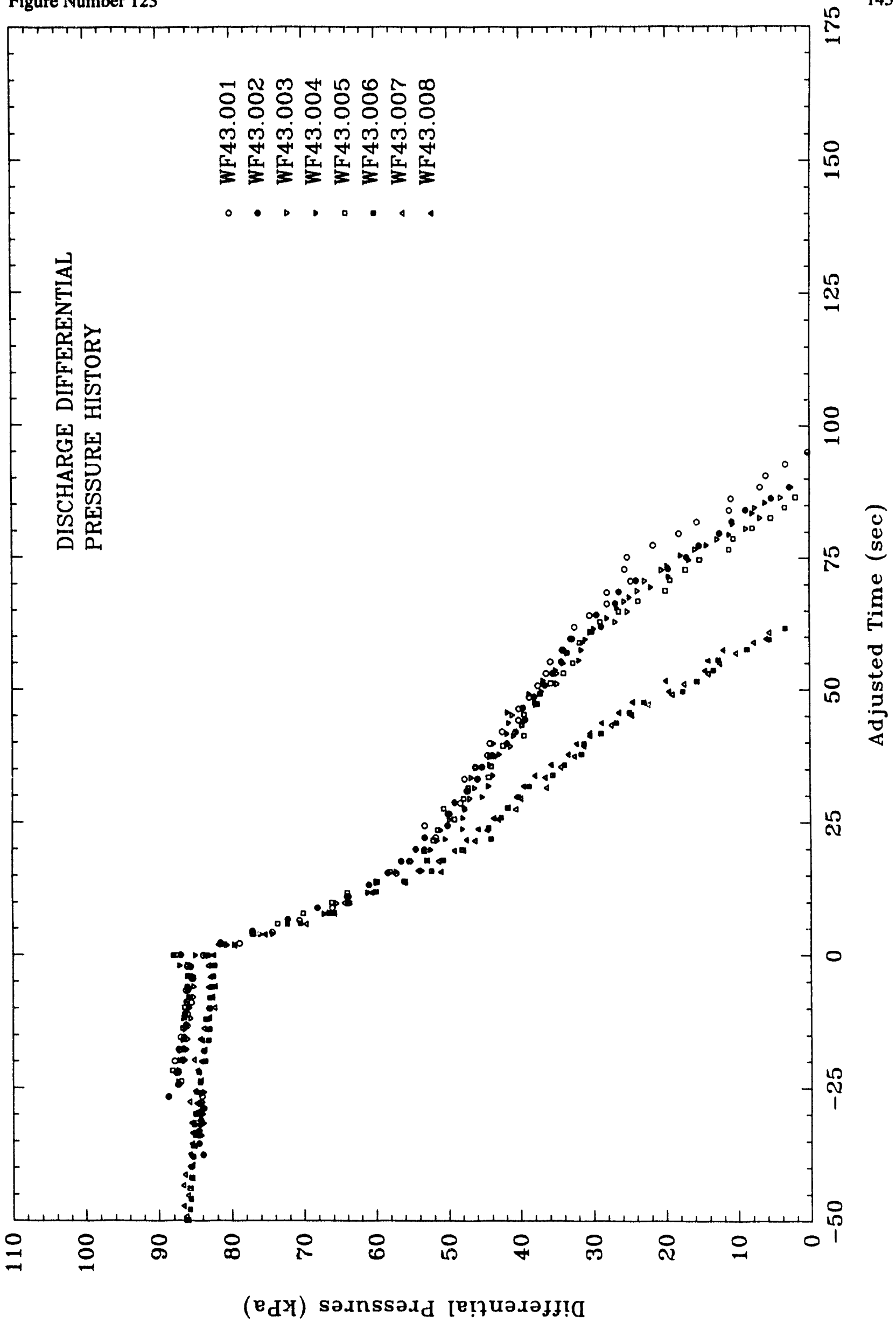




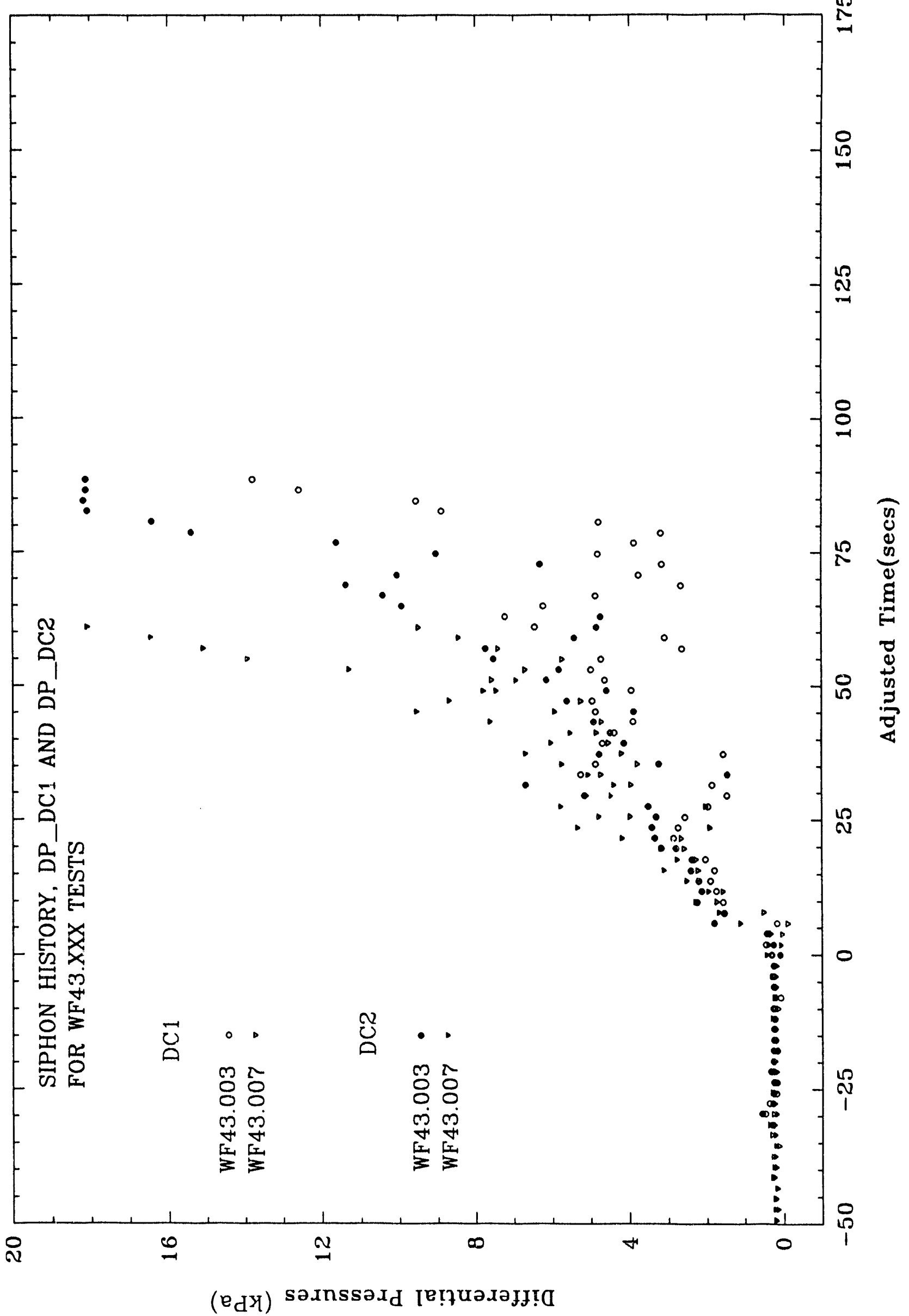




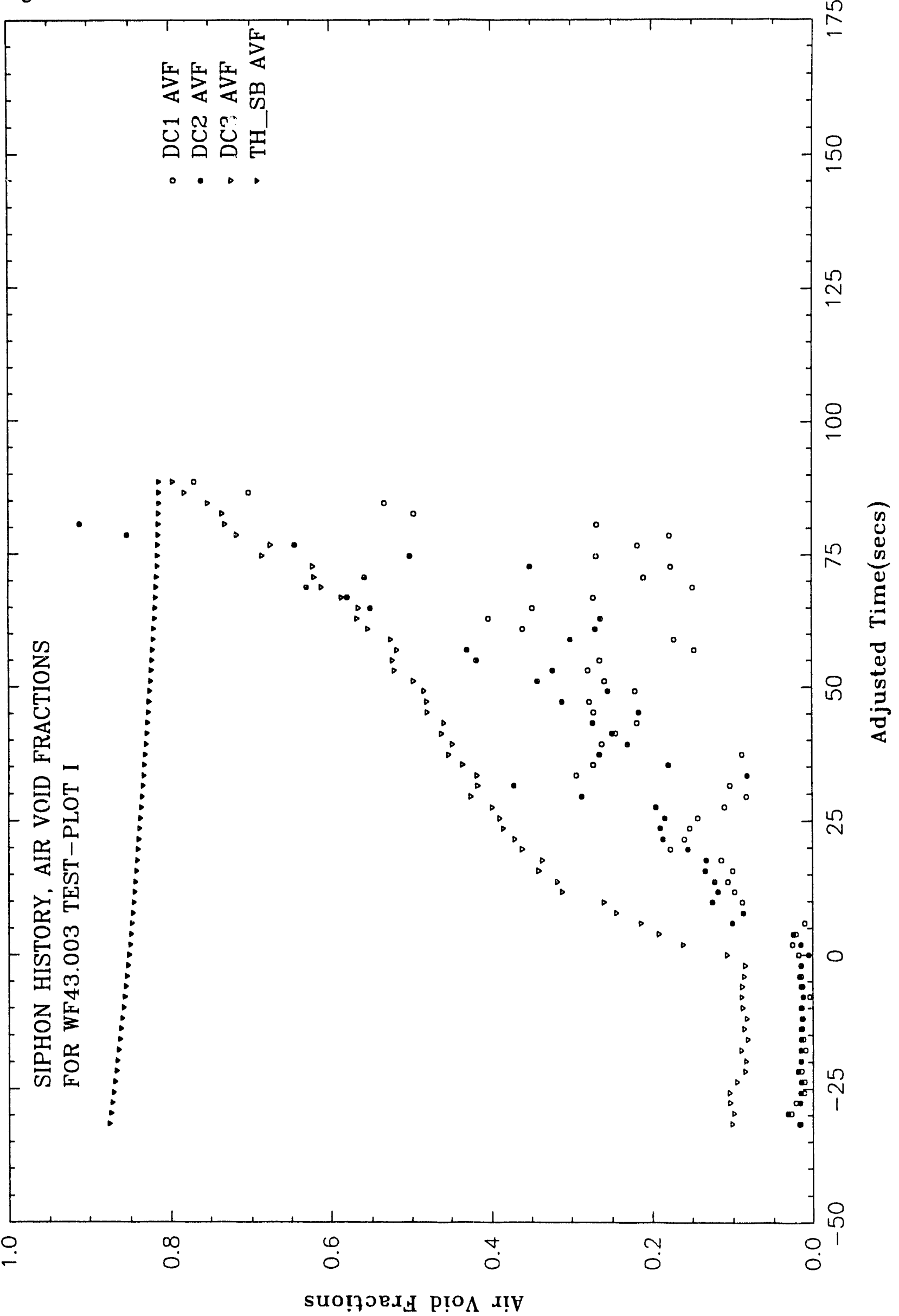




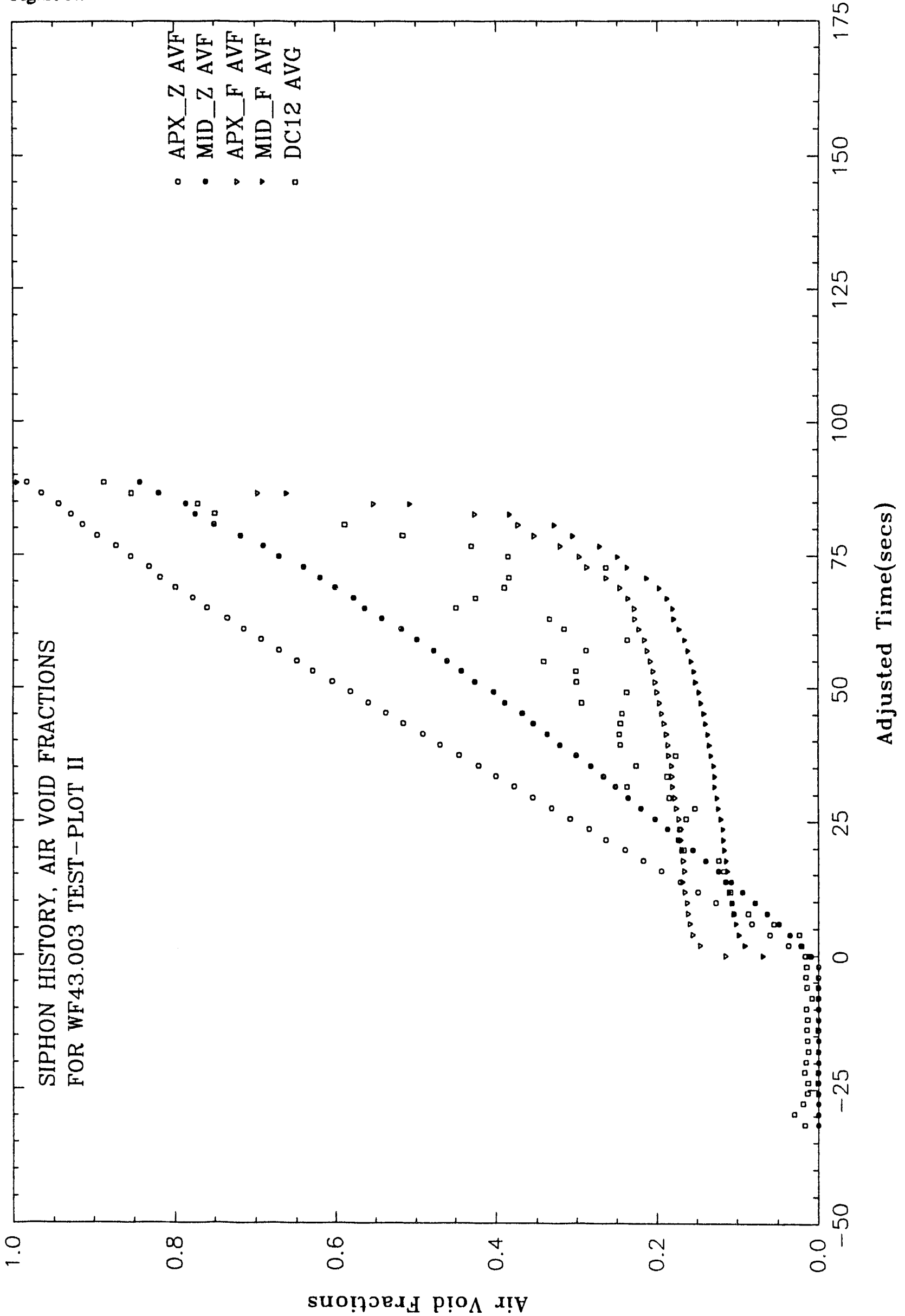


Figure Number 127

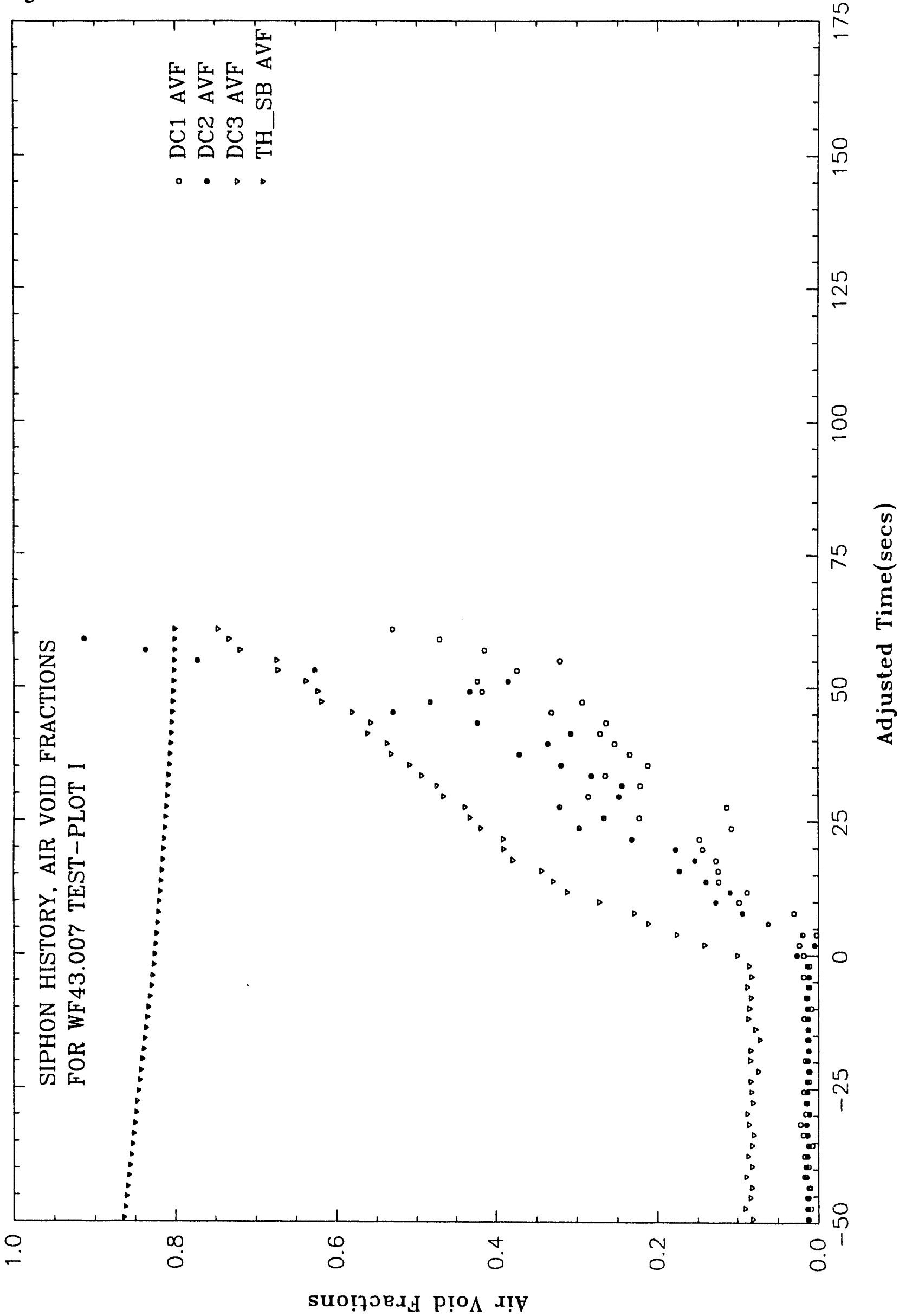


Figure Number 128

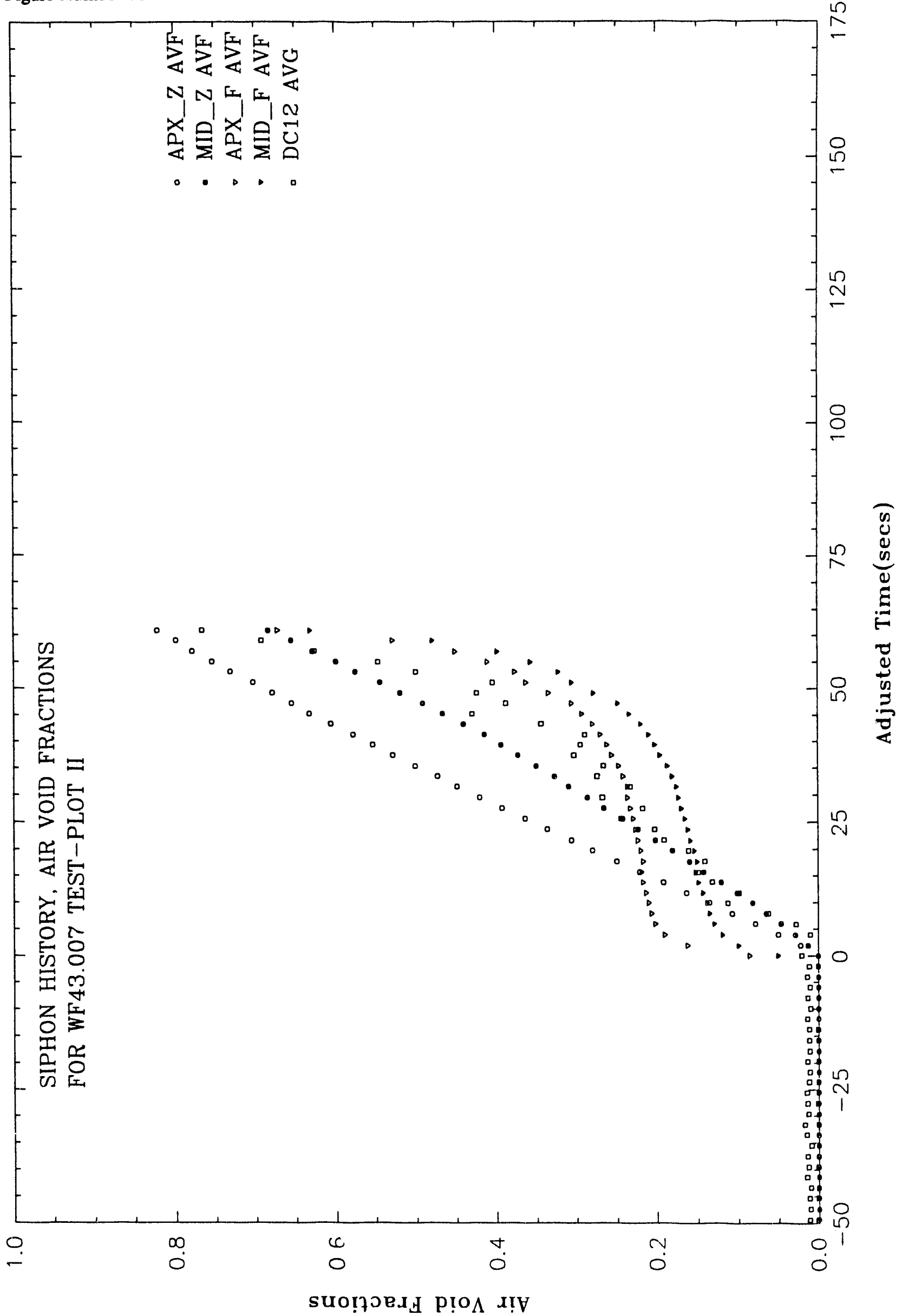


There is, of course, a step decrease at adjusted time zero caused by the introduction of anti-siphon air into the apex. And some 15 seconds after the anti-siphon air flow is started there is a gradual bump in the water flow which occurs over about 5 seconds. We believe this bump occurs when the bubbly, two phase flow reaches the discharge of the downcomer. The fact that the bump appears as a slight increase in the water flow is a mystery. Another smaller bump occurs in the flow rate at about 90 seconds; it appears as a slight decrease in the water flow.

Figure 109 shows the anti-siphon air flow rates behaving as usual. There is an initial lag, probably due to sluggishness in the turbine rotor, but eventualiy the air flow becomes nearly constant. After about 50 seconds the air flows appear to start scattering and even cycling.

Figure 110 shows that the apex pressures step to less negative values when the anti-siphon valve is opened. Then they slowly become more negative, presumably due to the lowering upper tank water level, until about 110 seconds when they turn upward. There is a hint of such direction changes in the wF33 tests.

Figure 111 shows three distinct regions in the downcomer differential pressure data after the anti-siphon air flow is started. During the first 15 seconds the data rise rapidly. Then the slope decreases quickly and settles to a constant value. This slope decrease corresponds to the bubbly, two-phase flow reaching the downcomer discharge. The slope remains nearly constant until about 100 seconds when it starts to increase again. We believe this intermediate, constant slope portion corresponds to partial sweep-out of the air. During the third portion the slope increases and approaches the same value as it had during the first 15 seconds. We believe the sweep-out of air has diminished to near zero due to the lower water flow rate. This third portion corresponds to the unexplained upturn in the apex pressure evident on Figure 110. A review of the video tape record of these tests leads us to suggest that the intermediate, constant slope portion corresponds to a period of intense, bubbly, two-phase flow along the entire downcomer and the third portion corresponds to the onset of a water-fall at the top of the downcomer.

Figure 112 shows that the discharge differential pressure data exhibit three different portions which correspond very closely to those of the downcomer differential pressures.

Figure 113 shows the differential pressures measured over the two 6-foot long sections near the middle of the downcomer. While the data are quite scattered, the slow increase in the differential pressure due to increased air bubbles in the water is quite apparent. However, after about 90 seconds the data 
become more scattered and start to show the surges typical of mini-water fall bubbles. Again, as in previous test series, a water fall appears to pass the upper dp cell, DC2, but not the lower one, DCI, before the siphon breaks.

Figures 114-117 show the calculated air void fractions for the two tests in this series. The major interesting feature is that the downcomer air void fraction closely approaches the theoretical air void fraction to break a stagnant siphon, TH SB AVF. Since each of these plots 18 for only one test, the increasing cyclic nature of the air void fraction is quite evident.

Figures 118-128 show the plots for the WF43.XXX series of tests. Data collection for a relatively large number of the tests was successful from two different initial upper tank water levels.

Figure 118 shows that the upper tank volume histories followed the usual pattern except that there is considerable divergence at the end of the set of data for the tests started at the higher upper tank water levels.

Figure 119 shows that the water flow rates were very close to the same, prior to opening the anti-siphon air valve, except for test 008. After adjusted time zero all the water flows are nearly the same for about 15 seconds. We believe that 15 seconds is the time required for the bubbly, two-phase flow to reach the downcomer discharge. The flow rates separate after that 15 second mark due to the small difference in the antisiphon air flow rates caused by the different water levels in the upper tank.

Figure 120 shows a significant difference between the air flows for the two sets of tests run from different upper tank water levels. Although the air flow data are spread within each set of tests, we believe the air flows were actually much closer together and that the spread is due to difficulties with the turbine meter.

Figure 121 shows that the apex pressure data cross-over between the two test series. That effect is probably due to the 006-008 tests pulling in air much faster than the 001-005 tests.

Figure 122 shows that the downcomer differential pressures are essentially the same for all the tests until about 15 seconds after the anti-siphon air valve is opened. The data for the two test series diverge after that. The higher air flow for the 006-008 tests causes a faster increase in the air void fractions in the downcomer and there is only about a 20 second period of partial sweep-out. The steep slope during that period indicates that the sweep-out fraction is small. The data from the 001-005 
tests show about a 40 second period of partial sweep-out and the lower slopt indicates a larger sweep-out fraction.

Figure 123 shows similar separations in the discharge differential pressure measurements between the two test series. The data for all the tests are closely grouped until the bubbly, two-phase flow reaches the discharge orifice; then the data separate and start to scatter.

Figure 124 shows the differential pressures over the two 6-foot sections near the middle of the downcomer for only one test from each of the two sets of runs. Cycling of the data starts at about 15 seconds and continues to grow larger until the water fall passes the dp cell connections. Again, the water fall doesn't quite pass the lower dp cell, DC1.

Figures 125-128 show the calculated air void fractions for one test from each of the two sets of runs. As with the WF42 series the theoretical air void fraction to break a stagnant siphon is almost reached by the overall downcomer air void fraction. since each plot is for only one test, the cycling of the air void fractions is quite apparent. We believe this cycling is caused by the passage of large air bubbles which take the form of mini-water-falls. 


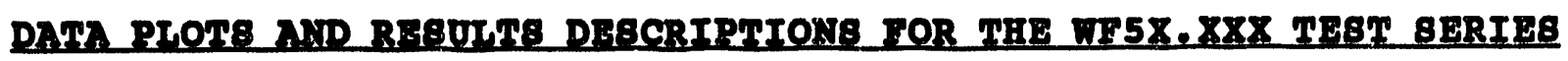

Figures 129-188 show the measured data and calculated air void fractions for the WF50, WF52, WF53, WG53, WG54, WG55, and WG56 family of tests. These plots are all grouped in one section to make comparisons easy.

The WG nomenclature was adopted when the rotor for the air turbine had to be replaced with one allowing larger flows. That replacement required a different calibration be used for data reduction so the test letter designation was changed. We also enlarged the holes through the tubing fittings in the antisiphon air inlet line in order to get larger air flows for a given apex pressure. We repeated some of the tests using the $\# 3$ air inlet orifice with the new rotor and air line to provide a before and after comparison. The before tests are labeled WF53 and the after tests are labeled WG53.

Figures 129-133 show the data for the three "water flow only" WF50 tests which were run early in the test program.

Figure 129 shows that the upper tank volume histories repeat very well for the three tests in the series.

Figure 130 shows that the water flow rates repeat very well to about 90 seconds adjusted time. The scatter in the water flow rates after that point indicates that a vortex formed in the upper tank outlet which sucked air into the upper tank discharge and the siphon upcomer. Such disruption is quite pronounced on the water flow plot but hardly visible on the upper tank volume plot.

Figure 131 shows a steady decrease in the apex pressure until about 90 seconds when the disruption in the water flow also affects the apex pressure.

Figure 132 shows a decreasing downcomer differential pressure due to the decreasing water flow rate.

Figure 133 shows the same decreasing pattern for the discharge differential pressure.

Figures 134-144 show the plots for the wF52 series of tests. The anti-siphon air flow is started at the same upper tank level for all tests in this series. Also, the siphon is always broken by draining the upper tank during these tests.

Figure 134 shows that the upper tank volume histories repeated very well for the four tests in this series. The siphon starts to break at about 90 seconds for each test even though the data continue on for another 15-20 seconds. 


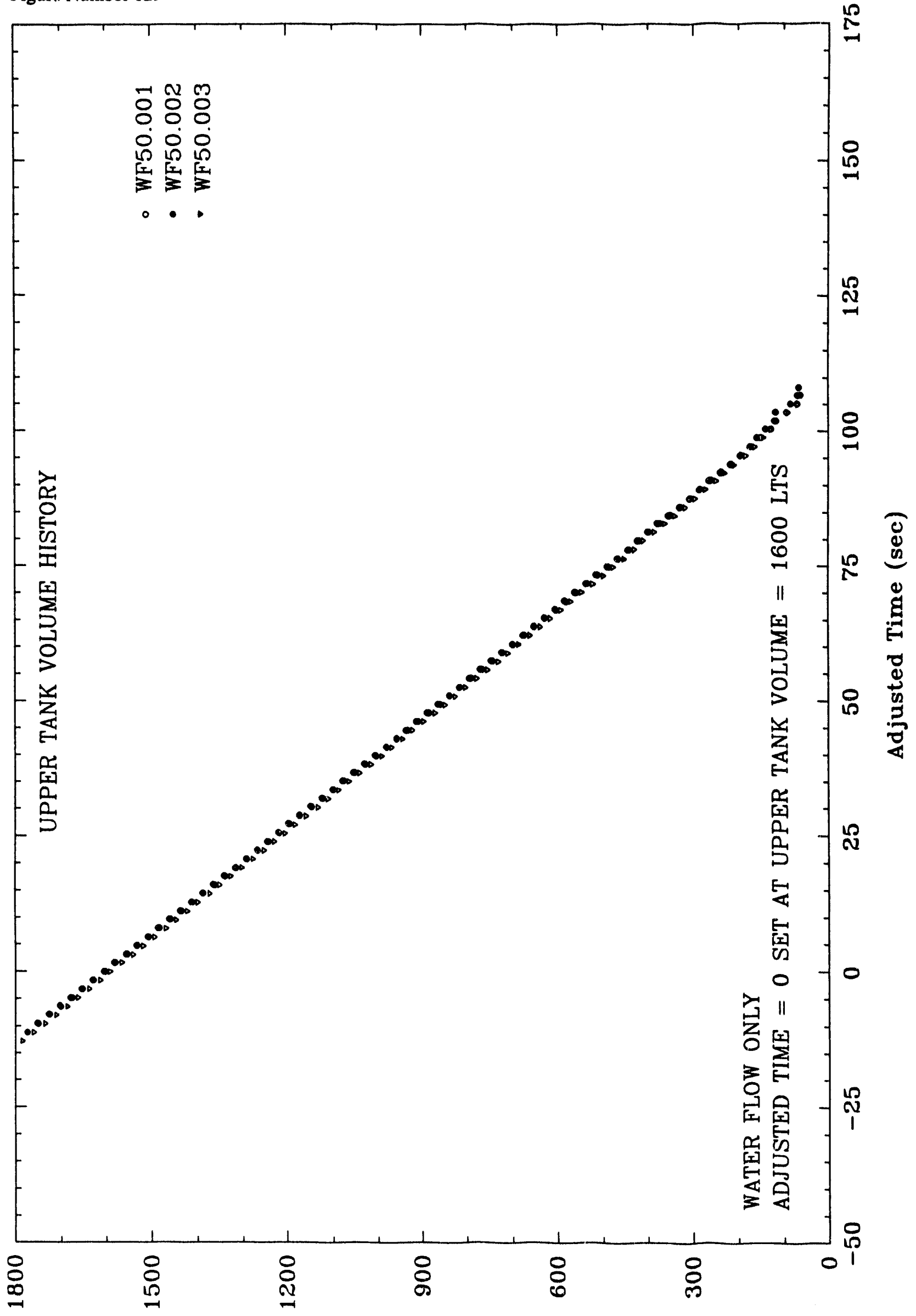

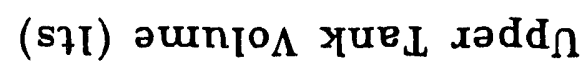


Figure Number 130

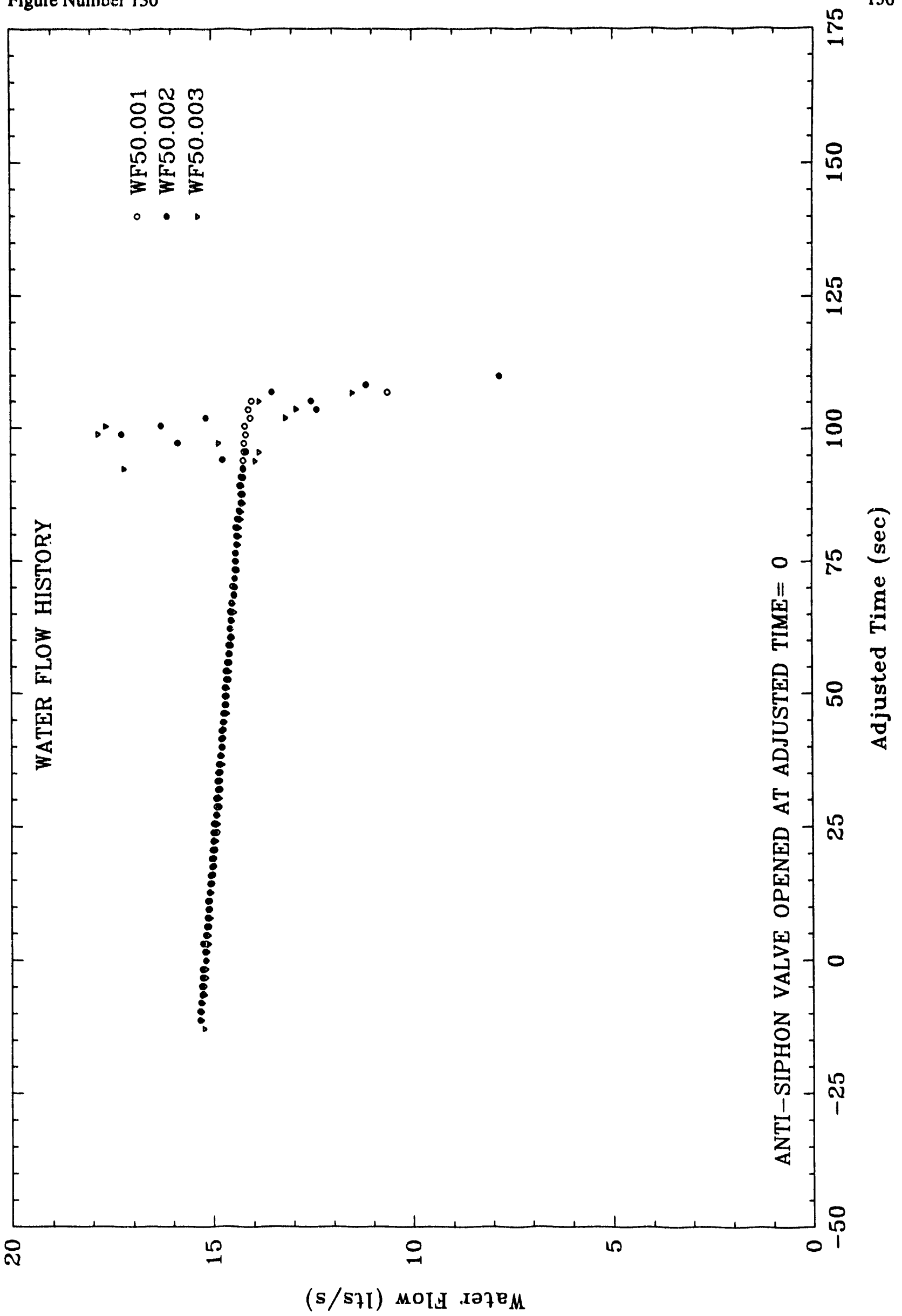




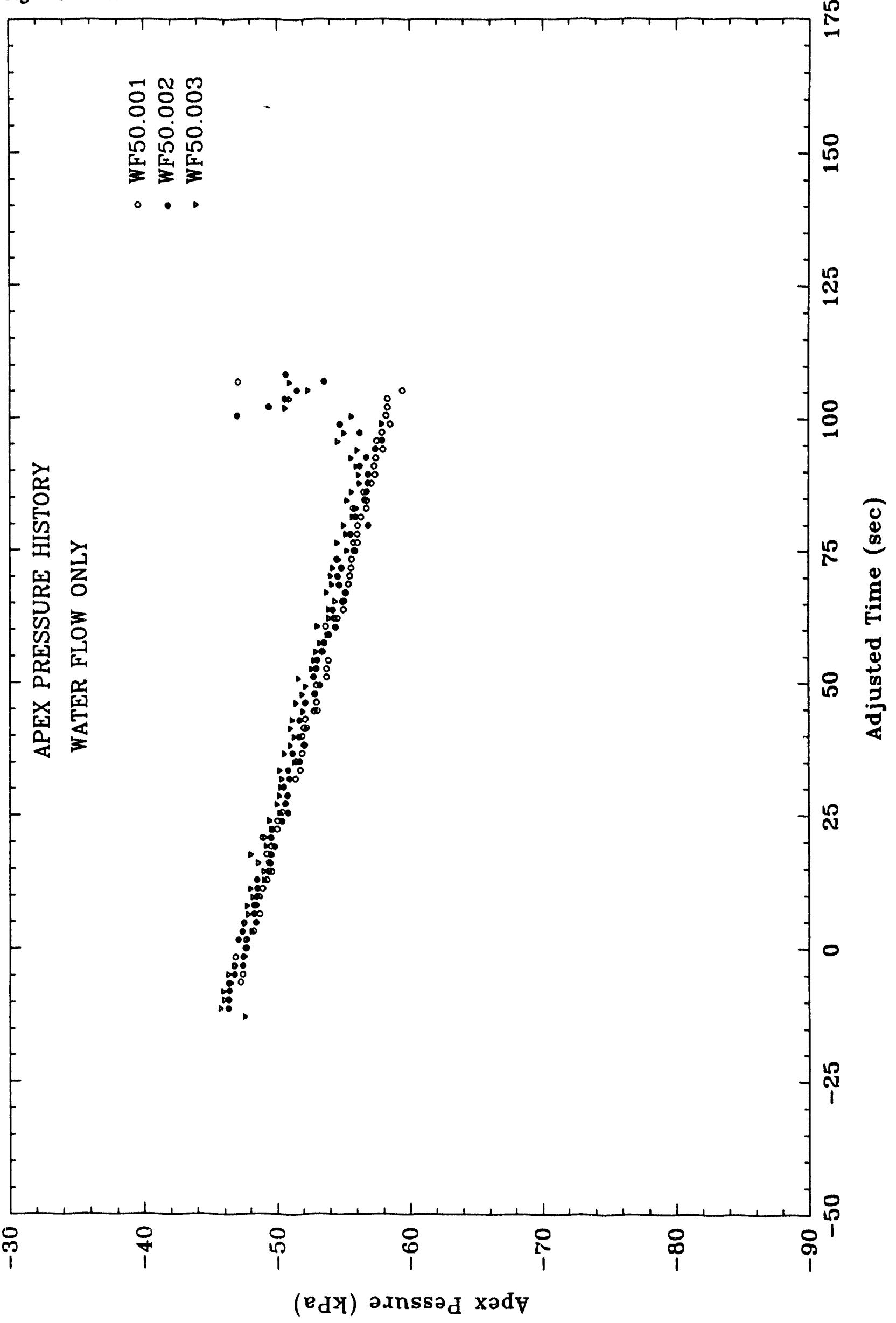


Figure Number 132

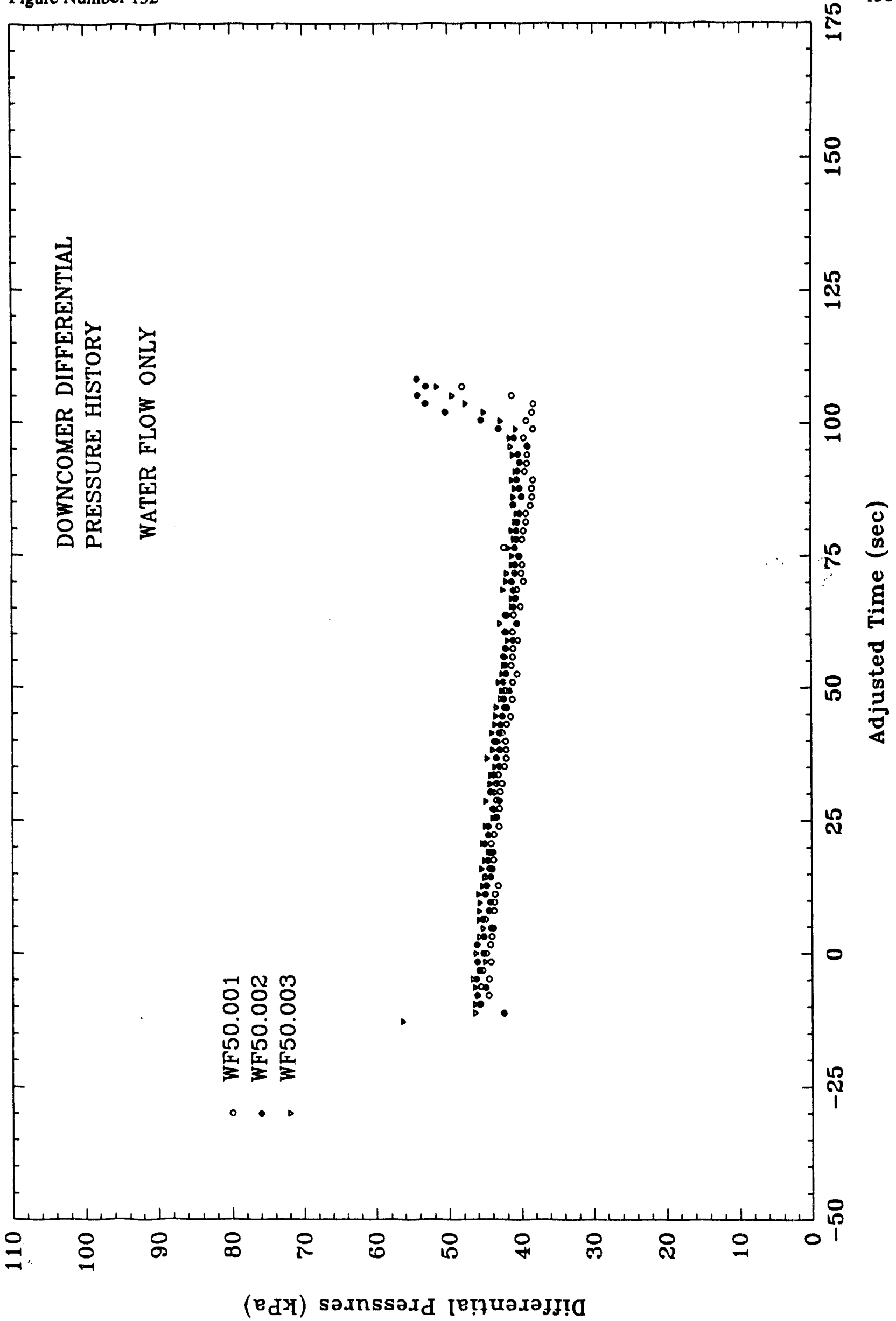


Figure Number 133

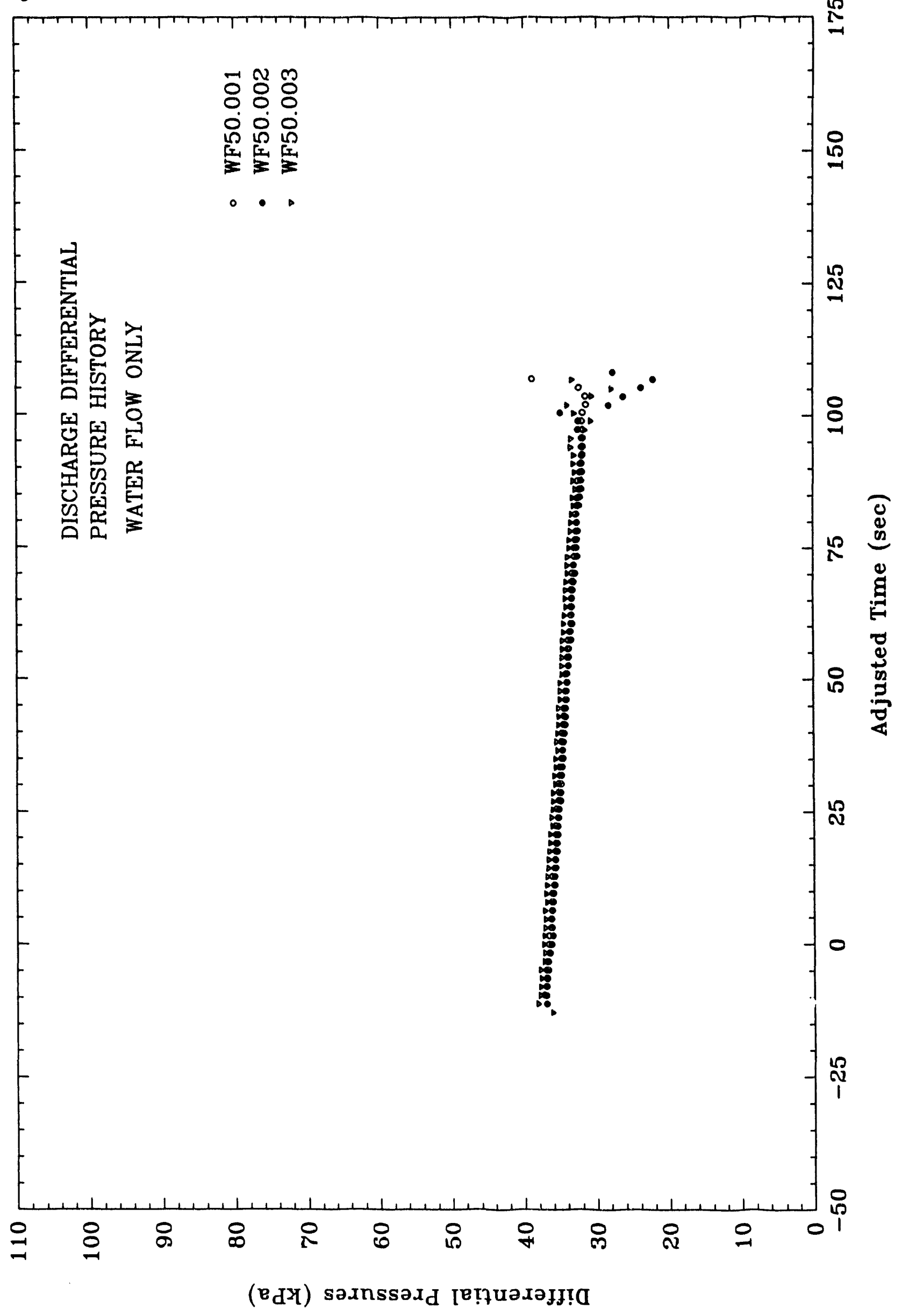




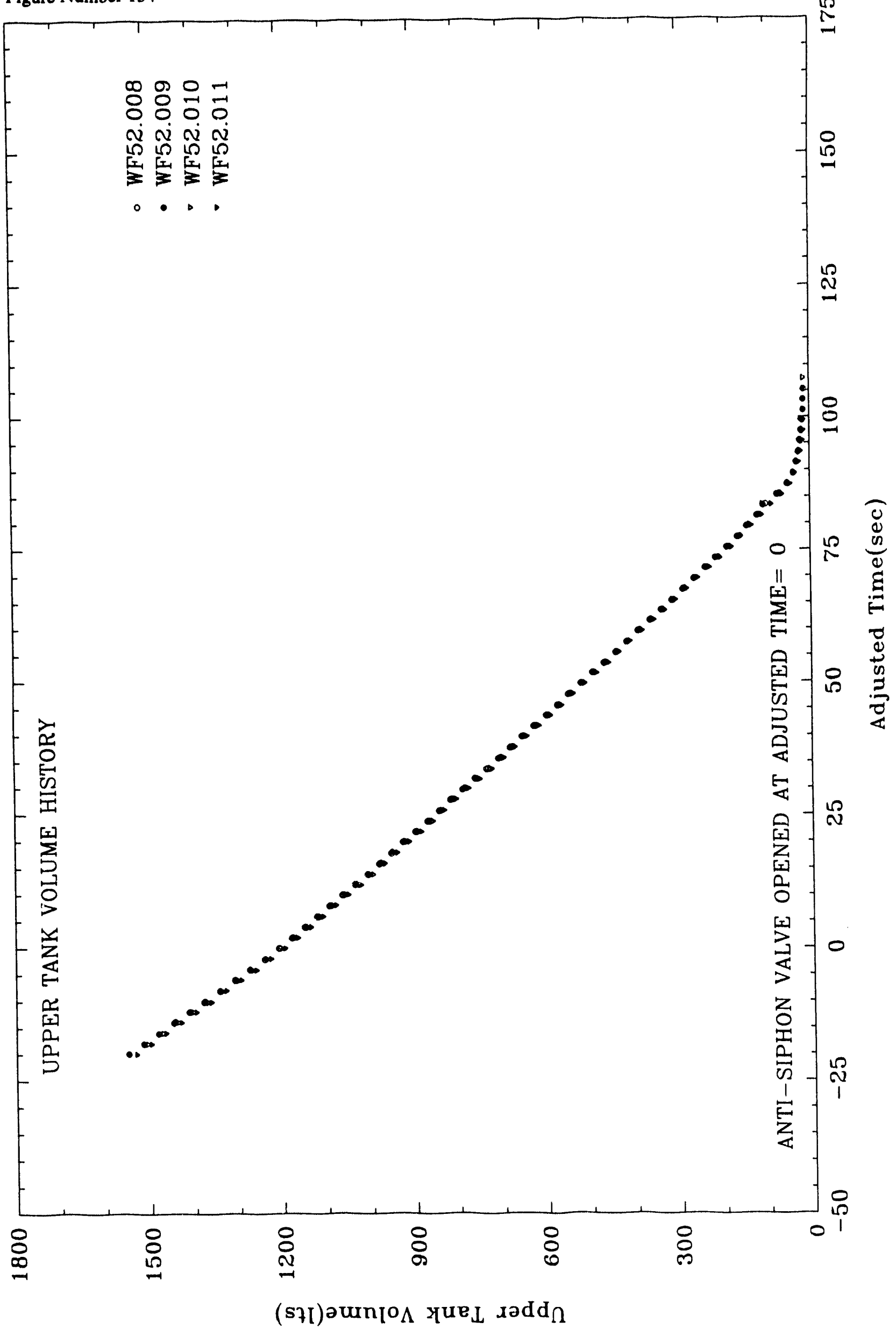


Figure Number 135

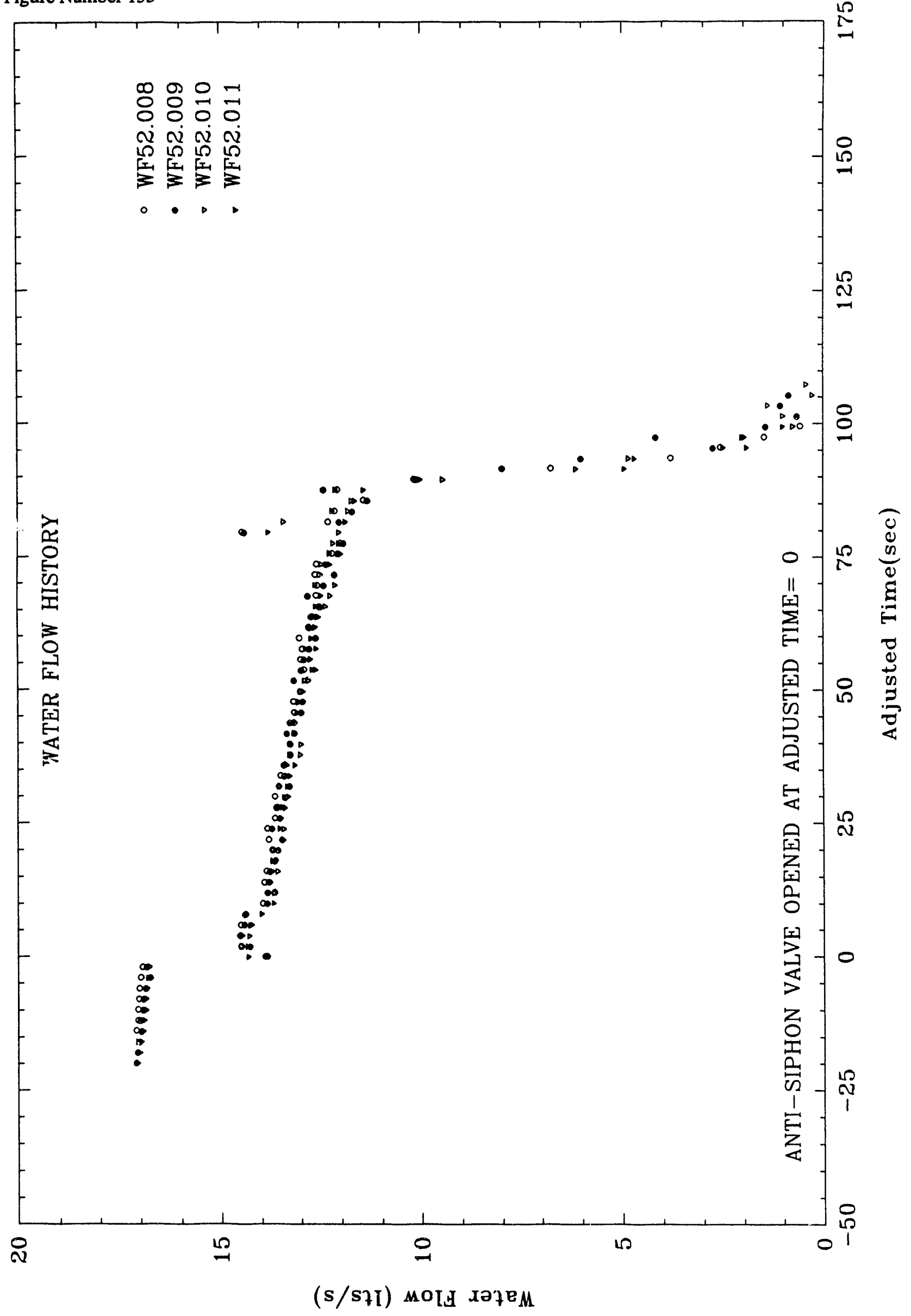




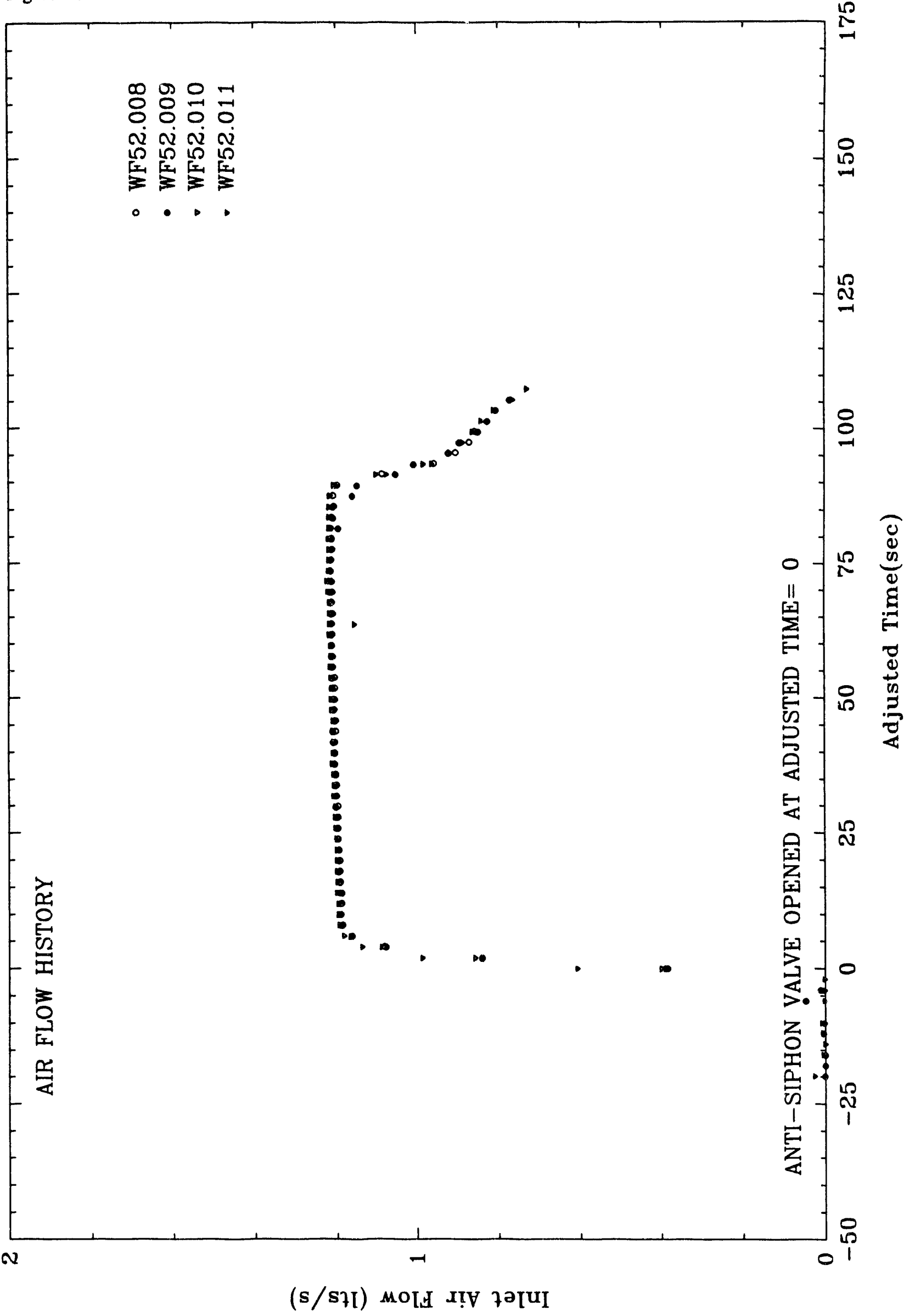




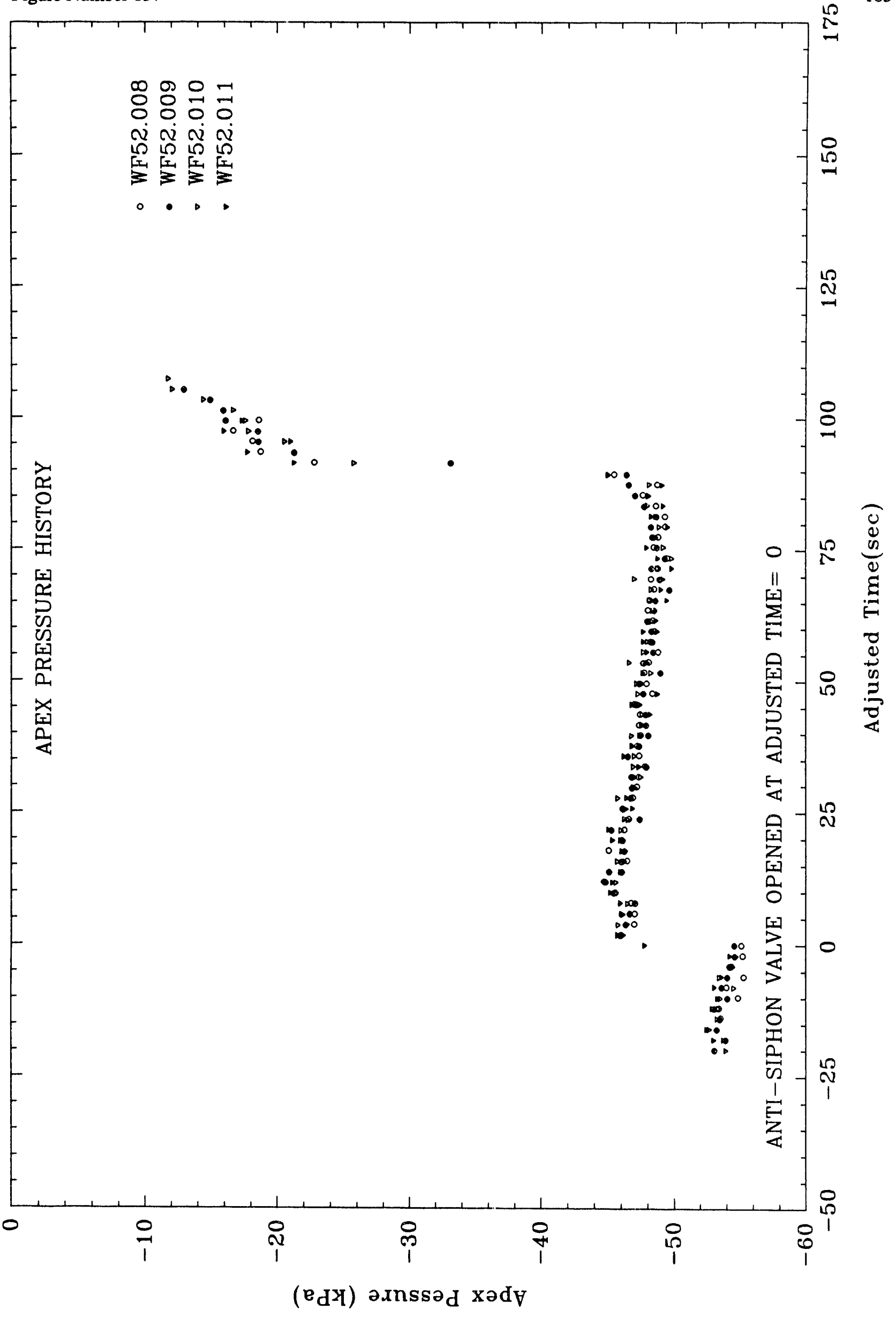




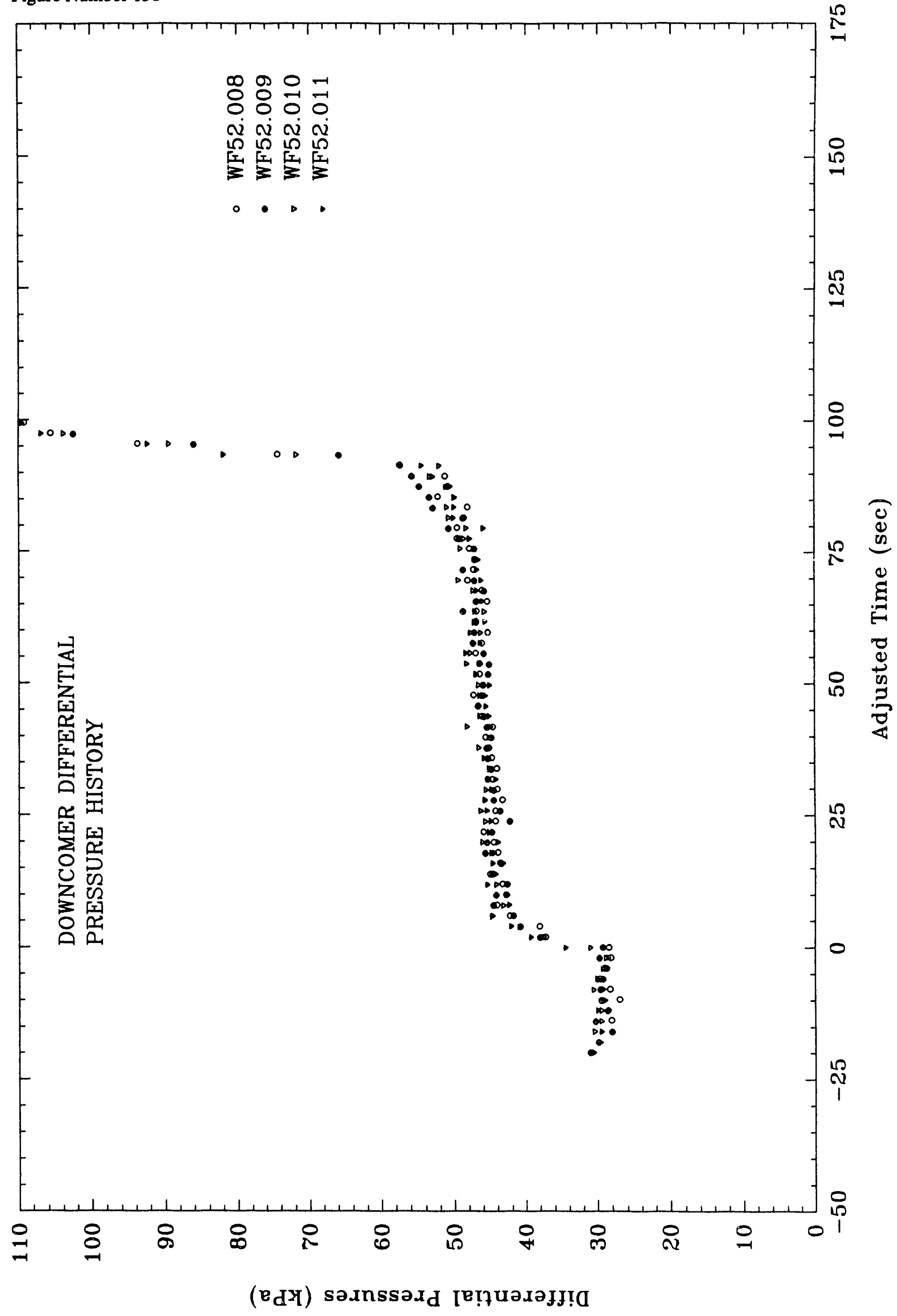


Figure Number 139

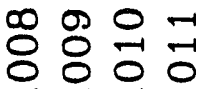

vi $v i v$

1)

昰昰

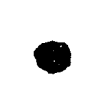

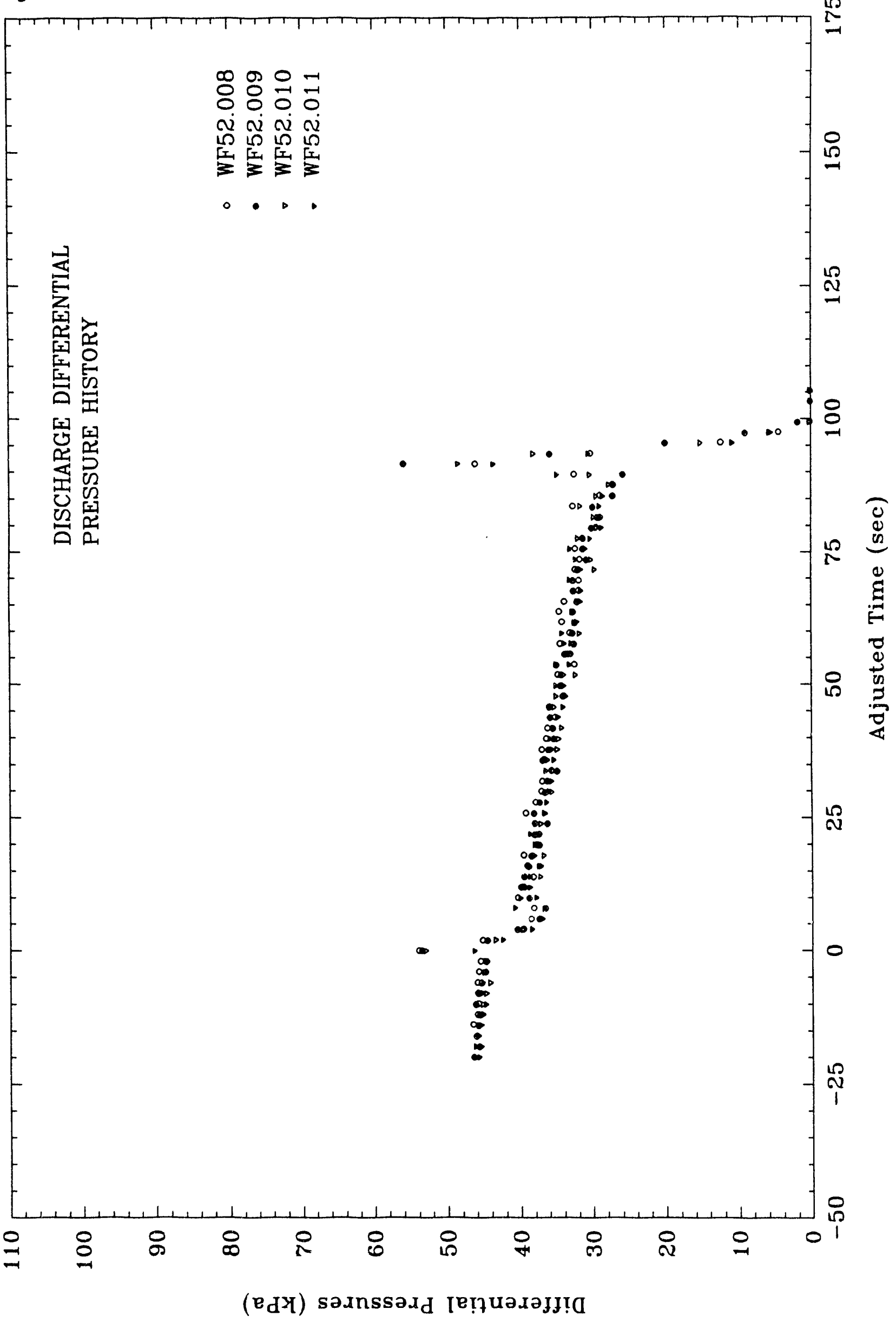

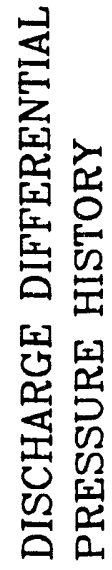

$\stackrel{1}{-1}$

-

0

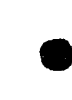

0 
Figure Number 140

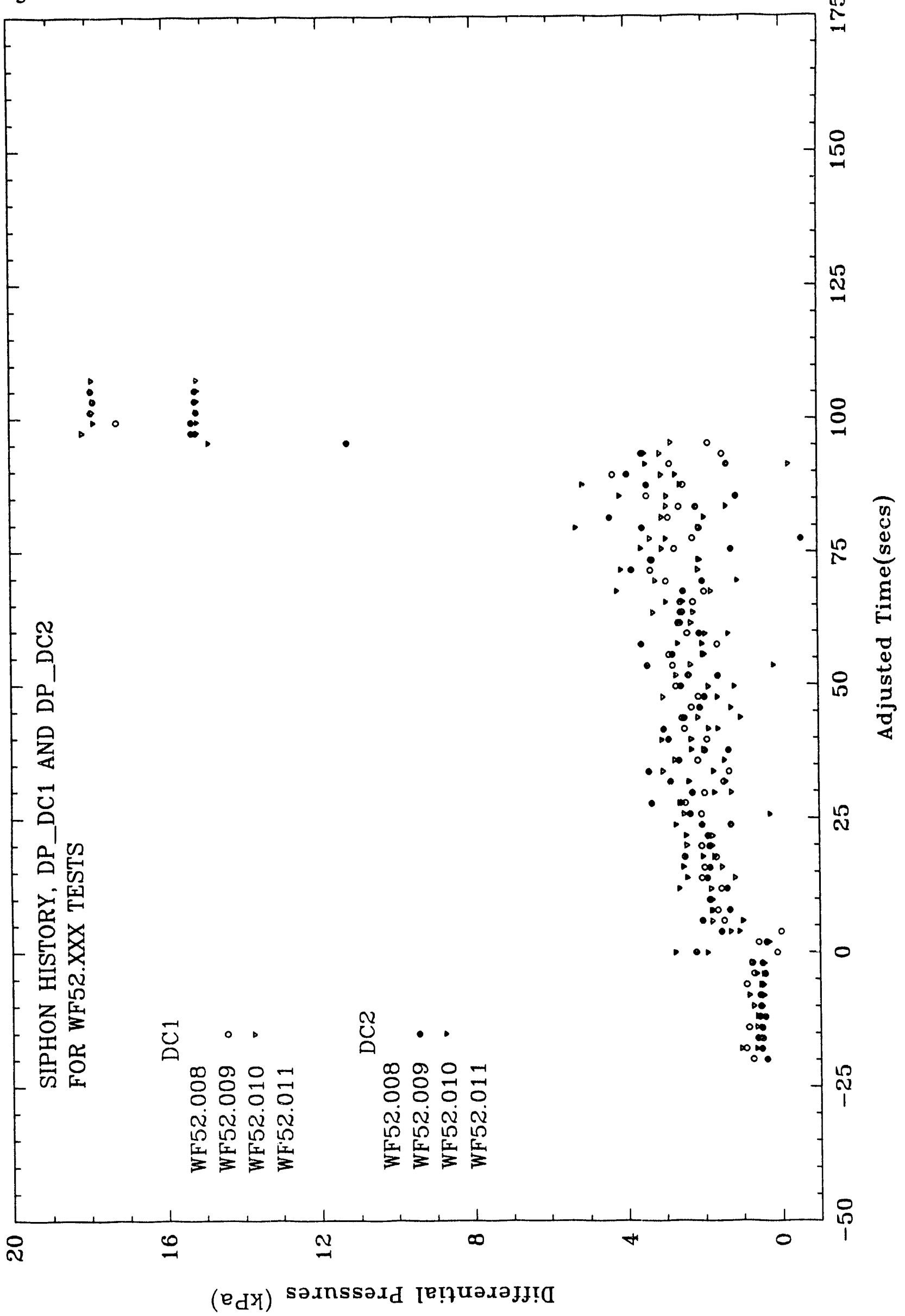




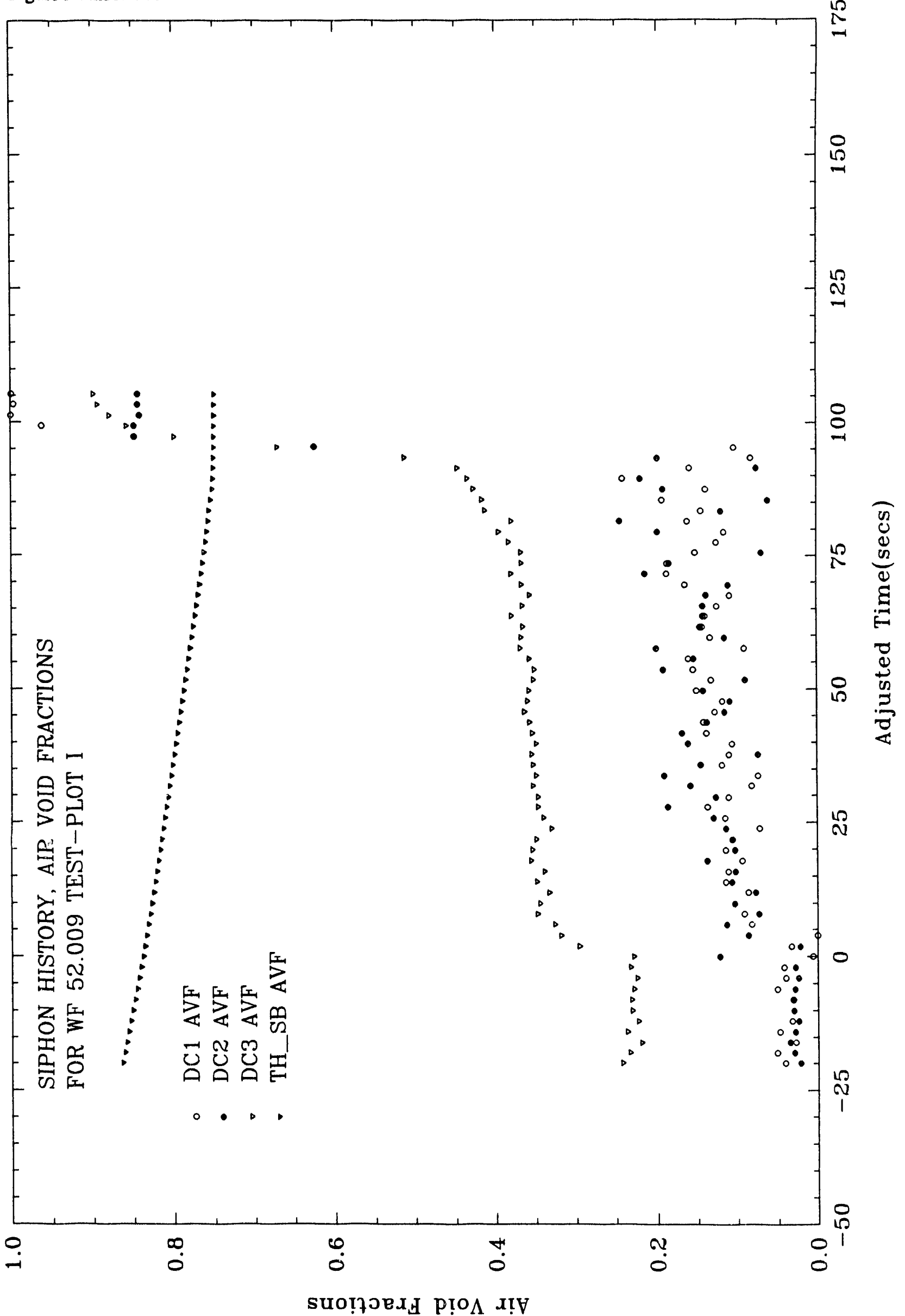




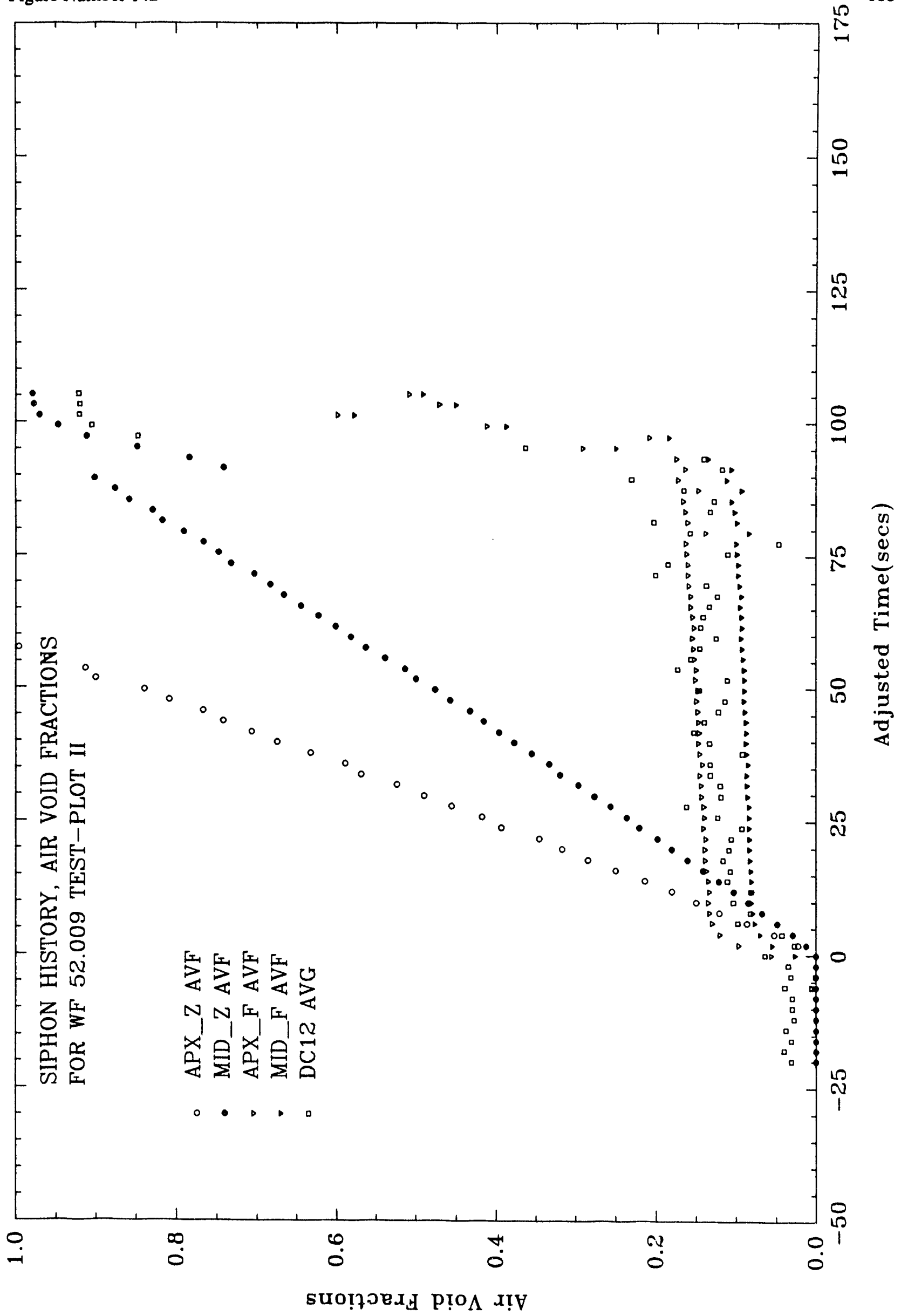




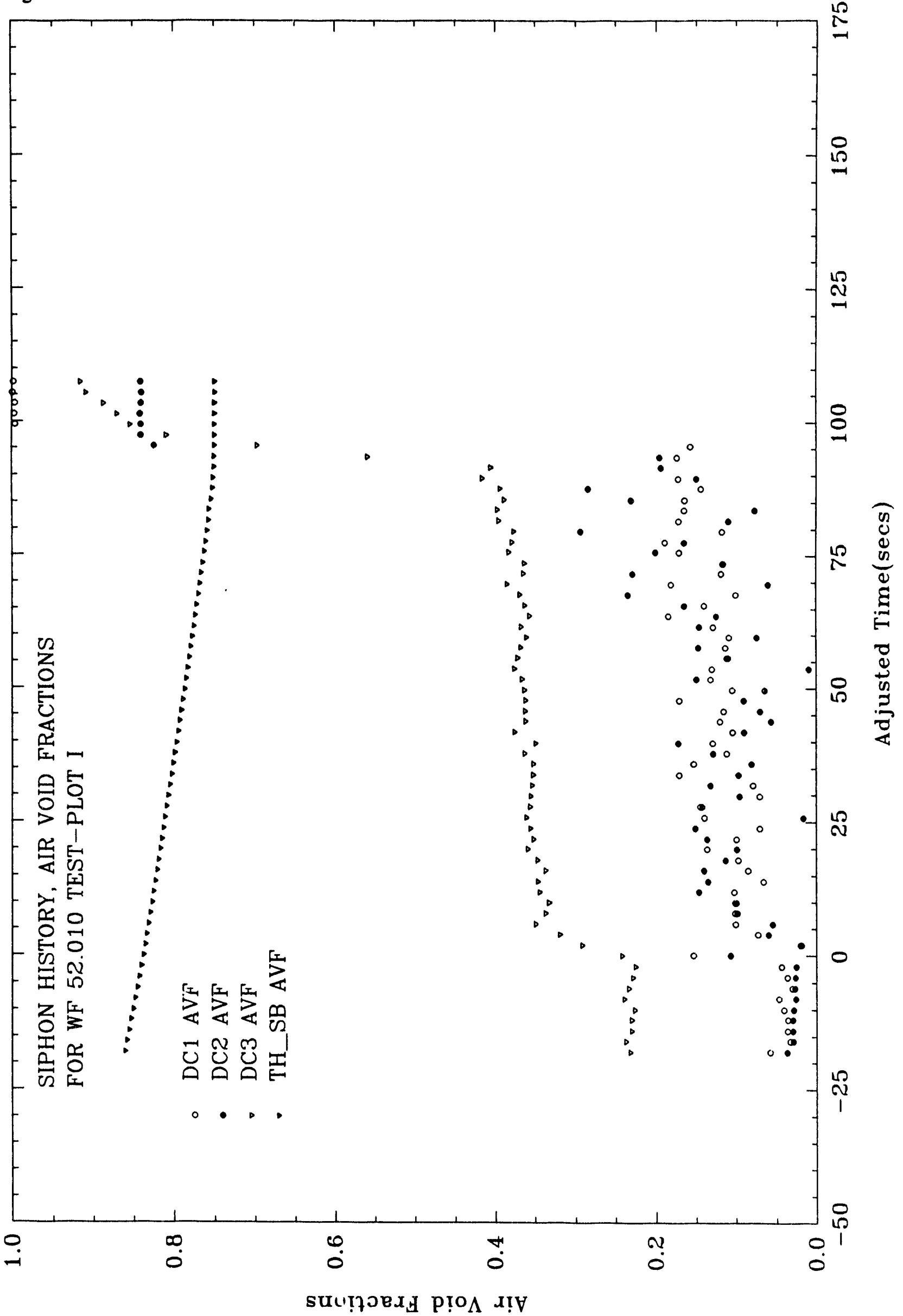




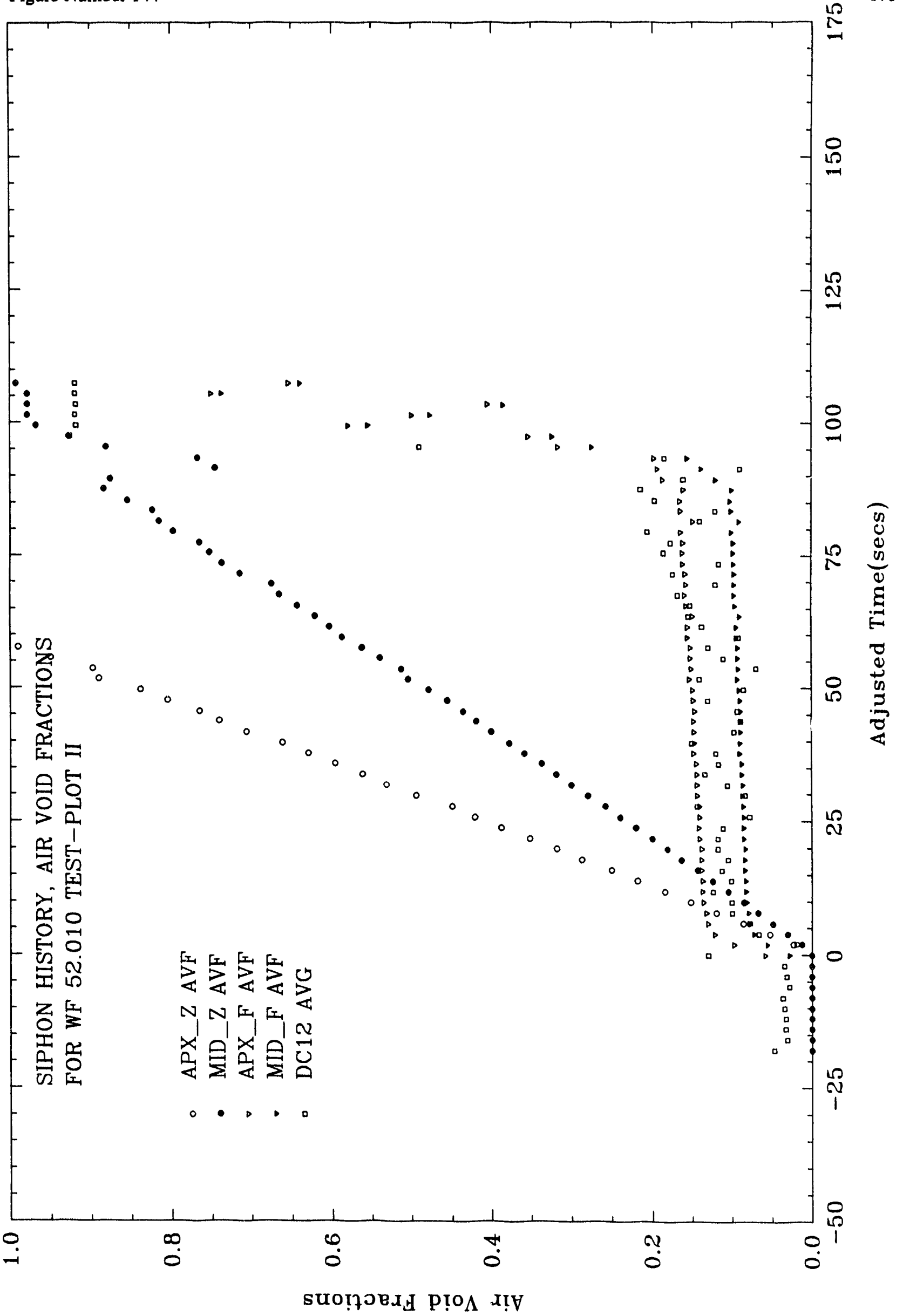




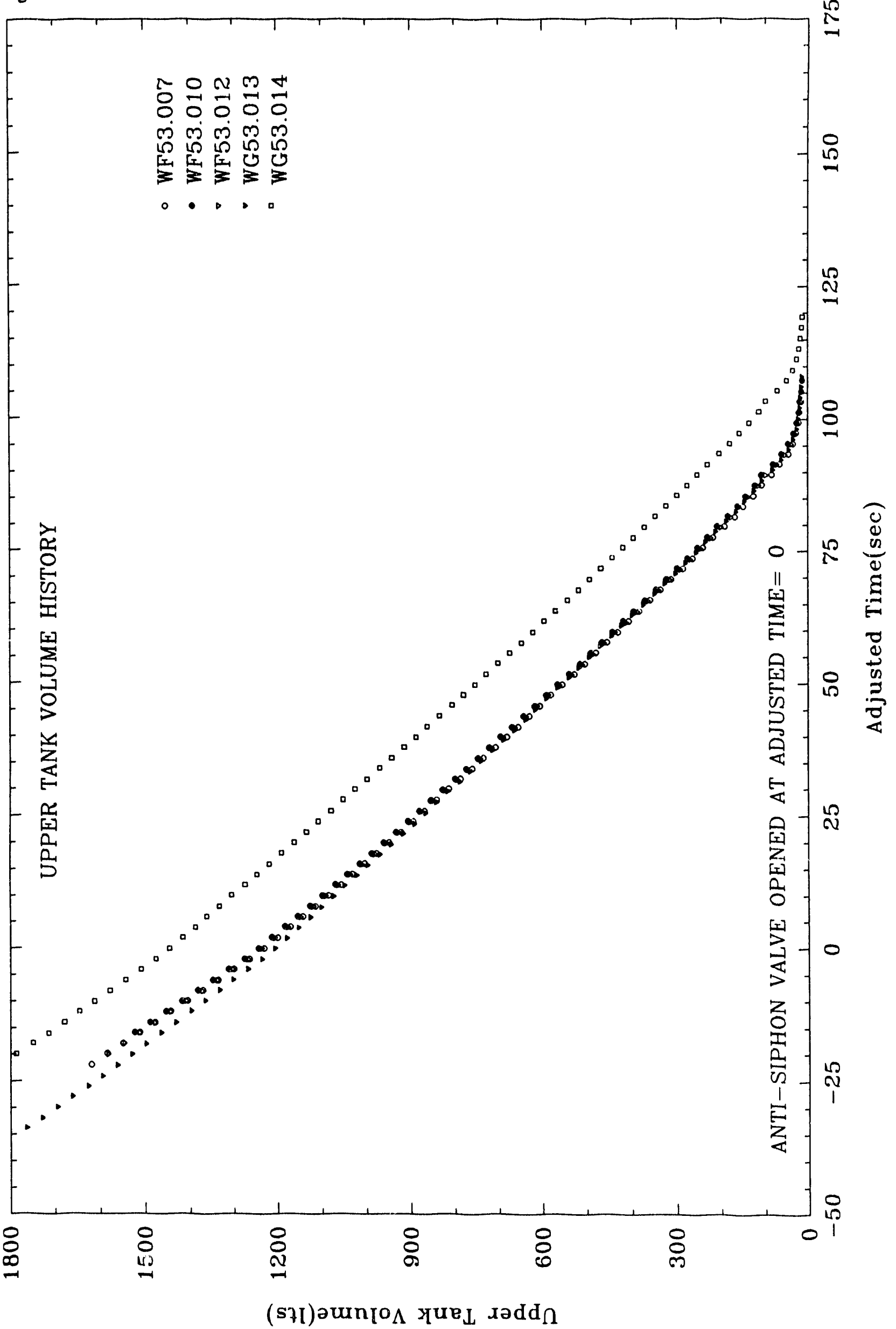




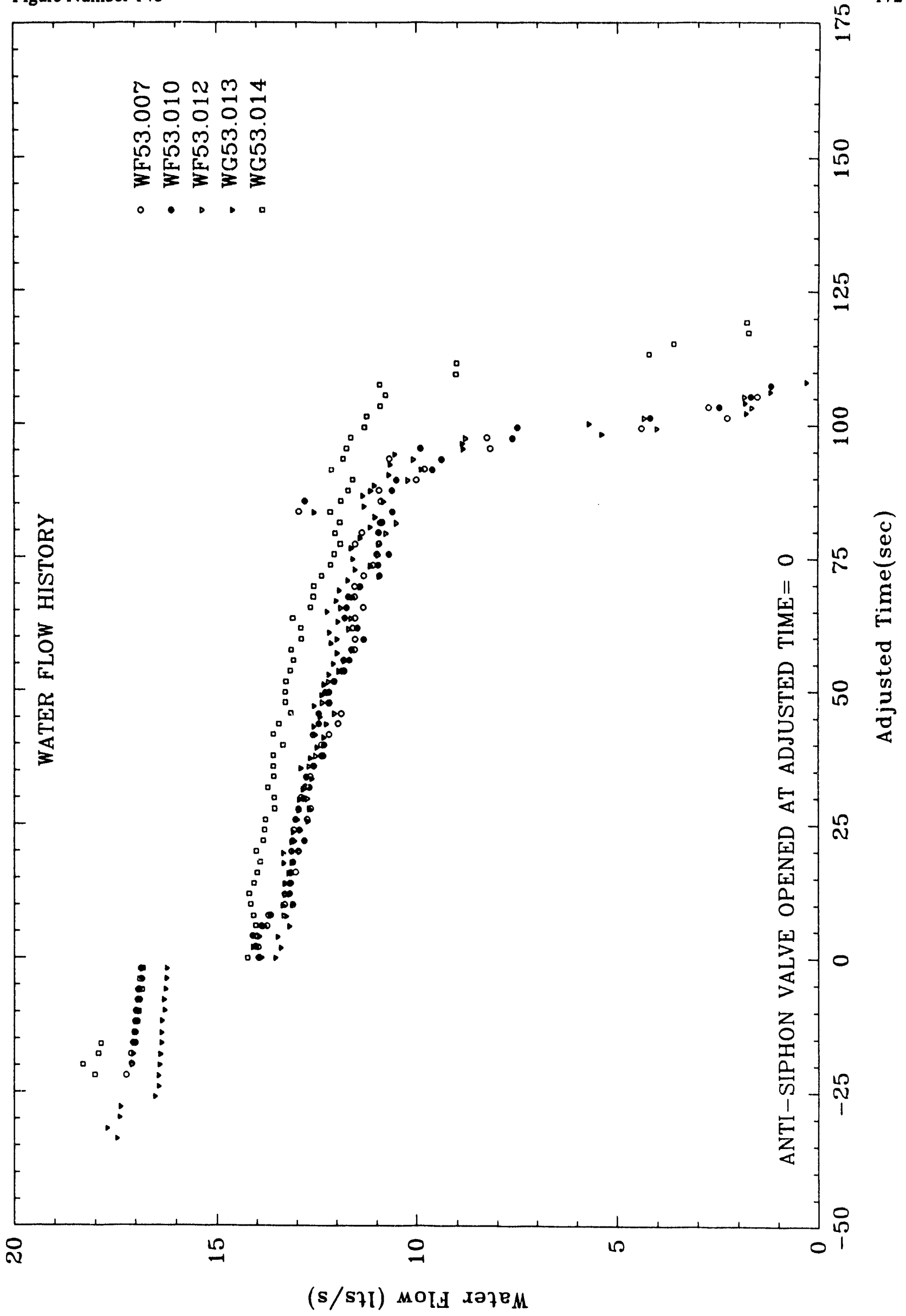




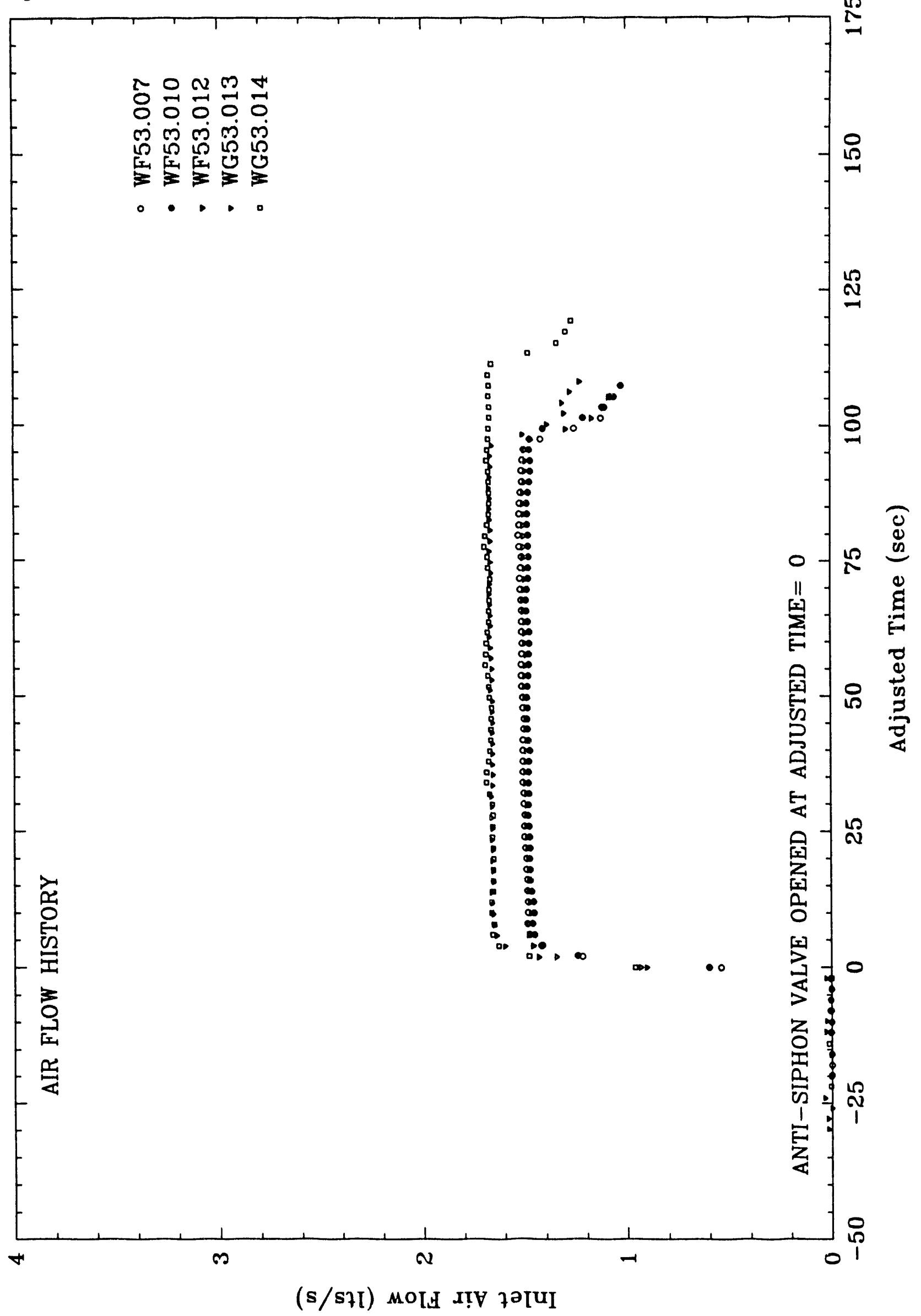




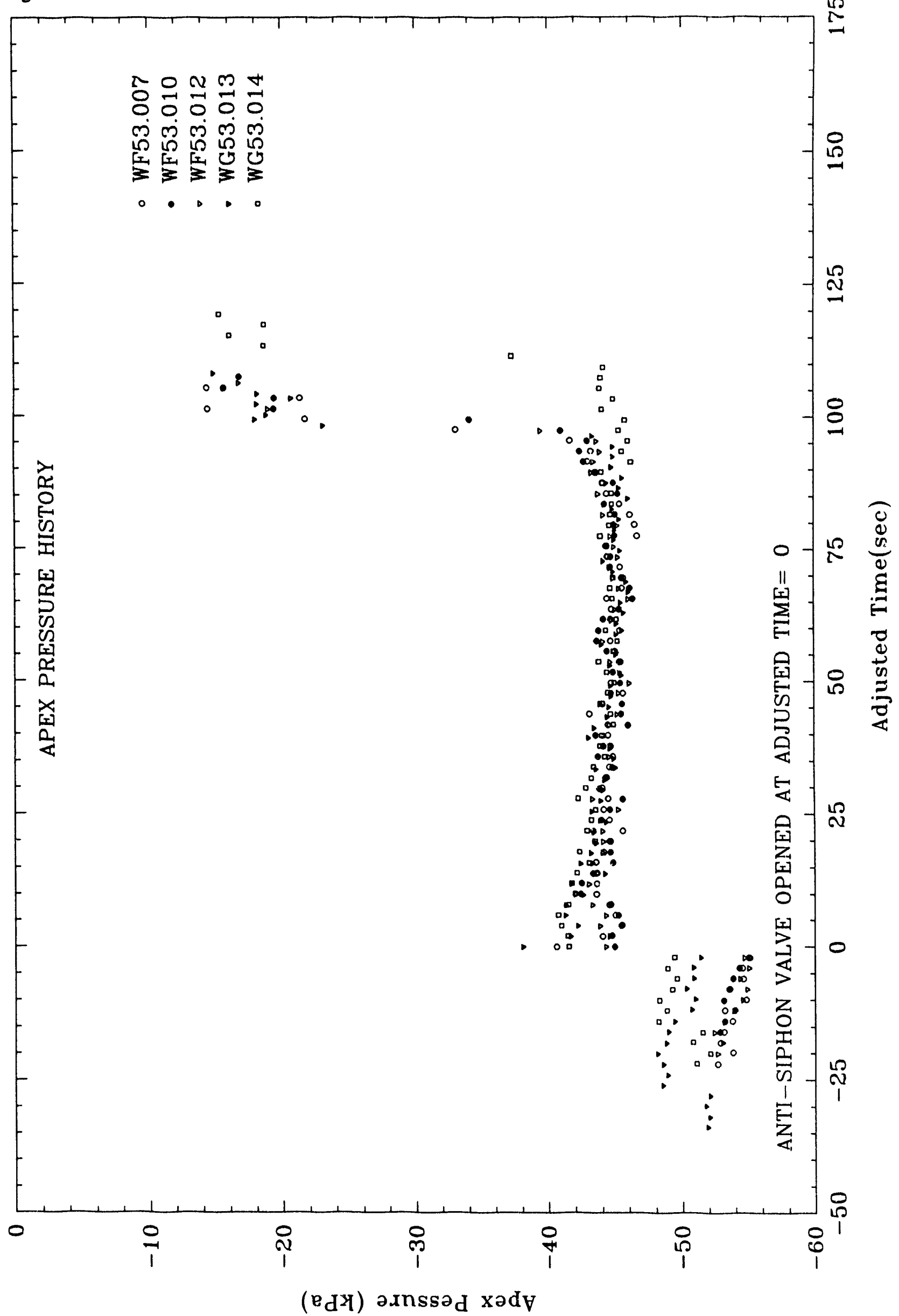


Figure Number 149

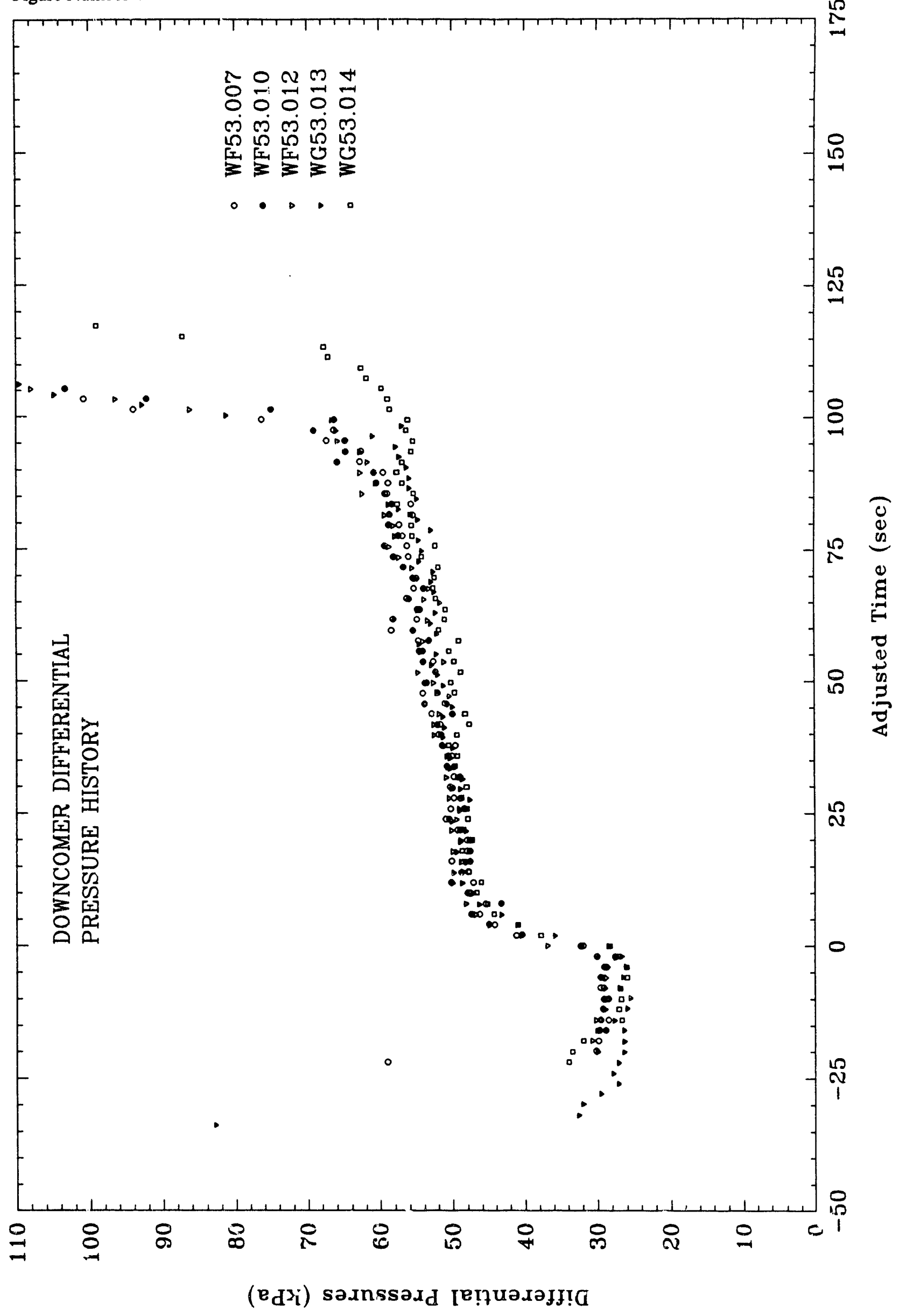




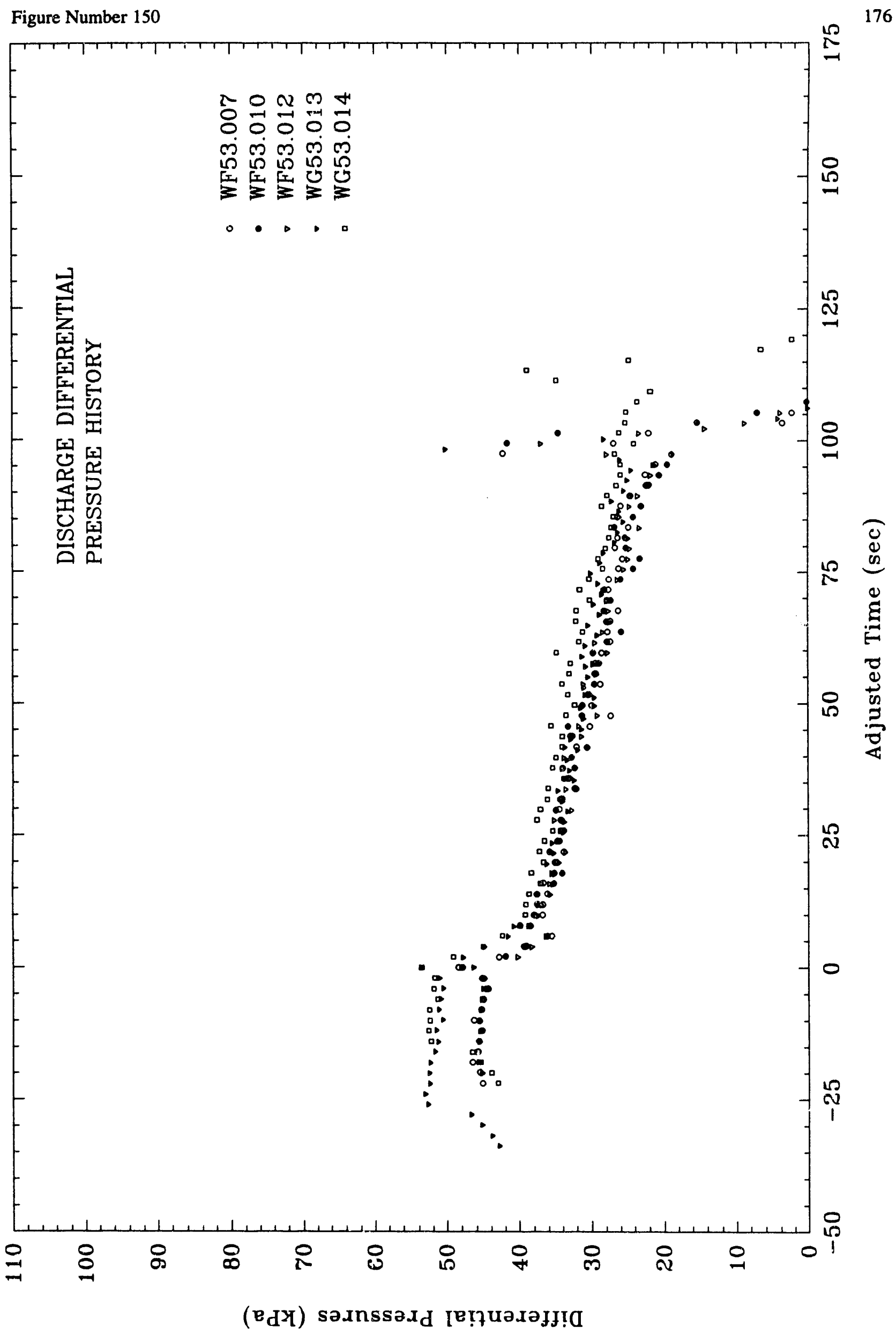




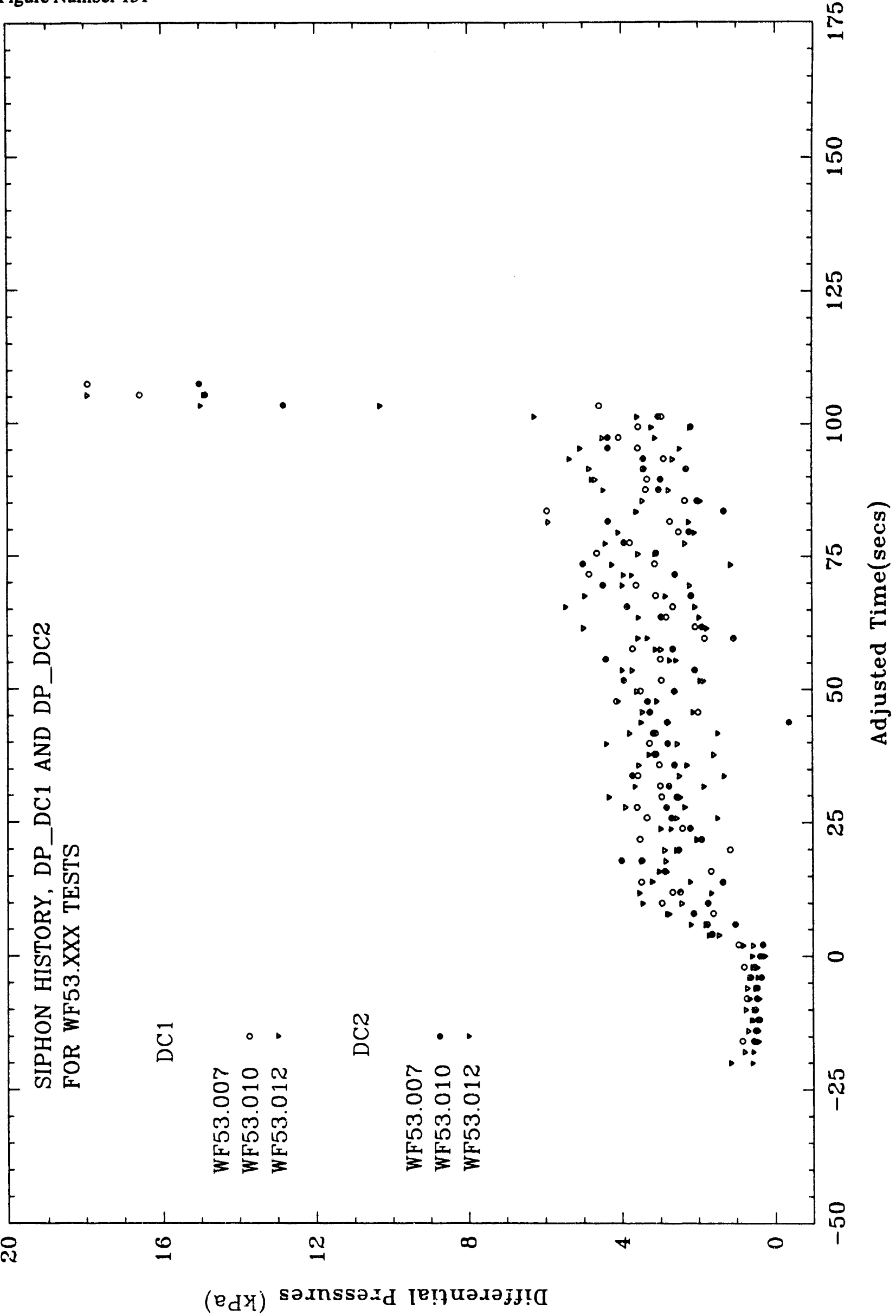




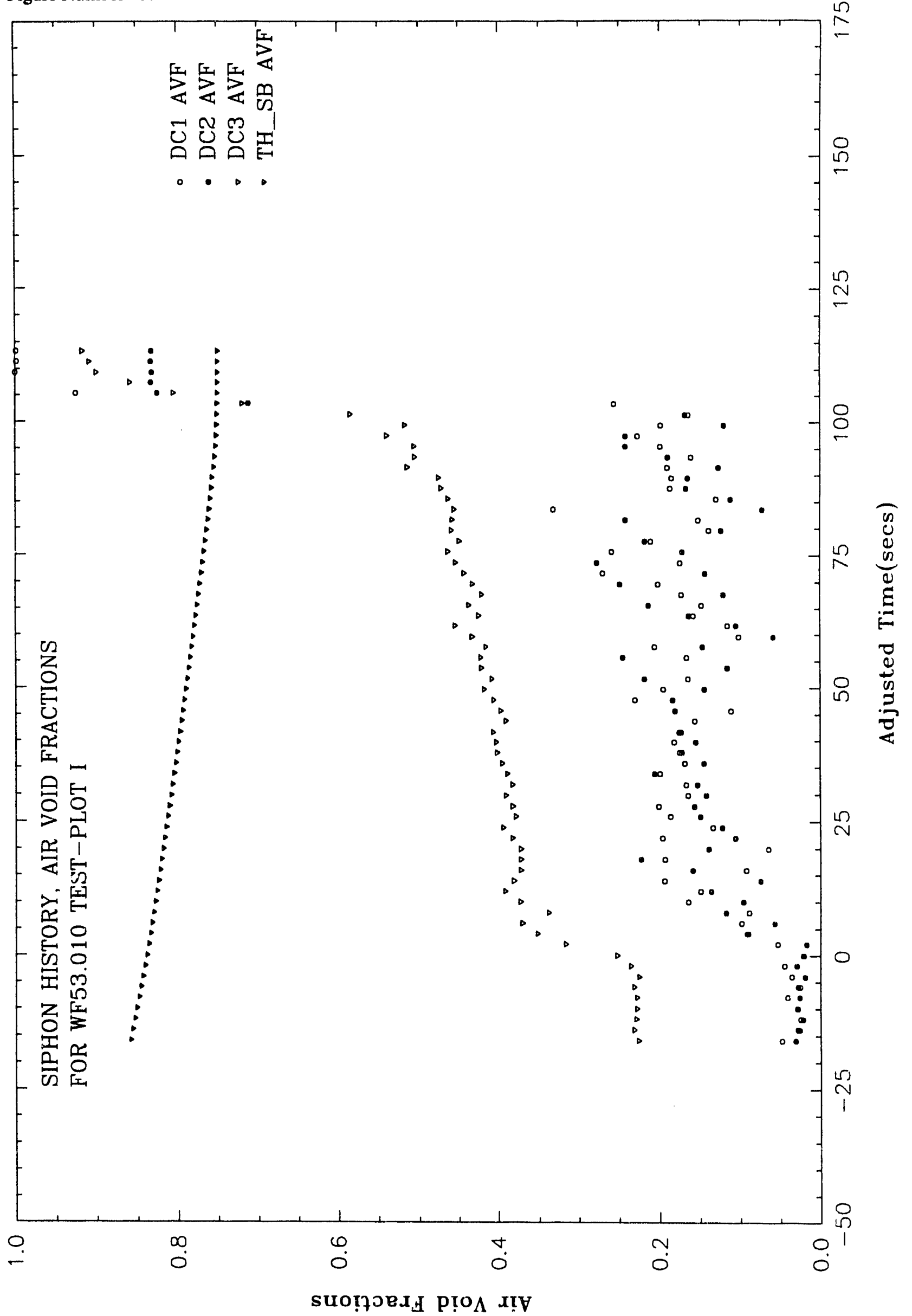




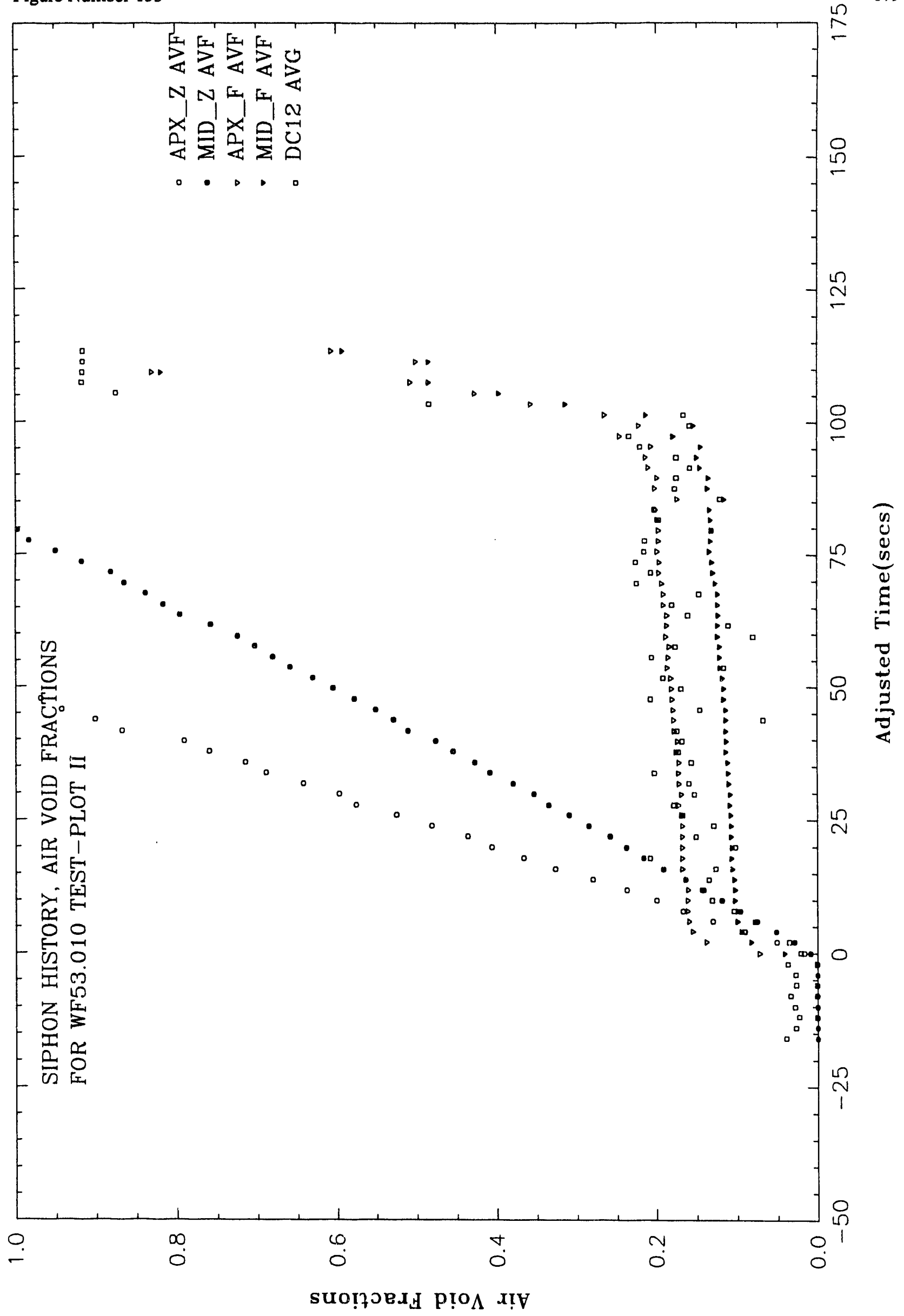




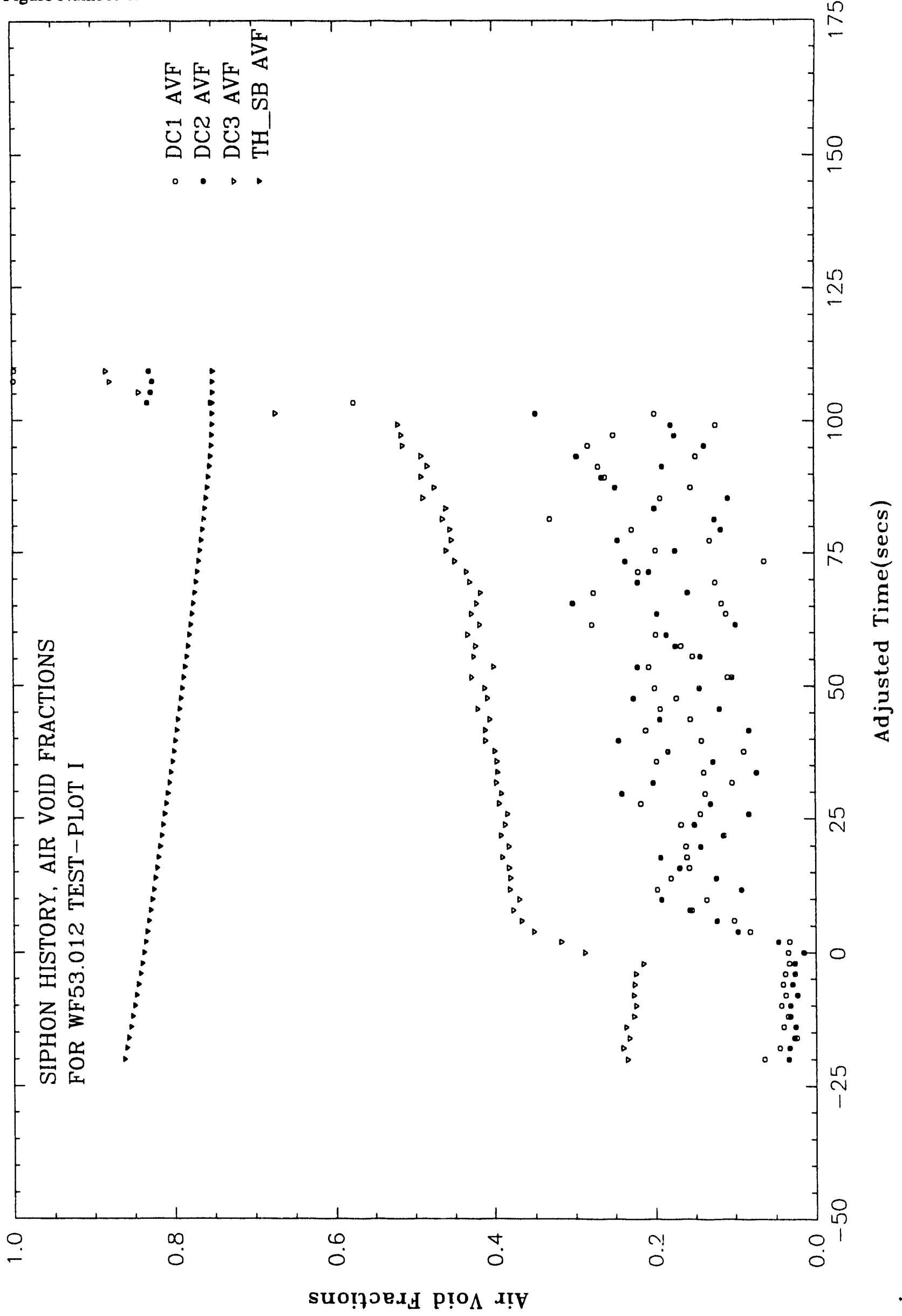




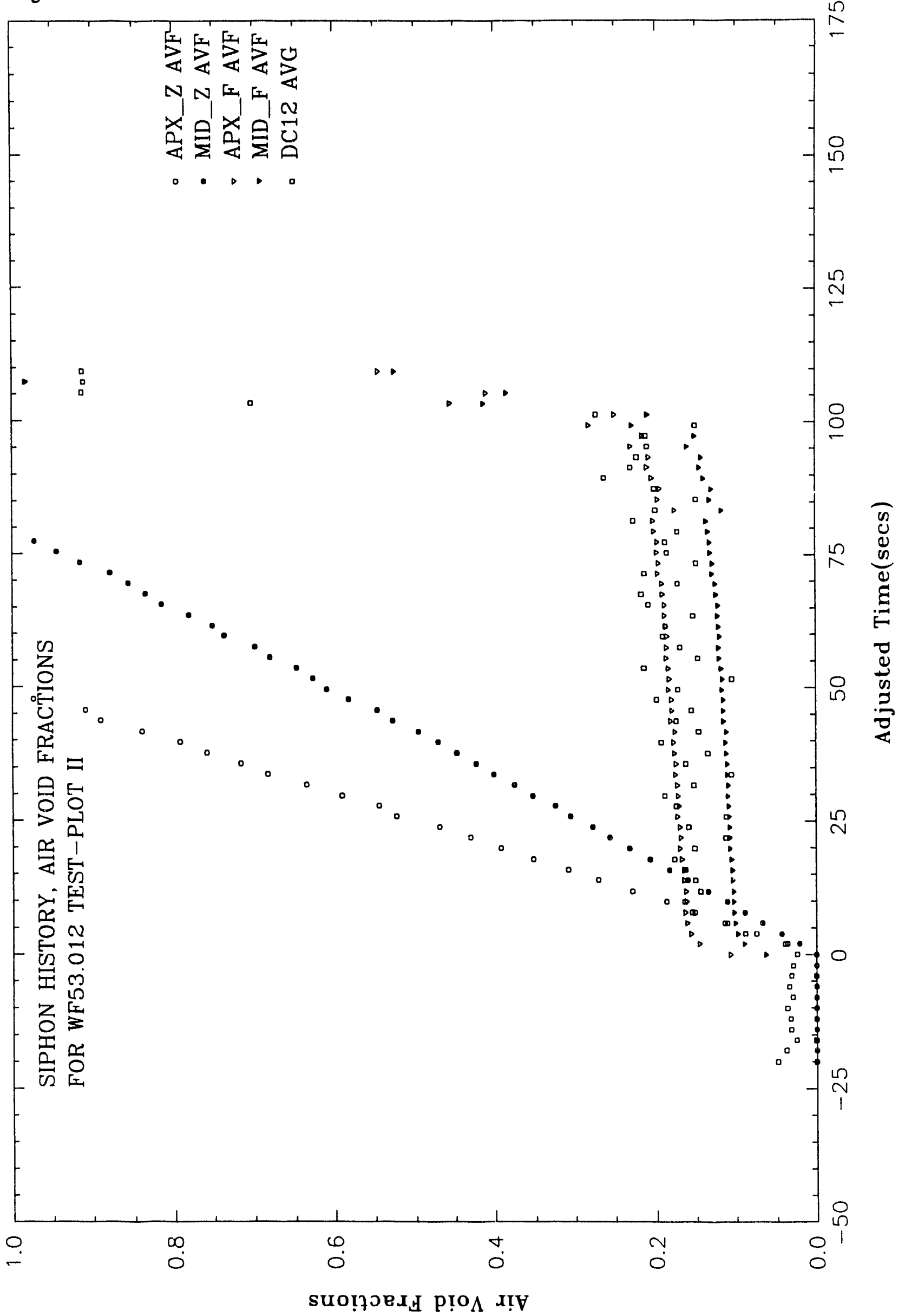




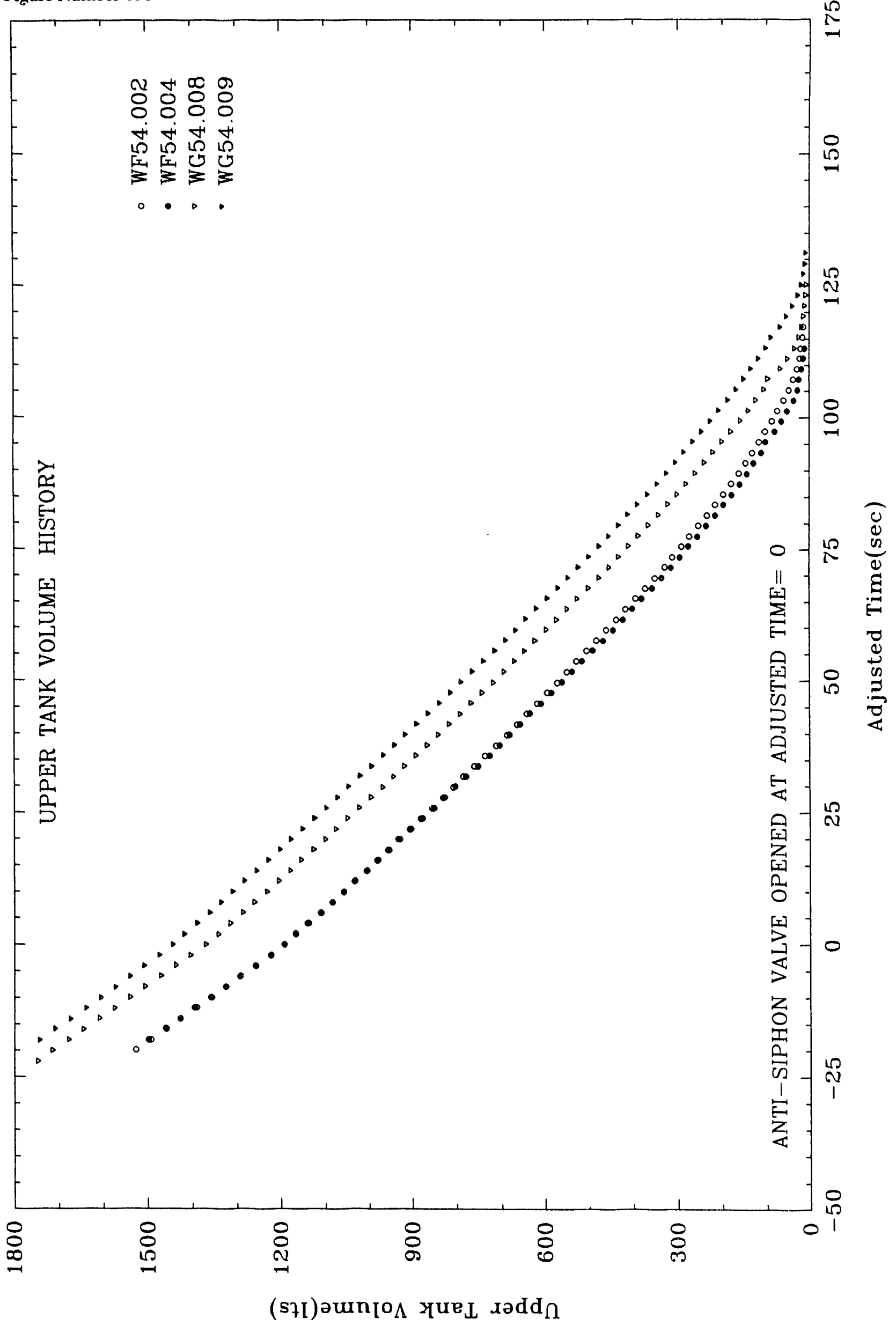


Figure Number 157

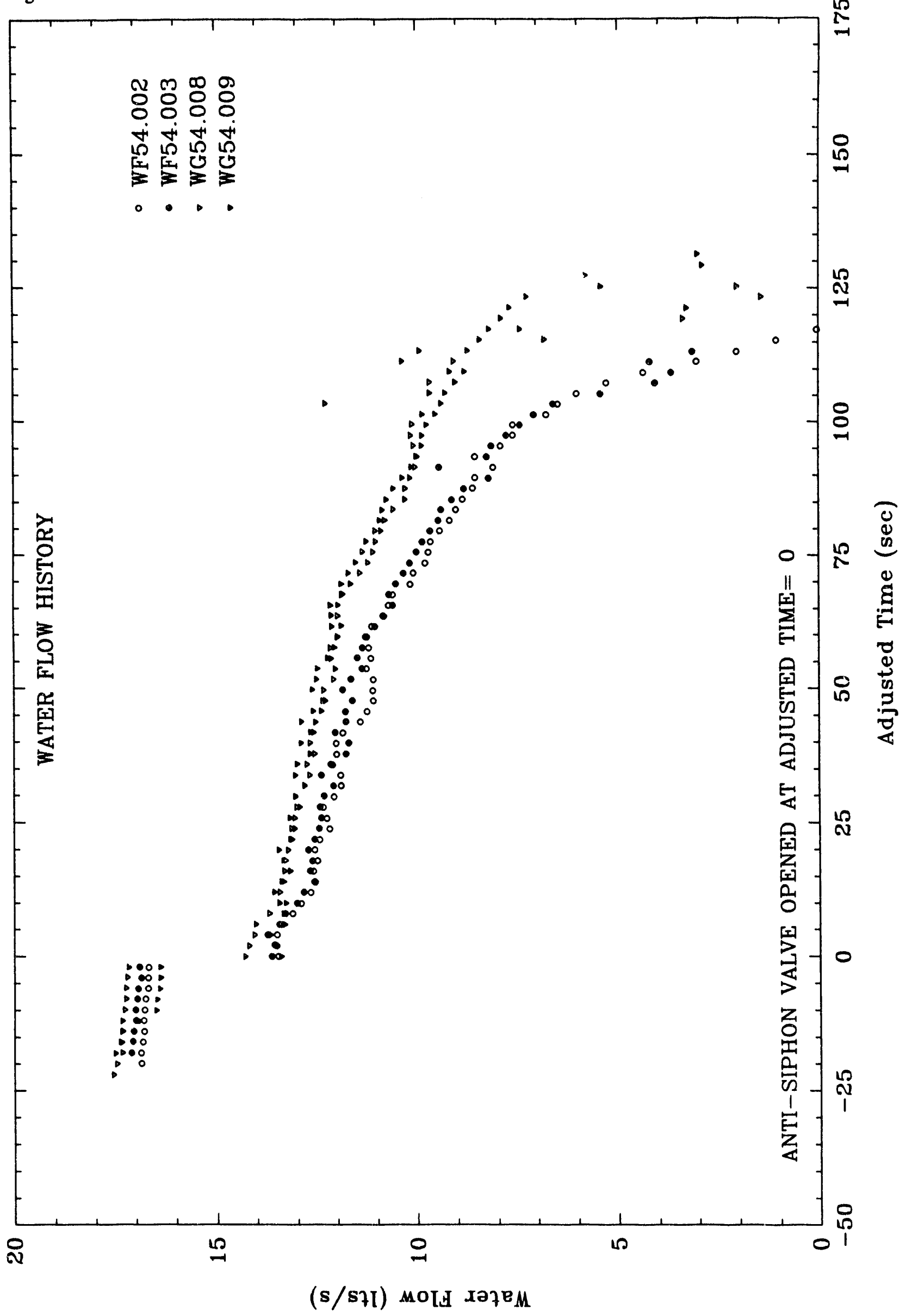




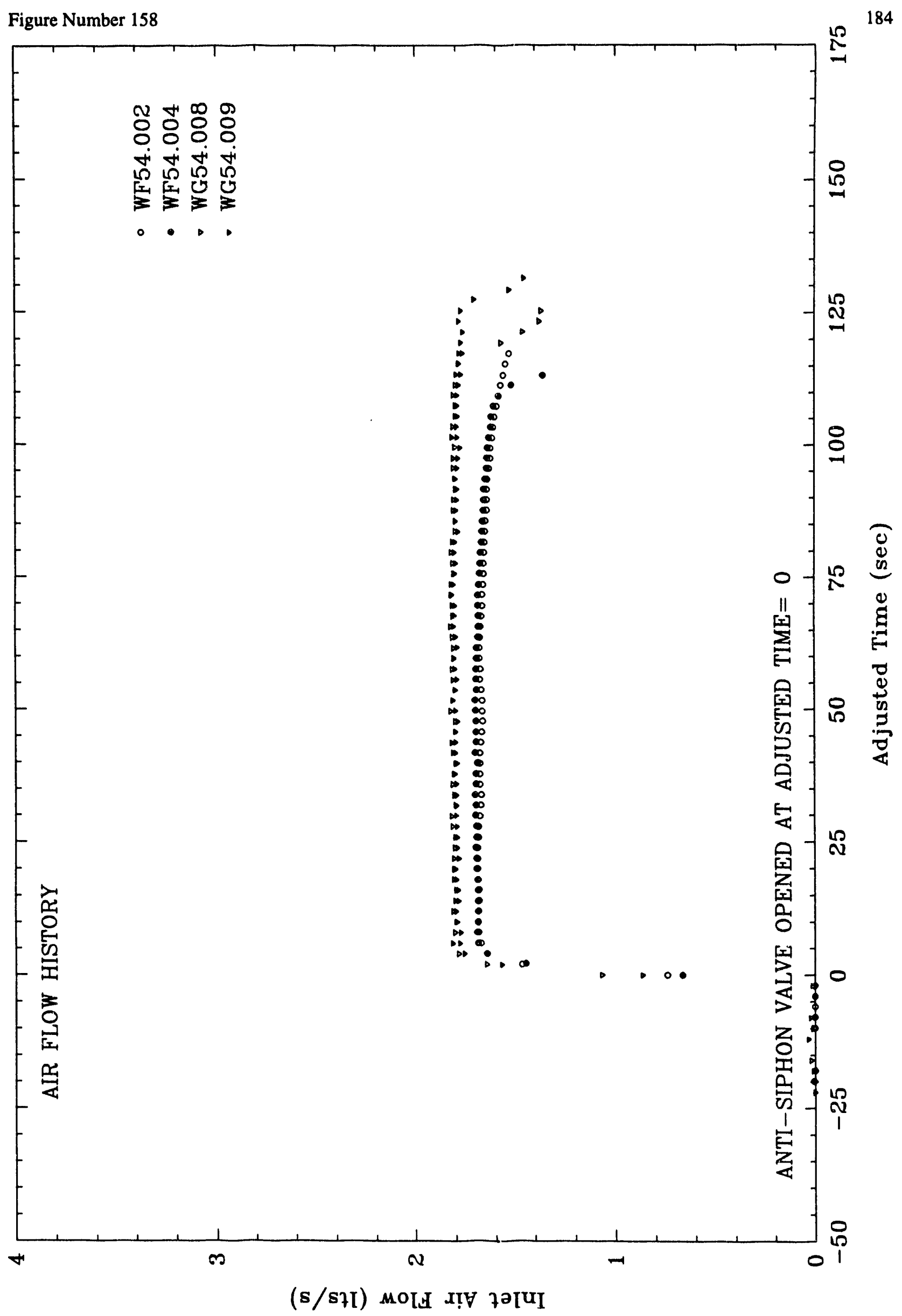




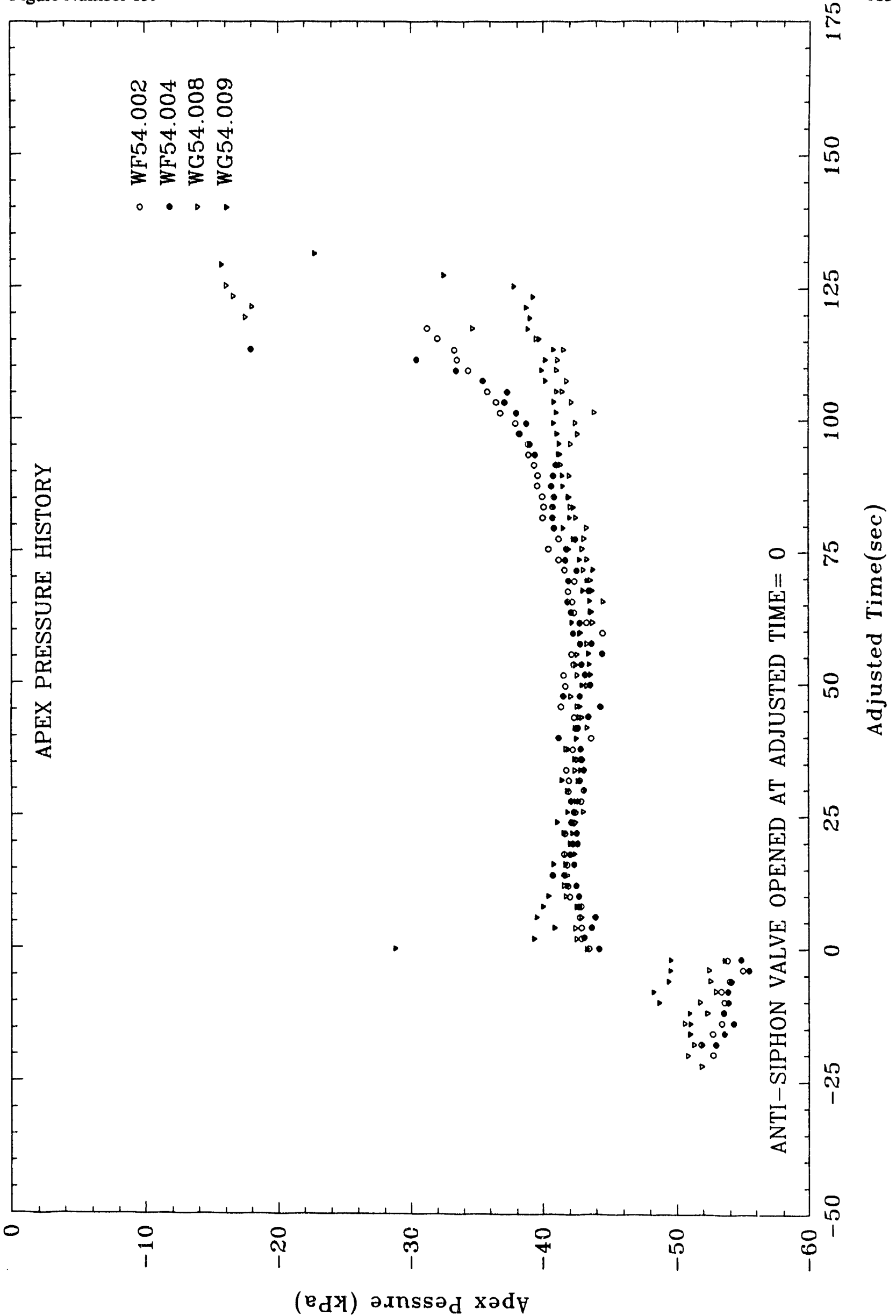




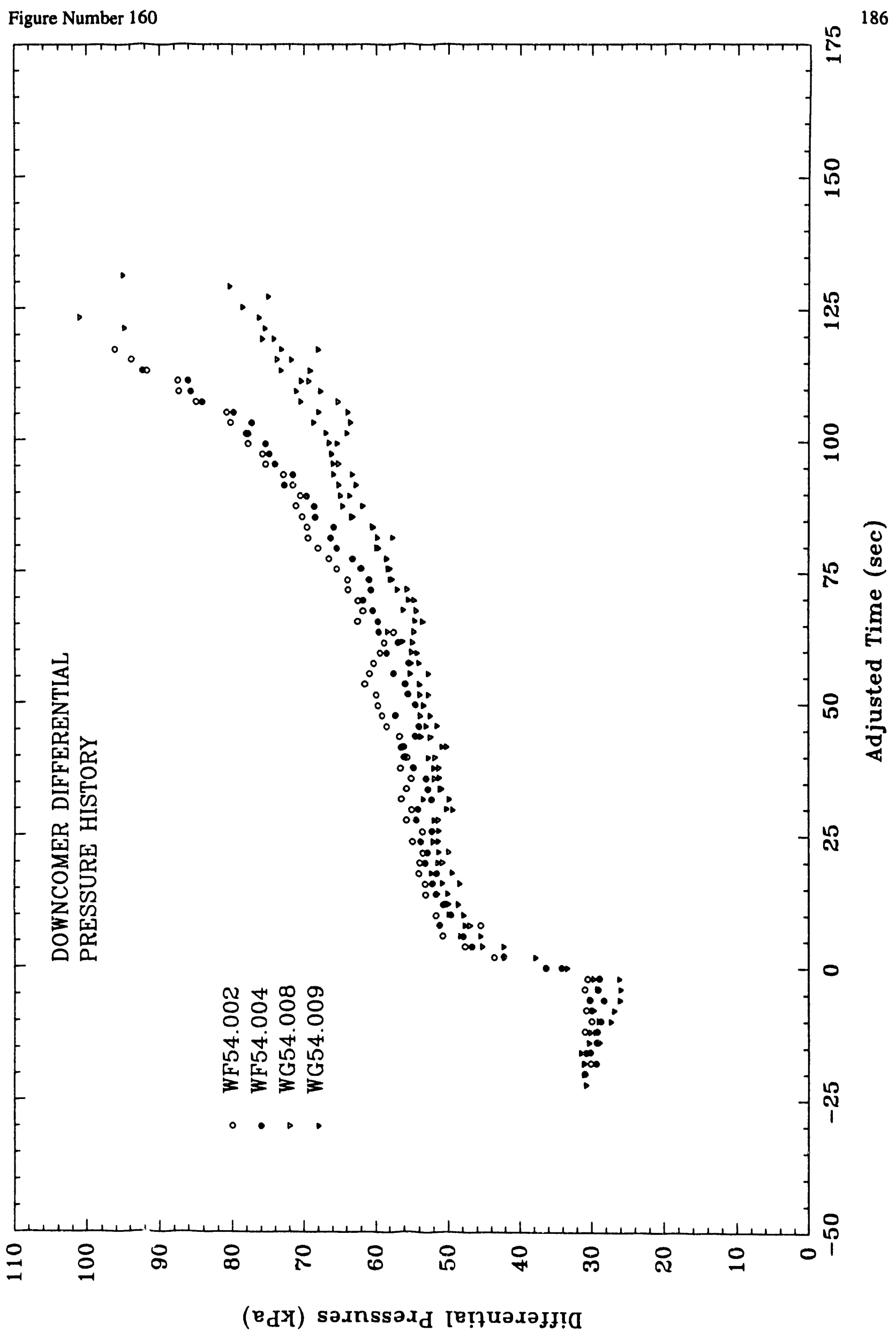




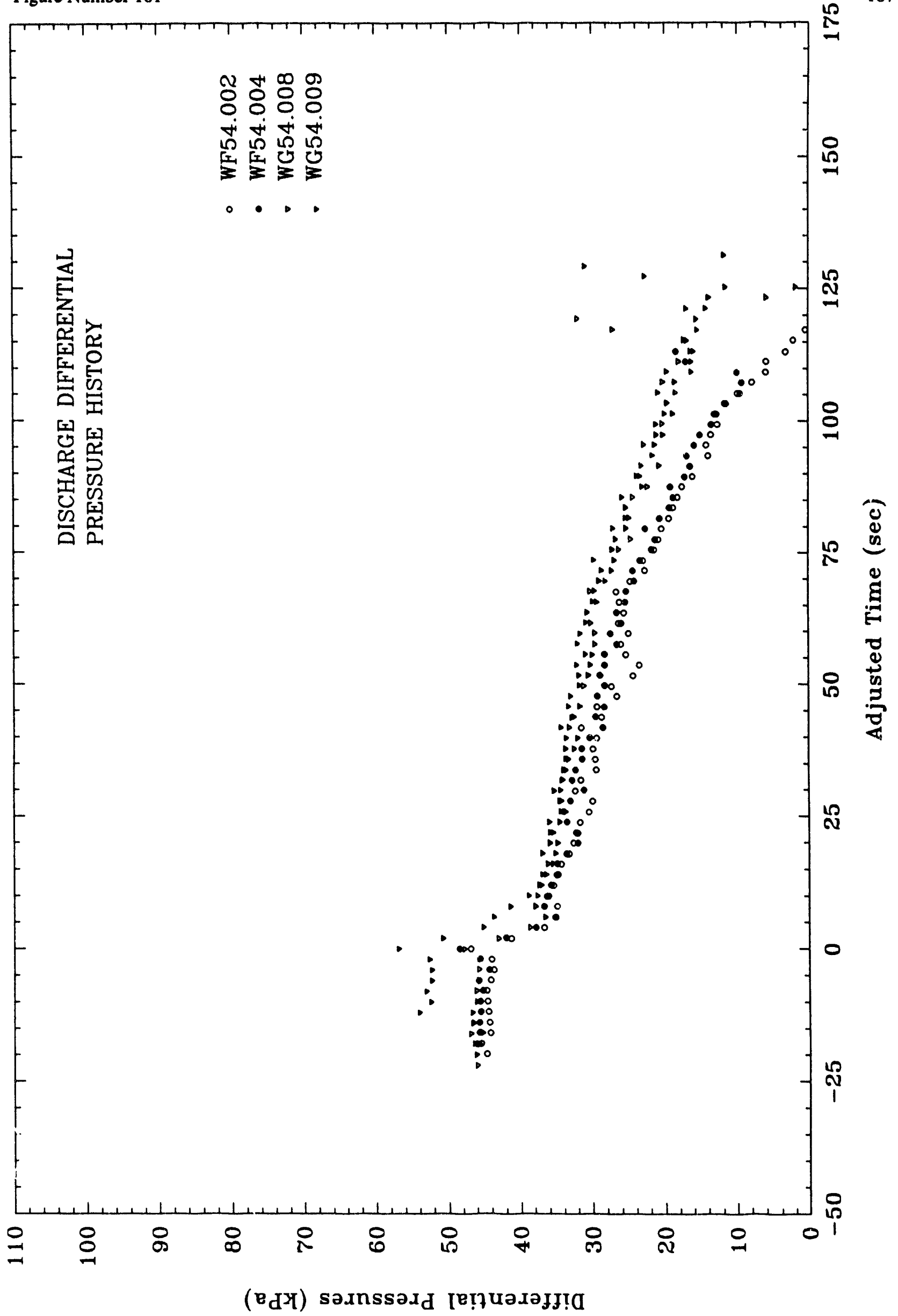




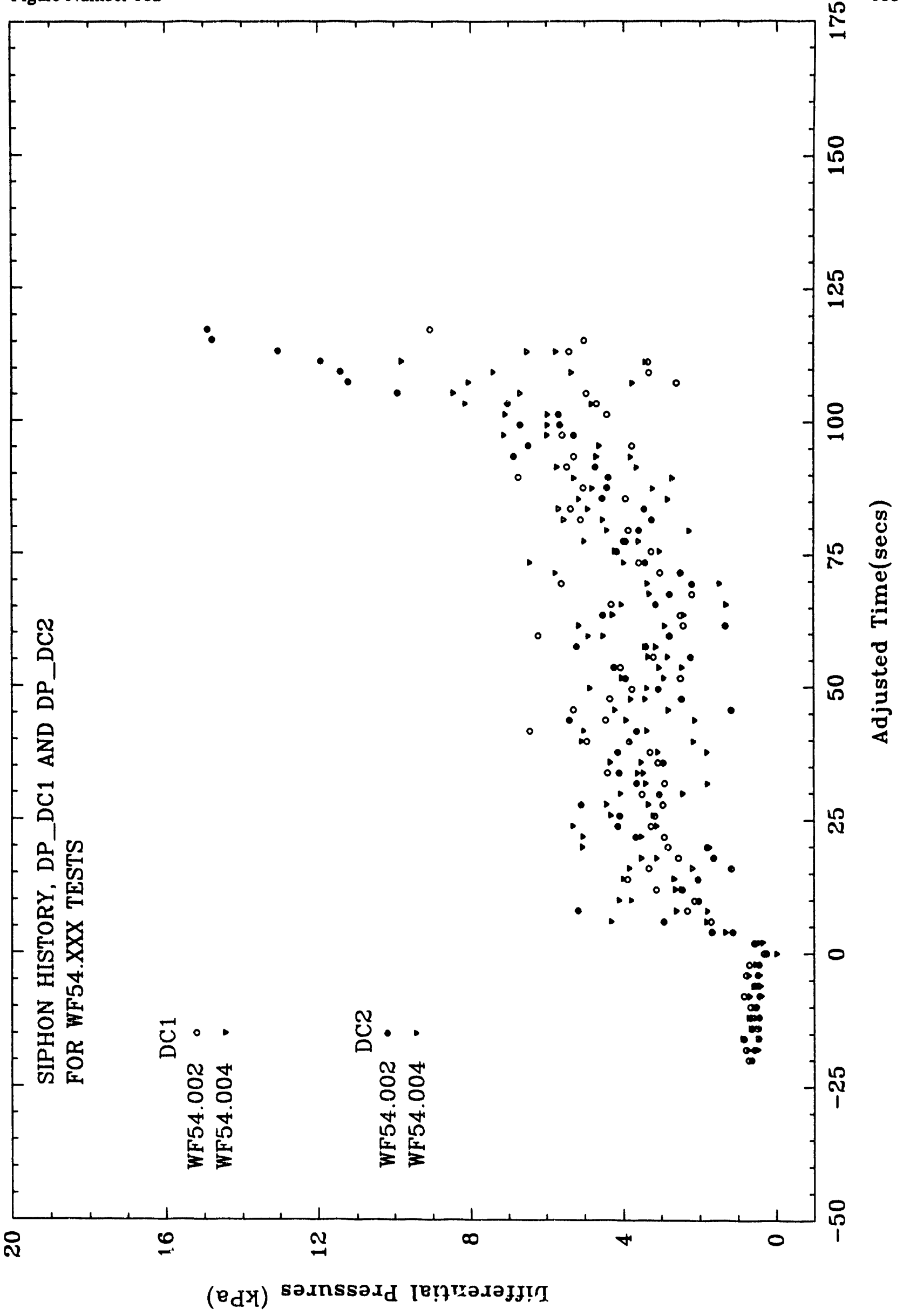




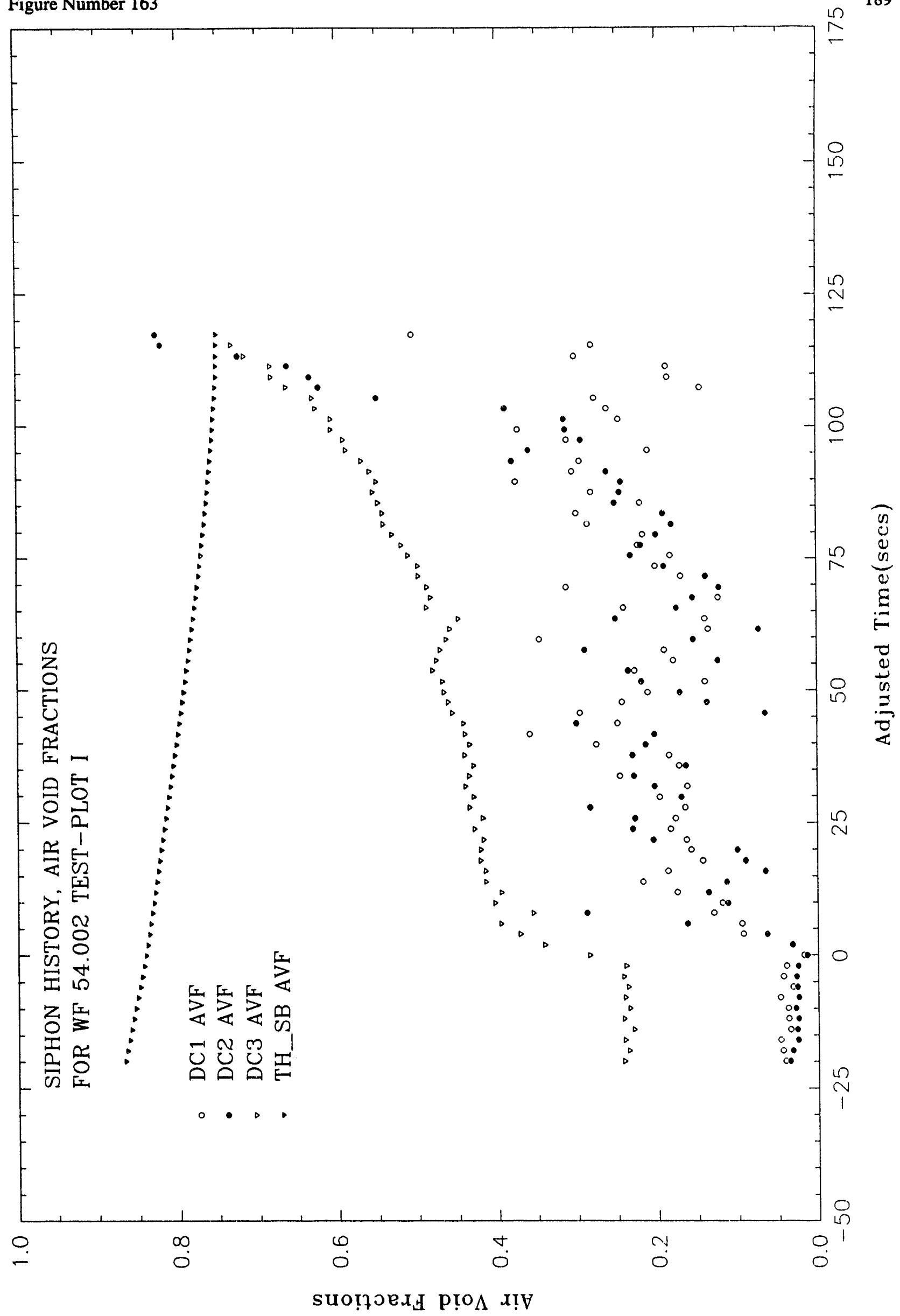


Figure Number 164

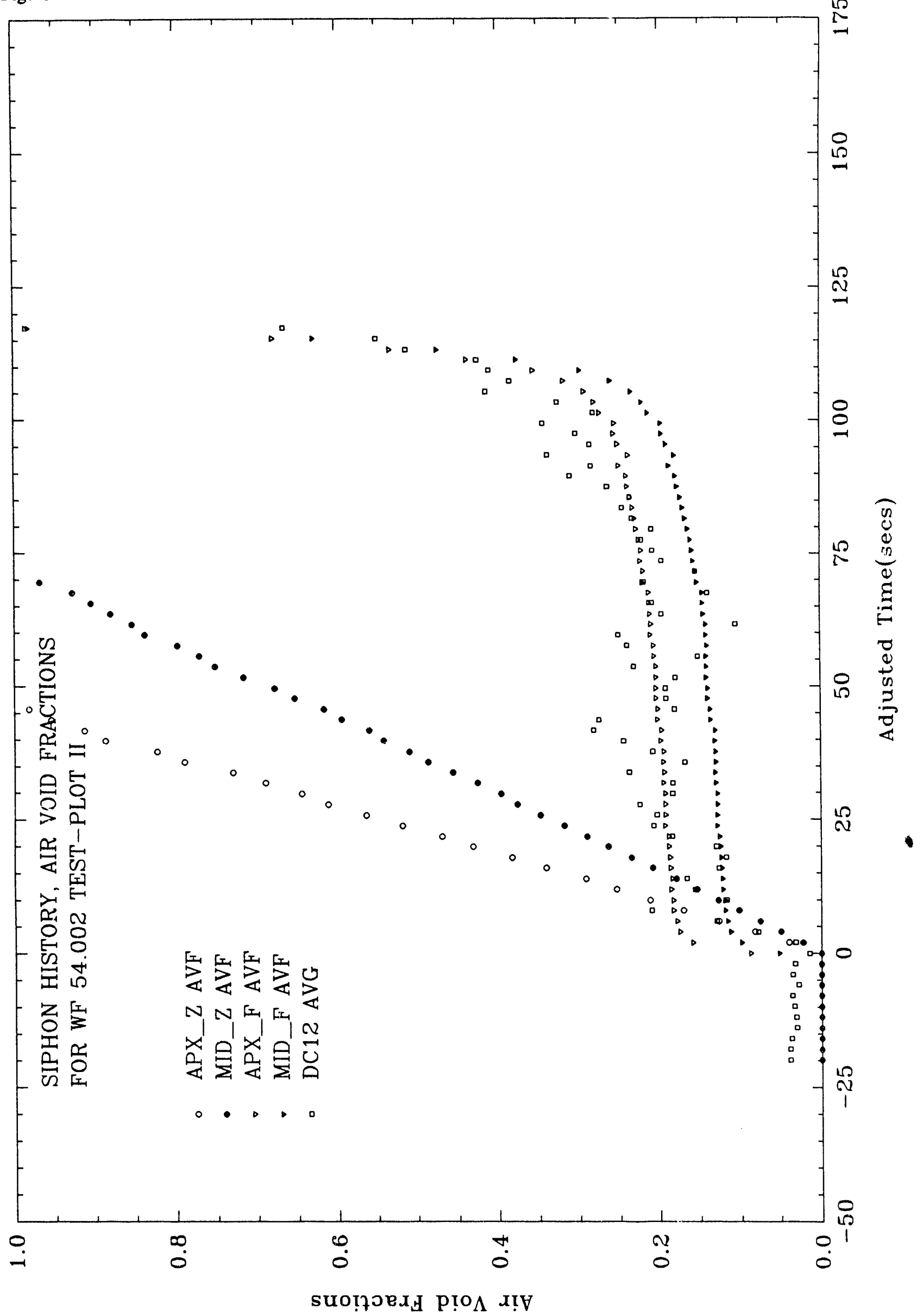




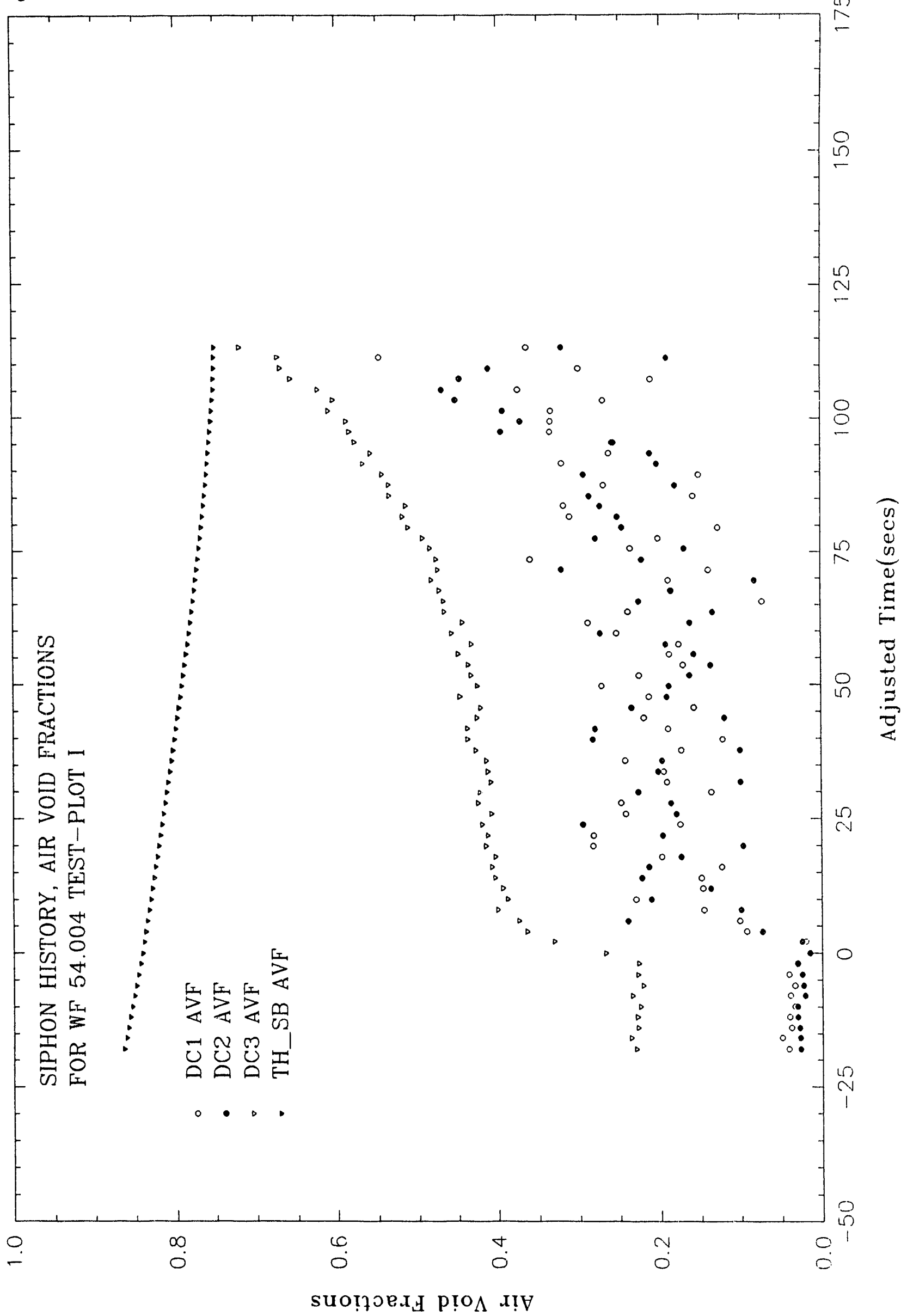




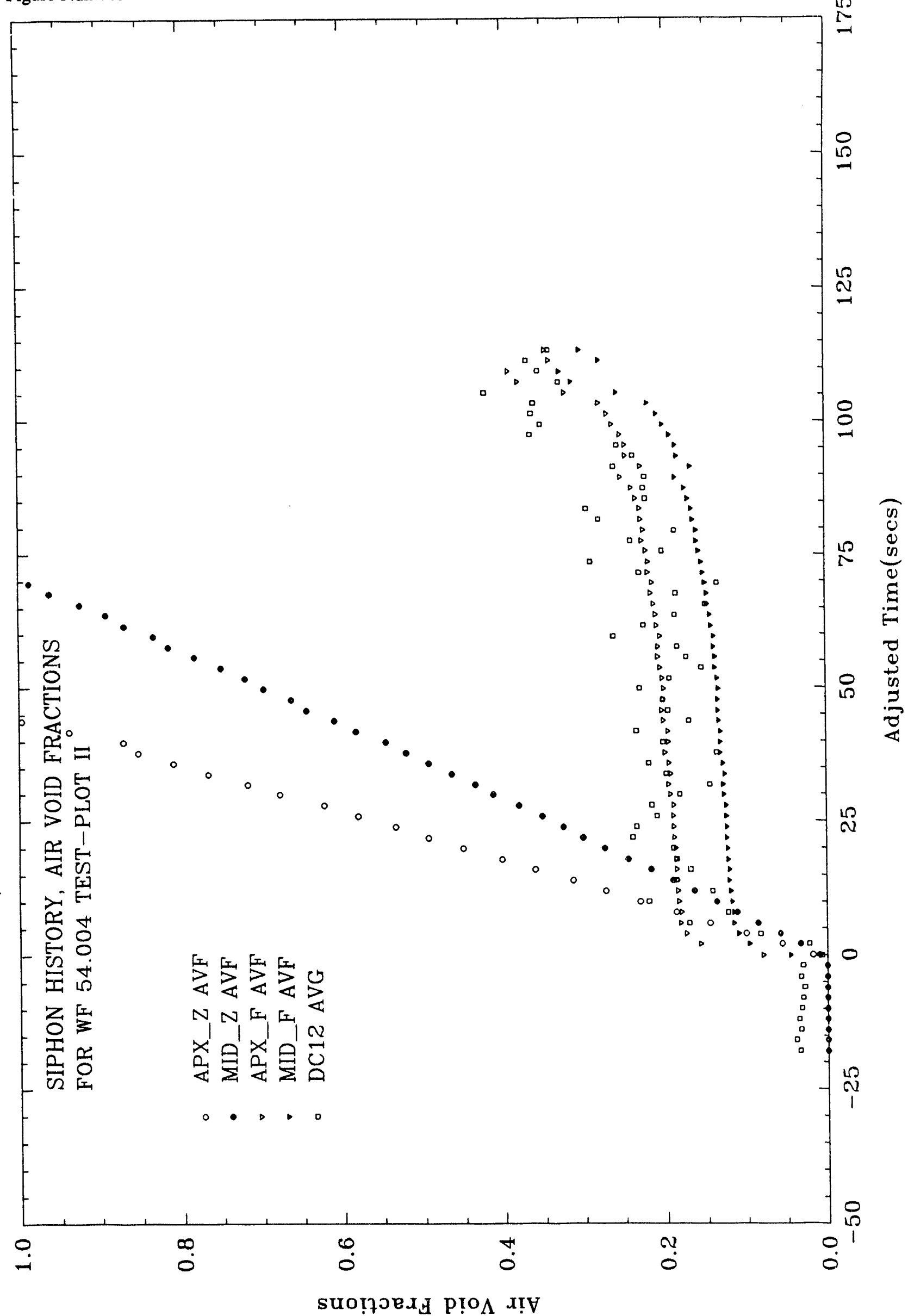




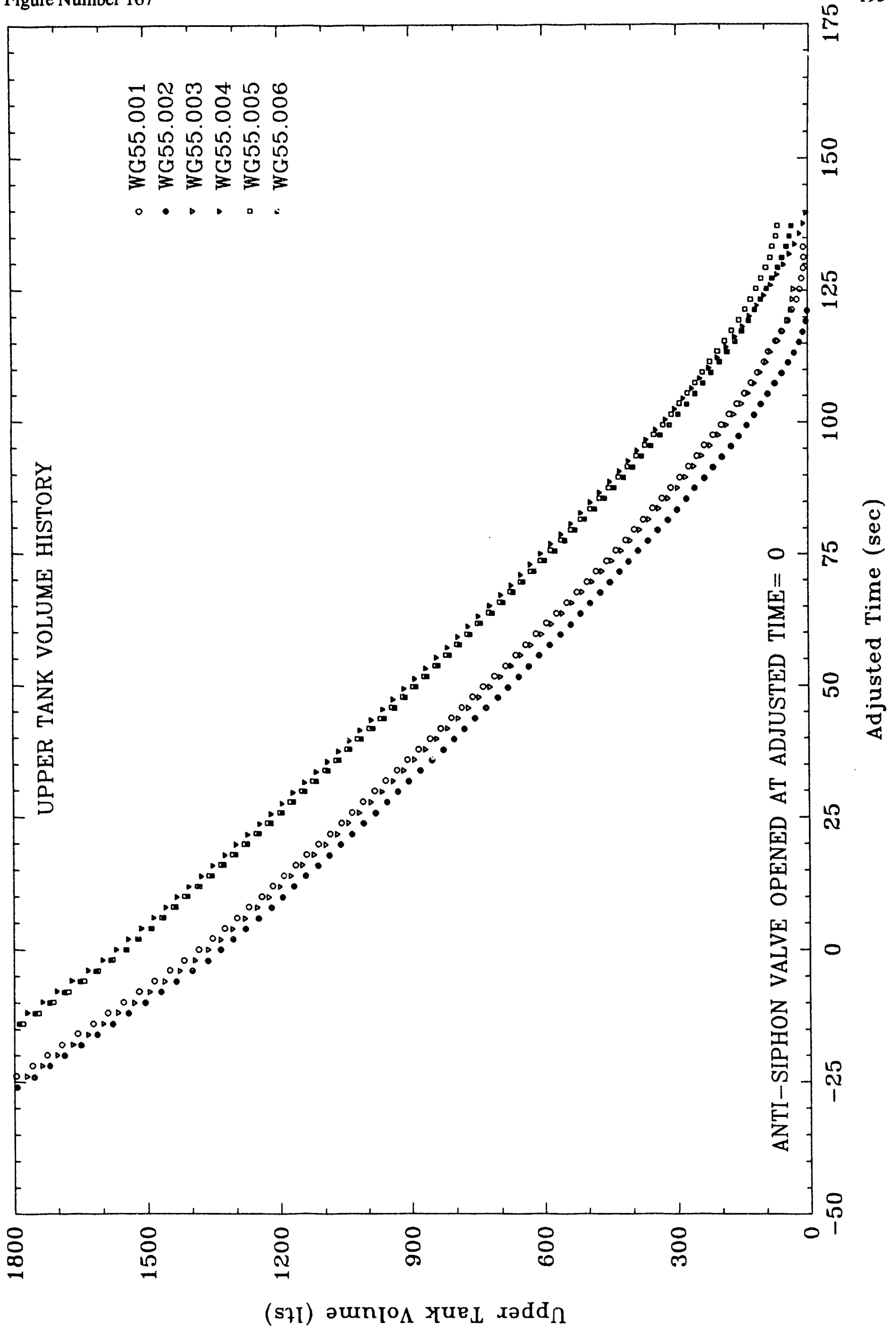




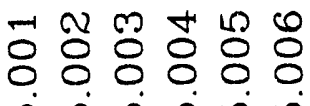

م

L 10 م

引

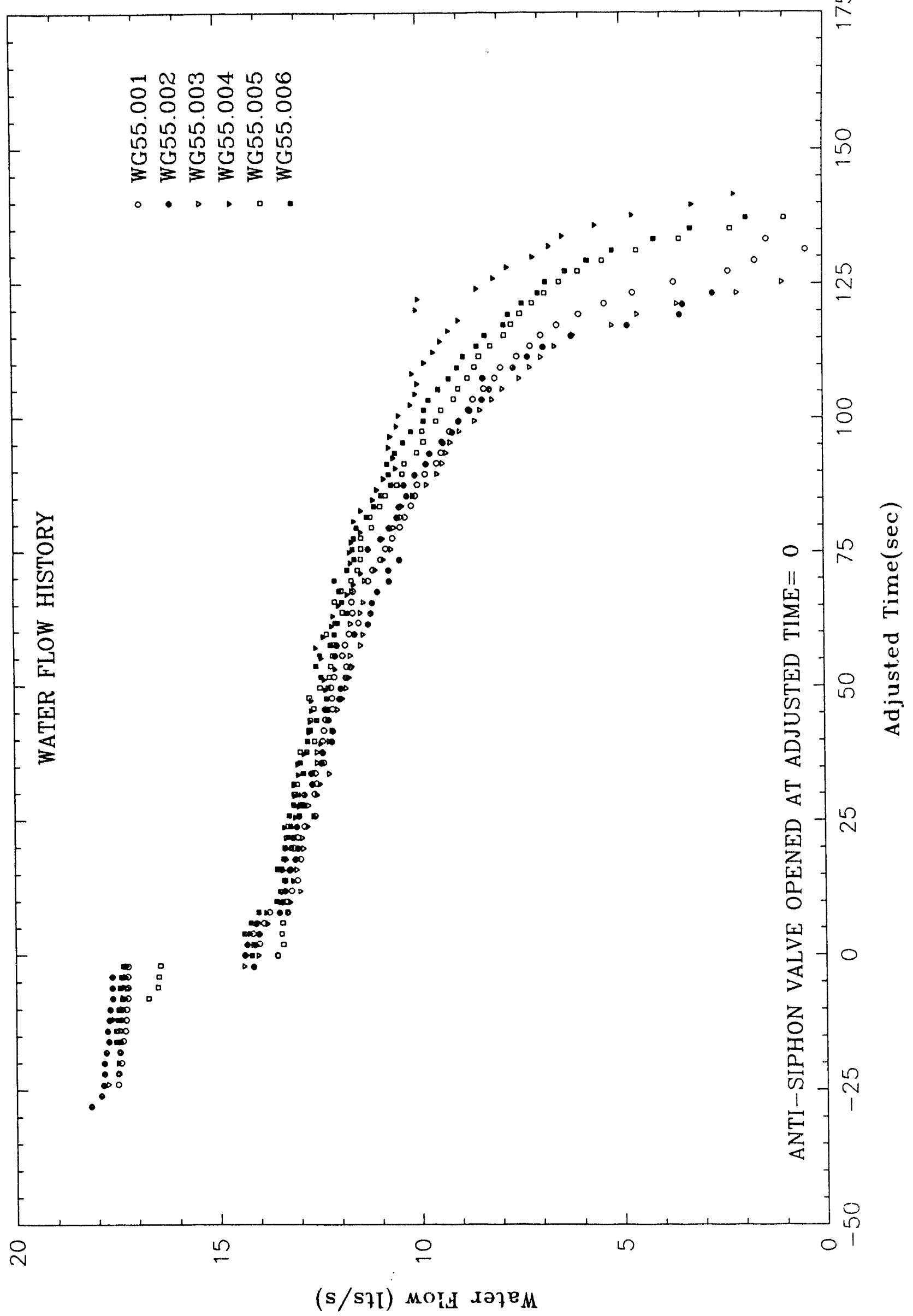


Figure Number 169

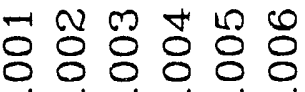

من

ก ถ

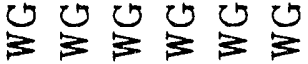

3

$\circ . D$.

3

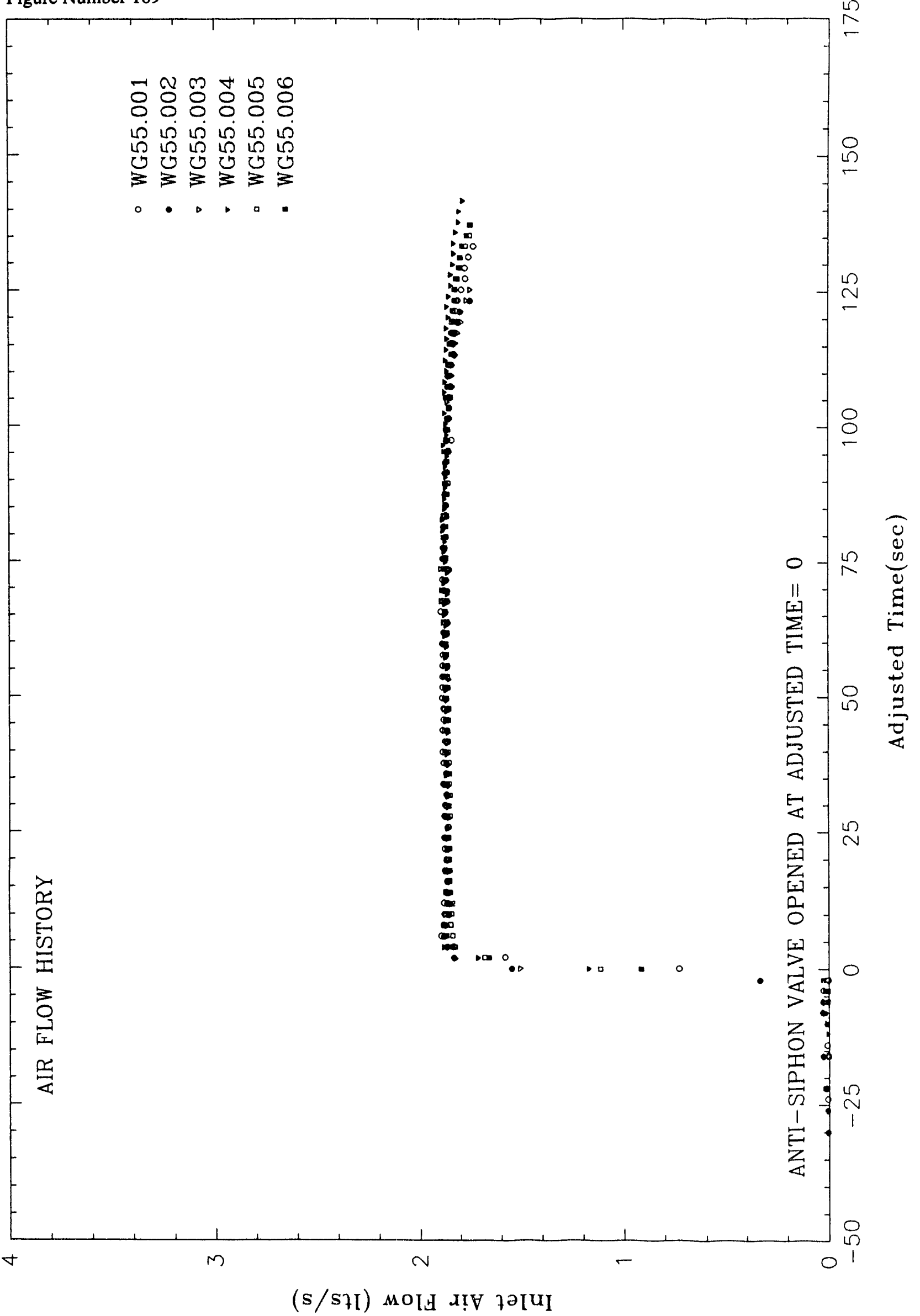

?

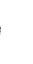


Figure Number 170

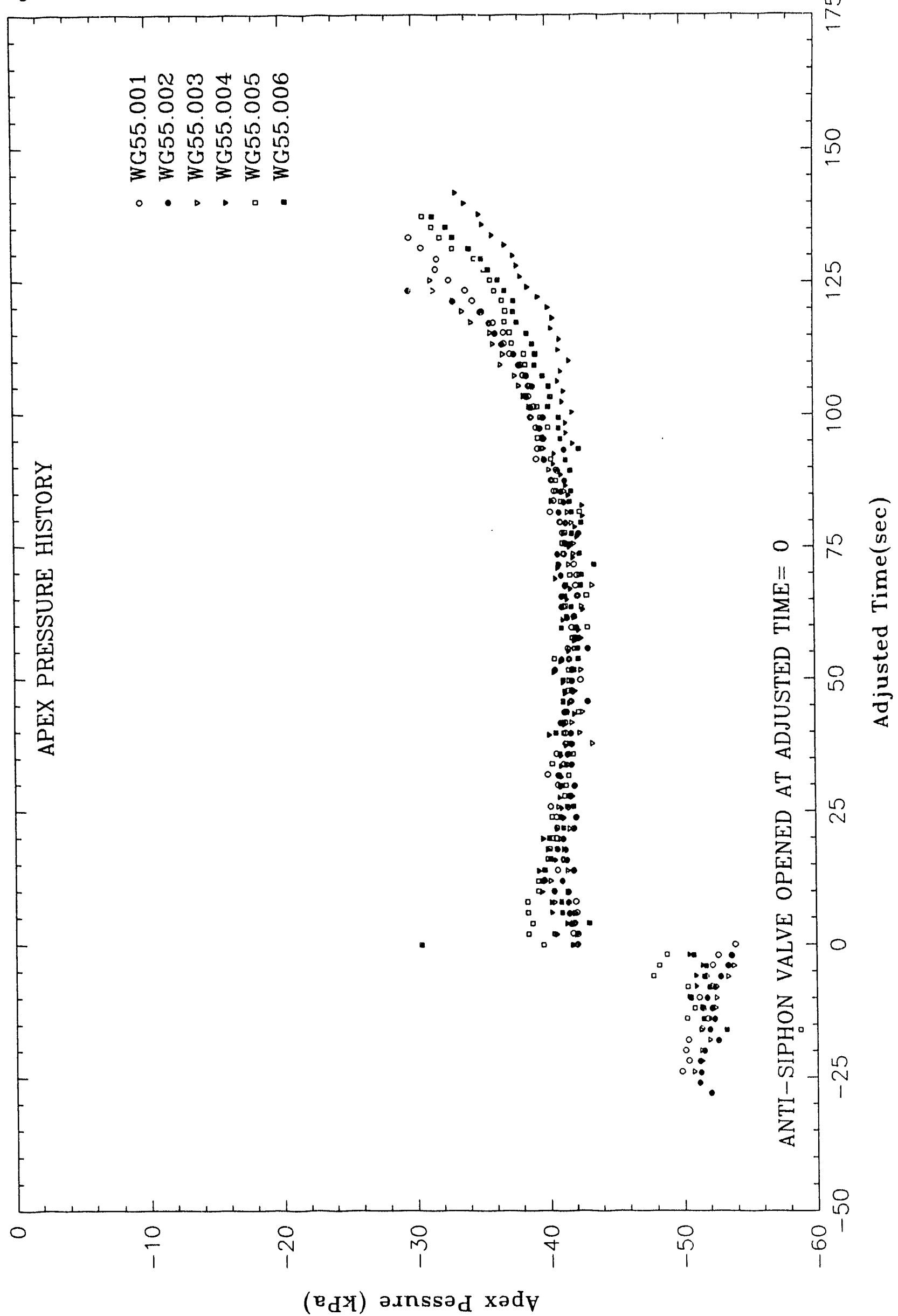




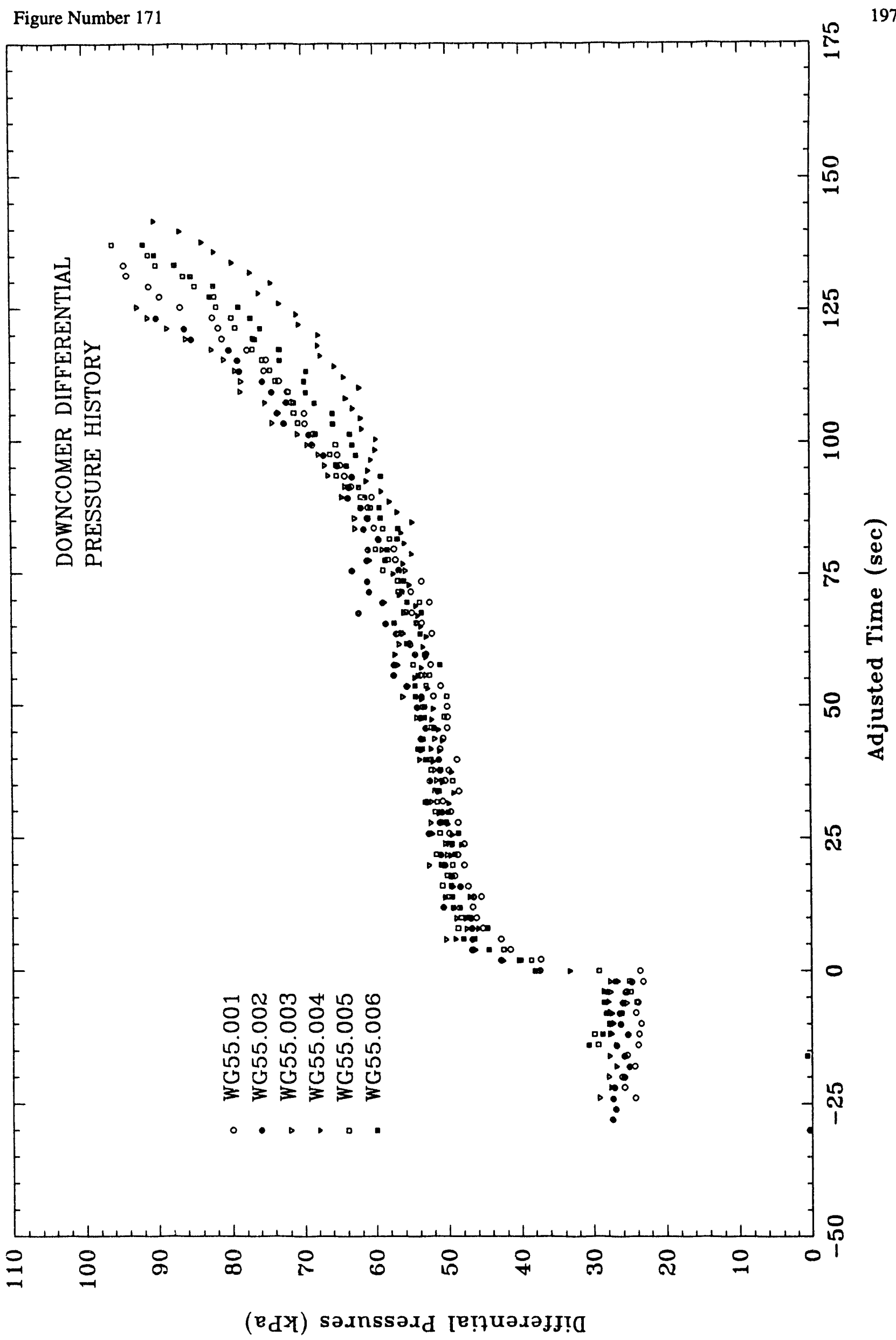


Figure Number 172

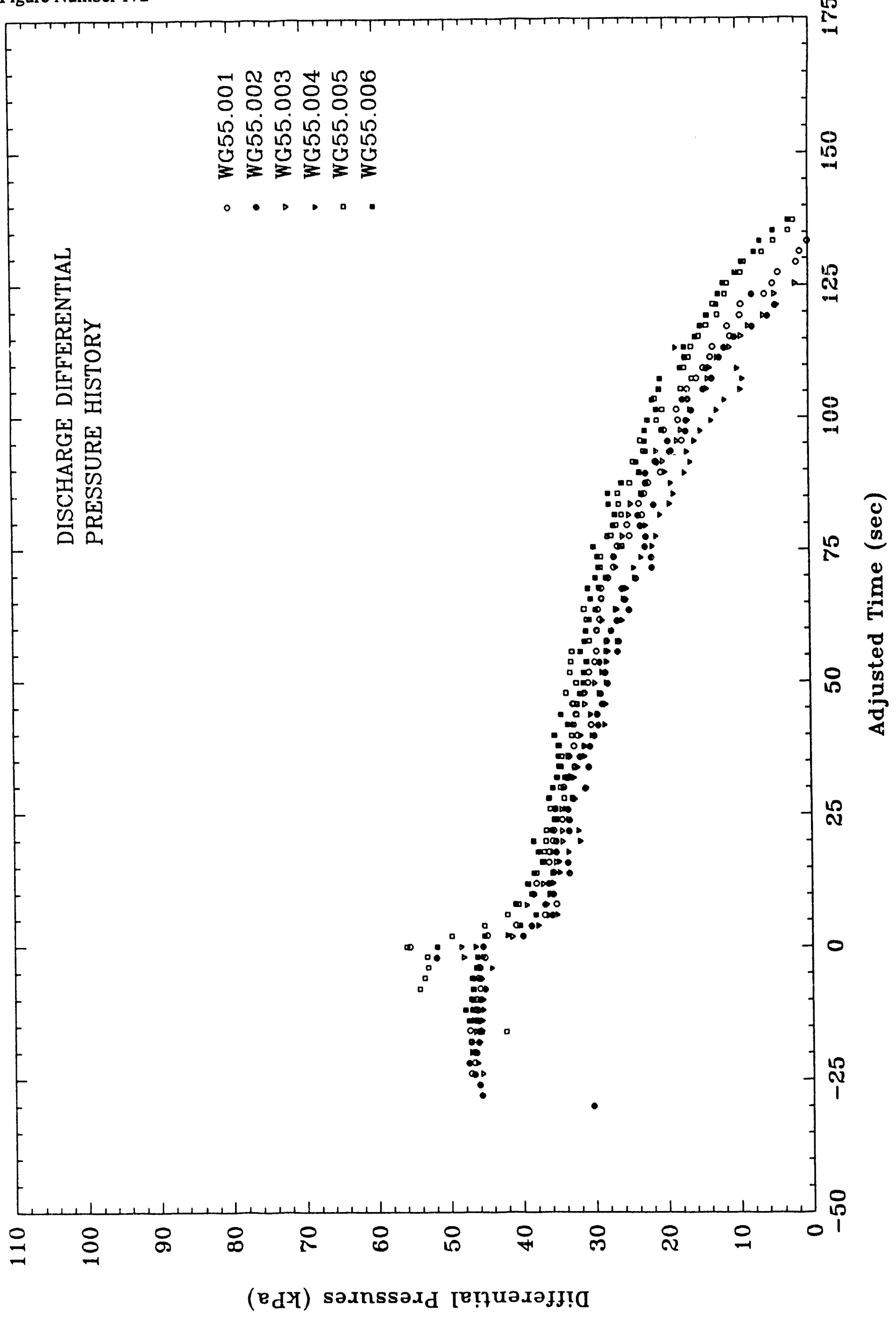


Figure Number 173

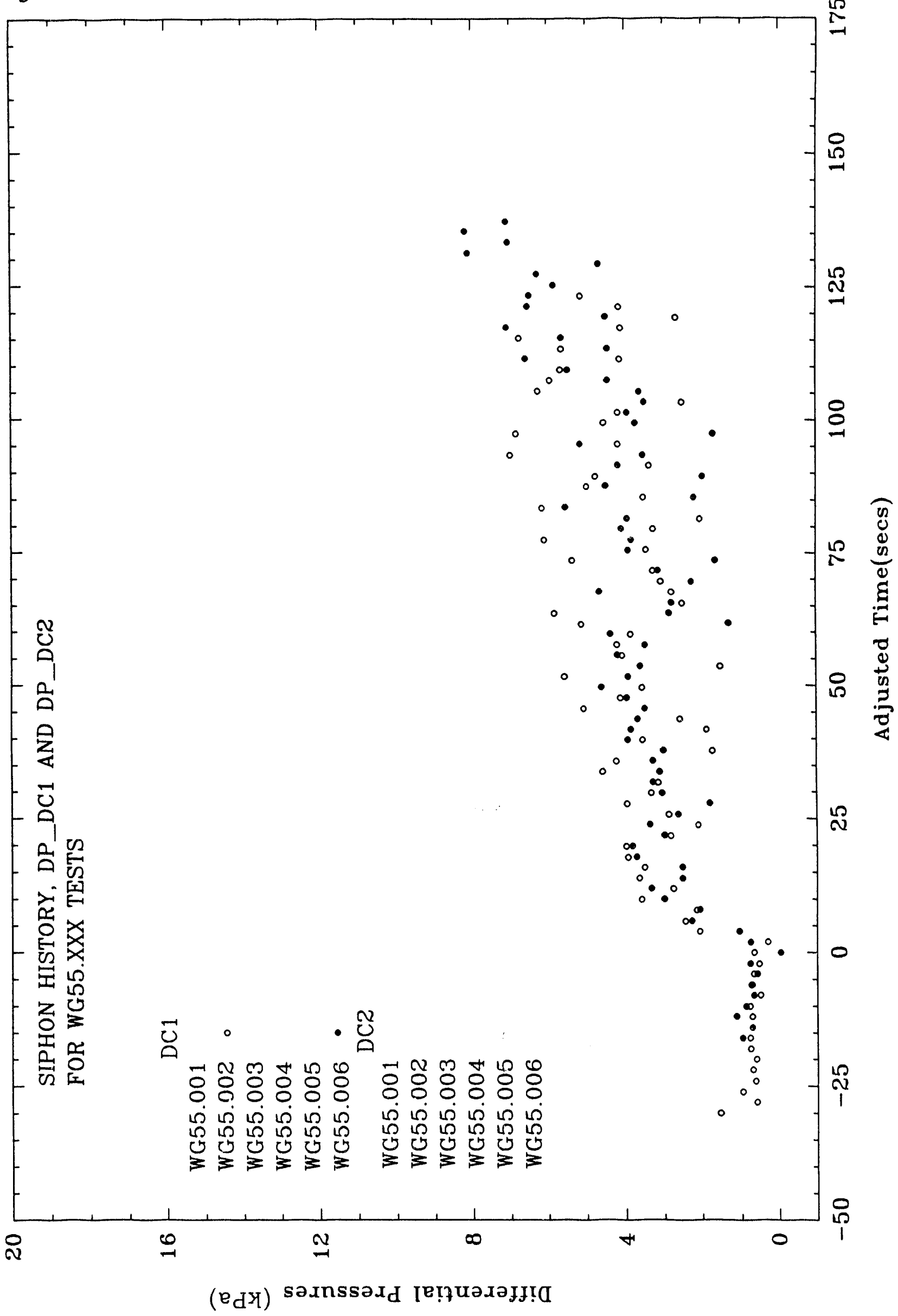




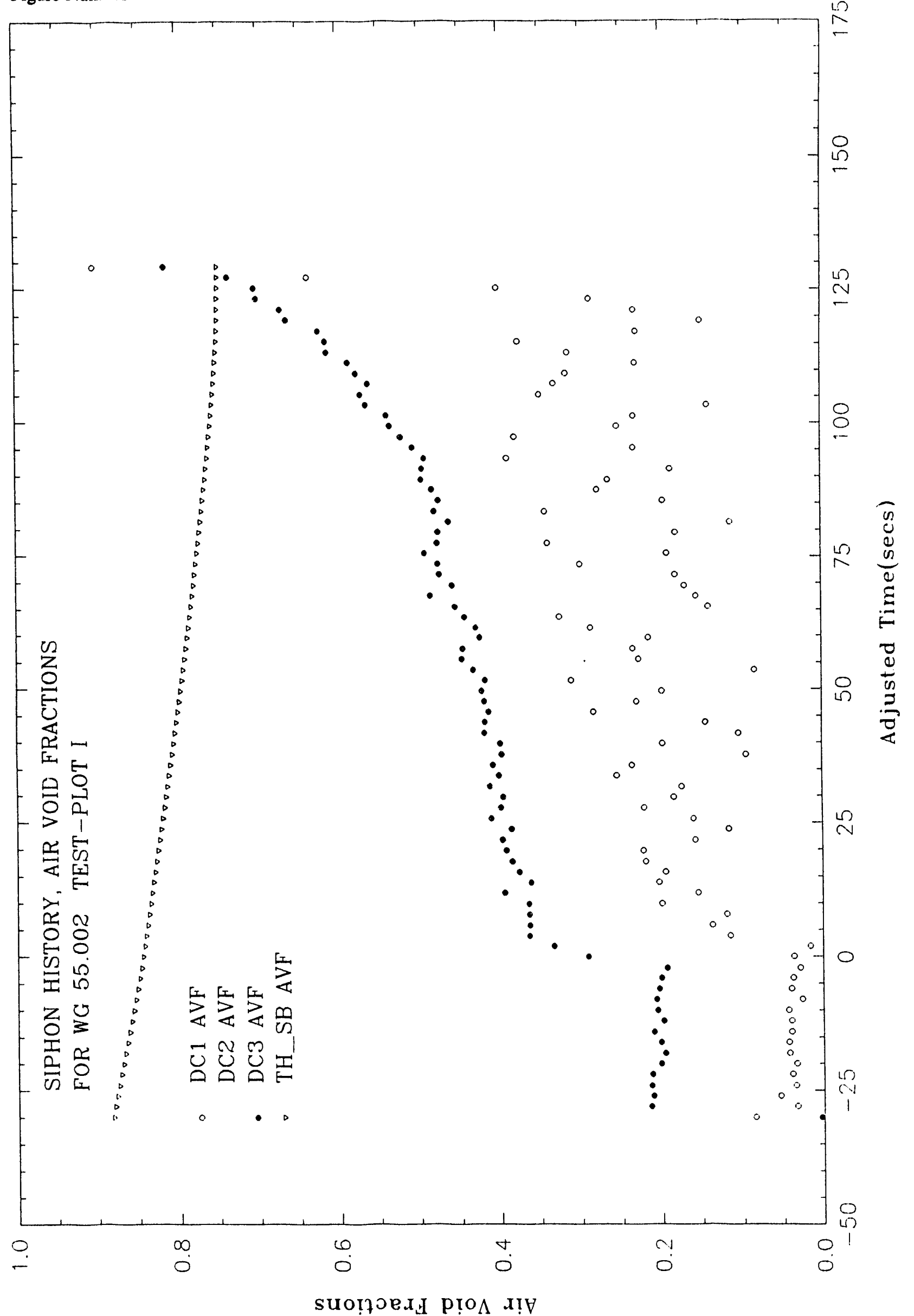




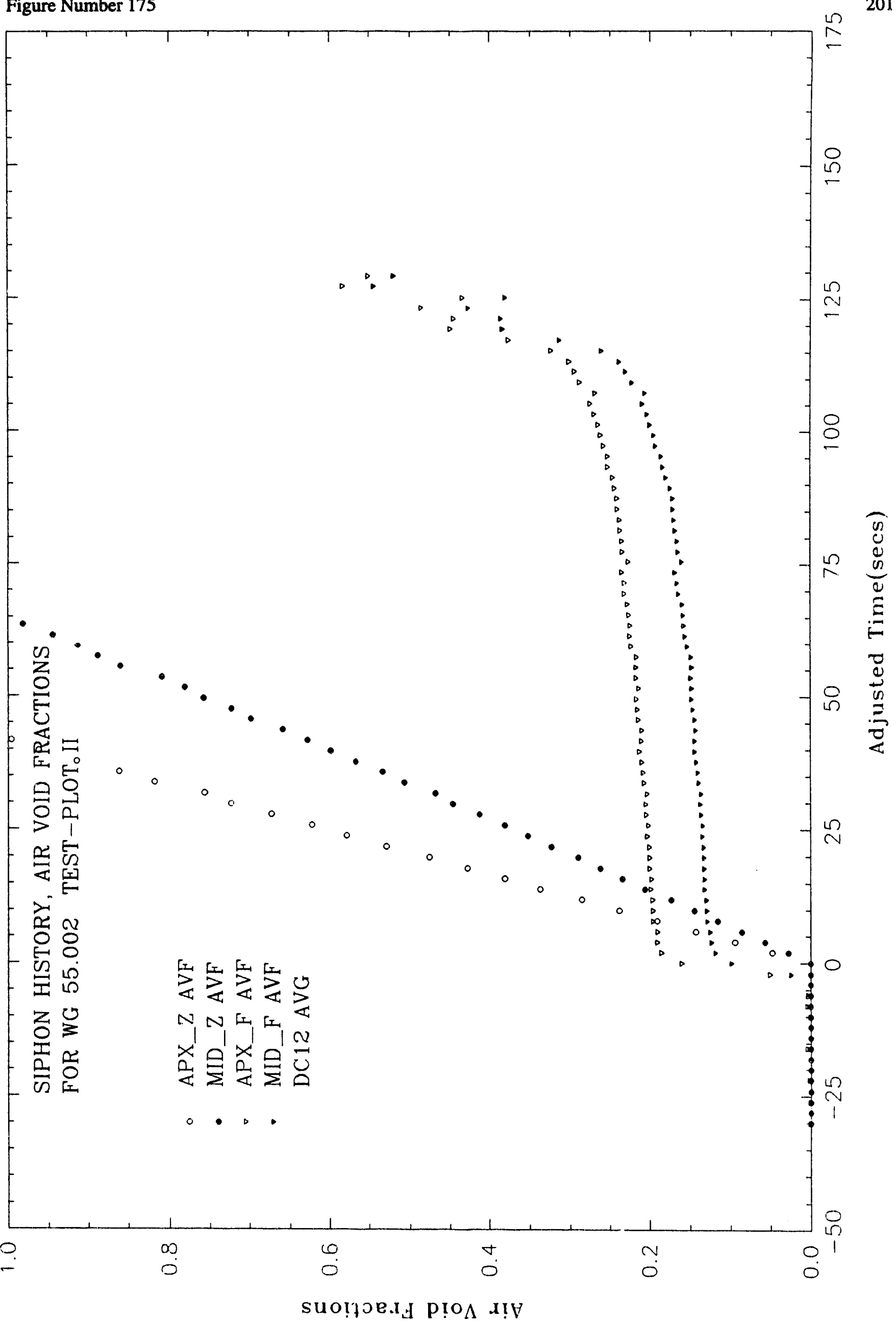




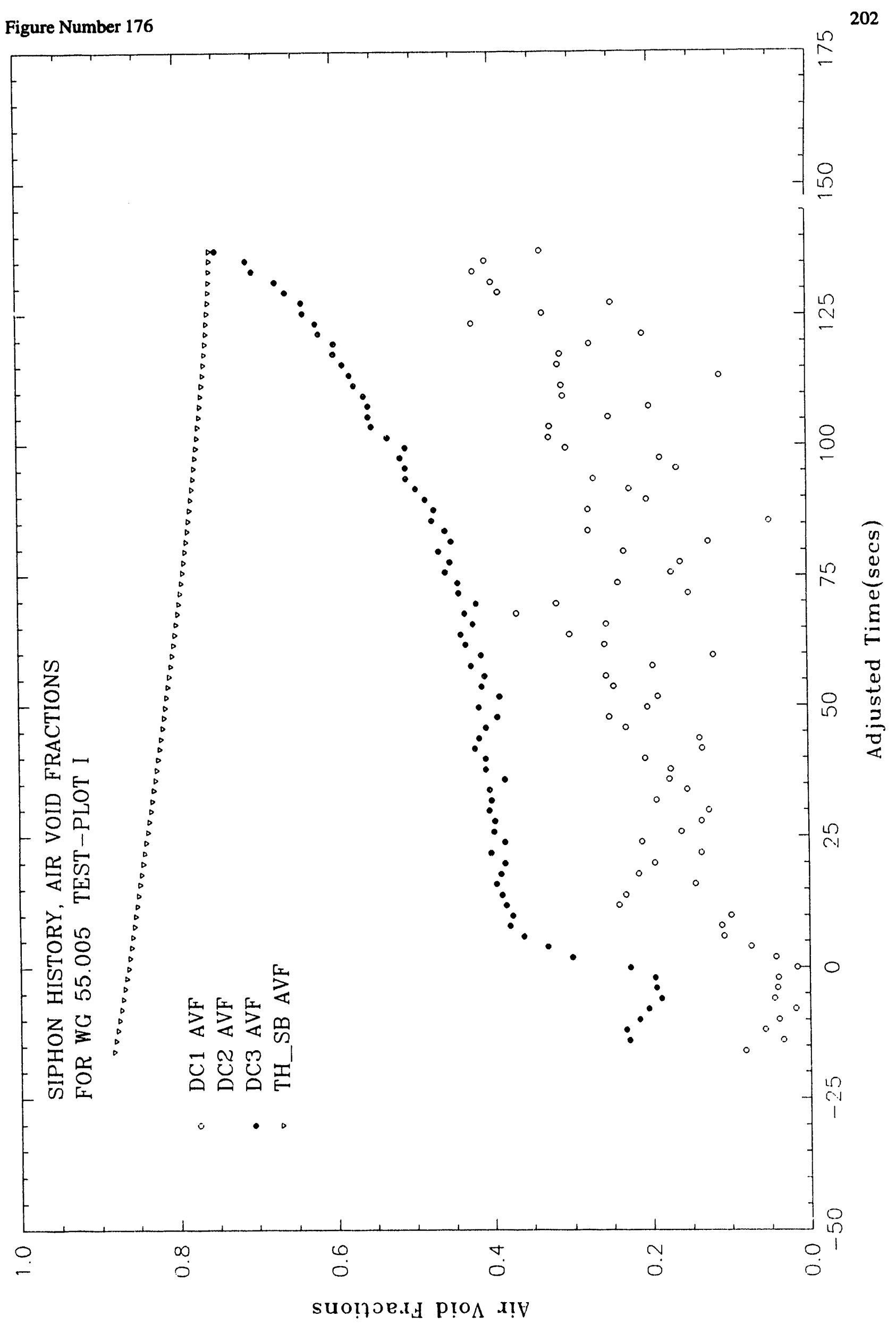




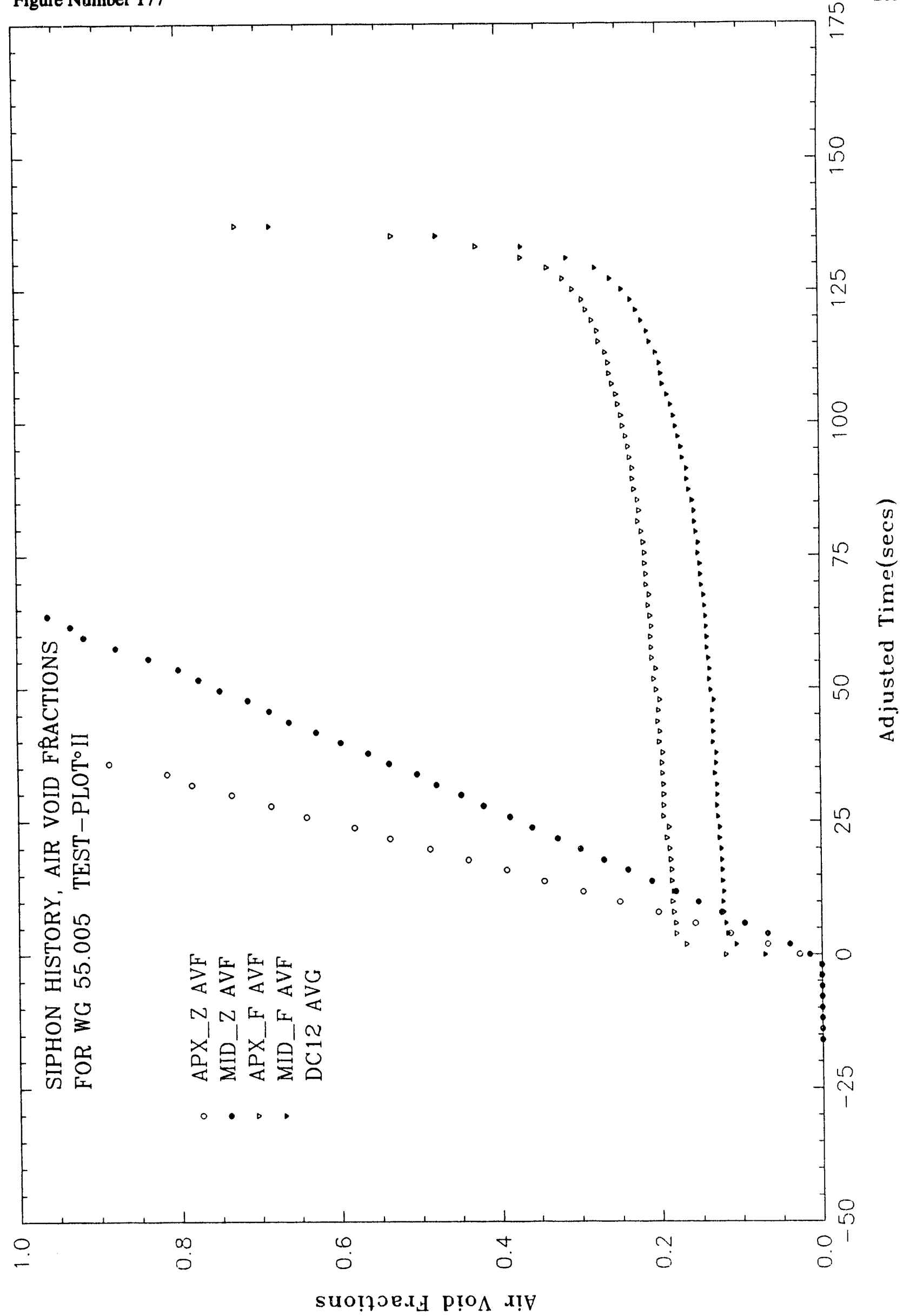




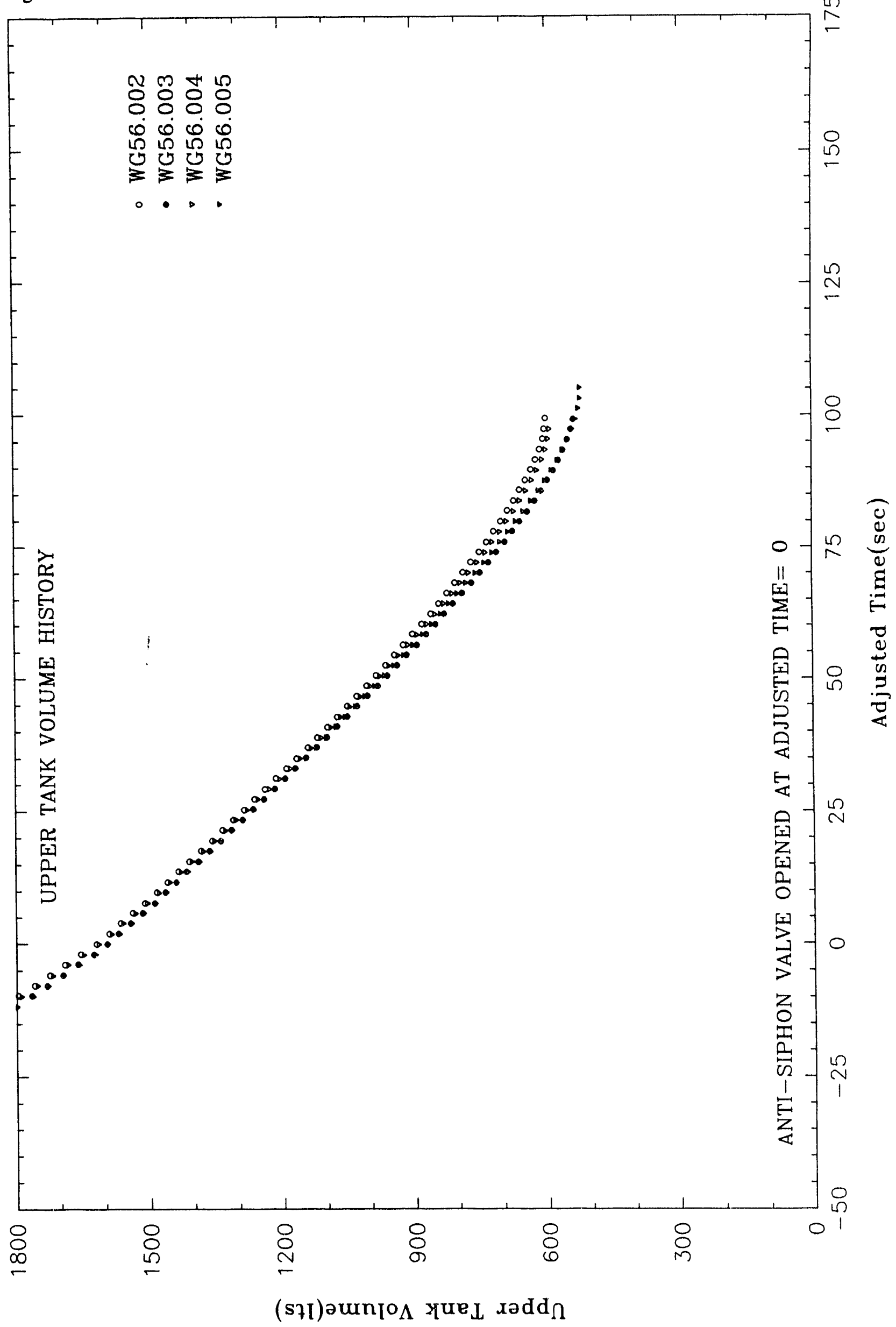


Figure Number 179

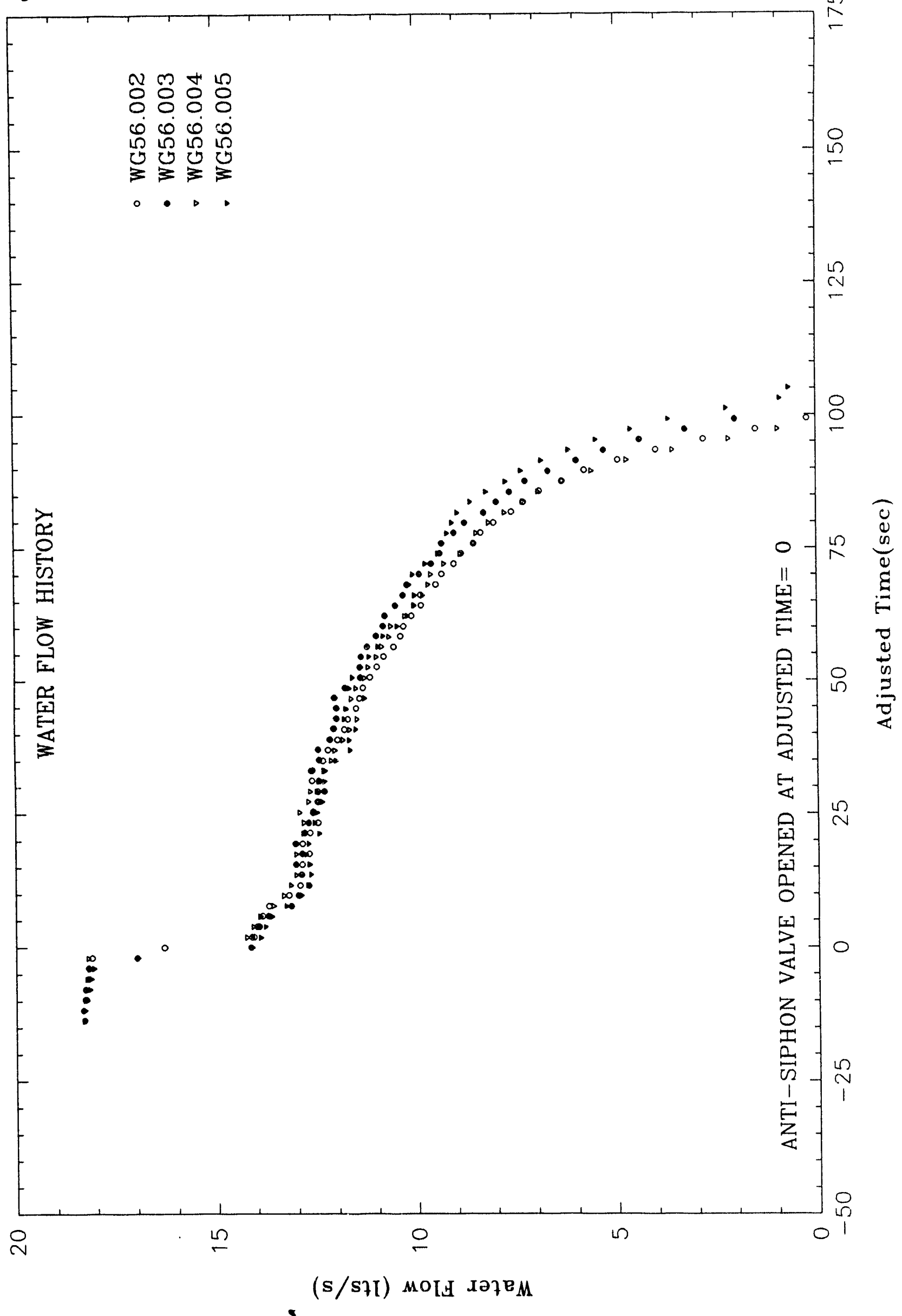



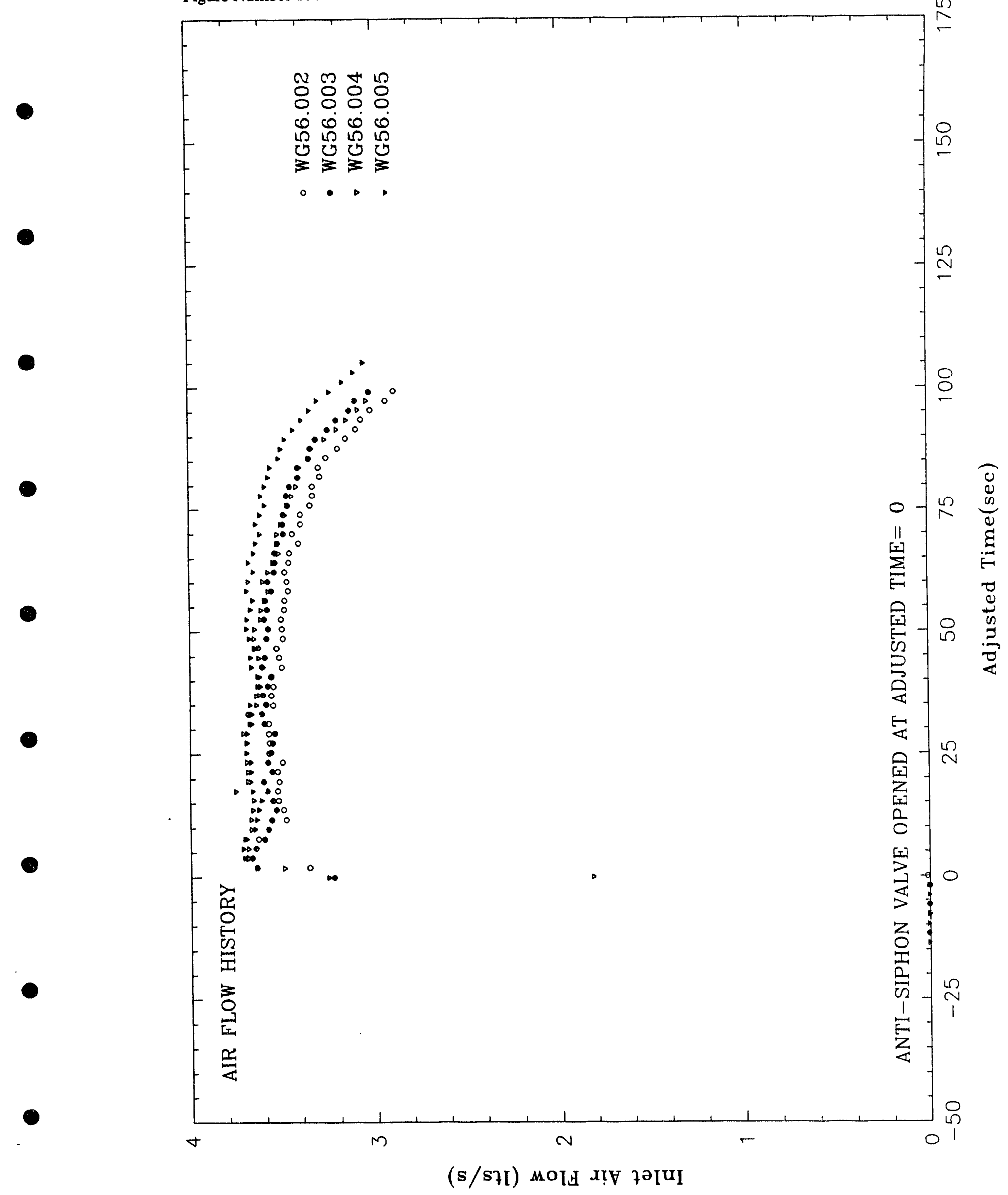


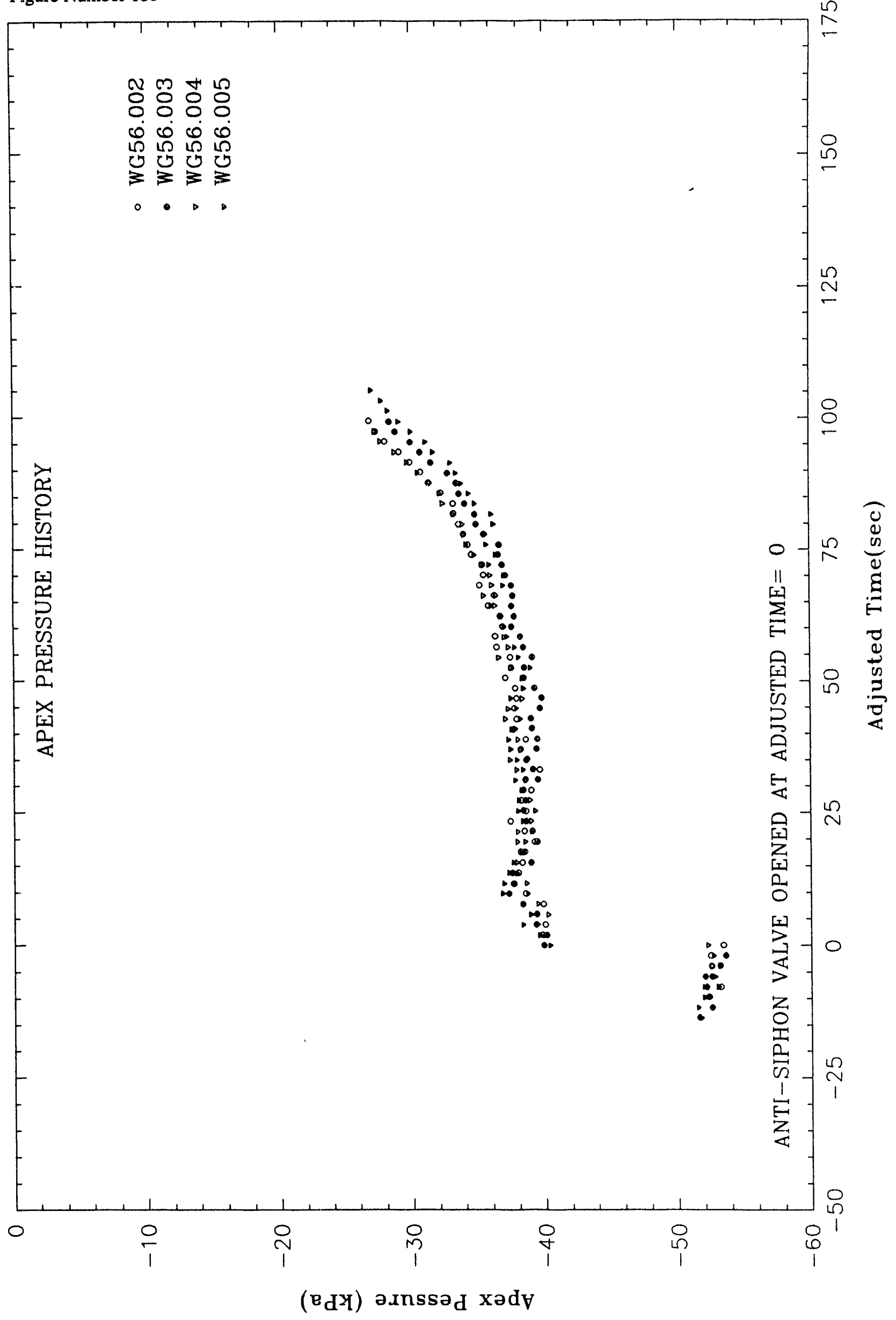




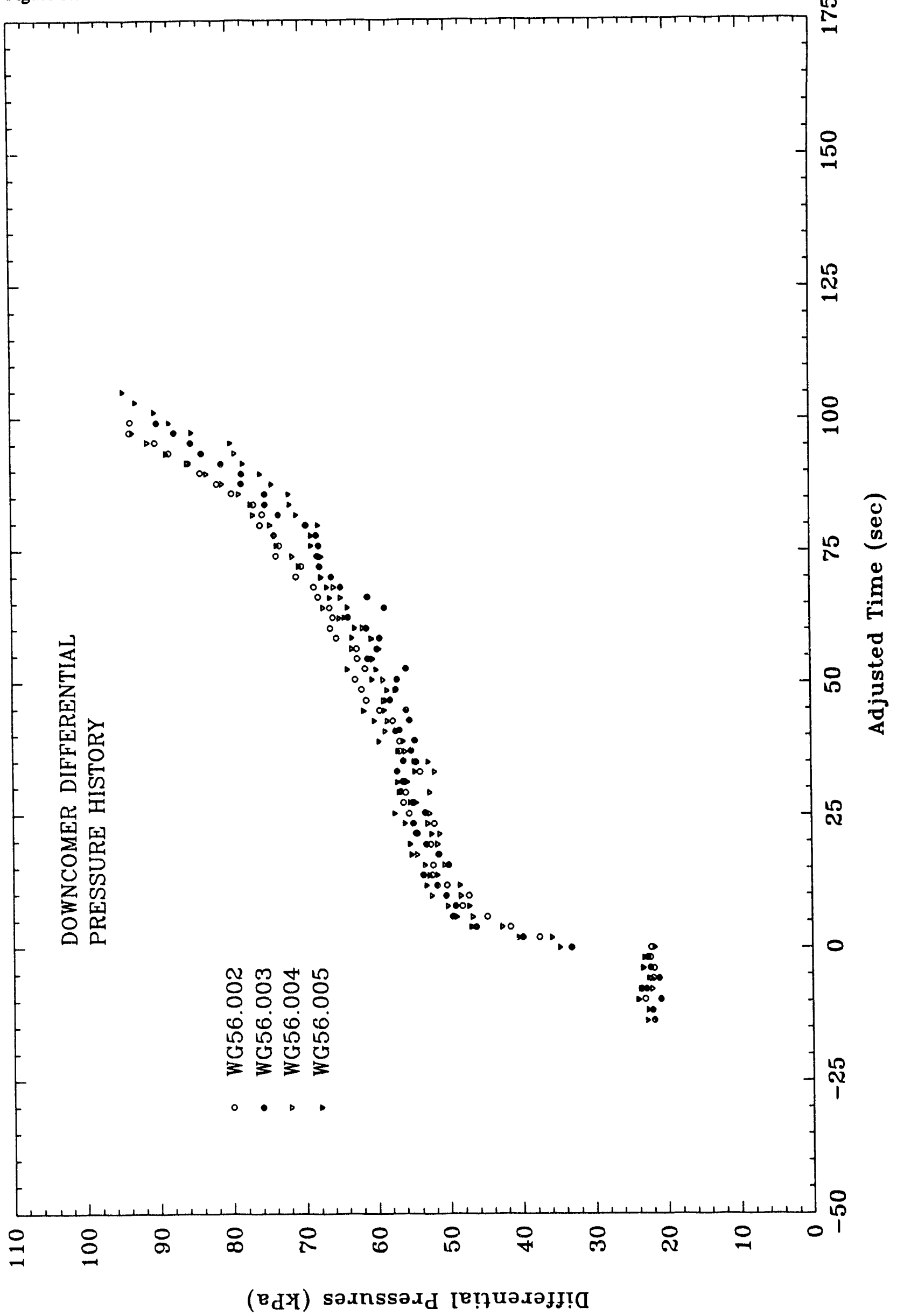


Figure Number 183

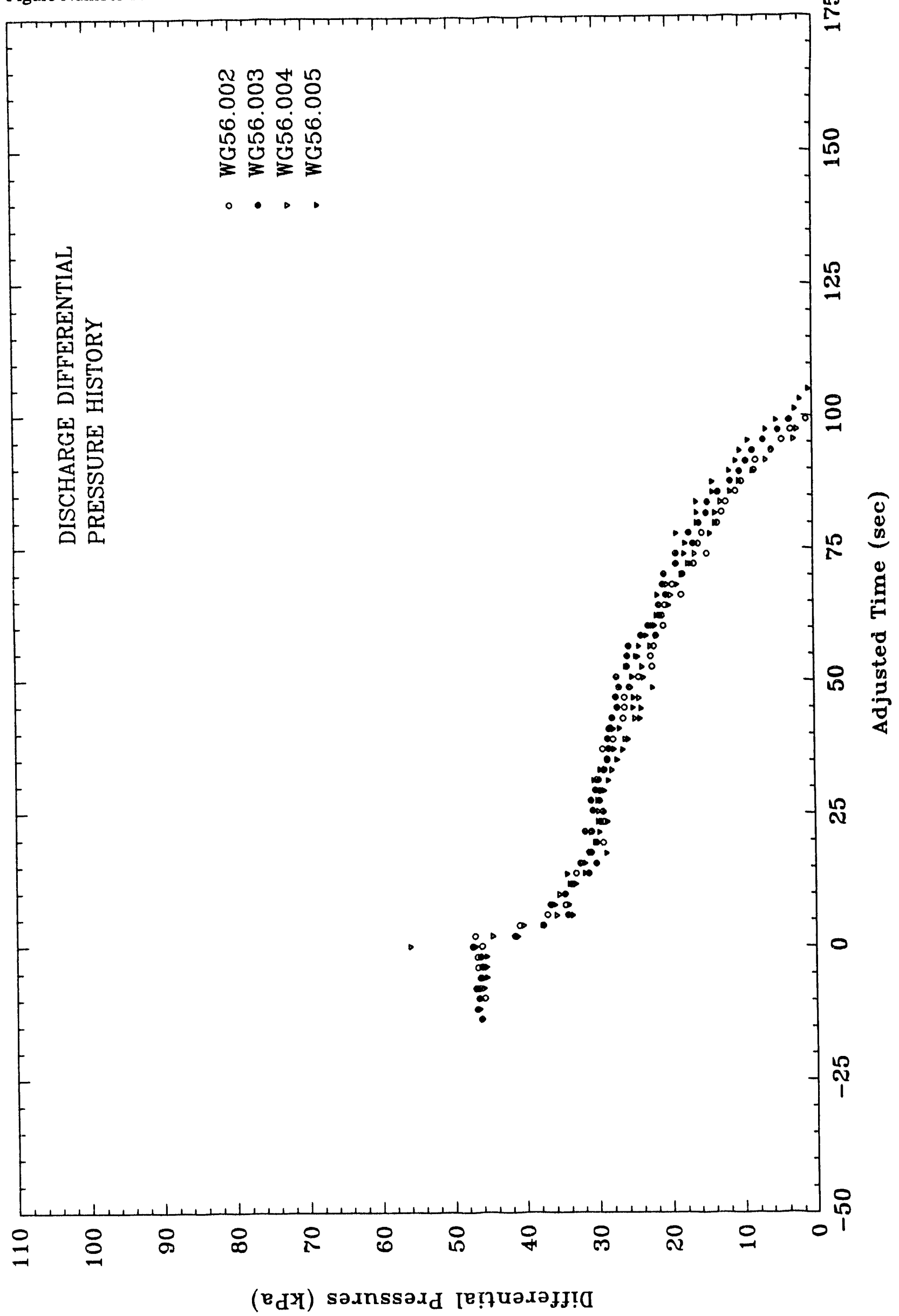




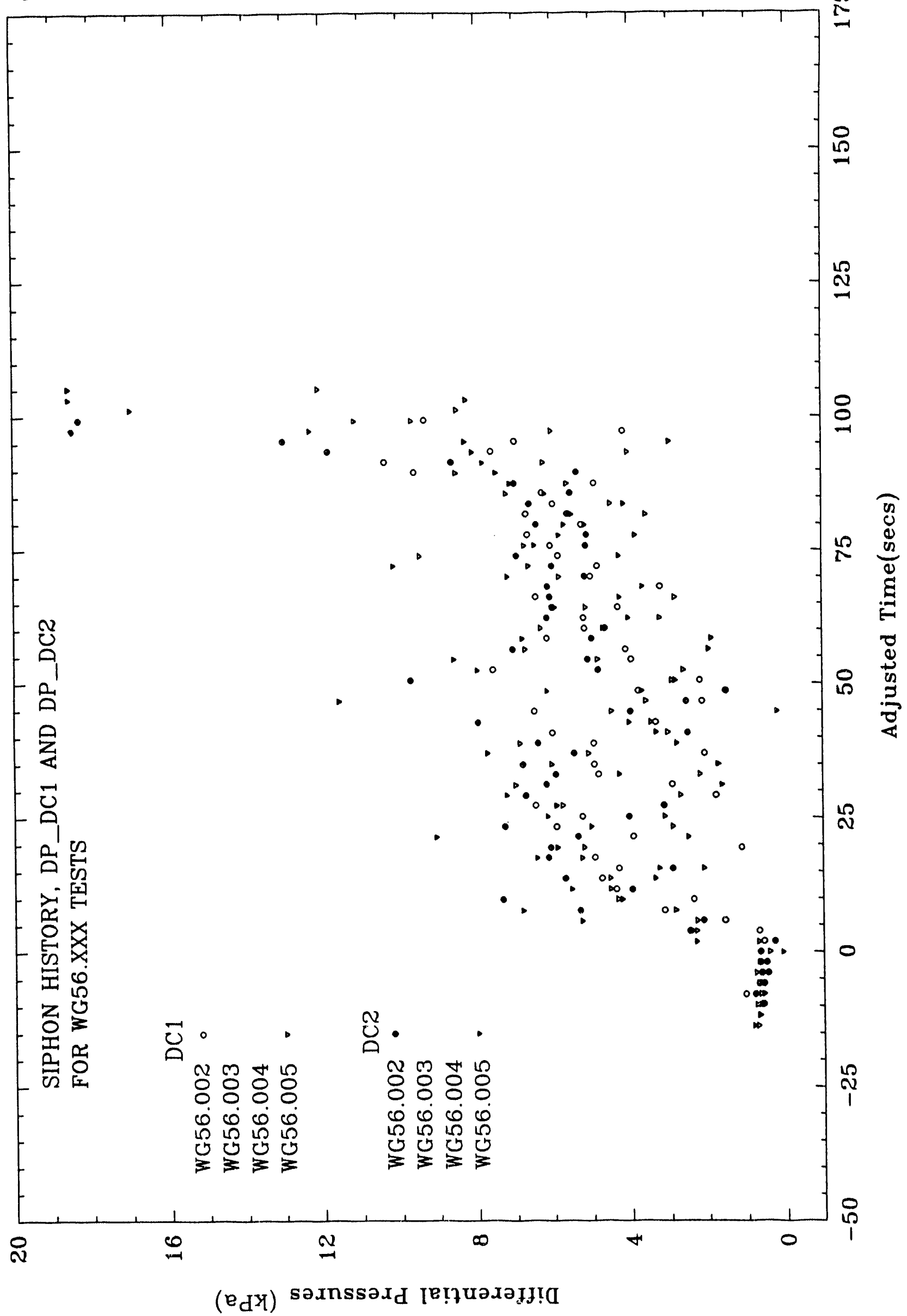




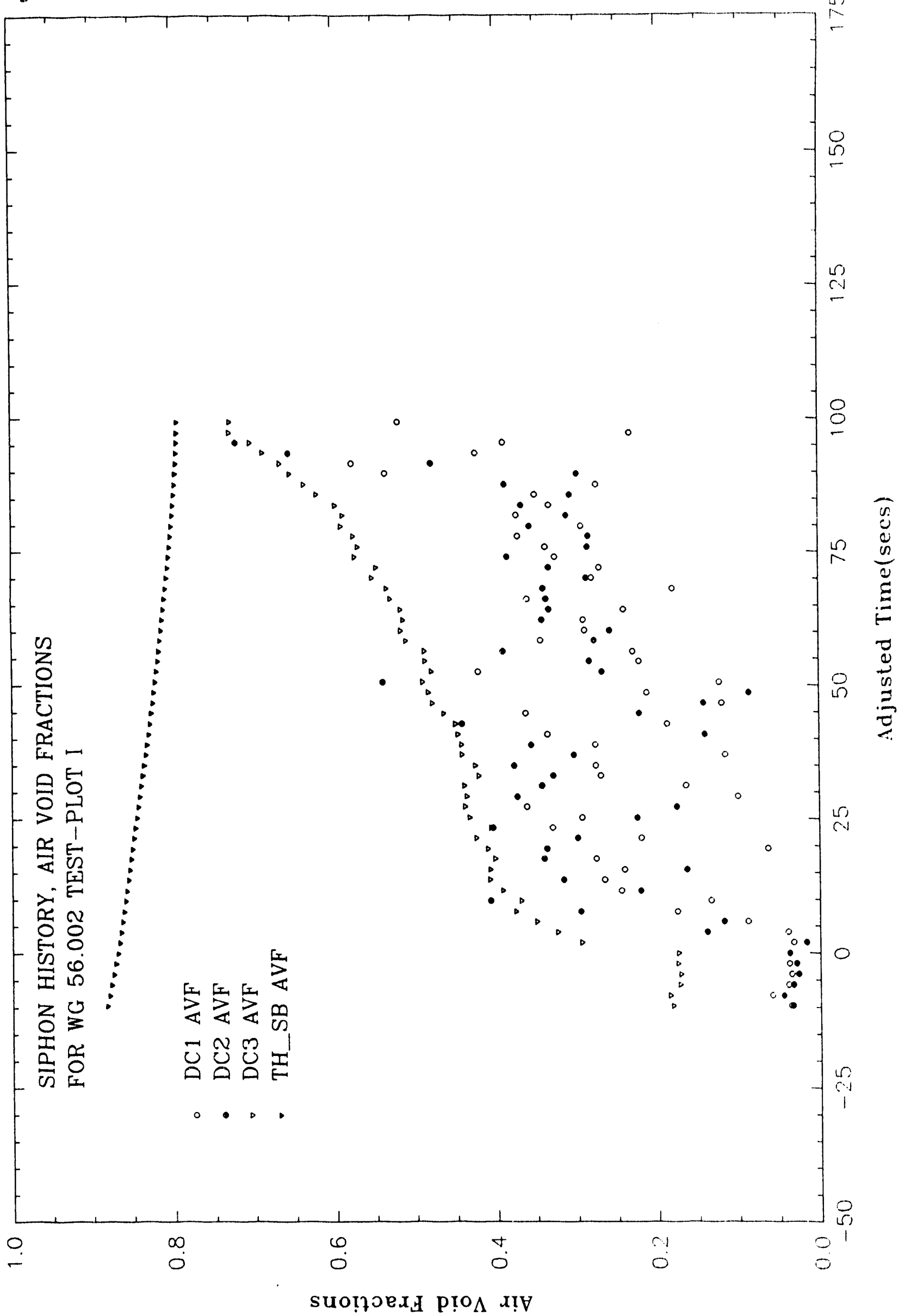




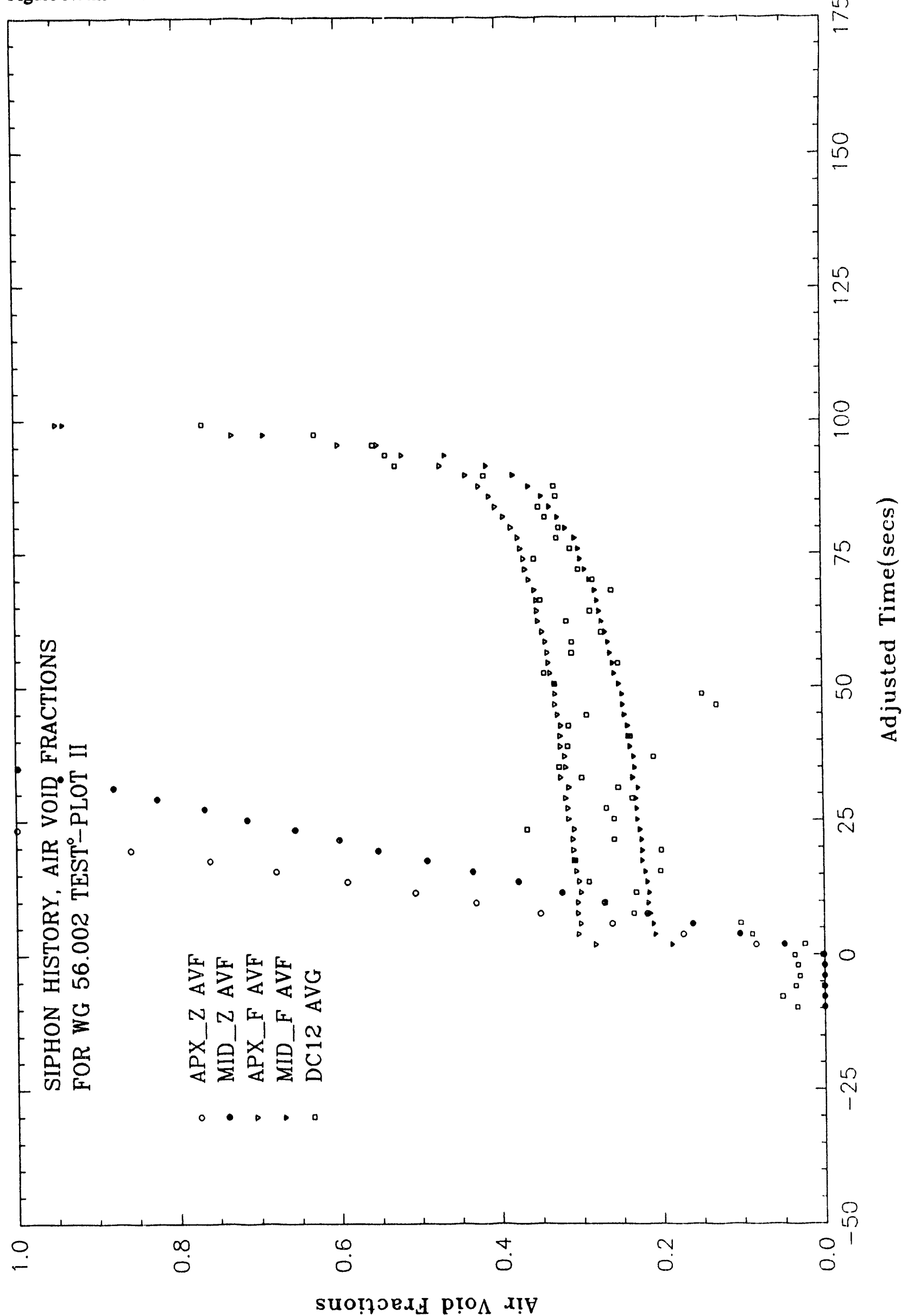




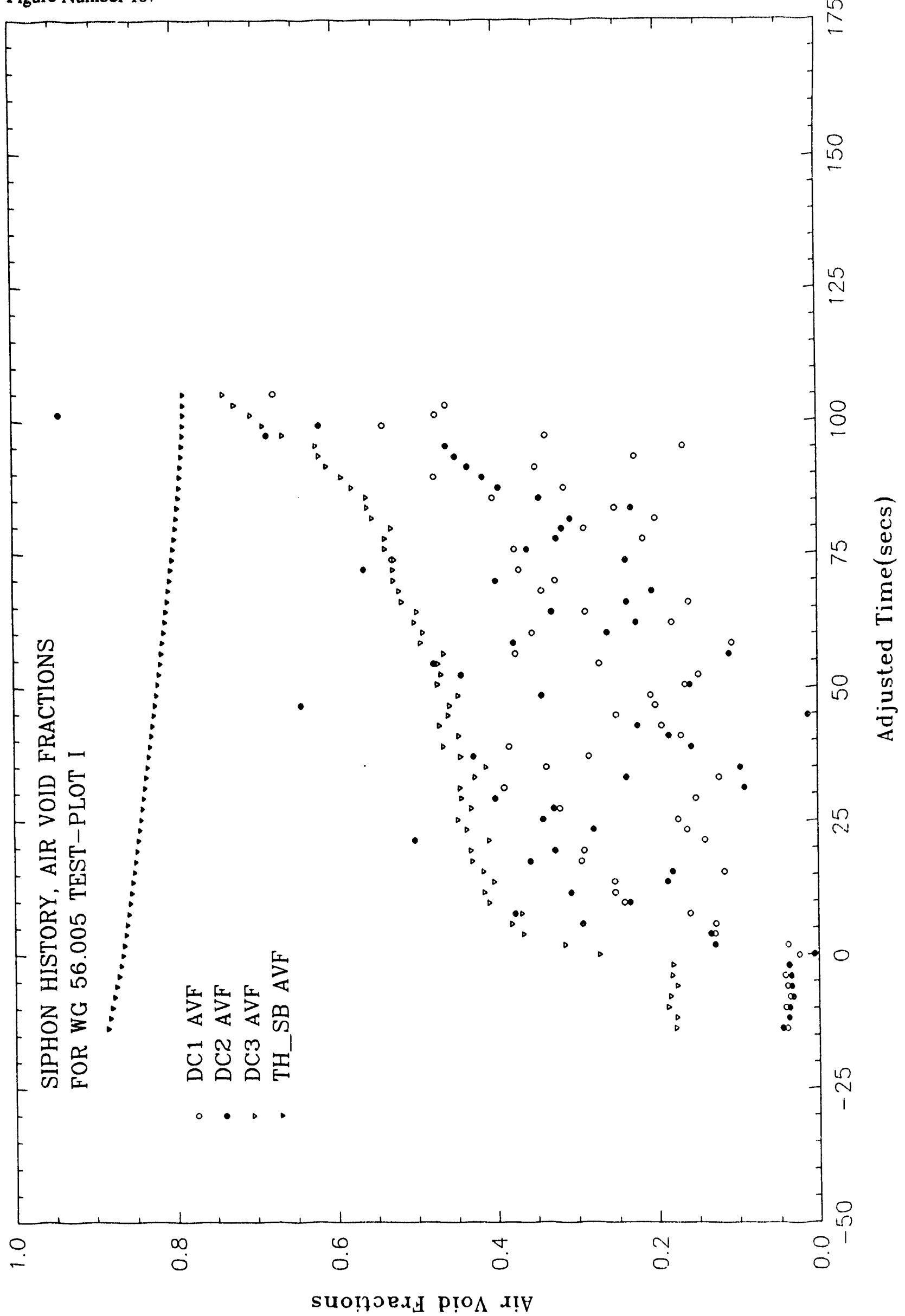




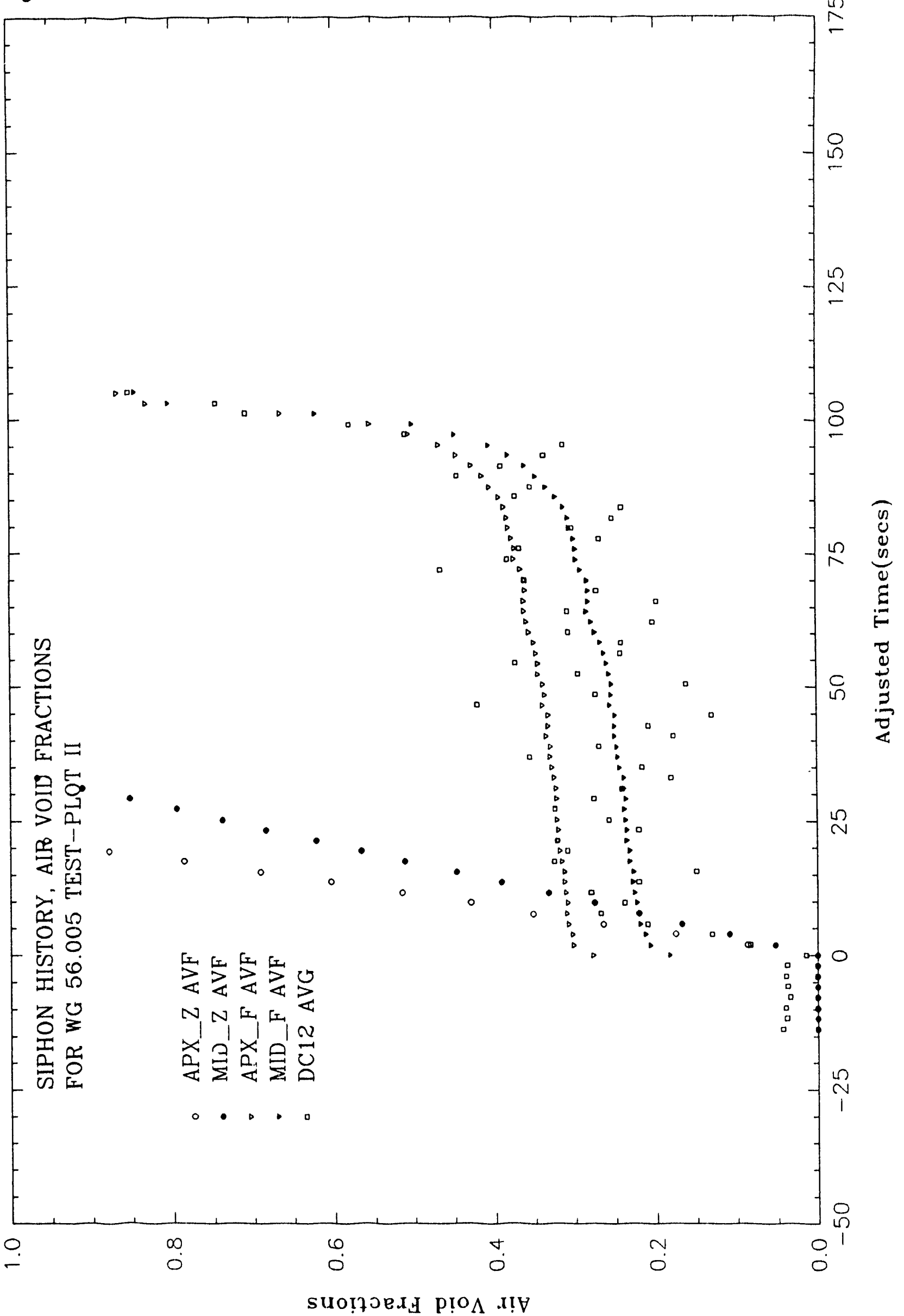


Figure 135 shows that the water flow rates are very consistent during the tests. The bump in the water flow rates at about 10 seconds is due to front of the bubbly, two-phase flow reaching the discharge orifice. After that bump, the water flow rate decreases steadily until air is susked into the upper tank outlet and disrupts the water flow measurements. All four tests show an early flow disruption at about 80 seconds but it is not sufficient to break the siphon so flow continues for another 10 seconds before the final break occurs.

Figure 136 shows the anti-siphon air flow rate increasing slowly until the siphon breaks. We have no explanation for the one lone, low air flow rate at about 65 seconds.

Figure 137 shows that the apex pressure becomes slightly less negative when the bubbly, two-phase flow reaches the discharge orifice at about 10 seconds. After that the apex pressures become more negative until the siphon starts to break.

Figure 138 shows a rapid increase in the downcomer differential pressure for about 10 seconds as the front of the bubbly, twophase flow moves down the downcomer. Then the differential pressure becomes nearly constant until the siphon starts to break. This nearly constant differential pressure indicates that ir is being swept out of the downcomer almost as fast as it is being sucked into the apex; very nearly a full sweep-out condition. Presumably the anti-siphon air contributes very little to breaking the siphon under these conditions.

Figure 139 stows a small increase in the discharge differential pressure as the bubbly, two-phase flow reaches the discharge orifice. After that the discharge differential pressure decreases slowly with the decreasing water flow rate until the siphon breaks.

Figure 140 shows the differential pressures measured across the two 6-foot long sections near the middle of the downcomer for the 009 and 010 tests. The five second delay until the bubbly, two-phase flow reaches the dp cell connections is apparent. Then the differential pressure measurements increase for a few seconds and start to cycle as large air bubbles in the form of mini-water falls progress down the downcomer. The time lag between tile upper and lower $d p$ cells, DC2 and DC1 respectively, is not visible during these tests. The large increase in the differential pressure after about 90 seconds is due to the water being sucked into the downcomer through the upper tank outlet.

Figures 141-144 show the calculated air void fractions for the 009 and 010 tests. Notice that the overall downcomer air void fraction, DC3 AVF, goes above the theoretical air void fraction to break a stagnant siphon, TH SB, only after air is sucked into the upper tank outlet at about 90 seconds. At 90 seconds the 
DC3 AVF is far below the TH SB value. The full sweep-out calculated air void fractions, APX_F AVF and MID_F AVF, run almost parallel to the overall downcomer air void fraction, DC3 AVF, as expected for a full sweep-out condition. The cycling of the calculated air void fractions due to the passage of the mini-water-fall air bubbles is quite apparent on these plots.

Figures 145-155 show the plots for the WF53 and WG53 series of tests. The mixed WF and WG designations occur because we changed to a larger capacity rotor in the air turbine meter.

Figure 145 shows the upper tank water volume history during the tests. Only one test, 014, in the series is run from a different upper tank water level. The siphon broke by draining the upper tank for all the tests. Test 013 appears to have a slightly lower slope prior to adjusted time zero than the other tests. Perhaps the siphon block valve in the downcomer, which is opened to start water flow, was not fully opened for the 013 test. Also, the 013 test has a slightly lower upper tank water level at adjusted time zero than the 007,010 and 012 tests. We were probably late opening the anti-siphon air valve for the 013 test. The adjusted time was always set to zero when the antisiphon air flow actually started.

Figure 146 shows the water flow measurements. The data support the idea that the siphon block valve was not fully opened for the 013 test; however once the anti-siphon air valve is opened all the data, save that for the 014 test, come together. The 014 test flow rates are 2 bit higher than the others because it is run from a higher upper tank water level. The differences in the water flow rates become a bit larger as the tests progress but the effect isn't great. There are other interesting differences between the 013 and 014 data. Notice that at about 10 seconds the WF data all bump down as the two-phase flow reaches the downcomer discharge. But the WG.013 data show very little change and the WF.014 data actually bump up. Again, we have no explanation for these effects.

Figure 147 shows that the anti-siphon air flows are different between the WF53 and WG53 tests. The air flows during the two WG53 tests are surely higher due to reduced restriction on air flow caused by the higher capacity air turbine rotor and by the enlarged holes in the brass fittings used in a portion of the air inlet line. However, since the WG.014 test was run at a higher upper tank water level, it should have a larger air flow than the WG.013 test. The fact that it doesn't indicates choking somewhere in the air flow line. The effect of the full sweep-out condition is further demonstrated since the different air flows have little to do with the siphon break point. The WG. 013 siphon breaks at the same point as the WF tests even though it has a significantly higher air flow. 
Figure 148 shows that the apex pressure data are essentially the same for all the tests once the anti-siphon air valve is open. Usually the apex pressure will be more negative for lower upper tank water levels but that is true here only before the anti-siphon air valve is opened. The apex pressures became more negative as the upper tank water level decreased until the siphon started to break. Again, this effect is due to the full sweep-out condition preventing appreciable accumulation of air in the downcomer.

Figure 149 shows the downcomer differential pressure data. There is a rapid increase in the differential pressure for about 10 seconds until the bubbly, two-phase flow reaches the discharge orifice; then the differential pressure becomes constant due to the full sweep-out condition. The differential pressure remains constant until about 40 seconds when it starts to slope upward and to scatter. At that time we believe the water flow rate is below that required to maintain full sweepout. Thereafter, air slowly accumulates until the upper tank is nearly empty and air is sucked into the upper tank outlet.

Figure 150 shows the discharge differential pressure data. Note that the differential pressures prior to adjusted time zero are higher for the WG.013 and WG.014 tests even though their water flows are different. We have no explanation for why the WG.013 data isn't equal to the WF test data since they have the same water flow rates. The difference in the data is maintained for the first 10 seconds until the bubbly, two-phase flow reaches the discharge orifice. From 10 seconds until about 40 seconds the data are closer together and slope smoothly downward as the water flow decreases slowly. After 40 seconds the data begin to scatter more; this increased scatter may be due to the increasing size of the air bubbles in the two-phase flow.

Figure 151 shows the differential pressure measured over the two 6-foot long sections near the middle of the downcomer. The data rise rapidiy during the first 10 seconds and then start to cycle in response to the mini-water fall bubbles that move slowly down the downcomer.

Figures 152-155 show the calculated air void fractions for two of the tests. The contrast in cyclic nature of the data from the two dp cells compared to that from the overall downcomer dp cell, DC3, is quite apparent. The theoretical air void fraction to break a stagnant siphon, TH SB AVF, remains well above the overall air void fraction until the siphon starts to break. The effect of the full sweep-out operation causes the extreme difference between the calculated air void fractions under full and zero sweep-out assumptions as shown on Figures 153 and 155 .

Figures 156-166 are the plots for the WF54 and WG54 series of tests. Again there are both WF and WG test in the series. 
Figure 156 shows the upper tank volume histories and that these tests are identical except for the different upper tank water levels at adjusted time zero. The tests were run from three different water levels at adjusted time zero but neither of the two WG tests duplicates any of the WF tests.

Figure 157 shows the water flow data. The water flow only data are clearly separated more than they should be; again suggesting some differences in the siphon block valve position. The data bump down at about 10 seconds when the bubbly two-phase flow reaches the discharge orifice. After that bump, the flow rates separate with the WF data decreasing faster than the WG data although the WG tests have higher anti-siphon air flow. We believe the principal reason for this flow separation is the different upper tank water levels.

Figure 158 shows the anti-siphon air flow rate. The air flow rate remains virtually constant throughout the test until the siphon starts to break. The wG tests have slightly higher air flow than the WF tests due to the changes in the air turbine and the inlet line. This extra air flow has little effect on the siphon break point since most of the air is being swept out.

Figure 159 shows that the apex pressure is essentially the same for both WF and WG tests. The data become slightly more negative until about 60 seconds and then turn slowly upward due to the slowing of the water flow. The data separate at about 90 seconds due to the siphon breaking earlier for the wF tests.

Figure 160 shows the downcomer differential pressure data. The data increase rapidly until the bubbly two-phase flow reaches the discharge at about 10 seconds. After about ' 0 seconds the WF tests show a faster increase in differential pressure than the WG tests indicating a faster increase in the air void fraction. This difference is probably due to the lower water flows and hence a shorter full-sweep out period during the wF tests.

Figure 161 shows that the discharge differential pressure decreases faster for the WF tests than for the WG tests again due to the slightly lower water flow rates.

Figure 162 shows the differential pressures measured over the two 6-foot long sections near the middle of the downcomer for only the two WF tests. The data rise rapidly during the first few seconds and then begin to scatter and cycle throughout the rest of the run. We believe the passage of large water-fall bubbles causes the scattering and cycling.

Figures 163-166 show the calculated air void fractions for the two WF test runs. The downcomer overall air void fraction, DC3 AVF, rises close to the theoretical air void fraction required 
to break a stagnant siphon, TH_SB AVF, only well after the siphon has started to break.

Figures 167-177 show the series of plots for the WG55 family of tests. These tests were all run after the modifications to the anti-siphon air inlet system and hence all have the WG designation.

Figure 167 shows the upper tank volume history. The 001, 002 and 003 tests were run from a higher water level than the 004 , 005 and 006 tests. Obviously we didn't open the anti-siphon air valve at exactly the same water level for each group of tests but they do separate into two rough groups. The siphon flow continued until a vortex formed at the upper tank outlet and sucked air into the upcomer. It is possible that the siphon break for the 005 and 006 tests was due primarily to the antisiphon air flow rather than air sucked into the upper tank outlet.

Figure 167 shows that the water flows are very nearly identical prior to adjusted time zero and for about 10 seconds thereafter. Then the water flows bump down as the bubbly, two-phase flow reaches the downcomer discharge and then slowly separate as the upper tank drains.

Figure 169 shows that the air flows are nearly identical and constant for all the tests. The fact that the air flows are not different for the two groups of tests run at different upper tank water levels indicates that the air flow was choked somewhere in the inlet line. The air flows diverge a bit only after the siphon break process starts.

Figure 170 shows that the apex pressures become more negative as the tests progress due to the lowering of the water level in the upper tank. The apex pressures start to become less negative at about 75 seconds due to gradual slowing of the water flow.

Figure 171 shows that the downcomer differential pressure increase slowly after the initial jump. That slow increase indicates that full sweep-out was not present during these tests even at the earliest times.

Figure 172 shows that the discharge differential pressure drops rapidly for the first 10 seconds, then slowly decreases until the siphon breaks. The slowly decreasing period corresponds to the partial sweep-out of the air from the downcomer.

Figure 173 shows the differential pressures measured over only one of the 6-foot sections near the middle of the downcomer and for only the 002 and 005 tests. The upper dp cell, DC2, was not working during any of the tests in this series. The DC1 measurements start up five seconds or so after the anti-siphon 
valve is opened and immediately start to cycle as mini-water fall air bubbles work down the downcomer.

Figures 174-177 show the calculated void fractions for the 002 and 005 tests. The cyclic nature of the DC1 measurements is particularly noticeable on Figures 174 and 176 . The overall downcomer air void fraction, DC3 AVF, approaches the theoretical air void fraction required to break a stagnant siphon, Th SB AVF, only after the siphon break process has been underway for sometime. The DC12 AVG air void fraction is not on Figures 175 and 177 since no DC2 data were obtained.

Figures 178-188 show the plots for the wG56 series of tests. These tests were all run after the modifications to the antisiphon air inlet system and hence all bear the WG designation.

Figure 178 shows the upper tank volume history. The anti-siphon air flow is started at the same upper tank water level and caused the siphon to break for all these tests.

Figure 179 shows that the water flow bumps down as soon as the bubbly, two-phase flow reaches the downcomer discharge. The water flow then slowly decreases as air accumulates in the downcomer. The slight divergence in the water flows as the tests progress is due to the magnitude of the random factors in the complete process.

Figure 180 shows that differences in the anti-siphon air flow were surely the largest random factors in the complete process. We have no idea why the air flows are so different for otherwise identical tests particularly since we believe the flow is choked somewhere in the air line.

Figure 181 shows that the apex pressures become less negative as soon as the bubbly, two-phase flow reaches the downcomer discharge orifice at an adjusted time of about 10 seconds. Then they become more negative for another 10 seconds before leveling-off and starting to slowly become less negative as the water flow slows.

Figure 182 shows that the downcomer differential pressures jump rapidly as the bubbly, two-phase flow front passes down the downcomer. There may be a very brief period of constant differential pressure indicating full sweep-out but it is short lived. Then the differential pressures start to increase indicating that there is only partial sweep-out during the remainder of the test.

Figure 183 shows the discharge differential pressure data. There are three distinct patterns to the data after adjusted time zero. The first is the rapid drop as the water flow decreases in response to opening the anti-siphon valve. The 
second is an almost linear decrease for about 10 seconds following the rapid drop. And the third is a curving decrease until the siphon breaks. We believe the second region corresponds to a period of full sweep-out and that the third region results when air starts to accumulate in the downcomer under partial sweep-out.

Figure 184 shows the differential pressures measured over the two 6-foot long sections near the middle of the downcomer for two of the tests. There is an immediate onset of very large cyclic swings in the measurements due to large air bubbles moving slowly down the downcomer.

Figures 185-188 show the calculated air void fractions for the same two tests used for Figure 184. The difference in the size of the swings in the air void fractions and hence the measured pressure differences is quite striking. The average of the two midsection values, DC12 AVF on Figures 186 and 188 , show wide swings although much less than the individual values, DC1 AVF and DC2 AVF on Figures 185 and 187. As usual, the overall air void fraction, DC3 AVF, is well below the theoretical air void fraction to break a stagnant siphon, TH_SB AVF, until the siphon breaks. The very rapid increase in the zero sweep-out air void fractions, APX $\mathrm{Z}$ and MID_z on Figures 186 and 188 , to values approaching $1 . \overline{0}$ some 20 to 40 seconds before the siphon breaks is a striking evidence of the amount of air being swept out of the downcomer during the tests. Nevertheless, the slight upward slope of the full sweep-out air void fractions indicates that there is only partial sweep-out during the tests. 


\section{CONCIOBIOLIS}

This series of tests confirms that there are three separate modes of siphon breaker performance as described below.

There is a zero sweep-out mode in which the anti-siphon air accumulates as a large bubble at the top of the downcomer and through which the water flows as in a water-fall. The additional kinetic energy of the water required to increase its velocity through the air bubble and the potential energy of the water gained while falling through the air bubble may be completely dissipated at the base of the weter fall. We believe the net effect of this energy loss will cause an increased antisiphon air flow and hence break the siphon sooner than it would if such losses didn't occur.

There is a partial sweep-out mode in which a significant fraction of the anti-siphon air is swept out of the downcomer discharge. The two-phase flow for this mode has two possibly different regimes: a bubbly flow characterized by relatively small air bubbles and a mini water-fall flow characterized by large bubbles which appear to move down the downcomer slower than the average water velocity. We did not see any cases where the large air bubbles moved up the downcomer against the downward watar flow. The "friction" losses for these two twophase flow regimes may be significantly different. In any case, accumulating sufficient air within the downcomer to break the siphon is a slow process because so much air is swept out the discharge.

Finally, there is a full sweep-out mode in which all the antisiphon air is swept out the downcomer discharge. The two-phase flow regime is bubbly flow characterized by relatively small air bubbles; however, we saw large eddies of bubbly flow the which may be precursors to the formation of mini water-falls. Antisiphon air is not accumulated in the downcomer while in this mode and the siphon will not break until after the flow slows enough for a transition to the partial sweep-out mode.

The key to a successful code for siphon breaker design will be the modeling of the transition from a full sweep-out mode to a partial sweep-out mode and, perhaps to a lesser extent, from a partial sweep-out mode to a zero sweep-out mode. 

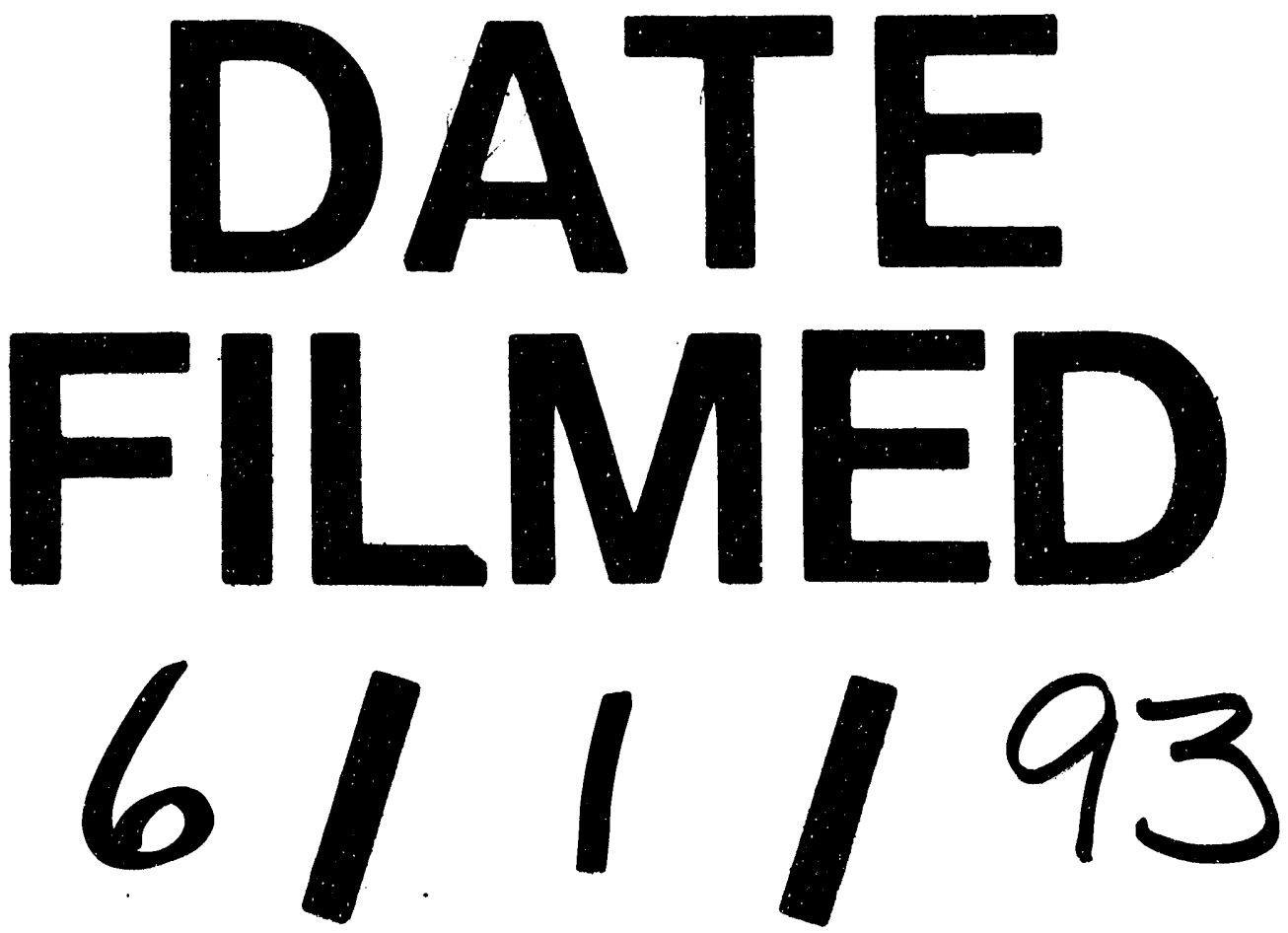
